\title{
Copper-catalyzed Tertiary Alkylative Cyanation for the Synthesis of Cyanated Peptide Building Blocks
}

Naoki Miwa ${ }^{a}$, Chihiro Tanaka ${ }^{a}$, Syo Ishida ${ }^{a}$, Goki Hirata $^{a}$, Jizhou Song ${ }^{b}$, Takeru Torigoe $^{b, c}$, Yoichiro Kuninobu ${ }^{* b, c}$ and Takashi Nishikata*a

a Graduate School of Science and Engineering, Yamaguchi University, Ube, Yamaguchi, 755-8611, Japan

b Interdisciplinary Graduate School of Engineering Sciences, Kyushu University, 6-1 Kasugakoen, Kasuga, Fukuoka 816-8580, Japan

c Institute for Materials Chemistry and Engineering, Kyushu University, 6-1 Kasugakoen, Kasuga, Fukuoka 816-8580, Japan

Corresponding Author: kuninobu@.cm.kyushu-u.ac.jp and nisikata@yamaguchi-u.ac.jp

\section{Supporting Information}

Table of Contents

1. General Procedures

2. Synthesis of cyanated carboxamide

3. Synthesis of cyanated carboxamide possessing peptide

4. Transformations of cyanated carboxamide

5. Modification of cyanated carboxamide possessing peptide

6. Optimization tables for cyanations (Tables S1 \& S2)

S19

7. Spectral charts for products 


\section{General procedures \\ General Information}

All reactions were carried out under nitrogen (99.95\%) atmosphere. For TLC analyses precoated Kieselgel 60 F254 plates (Merck, $0.25 \mathrm{~mm}$ thick) were used; for column chromatography Silica Flash ${ }^{\circledR}$ P60 (SiliCycle, 40-63 $\mu \mathrm{m}$ ) was used. Visualization was accomplished by UV light ( $254 \mathrm{~nm}$ ), ${ }^{1} \mathrm{H}$ and ${ }^{13} \mathrm{C}$ NMR spectra were obtained using a JEOL $500 \mathrm{MHz}$ NMR spectrometer. Chemical shifts for ${ }^{1} \mathrm{H}$ NMR were described in parts per million (chloroform as an internal standard $\delta=7.26$ ) in $\mathrm{CDCl}_{3}$, unless otherwise noted. Chemical shifts for ${ }^{13} \mathrm{C}$ NMR were expressed in parts per million in $\mathrm{CDCl}_{3}$ as an internal standard $(\delta=77.16)$, unless otherwise noted. High resolution mass analyses were obtained using an ACQUITY UPLC/ TOF-MS for ESI. Anhydrous solvents were purchased from Kanto Chemical Co., Ltd. Other chemicals were purchased from TCI, Aldrich and Wako and directly used from the bottles.

\section{Synthesis of cyanated carboxamide} General procedure for the synthesis of 3.

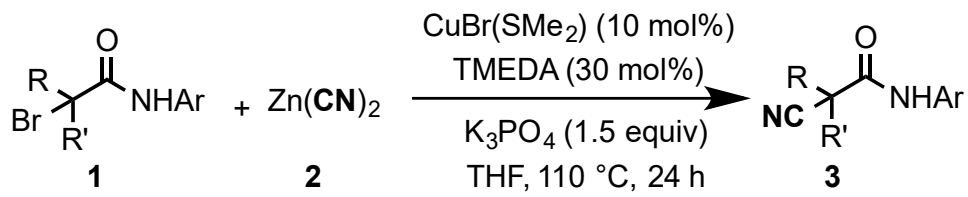

$\mathrm{CuBr} \cdot \mathrm{SMe}_{2}(10.27 \mathrm{mg}, 0.05 \mathrm{mmol}), \mathrm{Zn}(\mathrm{CN})_{2}(2,58.7 \mathrm{mg}, 0.5 \mathrm{mmol}), \mathrm{K}_{3} \mathrm{PO}_{4}(159.6 \mathrm{mg}, 0.75 \mathrm{mmol})$, and $\alpha$-bromocarboxamide $\mathbf{1}(0.5 \mathrm{mmol})$ were sequentially added under air to a sealed tube equipped with a stir bar. TMEDA $(22 \mu \mathrm{L}, 0.15 \mathrm{mmol})$ and dried THF $(0.5 \mathrm{~mL})$ were added by syringe, and the resulting mixture was vigorously stirred under nitrogen atmosphere [charged by $\mathrm{N}_{2}(99.95 \%)$ gas flow] for $24 \mathrm{~h}$ at $110^{\circ} \mathrm{C}$. After this time, the contents of the flask were filtered through a plug of silica gel and then concentrated by rotary evaporation. The crude residue was purified by column chromatography over silica-gel, eluting with hexane/AcOEt to afford the product 3 .

2-cyano-2-methyl- $N$-phenylpropanamide (3a)<smiles>CC(C)(C#N)C(=O)Nc1ccccc1</smiles>

Following the general procedure above, using $1 \mathrm{a}(121.0 \mathrm{mg}, 0.50 \mathrm{mmol}), \mathrm{Zn}(\mathrm{CN})_{2}(59.5 \mathrm{mg}, 0.5$ $\mathrm{mmol}), \mathrm{CuBr} \cdot \mathrm{SMe}_{2}(10.0 \mathrm{mg}, 0.05 \mathrm{mmol})$, TMEDA $(22 \mu \mathrm{L}, 0.15 \mathrm{mmol}), \mathrm{K}_{3} \mathrm{PO}_{4}(159.1 \mathrm{mg}, 0.75$ $\mathrm{mmol})$, and THF $(0.5 \mathrm{~mL})$ for $24 \mathrm{~h}$ at $110{ }^{\circ} \mathrm{C}$. The crude residue was purified by column chromatography over silica-gel, eluting with AcOEt/hexane $(1 / 10=\mathrm{v} / \mathrm{v})$ to afford the desired compound 3a (78.0 mg, $0.414 \mathrm{mmol}, 83 \%)$ as a white solid; $\mathrm{Mp}=94-95{ }^{\circ} \mathrm{C} ;{ }^{1} \mathrm{H}$ NMR $(500 \mathrm{MHz}$, $\left.\mathrm{CDCl}_{3}\right) \delta: 7.91(\mathrm{br}, 1 \mathrm{H}), 7.53(\mathrm{~d}, J=8.0 \mathrm{~Hz}, 2 \mathrm{H}), 7.37(\mathrm{t}, J=8.1 \mathrm{~Hz}, 2 \mathrm{H}), 7.19(\mathrm{t}, J=7.4 \mathrm{~Hz}, 1 \mathrm{H})$, $1.69(\mathrm{~s}, 6 \mathrm{H}) .{ }^{13} \mathrm{C}$ NMR $\left(125 \mathrm{MHz}, \mathrm{CDCl}_{3}\right) \delta 166.6,136.8,129.3,125.6,122.6,120.5,39.7,25.2$, FT-IR (neat, $\mathrm{cm}^{-1}$ ) $3252,2941,2240,1595,1441,1318,928,751,694$. HRMS (ESI-MS) $\mathrm{m} / \mathrm{z}$ $\left[\mathrm{M}+\mathrm{H}^{+}\right]$Calcd for $\mathrm{C}_{11} \mathrm{H}_{13} \mathrm{ON}_{2}$ 189.1028, found 189.1028.

Gram scale synthesis of $\mathbf{3 a}$.

Following the general procedure above, using $1 \mathrm{a}(1211 \mathrm{mg}, 5 \mathrm{mmol}), \mathrm{Zn}(\mathrm{CN})_{2}(587.0 \mathrm{mg}, 5 \mathrm{mmol})$, $\mathrm{CuBr}^{\circ} \mathrm{SMe}_{2}(102.5 \mathrm{mg}, 0.5 \mathrm{mmol})$, TMEDA $(0.22 \mathrm{~mL}, 1.5 \mathrm{mmol}), \mathrm{K}_{3} \mathrm{PO}_{4}(1593 \mathrm{mg}, 7.5 \mathrm{mmol})$, and THF $(5 \mathrm{~mL})$ at $110^{\circ} \mathrm{C}$. The crude residue was purified by column chromatography over silica-gel, eluting with AcOEt/hexane $(1 / 10=\mathrm{v} / \mathrm{v})$ to afford the desired compound 3a $(762.9 \mathrm{mg}, 4.05 \mathrm{mmol}$, $81 \%)$ as a white solid. 
2-cyano-2-methyl- $N$-phenylpentanamide (3b)<smiles>CCCC(C)(C#N)C(=O)Nc1ccccc1</smiles>

Following the general procedure above, using $\mathbf{1 b}(135.3 \mathrm{mg}, 0.47 \mathrm{mmol}), \mathrm{Zn}(\mathrm{CN})_{2}(58.7 \mathrm{mg}, 0.5$ $\mathrm{mmol}), \mathrm{CuBr} \bullet \mathrm{SMe}_{2}(10.1 \mathrm{mg}, 0.05 \mathrm{mmol})$, TMEDA $(22.5 \mu \mathrm{L}, 0.15 \mathrm{mmol}), \mathrm{K}_{3} \mathrm{PO}_{4}(159.6 \mathrm{mg}, 0.75$ $\mathrm{mmol})$, and THF $(0.5 \mathrm{~mL})$ at $110^{\circ} \mathrm{C}$. The crude residue was purified by column chromatography over silica-gel, eluting with AcOEt/hexane $(1 / 20=\mathrm{v} / \mathrm{v})$ to afford the desired compound $\mathbf{3 b}(83.2 \mathrm{mg}$, $0.385 \mathrm{mmol}, 77 \%)$ as a yellow solid; $\mathrm{Mp}=71-74{ }^{\circ} \mathrm{C} .{ }^{1} \mathrm{H}$ NMR $\left(500 \mathrm{MHz}, \mathrm{CDCl}_{3}\right) \delta: 7.95(\mathrm{br}, 1 \mathrm{H})$, $7.53(\mathrm{~d}, J=7.6 \mathrm{~Hz}, 2 \mathrm{H}), 7.37(\mathrm{t}, J=7.8 \mathrm{~Hz}, 2 \mathrm{H}), 7.19(\mathrm{t}, J=7.6 \mathrm{~Hz}, 1 \mathrm{H}), 2.08-2.01(\mathrm{~m}, 1 \mathrm{H})$, $1.78-1.72(\mathrm{~m}, 1 \mathrm{H}), 1.66(\mathrm{~s}, 3 \mathrm{H}), 1.64-1.57(\mathrm{~m}, 1 \mathrm{H}), 1.50-1.41(\mathrm{~m}, 1 \mathrm{H}), 0.99(\mathrm{t}, J=7.4 \mathrm{~Hz}, 3 \mathrm{H}) .{ }^{13} \mathrm{C}$ NMR (125 MHz, $\left.\mathrm{CDCl}_{3}\right) \delta: 166.4,136.7,129.3,125.6,122.0,120.6,45.2,40.6,24.1,19.2,13.9$. FT-IR (neat, $\mathrm{cm}^{-1}$ ) 3299, 3146, 2968, 2936, 2251, 1654, 1605, 1546, 1439, 1390, 765, 692. HRMS (ESI-MS) $m / z\left[\mathrm{M}+\mathrm{H}^{+}\right]$Calcd for $\mathrm{C}_{13} \mathrm{H}_{17} \mathrm{O}_{2} \mathrm{~N}_{2} 217.1341$, found 217.1341 .

2-cyano-2-ethyl- $N$-phenylbutanamide (3c)<smiles>CCC(CC)(CC)C(=O)Nc1ccccc1</smiles>

Following the general procedure above, using $1 \mathrm{c}(135.1 \mathrm{mg}, 0.47 \mathrm{mmol}), \mathrm{Zn}(\mathrm{CN})_{2}(58.7 \mathrm{mg}, 0.5$ $\mathrm{mmol}), \mathrm{CuBr} \cdot \mathrm{SMe}_{2}(10.6 \mathrm{mg}, 0.05 \mathrm{mmol}), \mathrm{TMEDA}(22.5 \mu \mathrm{L}, 0.15 \mathrm{mmol}), \mathrm{K}_{3} \mathrm{PO}_{4}(159.4 \mathrm{mg}, 0.75$ $\mathrm{mmol})$, and THF $(0.5 \mathrm{~mL})$ at $110^{\circ} \mathrm{C}$. The crude residue was purified by column chromatography over silica-gel, eluting with AcOEt/hexane $(1 / 20=\mathrm{v} / \mathrm{v})$ to afford the desired compound $\mathbf{3 c}(87.7 \mathrm{mg}$, $0.359 \mathrm{mmol}, 76 \%)$ as a white solid; $\mathrm{Mp}=124{ }^{\circ} \mathrm{C} .{ }^{1} \mathrm{H}$ NMR $\left(500 \mathrm{MHz}, \mathrm{CDCl}_{3}\right) \delta: 7.98(\mathrm{br}, 1 \mathrm{H})$, $7.55(\mathrm{~d}, J=8.0 \mathrm{~Hz}, 2 \mathrm{H}), 7.37(\mathrm{t}, J=7.9 \mathrm{~Hz}, 2 \mathrm{H}), 7.20(\mathrm{t}, J=7.2 \mathrm{~Hz}, 1 \mathrm{H}), 2.13-2.05(\mathrm{~m}, 2 \mathrm{H})$, $1.89-1.81(\mathrm{~m}, 2 \mathrm{H}), 1.11(\mathrm{t}, J=7.5 \mathrm{~Hz}, 6 \mathrm{H}) .{ }^{13} \mathrm{C} \mathrm{NMR}\left(125 \mathrm{MHz}, \mathrm{CDCl}_{3}\right) \delta: 165.8,136.7,129.3$, 125.6, 121.1, 120.7, 52.8, 30.9, 10.1. FT-IR (neat, $\mathrm{cm}^{-1}$ ) 3301, 3057, 2971, 2880, 2242, 1654, 1596, 1529, 1443, 747, 692. HRMS (ESI-MS) $m / z\left[\mathrm{M}+\mathrm{H}^{+}\right]$Calcd for $\mathrm{C}_{13} \mathrm{H}_{17} \mathrm{ON}_{2} 217.1341$, found 217.1341 .

2-cyano-2-ethyl- $N$-phenylhexanamide (3d)<smiles>CCCCC(CC)(CC)C(=O)Nc1ccccc1</smiles>

Following the general procedure above, using 1d $(141.4 \mathrm{mg}, 0.47 \mathrm{mmol}), \mathrm{Zn}(\mathrm{CN})_{2}(58.8 \mathrm{mg}, 0.5$ $\mathrm{mmol}), \mathrm{CuBr} \cdot \mathrm{SMe}_{2}(10.3 \mathrm{mg}, 0.05 \mathrm{mmol}), \mathrm{TMEDA}(22.5 \mu \mathrm{L}, 0.15 \mathrm{mmol}), \mathrm{K}_{3} \mathrm{PO}_{4}(159.6 \mathrm{mg}, 0.75$ $\mathrm{mmol})$, and THF $(0.5 \mathrm{~mL})$ at $110^{\circ} \mathrm{C}$. The crude residue was purified by column chromatography over silica-gel, eluting with AcOEt/hexane $(1 / 30=\mathrm{v} / \mathrm{v})$ to afford the desired compound $\mathbf{3 d}(87.7 \mathrm{mg}$, $0.359 \mathrm{mmol}, 76 \%)$ as a white solid; $\mathrm{Mp}=82-83{ }^{\circ} \mathrm{C} .{ }^{1} \mathrm{H} \mathrm{NMR}\left(500 \mathrm{MHz}, \mathrm{CDCl}_{3}\right) \delta: 7.98(\mathrm{br}, 1 \mathrm{H})$, 7.55 (d, $J=7.6 \mathrm{~Hz}, 2 \mathrm{H}), 7.37$ (t, $J=8.0 \mathrm{~Hz}, 2 \mathrm{H}), 7.19(\mathrm{t}, J=7.5 \mathrm{~Hz}, 1 \mathrm{H}), 2.13-2.07(\mathrm{~m}, 1 \mathrm{H})$, 2.06-2.01 (m, 1H), 1.88-1.81 (m, 1H), 1.80-1.74 (m, 1H), 1.59-1.52 (m, 1H), 1.39-1.34 (m, 3H), 1.11 $(\mathrm{t}, J=7.4 \mathrm{~Hz}, 3 \mathrm{H}), 0.91(\mathrm{t}, J=7.1 \mathrm{~Hz}, 3 \mathrm{H}) \cdot{ }^{13} \mathrm{C} \mathrm{NMR}\left(125 \mathrm{MHz}, \mathrm{CDCl}_{3}\right) \delta 165.9,136.69,129.3$, 125.6, 121.3, 120.6, 51.9, 37.2, 31.3, 27.8, 22.6, 13.9, 10.0, FT-IR (neat, $\mathrm{cm}^{-1}$ ) 3299, 2957, 2931, 2871, 2244, 1659, 1599, 1539, 1490, 1443, 1301, 1250, 1161, 1082, 1029, 924, 867, 761, 697. HRMS (ESI-MS) $m / z\left[\mathrm{M}+\mathrm{H}^{+}\right]$Calcd for $\mathrm{C}_{15} \mathrm{H}_{21} \mathrm{ON}_{2} 245.1654$, found 245.1652. 
2-cyano-N-phenyl-2-propylpentanamide (3e)<smiles>CCCC(C)(CC)C(=O)Nc1ccccc1</smiles>

Following the general procedure above, using 1 e $(149.1 \mathrm{mg}, 0.50 \mathrm{mmol}), \mathrm{Zn}(\mathrm{CN})_{2}(58.9 \mathrm{mg}, 0.5$ $\mathrm{mmol}), \mathrm{CuBr} \cdot \mathrm{SMe}_{2}(10.4 \mathrm{mg}, 0.05 \mathrm{mmol}), \mathrm{TMEDA}(22.5 \mu \mathrm{L}, 0.15 \mathrm{mmol}), \mathrm{K}_{3} \mathrm{PO}_{4}(159.4 \mathrm{mg}, 0.75$ $\mathrm{mmol})$, and THF $(0.5 \mathrm{~mL})$ at $110^{\circ} \mathrm{C}$. The crude residue was purified by column chromatography over silica-gel, eluting with AcOEt/hexane $(1 / 30=\mathrm{v} / \mathrm{v})$ to afford the desired compound $\mathbf{3 e}(86.1 \mathrm{mg}$, $0.352 \mathrm{mmol}, 70 \%)$ as a white solid; $\mathrm{Mp}=94-95^{\circ} \mathrm{C} .{ }^{1} \mathrm{H}$ NMR $\left(500 \mathrm{MHz}, \mathrm{CDCl}_{3}\right) \delta: 7.98$ (brs, $\left.1 \mathrm{H}\right)$, $7.54(\mathrm{~d}, J=7.6 \mathrm{~Hz}, 2 \mathrm{H}), 7.37$ (t, $J=8.0 \mathrm{~Hz}, 2 \mathrm{H}), 7.19(\mathrm{t}, J=7.4 \mathrm{~Hz}, 1 \mathrm{H}), 2.05-1.99(\mathrm{~m}, 2 \mathrm{H})$, 1.78-1.72 (m, 2H), 1.66-1.58 (m, $2 \mathrm{H}), 1.47-1.37(\mathrm{~m}, 2 \mathrm{H}), 0.97(\mathrm{t}, J=7.2 \mathrm{~Hz}, 6 \mathrm{H}) .{ }^{13} \mathrm{C}$ NMR $(125$ $\left.\mathrm{MHz}, \mathrm{CDCl}_{3}\right) \delta 166.00,136.67,129.30,125.62,121.45,120.64,51.06,39.82,19.10,13.89 . \quad$ FT-IR (neat, $\mathrm{cm}^{-1}$ ) 3325, 3280, 2960, 2932, 2876, 2243, 1659, 1596, 1541, 1489, 1442, 1318, 1249, 1163, 1077, 1027, 894, 837, 791, 756, 693. HRMS (ESI-MS) $\mathrm{m} / \mathrm{z}\left[\mathrm{M}+\mathrm{H}^{+}\right]$Calcd for $\mathrm{C}_{15} \mathrm{H}_{21} \mathrm{ON}_{2}$ 245.1654 , found 245.1654 .

2-cyano-2-hexyl- $N$-phenyldecanamide (3f)

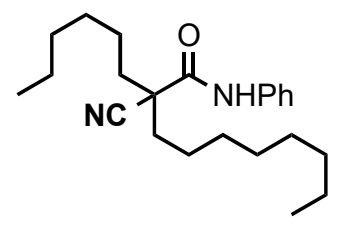

Following the general procedure above, using 1f $(205.3 \mathrm{mg}, 0.50 \mathrm{mmol}), \mathrm{Zn}(\mathrm{CN})_{2}(58.9 \mathrm{mg}, 0.5$ $\mathrm{mmol}), \mathrm{CuBr} \cdot \mathrm{SMe}_{2}(10.2 \mathrm{mg}, 0.05 \mathrm{mmol})$, TMEDA $(23 \mu \mathrm{L}, 0.15 \mathrm{mmol}), \mathrm{K}_{3} \mathrm{PO}_{4}(159.1 \mathrm{mg}, 0.75$ $\mathrm{mmol})$, and THF $(0.5 \mathrm{~mL})$ at $110^{\circ} \mathrm{C}$. The crude residue was purified by column chromatography over silica-gel, eluting with AcOEt/hexane $(1 / 40=\mathrm{v} / \mathrm{v})$ to afford the desired compound $\mathbf{3 f}$ ( $126.6 \mathrm{mg}$, $0.355 \mathrm{mmol}, 71 \%)$ as a yellow liquid. ${ }^{1} \mathrm{H}$ NMR $\left(500 \mathrm{MHz}, \mathrm{CDCl}_{3}\right) \delta: 7.97(\mathrm{brs}, 1 \mathrm{H}), 7.54(\mathrm{~d}, J=$ $7.6 \mathrm{~Hz}, 2 \mathrm{H}), 7.37(\mathrm{t}, J=8.0 \mathrm{~Hz}, 2 \mathrm{H}), 7.19(\mathrm{t}, J=7.5 \mathrm{~Hz}, 1 \mathrm{H}), 2.05-2.00(\mathrm{~m}, 2 \mathrm{H}), 1.79-1.73(\mathrm{~m}, 2 \mathrm{H})$, $1.69-1.58(\mathrm{~m}, 1 \mathrm{H}), 1.36-1.24(\mathrm{~m}, 19 \mathrm{H}), 0.86(\mathrm{t}, J=7.0 \mathrm{~Hz}, 6 \mathrm{H}) .{ }^{13} \mathrm{C} \mathrm{NMR}\left(125 \mathrm{MHz}, \mathrm{CDCl}_{3}\right) \delta$ : 166.0, 136.7, 129.3, 125.6, 121.6, 120.6, 51.2, 37.8, 31.9, 31.6, 29.4, 29.3, 29.2, 29.1, 25.7, 25.6, 22.8, 22.6, 14.2, 14.1. FT-IR (neat, $\mathrm{cm}^{-1}$ ) 3414, 3339, 2924, 2855, 2236, 1692, 1600, 1529, 1499, $1441,1311,1243,1193,1136,1078,903,750,690$. HRMS (ESI-MS) $m / z\left[\mathrm{M}+\mathrm{H}^{+}\right]$Calcd for $\mathrm{C}_{23} \mathrm{H}_{37} \mathrm{ON}_{2}$ 357.2906, found 357.2906.

1-cyano- $N$-phenylcyclobutane-1-carboxamide (3g)<smiles>N#CC1(C(=O)Nc2ccccc2)CCC1</smiles>

Following the general procedure above, using $1 \mathrm{~g}(127.4 \mathrm{mg}, 0.50 \mathrm{mmol}), \mathrm{Zn}(\mathrm{CN})_{2}(58.8 \mathrm{mg}, 0.5$ $\mathrm{mmol}), \mathrm{CuBr} \cdot \mathrm{SMe}_{2}(10.3 \mathrm{mg}, 0.05 \mathrm{mmol})$, TMEDA (22.5 $\left.\mu \mathrm{l}, 0.15 \mathrm{mmol}\right), \mathrm{K}_{3} \mathrm{PO}_{4}(159.8 \mathrm{mg}, 0.75$ $\mathrm{mmol})$, and THF $(0.5 \mathrm{~mL})$ at $110^{\circ} \mathrm{C}$. The crude residue was purified by column chromatography over silica-gel, eluting with AcOEt/hexane $(1 / 15=\mathrm{v} / \mathrm{v})$ to afford the desired compound $\mathbf{3 g}(50.2 \mathrm{mg}$, $0.251 \mathrm{mmol}, 50 \%)$ as a yellow solid; $\mathrm{Mp}=100-102{ }^{\circ} \mathrm{C} .{ }^{1} \mathrm{H} \mathrm{NMR}\left(500 \mathrm{MHz}, \mathrm{CDCl}_{3}\right) \delta: 7.71(\mathrm{brs}$, $1 \mathrm{H}), 7.54(\mathrm{~d}, J=7.4 \mathrm{~Hz}, 2 \mathrm{H}), 7.37(\mathrm{t}, J=8.0 \mathrm{~Hz}, 2 \mathrm{H}), 7.18(\mathrm{t}, J=7.4 \mathrm{~Hz}, 1 \mathrm{H}), 2.93-2.87(\mathrm{~m}, 2 \mathrm{H})$, 2.64-2.59 (m, 2H), 2.38-2.28 (m, 1H), 2.25-2.16 (m, 1H). ${ }^{13} \mathrm{C}$ NMR $\left(125 \mathrm{MHz}, \mathrm{CDCl}_{3}\right) \delta: 165.3$, $136.9,129.3,125.5,121.9,120.5,40.9,31.2,17.4$. FT-IR (neat, $\mathrm{cm}^{-1}$ ) 3247, 3191, 3128, 2954, $2875,2236,1664,1596,1535,1442,753,693$. HRMS (ESI-MS) $\mathrm{m} / z\left[\mathrm{M}+\mathrm{H}^{+}\right]$Calcd for $\mathrm{C}_{12} \mathrm{H}_{13} \mathrm{O}_{2} \mathrm{~N}_{2} 201.1028$, found 201.1028. 
1-cyano- $N$-phenylcyclopentane-1-carboxamide (3h)<smiles>N#CC1(C(=O)Nc2ccccc2)CCCC1</smiles>

Following the general procedure above, using $1 \mathrm{~h}(134.1 \mathrm{mg}, 0.50 \mathrm{mmol}), \mathrm{Zn}(\mathrm{CN})_{2}(58.9 \mathrm{mg}, 0.5$ $\mathrm{mmol}), \mathrm{CuBr} \cdot \mathrm{SMe}_{2}(10.3 \mathrm{mg}, 0.05 \mathrm{mmol})$, TMEDA (22.5 $\left.\mu 1,0.15 \mathrm{mmol}\right), \mathrm{K}_{3} \mathrm{PO}_{4}(159.8 \mathrm{mg}, 0.75$ $\mathrm{mmol})$, and THF $(0.5 \mathrm{~mL})$ at $110^{\circ} \mathrm{C}$. The crude residue was purified by column chromatography over silica-gel, eluting with AcOEt/hexane $(1 / 10=\mathrm{v} / \mathrm{v})$ to afford the desired compound $\mathbf{3 h}(73.8 \mathrm{mg}$, $0.344 \mathrm{mmol}, 69 \%)$ as a yellow solid; $\mathrm{Mp}=68-69^{\circ} \mathrm{C} .{ }^{1} \mathrm{H}$ NMR $\left(500 \mathrm{MHz}, \mathrm{CDCl}_{3}\right) \delta: 7.96$ (brs, $1 \mathrm{H}), 7.53(\mathrm{~d}, J=7.7 \mathrm{~Hz}, 2 \mathrm{H}), 7.37(\mathrm{t}, J=8.0 \mathrm{~Hz}, 2 \mathrm{H}), 7.37(\mathrm{t}, J=7.4 \mathrm{~Hz}, 1 \mathrm{H}), 2.43-2.37(\mathrm{~m}, 2 \mathrm{H})$, 2.33-2.28 (m, 2H), 2.01-1.88 (m, 4H). ${ }^{13} \mathrm{C}$ NMR $\left(125 \mathrm{MHz}, \mathrm{CDCl}_{3}\right) \delta: 166.5,137.0,129.3,125.5$, 122.9, 120.5, 48.9, 38.3, 25.7. FT-IR (neat, $\mathrm{cm}^{-1}$ ) 3334, 3058, 2955, 2874, 2233, 1698, 1599, 1542, 1489, 1438, 752, 691. HRMS (ESI-MS) $\mathrm{m} / z\left[\mathrm{M}+\mathrm{H}^{+}\right]$Calcd for $\mathrm{C}_{13} \mathrm{H}_{15} \mathrm{ON}_{2} 215.1184$, found 215.1184 .

1-cyano- $N$-phenylcyclohexane-1-carboxamide (3i)<smiles>N#CC1(C(=O)Nc2ccccc2)CCCCC1</smiles>

Following the general procedure above, using $1 \mathbf{i}(141.4 \mathrm{mg}, 0.50 \mathrm{mmol}), \mathrm{Zn}(\mathrm{CN})_{2}(58.6 \mathrm{mg}, 0.5$ $\mathrm{mmol}), \mathrm{CuBr} \cdot \mathrm{SMe}_{2}(10.5 \mathrm{mg}, 0.05 \mathrm{mmol})$, TMEDA (22.5 $\left.\mu \mathrm{l}, 0.15 \mathrm{mmol}\right), \mathrm{K}_{3} \mathrm{PO}_{4}(159.2 \mathrm{mg}, 0.75$ $\mathrm{mmol})$, and THF $(0.5 \mathrm{~mL})$ at $110{ }^{\circ} \mathrm{C}$. The crude residue was purified by column chromatography over silica-gel, eluting with AcOEt/hexane $(1 / 20=\mathrm{v} / \mathrm{v})$ to afford the desired compound $\mathbf{3 i}(36.5 \mathrm{mg}$, $0.160 \mathrm{mmol}, 32 \%)$ as a white solid; $\mathrm{Mp}=104-106{ }^{\circ} \mathrm{C} .{ }^{1} \mathrm{H} \mathrm{NMR}\left(500 \mathrm{MHz}, \mathrm{CDCl}_{3}\right) \delta: 7.92$ (brs, $1 \mathrm{H}), 7.54(\mathrm{~d}, J=7.6 \mathrm{~Hz}, 2 \mathrm{H}), 7.37(\mathrm{t}, J=7.9 \mathrm{~Hz}, 2 \mathrm{H}), 7.18(\mathrm{t}, J=7.3 \mathrm{~Hz}, 1 \mathrm{H}), 2.12-2.08(\mathrm{~m}, 2 \mathrm{H})$, 2.04-1.98 (m, 2H), 1.91-1.87 (m, 2H), 1.84-1.80 (m, 1H), 1.73-1.63 (m, 2H), 1.37-1.30 (m, 1H). ${ }^{13} \mathrm{C}$ NMR $\left(125 \mathrm{MHz}, \mathrm{CDCl}_{3}\right) \delta: 166.5,136.9,129.3,125.5,121.3,120.5,47.6,33.3,24.7,22.8$. FT-IR (neat, $\mathrm{cm}^{-1}$ ) 3255, 2943, 2854, 2239, 1664, 1595, 1528, 1490, 1440, 1319, 1251, 967, 942, 912, 754, 692. HRMS (ESI-MS) $m / z\left[\mathrm{M}+\mathrm{H}^{+}\right]$Calcd for $\mathrm{C}_{14} \mathrm{H}_{17} \mathrm{ON}_{2} 229.1341$, found 229.1341 .

2-cyano- $N$-(4-methoxyphenyl)-2-methylpropanamide (3j)<smiles>COc1ccc(NC(=O)C(C)(C)C#N)cc1</smiles>

Following the general procedure above, using $1 \mathbf{j}(136.5 \mathrm{mg}, 0.50 \mathrm{mmol}), \mathrm{Zn}(\mathrm{CN})_{2}(58.8 \mathrm{mg}, 0.5$ mmol), $\mathrm{CuBr} \cdot \mathrm{SMe}_{2}(10.1 \mathrm{mg}, 0.05 \mathrm{mmol})$, TMEDA (22.5 $\left.\mu 1,0.15 \mathrm{mmol}\right), \mathrm{K}_{3} \mathrm{PO}_{4}(159.6 \mathrm{mg}, 0.75$ $\mathrm{mmol})$, and THF $(0.5 \mathrm{~mL})$ at $110^{\circ} \mathrm{C}$. The crude residue was purified by column chromatography over silica-gel, eluting with AcOEt/hexane $(1 / 10=\mathrm{v} / \mathrm{v})$ to afford the desired compound $\mathbf{3 j} \mathbf{j}(75.7 \mathrm{mg}$, $0.347 \mathrm{mmol}, 70 \%)$ as a brown solid; $\mathrm{Mp}=87-88^{\circ} \mathrm{C} .{ }^{1} \mathrm{H}$ NMR $\left(500 \mathrm{MHz}, \mathrm{CDCl}_{3}\right) \delta: 7.83($ brs, $1 \mathrm{H})$, $7.42(\mathrm{~d}, J=9.0 \mathrm{~Hz}, 2 \mathrm{H}), 6.89(\mathrm{~d}, J=9.0 \mathrm{~Hz}, 2 \mathrm{H}), 3.81(\mathrm{~s}, 3 \mathrm{H}), 1.68(\mathrm{~s}, 6 \mathrm{H}) .{ }^{13} \mathrm{C} \mathrm{NMR}(125 \mathrm{MHz}$, $\left.\mathrm{CDCl}_{3}\right) \delta 116.6,157.3,129.8,122.7,122.5,114.4,55.6,39.5,25.3$. FT-IR (neat, $\left.\mathrm{cm}^{-1}\right) 3250,3061$, $2838,2239,1664,1603,15541,1509,1233,1031,832,799$. HRMS (ESI-MS) $m / z\left[\mathrm{M}+\mathrm{H}^{+}\right] \mathrm{Calcd}$ for $\mathrm{C}_{12} \mathrm{H}_{15} \mathrm{O}_{2} \mathrm{~N}_{2} 219.1134$, found 219.1134. 
<smiles>COc1cc(NC(=O)C(C)(C)C)cc(OC)c1</smiles>

Following the general procedure above, using $1 \mathrm{k}(151.4 \mathrm{mg}, 0.50 \mathrm{mmol}), \mathrm{Zn}(\mathrm{CN})_{2}(58.9 \mathrm{mg}, 0.5$ mmol), $\mathrm{CuBr} \cdot \mathrm{SMe}_{2}(10.5 \mathrm{mg}, 0.05 \mathrm{mmol})$, TMEDA (22.5 $\left.\mu \mathrm{l}, 0.15 \mathrm{mmol}\right), \mathrm{K}_{3} \mathrm{PO}_{4}(159.3 \mathrm{mg}, 0.75$ $\mathrm{mmol})$, and THF $(0.5 \mathrm{~mL})$ at $110^{\circ} \mathrm{C}$. The crude residue was purified by column chromatography over silica-gel, eluting with AcOEt/hexane $(1 / 6=\mathrm{v} / \mathrm{v})$, and GPC to afford the desired compound $\mathbf{3 k}$ $(89.7 \mathrm{mg}, 0.361 \mathrm{mmol}, 72 \%)$ as a yellow solid; $\mathrm{Mp}=86-88^{\circ} \mathrm{C} .{ }^{1} \mathrm{H}$ NMR $\left(500 \mathrm{MHz}, \mathrm{CDCl}_{3}\right) \delta$ : 7.85 (brs, $1 \mathrm{H}), 6.76(\mathrm{~d}, J=2.3 \mathrm{~Hz}, 2 \mathrm{H}), 6.30(\mathrm{t}, J=2.2 \mathrm{~Hz}, 1 \mathrm{H}), 3.79(\mathrm{~s}, 6 \mathrm{H}), 1.68(\mathrm{~s}, 6 \mathrm{H}) .{ }^{13} \mathrm{C}$ NMR $\left(125 \mathrm{MHz}, \mathrm{CDCl}_{3}\right) \delta: 166.2,161.2,138.5,121.7,98.6,98.0,55.6,46.0,32.0,23.6,10.1$. FT-IR (neat, $\mathrm{cm}^{-1}$ ) 3313, 3007, 2940, 2844, 2239, 1675, 1599, 1545, 1457, 1159, 907. HRMS (ESI-MS) $m / z\left[\mathrm{M}+\mathrm{H}^{+}\right]$Calcd for $\mathrm{C}_{13} \mathrm{H}_{17} \mathrm{O}_{3} \mathrm{~N}_{2} 249.1239$, found 249.1239 .

N-(4-acetylphenyl)-2-cyano-2-methylpropanamide (3I)<smiles>CC(=O)c1ccc(NC(=O)C(C)(C)C)cc1</smiles>

Following the general procedure above, using 11 (141.9 mg, $0.50 \mathrm{mmol}), \mathrm{Zn}(\mathrm{CN})_{2}(58.7 \mathrm{mg}, 0.5$ $\mathrm{mmol}), \mathrm{CuBr} \cdot \mathrm{SMe}_{2}(10.2 \mathrm{mg}, 0.05 \mathrm{mmol})$, TMEDA $(22.5 \mu \mathrm{L}, 0.15 \mathrm{mmol}), \mathrm{K}_{3} \mathrm{PO}_{4}(159.8 \mathrm{mg}, 0.75$ $\mathrm{mmol})$, and THF $(0.5 \mathrm{~mL})$ at $110^{\circ} \mathrm{C}$. The crude residue was purified by column chromatography over silica-gel, eluting with AcOEt/hexane $(1 / 5=\mathrm{v} / \mathrm{v})$ to afford the desired compound $\mathbf{3 1}(82.6 \mathrm{mg}$, $0.358 \mathrm{mmol}, 72 \%)$ as a white solid; $\mathrm{Mp}=125-127{ }^{\circ} \mathrm{C} .{ }^{1} \mathrm{H}$ NMR $\left(500 \mathrm{MHz}, \mathrm{CDCl}_{3}\right) \delta: 8.05$ (brs, $1 \mathrm{H}), 7.98(\mathrm{~d}, J=8.7 \mathrm{~Hz}, 2 \mathrm{H}), 7.66(\mathrm{~d}, J=8.7 \mathrm{~Hz}, 2 \mathrm{H}), 2.59(\mathrm{~s}, 3 \mathrm{H}), 1.70(\mathrm{~s}, 6 \mathrm{H}) .{ }^{13} \mathrm{C}$ NMR $(125$ $\left.\mathrm{MHz}, \mathrm{CDCl}_{3}\right) \delta 197.0,168.9,141.1,133.9,129.8,122.2,119.7,39.8,26.6,25.2 . \quad$ FT-IR (neat, $\left.\mathrm{cm}^{-1}\right)$ 3349, 2988, 2833, 2251, 1694, 1670, 1590, 1524, 1398, 1311, 1269, 1152, 949, 838, 658. HRMS (ESI-MS) $m / z\left[\mathrm{M}+\mathrm{H}^{+}\right]$Calcd for $\mathrm{C}_{13} \mathrm{H}_{15} \mathrm{O}_{2} \mathrm{~N}_{2} 231.1134$, found 231.1134 .

N-(4-iodophenyl)-2-cyano-2-methylpropanamide (3m)<smiles>CC(C)(C#N)C(=O)Nc1ccc(I)cc1</smiles>

Following the general procedure above, using $1 \mathbf{m}(184.4 \mathrm{mg}, 0.50 \mathrm{mmol}), \mathrm{Zn}(\mathrm{CN})_{2}(58.9 \mathrm{mg}, 0.5$ $\mathrm{mmol}), \mathrm{CuBr} \cdot \mathrm{SMe}_{2}(10.4 \mathrm{mg}, 0.05 \mathrm{mmol}), \mathrm{TMEDA}(22.5 \mu \mathrm{L}, 0.15 \mathrm{mmol}), \mathrm{K}_{3} \mathrm{PO}_{4}(159.3 \mathrm{mg}, 0.75$ $\mathrm{mmol})$, and THF $(0.5 \mathrm{~mL})$ at $110^{\circ} \mathrm{C}$. The crude residue was purified by column chromatography over silica-gel, eluting with AcOEt/hexane $(1 / 15=\mathrm{v} / \mathrm{v})$ to afford the desired compound $\mathbf{3 m}(111.6$ $\mathrm{mg}, 0.355 \mathrm{mmol}, 70 \%)$ as a white solid; $\mathrm{Mp}=133-135{ }^{\circ} \mathrm{C} .{ }^{1} \mathrm{H}$ NMR $\left(500 \mathrm{MHz}, \mathrm{CDCl}_{3}\right) \delta: 7.89$ (brs, $1 \mathrm{H}), 7.67(\mathrm{~d}, J=8.5 \mathrm{~Hz}, 2 \mathrm{H}), 7.32(\mathrm{~d}, J=8.5 \mathrm{~Hz}, 2 \mathrm{H}), 1.68(\mathrm{~s}, 6 \mathrm{H}) .{ }^{13} \mathrm{C}$ NMR $(125 \mathrm{MHz}$, $\left.\mathrm{CDCl}_{3}\right) \delta 166.7,138.2,136.7,122.4,122.0,89.1,39.6,25.1$. FT-IR (neat, $\mathrm{cm}^{-1}$ ) 3233, 3103, 2992, $2240,1677,1595,1525,1465,1392,1307,1005,813$. HRMS (ESI-MS) $m / z\left[\mathrm{M}+\mathrm{H}^{+}\right]$Calcd for $\mathrm{C}_{11} \mathrm{H}_{12} \mathrm{O} \mathrm{N} \mathrm{N}_{2} \mathrm{I} 314.9994$, found 314.9994 . 
2-cyano-2-methyl-N-(4-(4,4,5,5-tetramethyl-1,3,2-dioxaborolan-2-yl)phenyl)propanamide (3n)<smiles>CC(C)(C#N)C(=O)Nc1ccc(Br)cc1</smiles>

Following the general procedure above, using $1 \mathrm{n}(184.0 \mathrm{mg}, 0.50 \mathrm{mmol}), \mathrm{Zn}(\mathrm{CN})_{2}(58.7 \mathrm{mg}, 0.5$ $\mathrm{mmol}), \mathrm{CuBr} \cdot \mathrm{SMe}_{2}(10.3 \mathrm{mg}, 0.05 \mathrm{mmol})$, TMEDA (22.5 $\left.\mu 1,0.15 \mathrm{mmol}\right), \mathrm{K}_{3} \mathrm{PO}_{4}(159.5 \mathrm{mg}, 0.75$ $\mathrm{mmol})$, and THF $(0.5 \mathrm{~mL})$ at $110^{\circ} \mathrm{C}$. The crude residue was purified by column chromatography over silica-gel, eluting with AcOEt/hexane $(1 / 10=\mathrm{v} / \mathrm{v})$, and GPC to afford the desired compound $3 \mathbf{n}$ (46.1 $\mathrm{mg}, 0.147 \mathrm{mmol}, 29 \%)$ as a white solid; $\mathrm{Mp}=176-178{ }^{\circ} \mathrm{C} .{ }^{1} \mathrm{H}$ NMR $\left(500 \mathrm{MHz}, \mathrm{CDCl}_{3}\right) \delta$ : 7.95 (brs, $1 \mathrm{H}), 7.81(\mathrm{~d}, J=8.7 \mathrm{~Hz}, 2 \mathrm{H}), 7.55(\mathrm{~d}, J=8.4 \mathrm{~Hz}, 2 \mathrm{H}), 1.69$ (s, $6 \mathrm{H}), 1.34(\mathrm{~s}, 12 \mathrm{H}) .{ }^{13} \mathrm{C}$ NMR (125 MHz, CDCl $) \delta: 166.6,139.4,136.0,122.5,119.3,84.0,39.8,25.3,25.0$. FT-IR (neat, $\mathrm{cm}^{-1}$ ) 3362, 2981, 2933, 2245, 1689, 1589, 1512, 1355, 1138, 1088, 829. HRMS (ESI-MS) $\mathrm{m} / \mathrm{z}$ $\left[\mathrm{M}+\mathrm{H}^{+}\right]$Calcd for $\mathrm{C}_{17} \mathrm{H}_{24} \mathrm{O}_{3} \mathrm{~N}_{2} \mathrm{~B} 315.1880$, found 315.1880.

N-(4-(4-bromopiperidine-1-carbonyl)phenyl)-2-cyano-2-methylpropanamide (3o)<smiles>CC(C)(C)C(=O)Nc1ccc(C(=O)N2CCC(Br)CC2)cc1</smiles>

Following the general procedure above, using $10(216.3 \mathrm{mg}, 0.50 \mathrm{mmol}), \mathrm{Zn}(\mathrm{CN})_{2}(58.6 \mathrm{mg}, 0.5$ $\mathrm{mmol}), \mathrm{CuBr} \cdot \mathrm{SMe}_{2}(10.3 \mathrm{mg}, 0.05 \mathrm{mmol})$, TMEDA (22.5 $\left.\mu 1,0.15 \mathrm{mmol}\right), \mathrm{K}_{3} \mathrm{PO}_{4}(159.5 \mathrm{mg}, 0.75$ $\mathrm{mmol})$, and THF $(0.5 \mathrm{~mL})$ at $110^{\circ} \mathrm{C}$. The crude residue was purified by column chromatography over silica-gel, eluting with AcOEt/hexane $(1 / 20=\mathrm{v} / \mathrm{v})$ to afford the desired compound 3o $(128.0$ $\mathrm{mg}, 0.338 \mathrm{mmol}, 68 \%)$ as a white solid; $\mathrm{Mp}=73-75^{\circ} \mathrm{C} .{ }^{1} \mathrm{H} \mathrm{NMR}\left(500 \mathrm{MHz}, \mathrm{CDCl}_{3}\right) \delta: 8.12$ (brs, $1 \mathrm{H}), 7.58(\mathrm{~d}, J=8.6 \mathrm{~Hz}, 2 \mathrm{H}), 7.41(\mathrm{~d}, J=8.7 \mathrm{~Hz}, 2 \mathrm{H}), 4.46-4.42(\mathrm{~m}, 1 \mathrm{H}), 3.99-3.92(\mathrm{~m}, 1 \mathrm{H})$, 3.82-3.60 (m, 2H), 3.50-3.27 (m, 1H), 2.18-1.94 (m, 4H), 1.69 (s, 6H). ${ }^{13} \mathrm{C}$ NMR (125 MHz, $\left.\mathrm{CDCl}_{3}\right)$ $\delta: 170.0,167.0,138.4,132.2,128.1,122.3,120.6,48.8,46.0,40.5,39.7,36.0,35.3,25.1$. FT-IR (neat, $\left.\mathrm{cm}^{-1}\right)$ 3266, 3105, 2935, 2869, 2236, 1691, 1599, 1521, 1436, 1399, 955. HRMS (ESI-MS) $m / z\left[\mathrm{M}+\mathrm{H}^{+}\right]$Calcd for $\mathrm{C}_{17} \mathrm{H}_{21} \mathrm{O}_{2} \mathrm{~N}_{3} \mathrm{Br}$ 378.0817, found 378.0817.

3-bromopropyl 4-(2-cyano-2-methylpropanamido)benzoate (3p)<smiles>CC(C)(C)C(=O)Nc1ccc(C(=O)OCCCBr)cc1</smiles>

Following the general procedure above, using $1 p(203.7 \mathrm{mg}, 0.50 \mathrm{mmol}), \mathrm{Zn}(\mathrm{CN})_{2}(58.7 \mathrm{mg}, 0.5$ $\mathrm{mmol}), \mathrm{CuBr} \cdot \mathrm{SMe}_{2}(10.3 \mathrm{mg}, 0.05 \mathrm{mmol})$, TMEDA (22.5 $\left.\mu \mathrm{l}, 0.15 \mathrm{mmol}\right), \mathrm{K}_{3} \mathrm{PO}_{4}(159.3 \mathrm{mg}, 0.75$ $\mathrm{mmol}), \mathrm{Zn}^{0}(3.5 \mathrm{mg}, 0.05 \mathrm{mmol}), \mathrm{ZnBr}_{2}(11.1 \mathrm{mg}, 0.05 \mathrm{mmol})$, and THF $(0.5 \mathrm{~mL})$ at $110^{\circ} \mathrm{C}$. The crude residue was purified by column chromatography over silica-gel, eluting with AcOEt/hexane $(1 / 5=\mathrm{v} / \mathrm{v})$, and GPC to afford the desired compound $\mathbf{3 p}(64.2 \mathrm{mg}, 0.182 \mathrm{mmol}, 36 \%)$ as a colorless oil; $\mathrm{Mp}=93-94{ }^{\circ} \mathrm{C} . \quad{ }^{1} \mathrm{H}$ NMR $\left(500 \mathrm{MHz}, \mathrm{CDCl}_{3}\right) \delta: 8.07$ (brs, $\left.1 \mathrm{H}\right), 8.04(\mathrm{~d}, J=8.8 \mathrm{~Hz}, 2 \mathrm{H}), 7.65$ (d, $J=8.9 \mathrm{~Hz}, 2 \mathrm{H}), 4.47$ (t, $J=6.3 \mathrm{~Hz}, 2 \mathrm{H}), 3.55$ (t, $J=6.3 \mathrm{~Hz}, 2 \mathrm{H}), 2.35-2.30(\mathrm{~m}, 2 \mathrm{H}), 1.70(\mathrm{~s}, 6 \mathrm{H})$. ${ }^{13} \mathrm{C}$ NMR $\left(125 \mathrm{MHz}, \mathrm{CDCl}_{3}\right) \delta: 166.8,165.8,141.1,131.0,125.2,122.3,119.7,62.9,39.8,31.9,29.6$, 25.2. FT-IR (neat, $\mathrm{cm}^{-1}$ ) 3367, 3111, 2890, 2248, 1700, 1597, 1529, 1460, 1404, 861, 766, 696. HRMS (ESI-MS) $m / z\left[\mathrm{M}+\mathrm{H}^{+}\right]$Calcd for $\mathrm{C}_{15} \mathrm{H}_{18} \mathrm{O}_{3} \mathrm{~N}_{2} \mathrm{Br} 353.0501$, found 353.0501. 
<smiles>CC(C)(C)C(=O)Nc1ccc(C(=O)OCC(CBr)(CBr)CBr)cc1</smiles>

Following the general procedure above, using $1 \mathrm{q}(296.7 \mathrm{mg}, 0.50 \mathrm{mmol}), \mathrm{Zn}(\mathrm{CN})_{2}(58.7 \mathrm{mg}, 0.5$ $\mathrm{mmol}), \mathrm{CuBr} \cdot \mathrm{SMe}_{2}(10.2 \mathrm{mg}, 0.05 \mathrm{mmol})$, TMEDA (22.5 $\left.\mu \mathrm{l}, 0.15 \mathrm{mmol}\right), \mathrm{K}_{3} \mathrm{PO}_{4}(159.5 \mathrm{mg}, 0.75$ $\mathrm{mmol}), \mathrm{Zn}^{0}(3.5 \mathrm{mg}, 0.05 \mathrm{mmol}), \mathrm{ZnBr}_{2}(11.2 \mathrm{mg}, 0.05 \mathrm{mmol})$, and THF $(0.5 \mathrm{~mL})$ at $110^{\circ} \mathrm{C}$. The crude residue was purified by column chromatography over silica-gel, eluting with AcOEt/hexane $(1 / 5=\mathrm{v} / \mathrm{v})$, and GPC to afford the desired compound $\mathbf{3 q}(110.3 \mathrm{mg}, 0.20 \mathrm{mmol}, 41 \%)$ as a colorless oil; ${ }^{1} \mathrm{H}$ NMR (500 MHz, $\left.\mathrm{CDCl}_{3}\right) \delta: 8.08$ (brs, $\left.1 \mathrm{H}\right), 8.02(\mathrm{~d}, J=8.8 \mathrm{~Hz}, 2 \mathrm{H}), 7.67$ (d, $\left.J=8.8 \mathrm{~Hz}, 2 \mathrm{H}\right)$, $4.46(\mathrm{~s}, 2 \mathrm{H}), 3.64(\mathrm{~s}, 6 \mathrm{H}), 1.71(\mathrm{~s}, 6 \mathrm{H}) .{ }^{13} \mathrm{C} \mathrm{NMR}\left(125 \mathrm{MHz}, \mathrm{CDCl}_{3}\right) \delta: 166.9$ 165.0, 141.5, 131.1, 126.0, 122.3, 120.0, 64.4, 43.2, 39.9, 34.3, 25.2. FT-IR (neat, $\mathrm{cm}^{-1}$ ) 3335, 3116, 2963, 2940, 2874, 2236, 1697, 1597, 1521, 1406, 1266, 1098, 855, 692. HRMS (ESI-MS) $m / z\left[\mathrm{M}+\mathrm{H}^{+}\right]$Calcd for $\mathrm{C}_{17} \mathrm{H}_{20} \mathrm{Br}_{3} \mathrm{O}_{3} \mathrm{~N}_{2}$ 536.9024, found 536.9024.

4-iodobenzyl 4-(2-cyano-2-methylpropanamido)benzoate (3r)<smiles>CC(C)(C#N)C(=O)Nc1ccc(C(=O)OCc2ccc(I)cc2)cc1</smiles>

Following the general procedure above, using $1 \mathbf{r}(251.3 \mathrm{mg}, 0.50 \mathrm{mmol}), \mathrm{Zn}(\mathrm{CN})_{2}(58.7 \mathrm{mg}, 0.5$ mmol), $\mathrm{CuBr} \cdot \mathrm{SMe}_{2}(10.6 \mathrm{mg}, 0.05 \mathrm{mmol})$, TMEDA (22.5 $\left.\mu \mathrm{l}, 0.15 \mathrm{mmol}\right), \mathrm{K}_{3} \mathrm{PO}_{4}(159.7 \mathrm{mg}, 0.75$ $\mathrm{mmol})$, and THF $(0.5 \mathrm{~mL})$ at $110^{\circ} \mathrm{C}$. The crude residue was purified by column chromatography over silica-gel, eluting with AcOEt/hexane $(1 / 5=\mathrm{v} / \mathrm{v})$ to afford the desired compound $\mathbf{3 r}(136.0 \mathrm{mg}$, $0.279 \mathrm{mmol}, 56 \%)$ as a yellow solid; $\mathrm{Mp}=99-101{ }^{\circ} \mathrm{C} . \quad{ }^{1} \mathrm{H}$ NMR $\left(500 \mathrm{MHz}, \mathrm{CDCl}_{3}\right) \delta: 8.06(\mathrm{~d}, J=$ $8.9 \mathrm{~Hz}, 2 \mathrm{H}), 8.05$ (brs, $1 \mathrm{H}), 7.73(\mathrm{~d}, J=7.9 \mathrm{~Hz}, 2 \mathrm{H}), 7.64(\mathrm{~d}, J=8.8 \mathrm{~Hz}, 2 \mathrm{H}), 7.20(\mathrm{~d}, J=7.7 \mathrm{~Hz}$, $2 \mathrm{H}), 5.29(\mathrm{~s}, 2 \mathrm{H}), 1.70(\mathrm{~s}, 6 \mathrm{H}) .{ }^{13} \mathrm{C} \mathrm{NMR}\left(125 \mathrm{MHz}, \mathrm{CDCl}_{3}\right) \delta 166.8,165.6,141.1,137.9,135.7$, 131.1, 130.2, 126.6, 122.2, 119.6, 94.1, 66.2, 39.9, 25.2. FT-IR (neat, $\mathrm{cm}^{-1}$ ) 3250, 3061, 2838, $2239,1664,1603,15541,1509,1233,1031,832,799$. HRMS (ESI-MS) $m / z\left[\mathrm{M}+\mathrm{H}^{+}\right]$Calcd for $\mathrm{C}_{19} \mathrm{H}_{18} \mathrm{~N}_{2} \mathrm{O}_{3} \mathrm{I} 449.0362$, found 449.0362 .

2-cyano- $N$-(3,5-dimethoxyphenyl)-2-methylbutanamide (3s)<smiles>CCC(C)(C)C(=O)Nc1cc(OC)cc(OC)c1</smiles>

Following the general procedure above, using $1 \mathrm{~s}(158.3 \mathrm{mg}, 0.50 \mathrm{mmol}), \mathrm{Zn}(\mathrm{CN})_{2}(58.9 \mathrm{mg}, 0.5$ $\mathrm{mmol}), \mathrm{CuBr} \cdot \mathrm{SMe}_{2}(10.5 \mathrm{mg}, 0.05 \mathrm{mmol})$, TMEDA (22.5 $\left.\mu \mathrm{l}, 0.15 \mathrm{mmol}\right), \mathrm{K}_{3} \mathrm{PO}_{4}(159.2 \mathrm{mg}, 0.75$ $\mathrm{mmol})$, and THF $(0.5 \mathrm{~mL})$ at $110^{\circ} \mathrm{C}$. The crude residue was purified by column chromatography over silica-gel, eluting with AcOEt/hexane $(1 / 8=\mathrm{v} / \mathrm{v})$ to afford the desired compound 3s $(96.6 \mathrm{mg}$, $0.368 \mathrm{mmol}, 74 \%)$ as a colorless oil; $\mathrm{Mp}=121-122{ }^{\circ} \mathrm{C} .{ }^{1} \mathrm{H} \mathrm{NMR}\left(500 \mathrm{MHz}, \mathrm{CDCl}_{3}\right) \delta: 7.89(\mathrm{brs}$, $1 \mathrm{H}), 6.77(\mathrm{~d}, J=2.1 \mathrm{~Hz}, 2 \mathrm{H}), 6.30(\mathrm{t}, J=2.2 \mathrm{~Hz}, 1 \mathrm{H}), 3.79(\mathrm{~s}, 6 \mathrm{H}), 2.14-2.07(\mathrm{~m}, 1 \mathrm{H}), 1.87-1.80(\mathrm{~m}$, $1 \mathrm{H}), 1.65(\mathrm{~s}, 3 \mathrm{H}), 1.12(\mathrm{t}, J=7.7 \mathrm{~Hz}, 3 \mathrm{H}) .{ }^{13} \mathrm{C} \mathrm{NMR}\left(125 \mathrm{MHz}, \mathrm{CDCl}_{3}\right) \delta: 166.2,161.2$, 138.5,121.7, 98.6, 98.0, 55.6, 46.1, 32.0, 23.6, 10.1. FT-IR (neat, $\mathrm{cm}^{-1}$ ) 3325, 2100, 2956, 2838, $2247,1656,1620,1596,1551,1450,1157,850$. HRMS (ESI-MS) $m / z\left[\mathrm{M}+\mathrm{H}^{+}\right]$Calcd for $\mathrm{C}_{14} \mathrm{H}_{19} \mathrm{~N}_{2} \mathrm{O}_{3} 263.1396$, found 263.1396. 
2-cyano-2-ethyl- $N$-( $p$-tolyl)hexanamide (3t)<smiles>CCCCC(C)(CC)C(=O)Nc1ccc(C)cc1</smiles>

Following the general procedure above, using 1t $(161.2 \mathrm{mg}, 0.50 \mathrm{mmol}), \mathrm{Zn}(\mathrm{CN})_{2}(58.7 \mathrm{mg}, 0.5$ $\mathrm{mmol}), \mathrm{CuBr} \cdot \mathrm{SMe}_{2}(10.2 \mathrm{mg}, 0.05 \mathrm{mmol}), \mathrm{TMEDA}(23 \mu \mathrm{L}, 0.15 \mathrm{mmol}), \mathrm{K}_{3} \mathrm{PO}_{4}(159.2 \mathrm{mg}, 0.75$ $\mathrm{mmol})$, and THF $(0.5 \mathrm{~mL})$ at $110^{\circ} \mathrm{C}$. The crude residue was purified by column chromatography over silica-gel, eluting with AcOEt/hexane $(1 / 25=\mathrm{v} / \mathrm{v})$ to afford the desired compound $\mathbf{3 t}(91.5 \mathrm{mg}$, $0.354 \mathrm{mmol}, 71 \%)$ as a white solid. $\mathrm{Mp}=113-114{ }^{\circ} \mathrm{C} .{ }^{1} \mathrm{H}$ NMR $\left(500 \mathrm{MHz}, \mathrm{CDCl}_{3}\right) \delta: 7.93$ (brs, $1 \mathrm{H}), 7.42(\mathrm{~d}, J=8.4 \mathrm{~Hz}, 2 \mathrm{H}), 7.17(\mathrm{~d}, J=8.2 \mathrm{~Hz}, 2 \mathrm{H}), 2.34(\mathrm{~s}, 3 \mathrm{H}), 2.12-2.06(\mathrm{~m}, 1 \mathrm{H}), 2.05-2.00(\mathrm{~m}$, $1 \mathrm{H}), 1.87-1.80(\mathrm{~m}, 1 \mathrm{H}), 1.79-1.73(\mathrm{~m}, 1 \mathrm{H}), 1.55-1.52(\mathrm{~m}, 1 \mathrm{H}), 1.40-1.34(\mathrm{~m}, 3 \mathrm{H}), 1.10(\mathrm{t}, J=7.4 \mathrm{~Hz}$, $3 \mathrm{H}), 0.91(\mathrm{t}, J=7.2 \mathrm{~Hz}, 3 \mathrm{H}) .{ }^{13} \mathrm{C}$ NMR $\left(125 \mathrm{MHz}, \mathrm{CDCl}_{3}\right) \delta 165.8,135.4134 .1,129.8,121.4$, 120.7, 51.9, 37.2, 31.2, 27.8, 22.6, 21.1, 13.9, 10.0. FT-IR (neat, $\mathrm{cm}^{-1}$ ) 3307, 2956, 2930, 2872, $2244,1650,1602,1534,1509,1458,1404,1312,1251,1161,1021,918,868,813,694$. HRMS (ESI-MS) $m / z\left[\mathrm{M}+\mathrm{H}^{+}\right]$Calcd for $\mathrm{C}_{16} \mathrm{H}_{23} \mathrm{ON}_{2} 259.1810$, found 259.1810 .

\section{Synthesis of cyanated carboxamide possessing peptide General procedure for the synthesis of 5.}

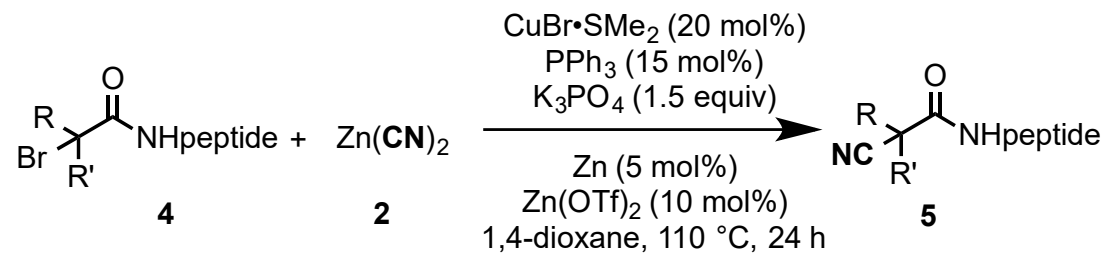

$4(0.50 \mathrm{mmol}), \mathrm{Zn}(\mathrm{CN})_{2}(58.4 \mathrm{mg}, 0.5 \mathrm{mmol}), \mathrm{CuBr} \cdot \mathrm{SMe}_{2}(20.4 \mathrm{mg}, 0.10 \mathrm{mmol}), \mathrm{PPh}_{3}(20.0 \mathrm{mg}$, $0.075 \mathrm{mmol}), \mathrm{K}_{3} \mathrm{PO}_{4}(165.4 \mathrm{mg}, 0.75 \mathrm{mmol}), \mathrm{Zn}(1.7 \mathrm{mg}, 0.025 \mathrm{mmol}), \mathrm{Zn}(\mathrm{OTf})_{2}(18.0 \mathrm{mg}, 0.050$ mmol) were sequentially added under air to a sealed tube equipped with a stir bar. Dried 1,4-dioxane $(1.0 \mathrm{~mL})$ was added by syringe, and the resulting mixture was vigorously stirred under nitrogen atmosphere [charged by $\mathrm{N}_{2}(99.95 \%)$ gas flow] for $24 \mathrm{~h}$ at $110^{\circ} \mathrm{C}$. After this time, the contents of the flask were filtered through a plug of silica gel and then concentrated by rotary evaporation. The crude residue was purified with silica-gel column chromatography, eluting with AcOEt/hexane to afford the product $\mathbf{5}$.

methyl (2-cyano-2-methylpropanoyl)glycinate (5a)<smiles>CC(=O)CNC(=O)C(C)(C)C#N</smiles>

Following the general procedure above, using $4 \mathrm{a}(119.0 \mathrm{mg}, 0.50 \mathrm{mmol}), \mathrm{Zn}(\mathrm{CN})_{2}(58.4 \mathrm{mg}, 0.5$ $\mathrm{mmol}), \mathrm{CuBr} \cdot \mathrm{SMe}_{2}(20.4 \mathrm{mg}, 0.10 \mathrm{mmol}), \mathrm{PPh}_{3}(20.0 \mathrm{mg}, 0.075 \mathrm{mmol}), \mathrm{K}_{3} \mathrm{PO}_{4}(165.4 \mathrm{mg}, 0.75$ $\mathrm{mmol}), \mathrm{Zn}(1.7 \mathrm{mg}, 0.025 \mathrm{mmol}), \mathrm{Zn}(\mathrm{OTf})_{2}(18.0 \mathrm{mg}, 0.050 \mathrm{mmol})$, and 1,4-dioxane $(1 \mathrm{~mL})$ at $110{ }^{\circ} \mathrm{C}$. The crude residue was purified by column chromatography over silica-gel, eluting with AcOEt/hexane $(1 / 3=\mathrm{v} / \mathrm{v})$ to afford the desired compound $\mathbf{5 a}(47.4 \mathrm{mg}, 0.258 \mathrm{mmol}, 52 \%)$ as a colorless oil; ${ }^{1} \mathrm{H}$ NMR $\left(500 \mathrm{MHz}, \mathrm{CDCl}_{3}\right) \delta$ : 6.77 (brs, $\left.1 \mathrm{H}\right), 4.07(\mathrm{~d}, J=7.9 \mathrm{~Hz}, 2 \mathrm{H}), 3.78(\mathrm{~s}, 3 \mathrm{H})$, $1.61(\mathrm{~s}, 6 \mathrm{H}) .{ }^{13} \mathrm{C}$ NMR $\left(125 \mathrm{MHz}, \mathrm{CDCl}_{3}\right) \delta: 169.6,169.1,122.2,52.7,41.8,38.9,25.0$. FT-IR (neat, $\mathrm{cm}^{-1}$ ) 3361, 2990, 2954, 2239, 1744, 1670, 1526, 1438, 1368, 1208, 1178, 1021, 980, 866, 705 . HRMS (ESI-MS) $m / z\left[\mathrm{M}+\mathrm{H}^{+}\right]$Calcd for $\mathrm{C}_{8} \mathrm{H}_{13} \mathrm{O}_{3} \mathrm{~N}_{2}$ 185.0926, found 185.0926. 
methyl (2-cyano-2-methylbutanoyl)glycinate (5b)<smiles>CCC(C)(C)C(=O)NCC(C)=O</smiles>

Following the general procedure above, using $4 \mathbf{b}(126.3 \mathrm{mg}, 0.50 \mathrm{mmol}), \mathrm{Zn}(\mathrm{CN})_{2}(58.7 \mathrm{mg}, 0.5$ $\mathrm{mmol}), \mathrm{CuBr} \cdot \mathrm{SMe}_{2}(30.6 \mathrm{mg}, 0.15 \mathrm{mmol}), \mathrm{PPh}_{3}(39.3 \mathrm{mg}, 0.15 \mathrm{mmol}), \mathrm{K}_{3} \mathrm{PO}_{4}(159.1 \mathrm{mg}, 0.75$ $\mathrm{mmol}), \mathrm{Zn}(1.7 \mathrm{mg}, 0.025 \mathrm{mmol}), \mathrm{Zn}(\mathrm{OTf})_{2}(18.2 \mathrm{mg}, 0.50 \mathrm{mmol})$, and 1,4-dioxane $(1 \mathrm{~mL})$ at $110{ }^{\circ} \mathrm{C}$. The crude residue was purified by column chromatography over silica-gel, eluting with AcOEt/hexane $(1 / 3=\mathrm{v} / \mathrm{v})$ to afford the desired compound $\mathbf{5 b}(25.5 \mathrm{mg}, 0.129 \mathrm{mmol}, 26 \%)$ as a colorless oil; ${ }^{1} \mathrm{H}$ NMR $\left(500 \mathrm{MHz}, \mathrm{CDCl}_{3}\right) \delta: 6.79$ (brs, $\left.1 \mathrm{H}\right), 4.11$ (dd, $J=5.5$ and $\left.18.4 \mathrm{~Hz}, 1 \mathrm{H}\right), 4.04$ (dd, $J=5.5$ and $18.2 \mathrm{~Hz}, 1 \mathrm{H}), 3.78(\mathrm{~s}, 3 \mathrm{H}), 2.07-1.99(\mathrm{~m}, 1 \mathrm{H}), 1.81-1.74(\mathrm{~m}, 1 \mathrm{H}), 1.58(\mathrm{~s}, 3 \mathrm{H}), 1.09$ (t, $J=7.4 \mathrm{~Hz}, 3 \mathrm{H}) .{ }^{13} \mathrm{C}$ NMR $\left(125 \mathrm{MHz}, \mathrm{CDCl}_{3}\right) \delta 169.5,168.7,121.5,52.7,45.2,41.8,31.8,23.6$, 9.9. $\quad$ FT-IR (neat, $\mathrm{cm}^{-1}$ ) 3363, 2954, 2239, 1749, 1671, 1523, 1437, 1367, 1207, 1008, 978, 807, 703. HRMS (ESI-MS) $m / z\left[\mathrm{M}+\mathrm{H}^{+}\right]$Calcd for $\mathrm{C}_{9} \mathrm{H}_{15} \mathrm{O}_{3} \mathrm{~N}_{2}$ 199.1083, found 199.1083 .

methyl (2-cyano-2-methylpropanoyl)- $D$-alaninate (5d)<smiles>CC(=O)C(C)NC(=O)C(C)(C)C#N</smiles>

Following the general procedure above, using $4 \mathbf{d}(126.4 \mathrm{mg}, 0.50 \mathrm{mmol}), \mathrm{Zn}(\mathrm{CN})_{2}(58.4 \mathrm{mg}, 0.50$ $\mathrm{mmol}), \mathrm{CuBr} \cdot \mathrm{SMe}_{2}(20.5 \mathrm{mg}, 0.10 \mathrm{mmol}), \mathrm{PPh}_{3}(19.4 \mathrm{mg}, 0.075 \mathrm{mmol}), \mathrm{K}_{3} \mathrm{PO}_{4}(159.1 \mathrm{mg}, 0.75$ $\mathrm{mmol}), \mathrm{Zn}(1.7 \mathrm{mg}, 0.025 \mathrm{mmol}), \mathrm{Zn}(\mathrm{OTf})_{2}(18.1 \mathrm{mg}, 0.050 \mathrm{mmol})$, and 1,4-dioxane $(1 \mathrm{~mL})$ at $110{ }^{\circ} \mathrm{C}$. The crude residue was purified by column chromatography over silica-gel, eluting with AcOEt/hexane $(1 / 5=\mathrm{v} / \mathrm{v})$ to afford the desired compound $\mathbf{5 d}(61.2 \mathrm{mg}, 0.309 \mathrm{mmol}, 62 \%)$ as a colorless oil; ${ }^{1} \mathrm{H}$ NMR $\left(500 \mathrm{MHz}, \mathrm{CDCl}_{3}\right) \delta: 6.75(\mathrm{brs}, 1 \mathrm{H}), 4.56-4.51(\mathrm{~m}, 1 \mathrm{H}), 3.77(\mathrm{~s}, 3 \mathrm{H}), 1.59(\mathrm{~s}$, $3 \mathrm{H}), 1.58(\mathrm{~s}, 3 \mathrm{H}), 1.46(\mathrm{~d}, J=7.2 \mathrm{~Hz}, 3 \mathrm{H}) .{ }^{13} \mathrm{C} \mathrm{NMR}\left(125 \mathrm{MHz}, \mathrm{CDCl}_{3}\right) \delta 172.7,168.3,122.2$, $52.8,48.9,38.9,25.2,24.9,18.0$. FT-IR (neat, $\mathrm{cm}^{-1}$ ) 3554, 3352, 2991, 2946, 2240, 1739, 1669, $1523,1456,1375,1343,1302,1270,1213,1180,1155,1054,983,904,851,749$. HRMS (ESI-MS) $m / z\left[\mathrm{M}+\mathrm{H}^{+}\right]$Calcd for $\mathrm{C}_{9} \mathrm{H}_{15} \mathrm{O}_{3} \mathrm{~N}_{2}$ 199.1083, found 199.1083.

methyl (2-cyano-2-methylpropanoyl)- $D$-valinate (5e)<smiles>CC(=O)C(NC(=O)C(C)(C)C)C(C)C</smiles>

Following the general procedure above, using $4 \mathrm{e}(140.4 \mathrm{mg}, 0.50 \mathrm{mmol}), \mathrm{Zn}(\mathrm{CN})_{2}(58.5 \mathrm{mg}, 0.50$ $\mathrm{mmol}), \mathrm{CuBr} \mathrm{SMe}_{2}(30.6 \mathrm{mg}, 0.15 \mathrm{mmol}), \mathrm{PPh}_{3}(39.2 \mathrm{mg}, 0.15 \mathrm{mmol}), \mathrm{K}_{3} \mathrm{PO}_{4}(159.0 \mathrm{mg}, 0.75$ $\mathrm{mmol}), \mathrm{Zn}(1.7 \mathrm{mg}, 0.025 \mathrm{mmol}), \mathrm{Zn}(\mathrm{OTf})_{2}(18.5 \mathrm{mg}, 0.050 \mathrm{mmol})$, and 1,4-dioxane $(1 \mathrm{~mL})$ at $110{ }^{\circ} \mathrm{C}$. The crude residue was purified by column chromatography over silica-gel, eluting with AcOEt/hexane $(1 / 5=\mathrm{v} / \mathrm{v})$ to afford the desired compound $\mathbf{5 e}(58.2 \mathrm{mg}, 0.257 \mathrm{mmol}, 51 \%)$ as a colorless oil; ${ }^{1} \mathrm{H}$ NMR $\left(500 \mathrm{MHz}, \mathrm{CDCl}_{3}\right.$ ) $\delta: 6.67$ (brd, $\left.J=7.0 \mathrm{~Hz}, 1 \mathrm{H}\right), 4.50$ (dd, $J=4.9$ and $8.5 \mathrm{~Hz}$, $1 \mathrm{H}), 3.76$ (s, 3H), 2.25-2.19(m, 1H), 1.60 (s, 3H), 1.59 (s, 3H), 0.96 (d, $J=6.9 \mathrm{~Hz}, 3 \mathrm{H}), 0.93$ (d, $J=$ $6.9 \mathrm{~Hz}, 3 \mathrm{H}) .{ }^{13} \mathrm{C} \mathrm{NMR}\left(125 \mathrm{MHz}, \mathrm{CDCl}_{3}\right) \delta 171.7,168.7,122.2,57.8,52.5,39.1,31.2,2.1,25.0$, 19.0, 17.7, FT-IR (neat, $\mathrm{cm}^{-1}$ ) 3353, 2965, 2876, 2238, 1740, 1684, 1518, 1465, 1437, 1313, 1268, $1207,1182,1150,1000,966,877,697,665$. HRMS (ESI-MS) $m / z\left[\mathrm{M}+\mathrm{H}^{+}\right]$Calcd for $\mathrm{C}_{11} \mathrm{H}_{19} \mathrm{O}_{3} \mathrm{~N}_{2}$ 227.1396, found 227.1396. 
methyl (R)-2-(2-cyano-2-methylpropanamido)-2-phenylacetate (5f)<smiles>COC(=O)C(NC(=O)C(C)(C#N)C#N)c1ccccc1</smiles>

Following the general procedure above, using $4 \mathbf{f}(157.3 \mathrm{mg}, 0.50 \mathrm{mmol}), \mathrm{Zn}(\mathrm{CN})_{2}(58.7 \mathrm{mg}, 0.50$ $\mathrm{mmol}), \mathrm{CuBr} \cdot \mathrm{SMe}_{2}(30.6 \mathrm{mg}, 0.15 \mathrm{mmol}), \mathrm{PPh}_{3}(39.4 \mathrm{mg}, 0.15 \mathrm{mmol}), \mathrm{K}_{3} \mathrm{PO}_{4}(160.0 \mathrm{mg}, 0.75$ $\mathrm{mmol}), \mathrm{Zn}(1.5 \mathrm{mg}, 0.025 \mathrm{mmol}), \mathrm{Zn}(\mathrm{OTf})_{2}(18.3 \mathrm{mg}, 0.050 \mathrm{mmol})$, and 1,4-dioxane $(1 \mathrm{~mL})$ at $110^{\circ} \mathrm{C}$. The crude residue was purified by column chromatography over silica-gel, eluting with AcOEt/hexane $(1 / 4=\mathrm{v} / \mathrm{v})$ to afford the desired compound $\mathbf{5 f}(69.3 \mathrm{mg}, 0.266 \mathrm{mmol}, 53 \%)$ as a white solid; $\mathrm{Mp}=123-124{ }^{\circ} \mathrm{C},{ }^{1} \mathrm{H}$ NMR $\left(500 \mathrm{MHz}, \mathrm{CDCl}_{3}\right) \delta: 7.41-7.35(\mathrm{~m}, 5 \mathrm{H}), 7.17$ (brs, $\left.1 \mathrm{H}\right), 5.48(\mathrm{~d}, J$ $=6.7 \mathrm{~Hz}, 1 \mathrm{H}), 3.75(\mathrm{~s}, 3 \mathrm{H}), 1.62(\mathrm{~s}, 3 \mathrm{H}), 1.55(\mathrm{~s}, 3 \mathrm{H}) .{ }^{13} \mathrm{C} \mathrm{NMR}\left(125 \mathrm{MHz}, \mathrm{CDCl}_{3}\right) \delta 170.6,168.1$, 135.4, 129.3, 129.0, 127.3, 122.1, 57.2, 53.1, 38.8, 25.0, 24.8. FT-IR (neat, $\mathrm{cm}^{-1}$ ) 3276, 2994, 2952, $2238,1748,1657,1521,1456,1430,1332,1213,1164,1106,990,775,731,696$. HRMS (ESI-MS) $m / z\left[\mathrm{M}+\mathrm{H}^{+}\right]$Calcd for $\mathrm{C}_{14} \mathrm{H}_{17} \mathrm{O}_{3} \mathrm{~N}_{2} 261.1239$, found 261.1239 .

methyl (2-cyano-2-methylpropanoyl)phenylalaninate (5g)<smiles>CC(=O)C(Cc1ccccc1)NC(=O)C(C)(C)C#N</smiles>

Following the general procedure above, using $4 \mathrm{~g}(164.3 \mathrm{mg}, 0.50 \mathrm{mmol}), \mathrm{Zn}(\mathrm{CN})_{2}(58.9 \mathrm{mg}, 0.50$ $\mathrm{mmol}), \mathrm{CuBr} \cdot \mathrm{SMe}_{2}(30.5 \mathrm{mg}, 0.15 \mathrm{mmol}), \mathrm{PPh}_{3}(40.5 \mathrm{mg}, 0.15 \mathrm{mmol}), \mathrm{K}_{3} \mathrm{PO}_{4}(159.6 \mathrm{mg}, 0.75$ $\mathrm{mmol}), \mathrm{Zn}(2.0 \mathrm{mg}, 0.025 \mathrm{mmol}), \mathrm{Zn}(\mathrm{OTf})_{2}(18.1 \mathrm{mg}, 0.050 \mathrm{mmol})$, and 1,4-dioxane $(1 \mathrm{~mL})$ at $110^{\circ} \mathrm{C}$ for $24 \mathrm{~h}$. The crude residue was purified by column chromatography over silica-gel, eluting with AcOEt/hexane $(1 / 4=\mathrm{v} / \mathrm{v})$ to afford the desired compound $\mathbf{5 g}(67.5 \mathrm{mg}, 0.246 \mathrm{mmol}, 49 \%)$ as a colorless oil; ${ }^{1} \mathrm{H}$ NMR $\left(500 \mathrm{MHz}, \mathrm{CDCl}_{3}\right)$ 8: 7.33-7.30 (m, $\left.2 \mathrm{H}\right), 7.28-7.27(\mathrm{~m}, 1 \mathrm{H}), 7.13-7.12(\mathrm{~m}$, $2 \mathrm{H}), 6.61$ (brd, $J=6.9 \mathrm{~Hz}, 1 \mathrm{H}), 4.85-4.81(\mathrm{~m}, 1 \mathrm{H}), 3.76(\mathrm{~s}, 3 \mathrm{H}), 1.54(\mathrm{~s}, 3 \mathrm{H}), 1.47(\mathrm{~s}, 3 \mathrm{H}) .{ }^{13} \mathrm{C}$ NMR $\left(125 \mathrm{MHz}, \mathrm{CDCl}_{3}\right) \delta 171.2,168.3,135.3,129.3,128.9,127.6,122.0,53.7,52.7,38.9,37.8$, 24.97, 24.93. FT-IR (neat, $\mathrm{cm}^{-1}$ ) 3352, 2986, 2953, 2238, 1739, 1675, 1521, 1436, 1357, 1215, 1177, 1107, 1030, 804, 744, 700. HRMS (ESI-MS) $\mathrm{m} / \mathrm{z}\left[\mathrm{M}+\mathrm{NH}_{4}{ }^{+}\right]$Calcd for $\mathrm{C}_{15} \mathrm{H}_{22} \mathrm{O}_{3} \mathrm{~N}_{3}$ 292.1661 , found 292.1660 .

tert-butyl $O$-(tert-butyl)- $N$-(2-cyano-2-methylpropanoyl)- $L$-threoninate (5h)<smiles>CCCOC(=O)NC(C(=O)C(C)(C)C)C(C)OCCC</smiles>

Following the general procedure above, using $4 \mathrm{~h}(190.0 \mathrm{mg}, 0.50 \mathrm{mmol}), \mathrm{Zn}(\mathrm{CN})_{2}(59.1 \mathrm{mg}, 0.5$ $\mathrm{mmol}), \mathrm{CuBr} \cdot \mathrm{SMe}_{2}(30.4 \mathrm{mg}, 0.15 \mathrm{mmol}), \mathrm{PPh}_{3}(40.1 \mathrm{mg}, 0.15 \mathrm{mmol}), \mathrm{K}_{3} \mathrm{PO}_{4}(160.3 \mathrm{mg}, 0.75$ $\mathrm{mmol}), \mathrm{Zn}(1.3 \mathrm{mg}, 0.025 \mathrm{mmol}), \mathrm{Zn}(\mathrm{OTf})_{2}(17.9 \mathrm{mg}, 0.050 \mathrm{mmol})$, and 1,4-dioxane $(1 \mathrm{~mL})$ at $110{ }^{\circ} \mathrm{C}$. The crude residue was purified by column chromatography over silica-gel, eluting with AcOEt/hexane $(1 / 5=\mathrm{v} / \mathrm{v})$ to afford the desired compound $\mathbf{5 h}(44.9 \mathrm{mg}, 0.138 \mathrm{mmol}, 28 \%)$ as a colorless oil; ${ }^{1} \mathrm{H}$ NMR $\left(500 \mathrm{MHz}, \mathrm{CDCl}_{3}\right) \delta: 7.00$ (brd, $\left.J=8.1 \mathrm{~Hz}, 1 \mathrm{H}\right), 4.25-4.21(\mathrm{~m}, 2 \mathrm{H}), 1.62(\mathrm{~s}$, $3 \mathrm{H}), 1.61(\mathrm{~s}, 3 \mathrm{H}), 1.46(\mathrm{~s}, 9 \mathrm{H}), 1.20-1.17(\mathrm{~m}, 12 \mathrm{H}) .{ }^{13} \mathrm{C} \mathrm{NMR}\left(125 \mathrm{MHz}, \mathrm{CDCl}_{3}\right) \delta: 169.23$, 169.07, 122.26, 82.3, 74.2, 66.9, 59.2, 39.1, 28.7, 28.1, 25.2, 25.0, 21.5. FT-IR (neat, $\mathrm{cm}^{-1}$ ) 2977, 2937, 2236, 2116, 1728, 1691, 1506, 1367, 1284, 1144, 1080, 846, 806, 762. HRMS (ESI-MS) $\mathrm{m} / \mathrm{z}$ $\left[\mathrm{M}+\mathrm{H}^{+}\right]$Calcd for $\mathrm{C}_{17} \mathrm{H}_{31} \mathrm{O}_{4} \mathrm{~N}_{2}$ 327.2248, found 327.2248. 
methyl (2-cyano-2-methylpropanoyl)-D-tryptophanate (5j)<smiles>COC(=O)C(Cc1ccccc1)NC(=O)C(C)(C)C</smiles>

Following the general procedure above, using $4 \mathbf{j}(183.9 \mathrm{mg}, 0.50 \mathrm{mmol}), \mathrm{Zn}(\mathrm{CN})_{2}(58.7 \mathrm{mg}, 0.5$ $\mathrm{mmol}), \mathrm{CuBr} \cdot \mathrm{SMe}_{2}(20.6 \mathrm{mg}, 0.10 \mathrm{mmol}), \mathrm{PPh}_{3}(19.5 \mathrm{mg}, 0.075 \mathrm{mmol}), \mathrm{K}_{3} \mathrm{PO}_{4}(159.1 \mathrm{mg}, 0.75$ $\mathrm{mmol})$, Zn $(1.3 \mathrm{mg}, 0.025 \mathrm{mmol}), \mathrm{Zn}(\mathrm{OTf})_{2}(18.2 \mathrm{mg}, 0.050 \mathrm{mmol})$, and 1,4-dioxane $(1 \mathrm{~mL})$ at $110{ }^{\circ} \mathrm{C}$. The crude residue was purified by column chromatography over silica-gel, eluting with AcOEt/hexane $(1 / 3=\mathrm{v} / \mathrm{v})$ to afford the desired compound $\mathbf{5 j}(77.8 \mathrm{mg}, 0.248 \mathrm{mmol}, 50 \%)$ as a yellow viscous liquid; ${ }^{1} \mathrm{H}$ NMR (500 MHz, $\left.\mathrm{CDCl}_{3}\right) \delta: 8.16$ (brs, $\left.1 \mathrm{H}\right), 7.54(\mathrm{~d}, J=7.9 \mathrm{~Hz}, 1 \mathrm{H}), 7.37$ (dd, $J=7.1$ and $1.1 \mathrm{~Hz}, 1 \mathrm{H}), 7.20(\mathrm{dd}, J=7.1$ and $1.2 \mathrm{~Hz}, 1 \mathrm{H}), 7.13(\mathrm{dd}, J=7.1$ and $1.1 \mathrm{~Hz}, 1 \mathrm{H})$, 7.07 (d, $J=2.6 \mathrm{~Hz}, 1 \mathrm{H}), 6.70$ (brd, $J=7.3 \mathrm{~Hz}, 1 \mathrm{H}), 4.86-4.82(\mathrm{~m}, 1 \mathrm{H}), 3.71$ (s, $3 \mathrm{H}), 3.36(\mathrm{~d}, J=6.3$ $\mathrm{Hz}, 2 \mathrm{H}), 1.51$ (s, 3H), 1.45 (s, 3H). ${ }^{13} \mathrm{C}$ NMR $\left(125 \mathrm{MHz}, \mathrm{CDCl}_{3}\right) \delta 171.6,168.4,136.3,127.3$, $123.0,122.5,122.0,119.8,118.5,111.5,109.2,53.3,52.7,38.9,27.4,25.0,24.5$. FT-IR (neat, $\left.\mathrm{cm}^{-1}\right) 3363,2984,2951,2240,1734,1668,1509,1436,1341,1210,1177,1096,1009,741$. HRMS (ESI-MS) $m / z\left[\mathrm{M}+\mathrm{H}^{+}\right]$Calcd for $\mathrm{C}_{17} \mathrm{H}_{20} \mathrm{O}_{3} \mathrm{~N}_{3} 314.1505$, found 314.1505 .

methyl (2-cyano-2-methylpropanoyl)glycyl- $L$-leucinate (5k)<smiles>COC(=O)NC(CC(=O)NC(=O)C(C)(C)C)CC(C)C</smiles>

Following the general procedure above, using $4 \mathbf{k}(175.7 \mathrm{mg}, 0.50 \mathrm{mmol}), \mathrm{Zn}(\mathrm{CN})_{2}(58.8 \mathrm{mg}, 0.5$ $\mathrm{mmol}), \mathrm{CuBr} \cdot \mathrm{SMe}_{2}(30.7 \mathrm{mg}, 0.15 \mathrm{mmol}), \mathrm{PPh}_{3}(40.0 \mathrm{mg}, 0.15 \mathrm{mmol}), \mathrm{K}_{3} \mathrm{PO}_{4}(159.2 \mathrm{mg}, 0.75$ $\mathrm{mmol}), \mathrm{Zn}(1.3 \mathrm{mg}, 0.025 \mathrm{mmol}), \mathrm{Zn}(\mathrm{OTf})_{2}(18.1 \mathrm{mg}, 0.050 \mathrm{mmol})$, and 1,4-dioxane $(1 \mathrm{~mL})$ at $110{ }^{\circ} \mathrm{C}$. The crude residue was purified by column chromatography over silica-gel, eluting with AcOEt/hexane $(1.5 / 1=\mathrm{v} / \mathrm{v})$ to afford the desired compound 5k $(74.1 \mathrm{mg}, 0.249 \mathrm{mmol}, 50 \%)$ as a colorless oil; ${ }^{1} \mathrm{H}$ NMR $\left(500 \mathrm{MHz}, \mathrm{CDCl}_{3}\right) \delta$ : 7.04 (brs, $\left.1 \mathrm{H}\right), 6.28(\mathrm{brd}, J=8.1 \mathrm{~Hz}, 1 \mathrm{H}), 4.66-4.62(\mathrm{~m}$, $1 \mathrm{H}), 4.04-3.95(\mathrm{~m}, 2 \mathrm{H}), 3.74(\mathrm{~s}, 3 \mathrm{H}), 1.70-1.64(\mathrm{~m}, 2 \mathrm{H}), 1.60(\mathrm{~s}, 3 \mathrm{H}), 1.61(\mathrm{~s}, 3 \mathrm{H}), 1.58-1.54(\mathrm{~m}$, $1 \mathrm{H}), 0.95(\mathrm{~d}, J=2.1 \mathrm{~Hz}, 3 \mathrm{H}), 0.93(\mathrm{~d}, J=2.3 \mathrm{~Hz}, 3 \mathrm{H}) .{ }^{13} \mathrm{C} \mathrm{NMR}\left(125 \mathrm{MHz}, \mathrm{CDCl}_{3}\right) \delta 173.3$, 169.3, 167.7, 122.0, 52.6, 51.0, 43.5, 41.5, 38.9, 25.1, 25.0, 24.9, 22.8, 22.0. FT-IR $\left(\mathrm{CDCl}_{3}, \mathrm{~cm}^{-1}\right)$ $3317,2956,2953,2872,2240,1741,1654,1523,1437,1369,1206,1154,1012,725$. HRMS (ESI-MS) $m / z\left[\mathrm{M}+\mathrm{H}^{+}\right]$Calcd for $\mathrm{C}_{14} \mathrm{H}_{24} \mathrm{O}_{3} \mathrm{~N}_{4} 298.1767$, found 298.1767 .

methyl (2-cyano-2-methylpropanoyl)glycyl- $L$-alaninate (5l)<smiles>CC(=O)NC(C)NC(=O)CNC(=O)C(C)(C)C</smiles>

Following the general procedure above, using 41 (154.7 $\mathrm{mg}, 0.50 \mathrm{mmol}), \mathrm{Zn}(\mathrm{CN})_{2}(58.9 \mathrm{mg}, 0.5$ $\mathrm{mmol}), \mathrm{CuBr} \cdot \mathrm{SMe}_{2}(30.5 \mathrm{mg}, 0.15 \mathrm{mmol}), \mathrm{PPh}_{3}(39.6 \mathrm{mg}, 0.15 \mathrm{mmol}), \mathrm{K}_{3} \mathrm{PO}_{4}(162.0 \mathrm{mg}, 0.75$ $\mathrm{mmol}), \mathrm{Zn}(1.3 \mathrm{mg}, 0.025 \mathrm{mmol}), \mathrm{Zn}(\mathrm{OTf})_{2}(18.2 \mathrm{mg}, 0.050 \mathrm{mmol})$, and 1,4-dioxane $(1 \mathrm{~mL})$ at $110{ }^{\circ} \mathrm{C}$. The crude residue was purified by column chromatography over silica-gel with EtOAc/hexane $(1 / 2=\mathrm{v} / \mathrm{v})$ to afford the desired compound $\mathbf{5 l}(62.4 \mathrm{mg}, 0.244 \mathrm{mmol}, 49 \%)$ as a colorless oil; ${ }^{1} \mathrm{H}$ NMR $\left(500 \mathrm{MHz}, \mathrm{CDCl}_{3}\right) \delta: 6.99$ (brs, $1 \mathrm{H}$ ), 6.40 (brs, $1 \mathrm{H}$ ), 4.60 (quint, $J=7.2 \mathrm{~Hz}$, $1 \mathrm{H})$, 4.03-3.95 (m, 2H) $3.77(\mathrm{~s}, 3 \mathrm{H}), 1.62(\mathrm{~s}, 6 \mathrm{H}) .{ }^{13} \mathrm{C}$ NMR $\left(125 \mathrm{MHz}, \mathrm{CDCl}_{3}\right) \delta 173.2,169.3$, 167.4, 122.0, 52.8, 48.3, 43.4, 39.3, 25.1, 18.4. FT-IR (neat, $\mathrm{cm}^{-1}$ ) 3315, 2988, 2943, 2919, 2240, $1740,1654,1523,1452,1209,1155,1053,1014,850,725$. HRMS (ESI-MS) $m / z\left[\mathrm{M}+\mathrm{H}^{+}\right]$Calcd for $\mathrm{C}_{11} \mathrm{H}_{18} \mathrm{O}_{4} \mathrm{~N}_{3} 256.1297$, found 256.1297 . 
methyl (2-cyano-2-methylpropanoyl)alanylglycinate (5m)<smiles>CC(=O)CNC(=O)[C@H](C)NC(=O)C(C)(C)C</smiles>

Following the general procedure above, using $4 \mathrm{~m}(154.9 \mathrm{mg}, 0.50 \mathrm{mmol}), \mathrm{Zn}(\mathrm{CN})_{2}(59.0 \mathrm{mg}$, $0.5 \mathrm{mmol}), \mathrm{CuBr} \cdot \mathrm{SMe}_{2}(31.1 \mathrm{mg}, 0.15 \mathrm{mmol}), \mathrm{PPh}_{3}(39.7 \mathrm{mg}, 0.15 \mathrm{mmol}), \mathrm{K}_{3} \mathrm{PO}_{4}(159.1 \mathrm{mg}, 0.75$ $\mathrm{mmol}), \mathrm{Zn}(1.3 \mathrm{mg}, 0.025 \mathrm{mmol}), \mathrm{Zn}(\mathrm{OTf})_{2}(18.1 \mathrm{mg}, 0.050 \mathrm{mmol})$, and 1,4-dioxane $(1 \mathrm{~mL})$ at $110{ }^{\circ} \mathrm{C}$. The crude residue was purified by column chromatography over silica-gel with EtOAc/hexane $(1.5 / 1=\mathrm{v} / \mathrm{v})$ to afford the desired compound $\mathbf{5 m}(72.3 \mathrm{mg}, 0.283 \mathrm{mmol}, 57 \%)$ as a white solid; Mp. $=109-110{ }^{\circ} \mathrm{C},{ }^{1} \mathrm{H}$ NMR $\left(500 \mathrm{MHz}, \mathrm{CDCl}_{3}\right) \delta: 6.86(\mathrm{br}, J=6.2 \mathrm{~Hz}, 1 \mathrm{H}), 6.46(\mathrm{br}$, $1 \mathrm{H}), 4.52-4.46(\mathrm{~m}, 1 \mathrm{H}), 4.10-4.00(\mathrm{~m}, 2 \mathrm{H}), 3.76(\mathrm{~s}, 3 \mathrm{H}), 1.60(\mathrm{~s}, 3 \mathrm{H}), 1.59(\mathrm{~s}, 3 \mathrm{H}), 1.46(\mathrm{~d}, J=7.0$ $\mathrm{Hz}, 3 \mathrm{H}) .{ }^{13} \mathrm{C} \mathrm{NMR}\left(125 \mathrm{MHz}, \mathrm{CDCl}_{3}\right) \delta 171.6,170.1,168.8,122.0,52.6,49.4,41.3,39.0,25.2,24.9$, 18.1. FT-IR (neat, $\mathrm{cm}^{-1}$ ) 3302, 3262, 3070, 2980, 2240, 1745, 1639, 1542, 1435, 1393, 1219, 1185, $1117,1049,965,722,669$. HRMS (ESI-MS) $m / z\left[\mathrm{M}+\mathrm{H}^{+}\right]$Calcd for $\mathrm{C}_{11} \mathrm{H}_{18} \mathrm{O}_{4} \mathrm{~N}_{3} 256.1297$, found 256.1297 .

methyl (2-cyano-2-methylpropanoyl)- $L$-methionylglycinate (5n)<smiles>CCCC(NC(=O)C(C)(C)C)C(=O)NCC(C)=O</smiles>

Following the general procedure above, using $4 \mathbf{n}(184.4 \mathrm{mg}, 0.50 \mathrm{mmol}), \mathrm{Zn}(\mathrm{CN})_{2}(58.5 \mathrm{mg}, 0.5$ $\mathrm{mmol}), \mathrm{CuBr} \bullet \mathrm{SMe}_{2}(30.5 \mathrm{mg}, 0.15 \mathrm{mmol}), \mathrm{PPh}_{3}(39.2 \mathrm{mg}, 0.15 \mathrm{mmol}), \mathrm{K}_{3} \mathrm{PO}_{4}(159.0 \mathrm{mg}, 0.75$ $\mathrm{mmol}), \mathrm{Zn}(1.4 \mathrm{mg}, 0.025 \mathrm{mmol}), \mathrm{Zn}(\mathrm{OTf})_{2}(18.1 \mathrm{mg}, 0.050 \mathrm{mmol})$, and 1,4-dioxane $(1 \mathrm{~mL})$ at $110{ }^{\circ} \mathrm{C}$. The crude residue was purified by column chromatography over silica-gel, eluting with AcOEt/hexane $(1 / 1=\mathrm{v} / \mathrm{v})$ to afford the desired compound $\mathbf{5 n}(33.4 \mathrm{mg}, 0.106 \mathrm{mmol}, 21 \%)$ as a colorless oil; ${ }^{1} \mathrm{H}$ NMR $\left(500 \mathrm{MHz}, \mathrm{CDCl}_{3}\right) \delta: 7.13$ (brd, $\left.J=7.6 \mathrm{~Hz}, 1 \mathrm{H}\right), 6.68$ (brt, $J=4.6 \mathrm{~Hz}, 1 \mathrm{H}$ ), $4.66(\mathrm{q}, J=6.8 \mathrm{~Hz}, 1 \mathrm{H}), 4.14(\mathrm{dd}, J=6.0$ and $18.3 \mathrm{~Hz}, 1 \mathrm{H}), 4.00(\mathrm{dd}, J=5.1$ and $18.3 \mathrm{~Hz}, 1 \mathrm{H}) 3.76$ $(\mathrm{s}, 3 \mathrm{H}), 2.70-2.59(\mathrm{~m}, 2 \mathrm{H}), 2.15(\mathrm{~s}, 3 \mathrm{H}), 2.14-2.05(\mathrm{~m}, 2 \mathrm{H}), 1.62(\mathrm{~s}, 3 \mathrm{H}), 1.60(\mathrm{~s}, 6 \mathrm{H}) .{ }^{13} \mathrm{C} \mathrm{NMR}$ $\left(125 \mathrm{MHz}, \mathrm{CDCl}_{3}\right) \delta 170.5,169.9,168.9,121.9,52.6,41.2,39.0,30.7,30.0,25.1,24.9,15.1$. FT-IR $\left(\mathrm{CDCl}_{3}, \mathrm{~cm}^{-1}\right)$ 3310, 2987, 2953, 2919, 2853, 2253, 1749, 1654, 1526, 1508, 1438, 1369, 1287, 1209, 1181, 906, 725, HRMS (ESI-MS) $m / z\left[\mathrm{M}+\mathrm{H}^{+}\right]$Calcd for $\mathrm{C}_{13} \mathrm{H}_{22} \mathrm{O}_{4} \mathrm{~N}_{3} \mathrm{~S}$ 316.1331, found 316.1332 .

methyl (2-cyano-2-methylpropanoyl)glycyl- $L$-valinate (50)<smiles>COC(=O)C(C)C(C)NC(=O)CNC(=O)C(C)(C)C</smiles>

Following the general procedure above, using $40(168.5 \mathrm{mg}, 0.50 \mathrm{mmol}), \mathrm{Zn}(\mathrm{CN})_{2}(58.6 \mathrm{mg}, 0.5$ $\mathrm{mmol}$ ), $\mathrm{CuBr} \cdot \mathrm{SMe}_{2}(30.7 \mathrm{mg}, 0.15 \mathrm{mmol}), \mathrm{PPh}_{3}(39.46 \mathrm{mg}, 0.15 \mathrm{mmol}), \mathrm{K}_{3} \mathrm{PO}_{4}(159.7 \mathrm{mg}, 0.75$ $\mathrm{mmol}), \mathrm{Zn}(1.3 \mathrm{mg}, 0.025 \mathrm{mmol}), \mathrm{Zn}(\mathrm{OTf})_{2}(18.2 \mathrm{mg}, 0.050 \mathrm{mmol})$, and 1,4-dioxane $(1 \mathrm{~mL})$ at $110{ }^{\circ} \mathrm{C}$. The crude residue was purified by column chromatography over silica-gel, eluting with AcOEt/hexane $(1 / 2=\mathrm{v} / \mathrm{v})$ to afford the desired compound $50(82.9 \mathrm{mg}, 0.293 \mathrm{mmol}, 59 \%)$ as a colorless oil; ${ }^{1} \mathrm{H}$ NMR $\left(500 \mathrm{MHz}, \mathrm{CDCl}_{3}\right) \delta: 7.10$ (brs, $\left.1 \mathrm{H}\right), 6.49$ (brs, $\left.1 \mathrm{H}\right), 4.56$ (dd, $J=4.7$ and 8.7 $\mathrm{Hz}, 1 \mathrm{H}), 4.06-3.98(\mathrm{~m}, 2 \mathrm{H}), 3.75(\mathrm{~s}, 3 \mathrm{H}), 1.62(\mathrm{~s}, 3 \mathrm{H}), 1.61(\mathrm{~s}, 3 \mathrm{H}), 0.93(\mathrm{~d}, 6.9 \mathrm{~Hz}, 6 \mathrm{H}) .{ }^{13} \mathrm{C}$ NMR $\left(125 \mathrm{MHz}, \mathrm{CDCl}_{3}\right) \delta 172.3,169.4,168.1,122.0,57.4,52.4,48.3,43.7,38.9,31.2,25.1,25.0,19.0$, 17.8. FT-IR (neat, $\mathrm{cm}^{-1}$ ) 3278, 2965, 2242, 1739, 1655, 1522, 1465, 1437, 1372, 1267, 1208, 1151, 1012, 917, 730. HRMS (ESI-MS) $m / z\left[\mathrm{M}+\mathrm{H}^{+}\right]$Calcd for $\mathrm{C}_{13} \mathrm{H}_{22} \mathrm{O}_{3} \mathrm{~N}_{4} 284.1610$, found 284.1609. 
(2-cyano-2-methylpropanoyl)-L-aspartyl-Lphenylalanine methyl ester (5p)<smiles>CC(=O)CC(NC(=O)C(C)(C)C)C(=O)NC(Cc1ccccc1)C(C)=O</smiles>

Following the general procedure above, using $4 \mathbf{p}(228.5 \mathrm{mg}, 0.50 \mathrm{mmol}), \mathrm{Zn}(\mathrm{CN})_{2}(58.6 \mathrm{mg}, 0.5$ $\mathrm{mmol}), \mathrm{CuBr} \cdot \mathrm{SMe}_{2}(30.7 \mathrm{mg}, 0.15 \mathrm{mmol}), \mathrm{PPh}_{3}(39.46 \mathrm{mg}, 0.15 \mathrm{mmol}), \mathrm{K}_{3} \mathrm{PO}_{4}(159.7 \mathrm{mg}, 0.75$ $\mathrm{mmol})$, Zn $(1.3 \mathrm{mg}, 0.025 \mathrm{mmol}), \mathrm{Zn}(\mathrm{OTf})_{2}(18.2 \mathrm{mg}, 0.050 \mathrm{mmol})$, and 1,4-dioxane $(1 \mathrm{~mL})$ at $110{ }^{\circ} \mathrm{C}$. The crude residue was purified by column chromatography over silica-gel, eluting with $\mathrm{CH}_{2} \mathrm{Cl}_{2}$ to afford the desired compound $\mathbf{5 p}(151.7 \mathrm{mg}, 0.38 \mathrm{mmol}, 75 \%)$ as a colorless oil; ${ }^{1} \mathrm{H}$ NMR $\left(500 \mathrm{MHz}, \mathrm{CDCl}_{3}\right) \delta: 7.67(\mathrm{~d}, J=7.6 \mathrm{~Hz}, 1 \mathrm{H}), 7.30(\mathrm{t}, J=7.3 \mathrm{~Hz}, 2 \mathrm{H}), 7.24(\mathrm{t}, J=7.4 \mathrm{~Hz}, 1 \mathrm{H}), 7.11(\mathrm{~d}$, $J=7.0 \mathrm{~Hz}, 2 \mathrm{H}), 6.89(\mathrm{~d}, J=7.4 \mathrm{~Hz}, 1 \mathrm{H}), 4.84-4.64(\mathrm{~m}, 2 \mathrm{H}), 3.70(\mathrm{dd}, J=1.7,1.0 \mathrm{~Hz}, 6 \mathrm{H}), 3.18-2.92(\mathrm{~m}$, $3 \mathrm{H}), 2.65(\mathrm{dd}, J=17.1,6.8 \mathrm{~Hz}, 1 \mathrm{H}), 1.48(\mathrm{~d}, J=50.7 \mathrm{~Hz}, 6 \mathrm{H}) .{ }^{13} \mathrm{C} \mathrm{NMR}\left(125 \mathrm{MHz}, \mathrm{CDCl}_{3}\right) \delta 172.2$, 171.3, 169.1, 168.8, 135.4, 129.1, 128.7, 127.2, 121.5, 53.5, 52.4, 52.3, 49.6, 38.9, 37.3, 35.0, 24.8, 24.6. FT-IR (neat, $\mathrm{cm}^{-1}$ ) 3340, 2983, 2952, 2250, 1739, 1717, 1670, 1515, 1436, 1207, 909. HRMS (ESI-MS) $m / z\left[\mathrm{M}+\mathrm{H}^{+}\right]$Calcd for $\mathrm{C}_{20} \mathrm{H}_{25} \mathrm{O}_{3} \mathrm{~N}_{6} 403.1743$, found 403.1743 .

\section{Transformations of cyanated carboxamide}

2,2-dimethyl- $N$-phenylpropane-1,3-diamine (6)<smiles>CC(C)(CN)CNc1ccccc1</smiles>

To a stirred suspension of $\mathrm{LiAlH}_{4}(56.5 \mathrm{mg}, 1.5 \mathrm{mmol})$ in 1,4-dioxane $(0.4 \mathrm{~mL})$ was added a solution of 3a $(56.6 \mathrm{mg}, 0.30 \mathrm{mmol})$ in 1,4-dioxane $(0.2 \mathrm{~mL})$ at $0{ }^{\circ} \mathrm{C}$ under nitrogen atmosphere, and the mixture was stirred for $20 \mathrm{~h}$ at $80^{\circ} \mathrm{C}$. The mixture was diluted with $\mathrm{H}_{2} \mathrm{O}(0.05 \mathrm{~mL}), 12.7 \mathrm{wt} \%$ aqueous $\mathrm{NaOH}(0.06 \mathrm{~mL})$ and $\mathrm{H}_{2} \mathrm{O}(0.05 \mathrm{~mL} \times 3)$ and was extracted with EtOAc. The combined organic layer was dried over $\mathrm{Na}_{2} \mathrm{SO}_{4}$ and evaporated. The crude residue was purified by flash chromatography, eluting $\mathrm{MeOH}$ to afford the product $9(45.5 \mathrm{mg}, 0.255 \mathrm{mmol}, 85 \%)$ as a white solid. $\mathrm{Mp} .=62-63{ }^{\circ} \mathrm{C} .{ }^{1} \mathrm{H}$ NMR $\left(500 \mathrm{MHz}, \mathrm{CDCl}_{3}\right) \delta: 7.17(\mathrm{t}, J=7.8 \mathrm{~Hz}, 2 \mathrm{H}), 6.66(\mathrm{t}, J=7.3 \mathrm{~Hz}, 2 \mathrm{H})$, 6.63 (d, $J=7.9 \mathrm{~Hz}, 1 \mathrm{H}), 2.98$ (brs, $2 \mathrm{H}), 2.62$ (brs, $2 \mathrm{H}), 2.04$ (brs, 2H), 0.97 (s, $6 \mathrm{H}$ ), NH signals are not given. ${ }^{13} \mathrm{C}$ NMR $\left(125 \mathrm{MHz}, \mathrm{CDCl}_{3}\right) \delta 149.2,129.3,117.1,112.8,53.1,51.3,35.5,23.9$. FT-IR (neat, $\mathrm{cm}^{-1}$ ) 3442, 3326, 2953, 2635, 2123, 1600, 1523, 1437, 1487, 1369, 1309, 1257, 1176, 868, 812, 742, 688. HRMS (ESI-MS) $m / z\left[\mathrm{M}+\mathrm{H}^{+}\right]$Calcd for $\mathrm{C}_{11} \mathrm{H}_{19} \mathrm{~N}_{2}$ 179.1548, found 179.1548 .

2,2-dimethyl- $N^{1}$-phenylmalonamide (7)<smiles>CC(C)(C(N)=O)C(=O)Nc1ccccc1</smiles>

3a (37.7 mg, $0.20 \mathrm{mmol}), \mathrm{CuCN}(17.6 \mathrm{mg}, 0.20 \mathrm{mmol})$, and $\mathrm{K}_{3} \mathrm{PO}_{4}(63.6 \mathrm{mg}, 0.30 \mathrm{mmol})$ were sequentially added under air to a grass tube (for microwave) vial equipped with a stir bar and septa. TMEDA ( $89 \mu \mathrm{L}, 0.60 \mathrm{mmol}), \mathrm{H}_{2} \mathrm{O}(3.6 \mu \mathrm{L}, 0.1 \mathrm{mmol})$, and THF $(0.5 \mathrm{~mL})$ were added by syringe, and the resulting mixture was vigorously stirred under nitrogen atmosphere [charged by $\mathrm{N}_{2}(99.95 \%)$ gas flow] for $24 \mathrm{~h}$ at $110^{\circ} \mathrm{C}$. After this time, the contents of the flask were filtered through a plug of silica gel and then concentrated by rotary evaporation. The crude residue was purified by flash chromatography on silica gel with EtOAc/hexane $(1 / 1=\mathrm{v} / \mathrm{v})$ to afford the desired compound $7(21.4$ mg, $0.104 \mathrm{mmol}, 53 \%)$ as a white solid. $\mathrm{Mp}=183-184{ }^{\circ} \mathrm{C},{ }^{1} \mathrm{H}$ NMR $\left(500 \mathrm{MHz}, \mathrm{CDCl}_{3}\right) \delta: 8.88(\mathrm{brs}$, $1 \mathrm{H}), 7.55(\mathrm{~d}, J=7.8 \mathrm{~Hz}, 2 \mathrm{H}), 7.33(\mathrm{t}, J=7.9 \mathrm{~Hz}, 2 \mathrm{H}), 7.12(\mathrm{t}, J=7.4 \mathrm{~Hz}, 1 \mathrm{H}), 6.29$ (brs, $1 \mathrm{H}), 5.53$ (brs, 1H), $1.59(\mathrm{~s}, 6 \mathrm{H}),{ }^{13} \mathrm{C}$ NMR $\left(125 \mathrm{MHz}, \mathrm{CDCl}_{3}\right) \delta 170.67,165.74,137.83,129.13,124.61$, 
120.16, 50.5, 24.33, FT-IR (neat, $\mathrm{cm}^{-1}$ ) 3380, 3337, 3197, 1648, 1598, 1532, 1498, 1437, 1370, 1313, 1245, 1155, 1110, 902, 753, 692, HRMS (ESI-MS) $m / z\left[\mathrm{M}+\mathrm{H}^{+}\right]$Calcd for $\mathrm{C}_{11} \mathrm{H}_{15} \mathrm{~N}_{2} \mathrm{O}_{2} 207.1134$, found 207.1134 .

2,2-dimethyl- $N$-phenyl-malonamic acid (8)<smiles>CC(C)(C(=O)O)C(=O)Nc1ccccc1</smiles>

In a dried vial, $\mathrm{K}_{3} \mathrm{PO}_{4}(276.4 \mathrm{mg}, 2.0 \mathrm{mmol}), 3 \mathrm{a}(188.2 \mathrm{mg}, 1.0 \mathrm{mmol})$ were dissolved in 1,4-dioxane $(5 \mathrm{~mL})$ under nitrogen atmosphere. To the solution was added $35 \% \mathrm{H}_{2} \mathrm{O}_{2}$ solution at 0 ${ }^{\circ} \mathrm{C}$, and the mixture was stirred at r.t. for $24 \mathrm{~h}$. The reaction mixture was diluted with water, and extracted with dichloromethane for three times. The combined extracts were dired over $\mathrm{MgSO}_{4}$ and concentrated. The residue was purified by column chromatography over silica gel (eluent: $\left.\mathrm{CH}_{2} \mathrm{Cl}_{2}\right)$ to give the product $8(206.3 \mathrm{mg}, 0.99 \mathrm{mmol}, 99 \%)$ as a white solid. $\mathrm{Mp} .=90-93{ }^{\circ} \mathrm{C}$. ${ }^{1} \mathrm{H}$ NMR (500 MHz, D $\left.{ }_{3} \mathrm{COD}\right) \delta: 8.18(\mathrm{dd}, J=8.5,1.1 \mathrm{~Hz}, 2 \mathrm{H}), 7.96(\mathrm{dd}, J=8.5,7.5 \mathrm{~Hz}, 2 \mathrm{H}), 7.76(\mathrm{t}, J$ $=7.5 \mathrm{~Hz}, 1 \mathrm{H}), 2.18(\mathrm{~s}, 6 \mathrm{H}), 2.18(\mathrm{~s}, 1 \mathrm{H}), \mathrm{OH}$ signals are not given. ${ }^{13} \mathrm{C} \mathrm{NMR}\left(125 \mathrm{MHz}, \mathrm{D}_{3} \mathrm{COD}\right) \delta$ : $173.9,155.7,139.5,129.8,125.6,122.2,40.5,24.4$. FT-IR (neat, $\mathrm{cm}^{-1}$ ) 3376, 3193, 2984, 2768, $1647,1596,1528,1435,1369,1310,1241,900,751,690$. HRMS (ESI-MS) $\mathrm{m} / z$ [M+H $\left.{ }^{+}\right]$Calcd for $\mathrm{C}_{11} \mathrm{H}_{14} \mathrm{NO}_{3} 208.0974$, found 208.0974.

3-[[(1,1-dimethylethoxy)carbonyl]amino]-2,2-dimethyl- $N$-phenylpropanamide (9)<smiles>CC(C)(CNC(=O)OCc1ccccc1)C(=O)Nc1ccccc1</smiles>

To a solution of $\mathbf{3 a}(188.2 \mathrm{mg}, 1.0 \mathrm{mmol})$ in dry $\mathrm{MeOH}(5.0 \mathrm{~mL})$ was added $\mathrm{CoCl}_{2}(259.7 \mathrm{mg}, 2.0 \mathrm{mmol})$ at $0^{\circ} \mathrm{C}$. $\mathrm{NaBH}_{4}(151.3 \mathrm{mg}, 4.00 \mathrm{mmol})$ was added portionwise into the mixture. The resulting mixture was stirred at $0{ }^{\circ} \mathrm{C}$ for $30 \mathrm{~min}$ and stirred at r.t. for $4 \mathrm{~h}$. The reaction mixture was basified with aq. $\mathrm{NaOH}(1.0 \mathrm{M}, 2 \mathrm{~mL})$ and extracted with ethyl acetate. The combined extracts were dried over $\mathrm{MgSO}_{4}$ and concentrated. The residue was purified by column chromatography over silica gel (eluent: AcOEt $/$ hexane $=1 / 4(\mathrm{v} / \mathrm{v}))$ to give the product $9(254.7 \mathrm{mg}, 0.80 \mathrm{mmol}, 80 \%)$ as a white solid. Mp. $=$ 139-140 ${ }^{\circ} \mathrm{C} . \quad{ }^{1} \mathrm{H}$ NMR $\left(500 \mathrm{MHz}, \mathrm{CDCl}_{3}\right) \delta: 8.00(\mathrm{br}, 1 \mathrm{H}), 7.55(\mathrm{~d}, J=7.9 \mathrm{~Hz}, 1 \mathrm{H}), 7.30(\mathrm{dd}, J=7.3$, $7.3 \mathrm{~Hz}, 1 \mathrm{H}), 7.09$ (t, $J=7.3 \mathrm{~Hz}, 2 \mathrm{H}), 5.15$ (br, 1H), 3.35 (d, $J=6.5 \mathrm{~Hz}, 2 \mathrm{H}), 1.42$ (s, 9H), 1.29 (s, 6H). ${ }^{13} \mathrm{C} \mathrm{NMR}\left(125 \mathrm{MHz}, \mathrm{CDCl}_{3}\right) \delta 175.0,156.7,128.8,124.2,120.2,119.8,79.7,48.4,44.5,28.3,24.0,19.6$. FT-IR (neat, $\mathrm{cm}^{-1}$ ) 3359, 3304, 2970, 2821, 1689, 1658, 1521, 1437, 1245, 1158, 971, 745, 691. HRMS (ESI-MS) $m / z\left[\mathrm{M}+\mathrm{H}^{+}\right]$Calcd for $\mathrm{C}_{16} \mathrm{H}_{25} \mathrm{~N}_{2} \mathrm{O}_{3}$ 293.1865, found 293.1865. 


\section{Modification of cyanated carboxamide possessing peptide}

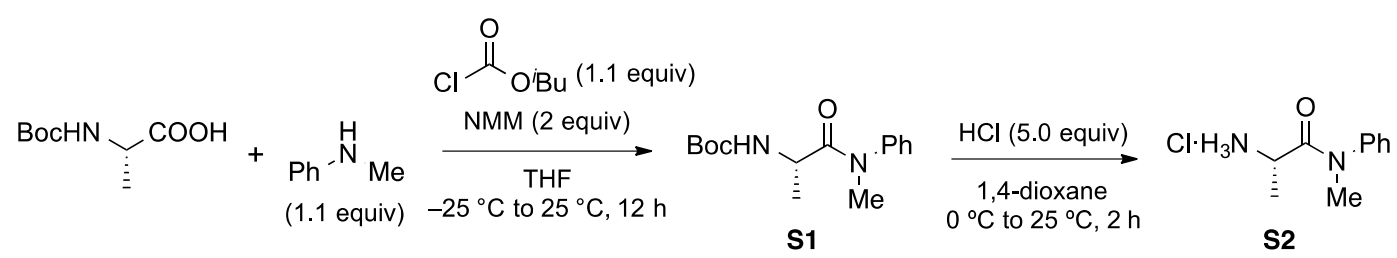

$80 \%$

$98 \%$<smiles>CC(NC(=O)CN)C(=O)Nc1ccccc1</smiles>

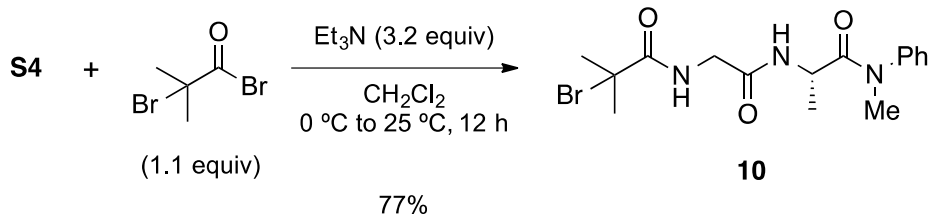

Synthesis of 10: $N$-Boc-alanine $(9.46 \mathrm{~g}, 50.0 \mathrm{mmol})$ and $N$-methylmorpholine $(10.1 \mathrm{~g}, 100 \mathrm{mmol})$ were dissolved in dry THF $(150 \mathrm{~mL})$. iso-Butylchloroformate $(7.30 \mathrm{~g}, 53.5 \mathrm{mmol})$ was added to the mixture at $-25{ }^{\circ} \mathrm{C}$. After $5 \mathrm{~min}$, aniline $(5.35 \mathrm{~g}, 50.0 \mathrm{mmol})$ was added to the mixture, and the reaction mixture was stirred at $25{ }^{\circ} \mathrm{C}$ for $12 \mathrm{~h}$. The volatiles were removed under reduced pressure, then ethyl acetate $(100 \mathrm{~mL})$ was added. The resulting mixture was washed with sat. aq. $\mathrm{NaHCO}_{3}(1 \mathrm{x}$ $100 \mathrm{~mL})$, citric acid $(1 \times 100 \mathrm{~mL})$ and brine $(1 \times 100 \mathrm{~mL})$, and was dried over anhydrous $\mathrm{MgSO}_{4}$. After filtration and removal of the volatiles under reduced pressure, the resulting crude material was purified by column chromatography on silica gel (dichloromethane/ethyl acetate $=30 / 1$ ) to give product S1 (11.1 g, 80\%) as a white solid.

aq. $\mathrm{HCl}(4.0 \mathrm{M}, 50 \mathrm{~mL})$ was dropwise to the solution of $\mathbf{S 1}(11.1 \mathrm{~g}, 40.0 \mathrm{mmol})$ in 1,4-dioxane $(30 \mathrm{~mL})$ at $0{ }^{\circ} \mathrm{C}$. The resulting mixture was stirred at $25^{\circ} \mathrm{C}$ for $2 \mathrm{~h}$. The volatiles were removed under reduced pressure and the resulting solid was washed with diethyl ether to give $\mathbf{S 2}$ $(8.35 \mathrm{~g}, 98 \%)$.

To a mixture of $N$-Boc-glycine $(6.83 \mathrm{~g}, 39.0 \mathrm{mmol}), \mathbf{S 2}(8.35 \mathrm{~g}, 39.0 \mathrm{mmol})$, and diisopropylethylamine $(15.1 \mathrm{~g}, 117 \mathrm{mmol})$ in dry $\mathrm{CH}_{2} \mathrm{Cl}_{2} \quad(120 \mathrm{~mL})$ was added 1-(3-dimethylaminopropyl)-3-ethylcarbodiimide hydrochloride (EDCI, $8.94 \mathrm{~g}, 46.8 \mathrm{mmol}$ ) and 1-hydroxybenzotriazole ( $\mathrm{HOBt}, 6.32 \mathrm{~g}, 46.8 \mathrm{mmol})$ in portions at $0^{\circ} \mathrm{C}$. The reaction mixture was stirred at $0^{\circ} \mathrm{C}$ for $2 \mathrm{~h}$ and stirred at $25^{\circ} \mathrm{C}$ for $12 \mathrm{~h}$. The mixture was washed with sat. aq. $\mathrm{NaHCO}_{3}(1$ x $100 \mathrm{~mL})$, citric acid $(1 \times 100 \mathrm{~mL})$ and $\mathrm{H}_{2} \mathrm{O}(1 \mathrm{x} 100 \mathrm{~mL})$, dried over anhydrous $\mathrm{MgSO}_{4}$, filtrated, and concentrated. The resulting crude material was purified by column chromatography on silica gel $\left(\mathrm{CHCl}_{3} / \mathrm{MeOH}=20 / 1\right)$ to provide $\mathbf{S 3}(12.0 \mathrm{~g}, 92 \%)$ as a white solid.

aq. $\mathrm{HCl}(4.0 \mathrm{M}, 45 \mathrm{~mL})$ was dropwise to the solution of $\mathbf{S 3}(12.0 \mathrm{~g}, 35.8 \mathrm{mmol})$ in 1,4-dioxane $(30 \mathrm{~mL})$ at $0{ }^{\circ} \mathrm{C}$. The resulting mixture was stirred at $25^{\circ} \mathrm{C}$ for $2 \mathrm{~h}$. The volatiles were removed under reduced pressure and the resulting solid was washed with diethyl ether to give S4 $(9.31 \mathrm{~g}, 96 \%)$.

To a mixture of S4 $(2.87 \mathrm{~g}, 10.6 \mathrm{mmol})$ and $\mathrm{NEt}_{3}(3.40 \mathrm{~g}, 33.7 \mathrm{mmol})$ in dry $\mathrm{CH}_{2} \mathrm{Cl}_{2}(50$ $\mathrm{mL})$ was added dropwise 2-bromoisobutyryl bromide $(2.56 \mathrm{~g}, 11.2 \mathrm{mmol})$ at $0^{\circ} \mathrm{C}$. The reaction mixture was stirred at $25^{\circ} \mathrm{C}$ for $12 \mathrm{~h}$. The resulting mixture was filtered, and the filtrate was washed with sat. aq. $\mathrm{NaHCO}_{3}(1 \times 50 \mathrm{~mL}), 1.0 \mathrm{M} \mathrm{HCl}(1 \times 50 \mathrm{~mL})$, and $\mathrm{H}_{2} \mathrm{O}(1 \times 50 \mathrm{~mL})$, then dried over anhydrous $\mathrm{MgSO}_{4}$, filtered, and concentrated. The resulting crude material was purified by column 
chromatography on silica gel (ethyl acetate) to give $\mathbf{1 0}(3.13 \mathrm{~g}, 77 \%)$ as a white solid. ${ }^{1} \mathrm{H}$ NMR (400 $\left.\mathrm{MHz}, \mathrm{CDCl}_{3}\right) \delta$ 7.43-7.49 (m, 2H), 7.37-7.41 (m, 1H), $7.35(\mathrm{~s}, 1 \mathrm{H}), 7.26(\mathrm{~d}, J=7.2 \mathrm{~Hz}, 2 \mathrm{H}), 6.83(\mathrm{~d}$, $J=8.0 \mathrm{~Hz}, 1 \mathrm{H}), 4.60(\mathrm{qd}, J=7.2 \mathrm{~Hz}, 1 \mathrm{H}), 3.97(\mathrm{dd}, J=17.2,4.8 \mathrm{~Hz}, 1 \mathrm{H}), 3.92(\mathrm{dd}, J=17.2,4.8$ $\mathrm{Hz}, 1 \mathrm{H}), 3.28(\mathrm{~s}, 3 \mathrm{H}), 1.97(\mathrm{~s}, 6 \mathrm{H}), 1.15(\mathrm{~d}, J=7.2 \mathrm{~Hz}, 3 \mathrm{H}) ;{ }^{13} \mathrm{C} \mathrm{NMR}\left(100 \mathrm{MHz}, \mathrm{CDCl}_{3}\right) \delta 172.4$, 172.2, 167.2, 142.4, 130.1, 128.5, 127.4, 61.4, 46.2, 43.4, 38.0, 32.3, 18.7; IR (/cm $\left.{ }^{-1}\right) 3283,2989$, 2939, 2358, 2341, 2238, 1685, 1642, 1593, 1540, 1395, 1275, 1262, 1187, 1117, 1074, 1037, 1009, 922, 765, 751; HRMS $\left(\mathrm{FAB}^{+}\right.$) calcd. for $\mathrm{C}_{16} \mathrm{H}_{23} \mathrm{BrN}_{3} \mathrm{O}_{3}{ }^{+}[\mathrm{M}+\mathrm{H}]^{+}$384.0917, found 384.0923.

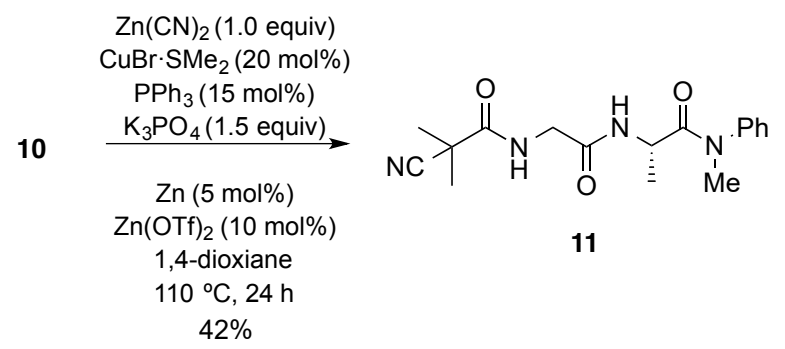

According to the general procedure shown in the section 3, $11(0.42 \mathrm{~g}, 42 \%)$ was obtained from 10 $(1.15 \mathrm{~g}, 3.00 \mathrm{mmol})$ as a white solid after purification by column chromatography on silica gel (ethyl acetate). ${ }^{1} \mathrm{H}$ NMR $\left(400 \mathrm{MHz}, \mathrm{CDCl}_{3}\right) \delta$ 7.40-7.46 (m, 2H), 7.32-7.40 (m, 2H), 7.27-7.32 (m, $\left.1 \mathrm{H}\right)$, $7.26(\mathrm{~d}, J=7.2 \mathrm{~Hz}, 2 \mathrm{H}), 4.57$ (qd, $J=7.2 \mathrm{~Hz}, 1 \mathrm{H}), 3.95(\mathrm{~d}, J=5.2 \mathrm{~Hz}, 2 \mathrm{H}), 3.25(\mathrm{~s}, 3 \mathrm{H}), 1.57(\mathrm{~s}$, $6 \mathrm{H}), 1.13(\mathrm{~d}, J=6.8 \mathrm{~Hz}, 3 \mathrm{H}) ;{ }^{3} \mathrm{C}$ NMR $\left(100 \mathrm{MHz}, \mathrm{CDCl}_{3}\right) \delta 172.6,168.8,167.1,142.3,130.0$, 128.4, 127.2, 121.9, 46.0, 43.0, 38.7, 37.9, 24.9, 18.4; IR $\left(/ \mathrm{cm}^{-1}\right)$ 3276, 3005, 2990, 2363, 2341, $2233,1685,1642,1593,1532,1493,1457,1423,1394,1365,1275,1261,1229,1118,1119,1072$, 1037, 1008, 922, 749; HRMS (EI $\left.{ }^{+}\right)$calcd. for $\mathrm{C}_{17} \mathrm{H}_{22} \mathrm{~N}_{4} \mathrm{O}_{3}{ }^{+}[\mathrm{M}]^{+} 330.1692$, found 330.1692 .

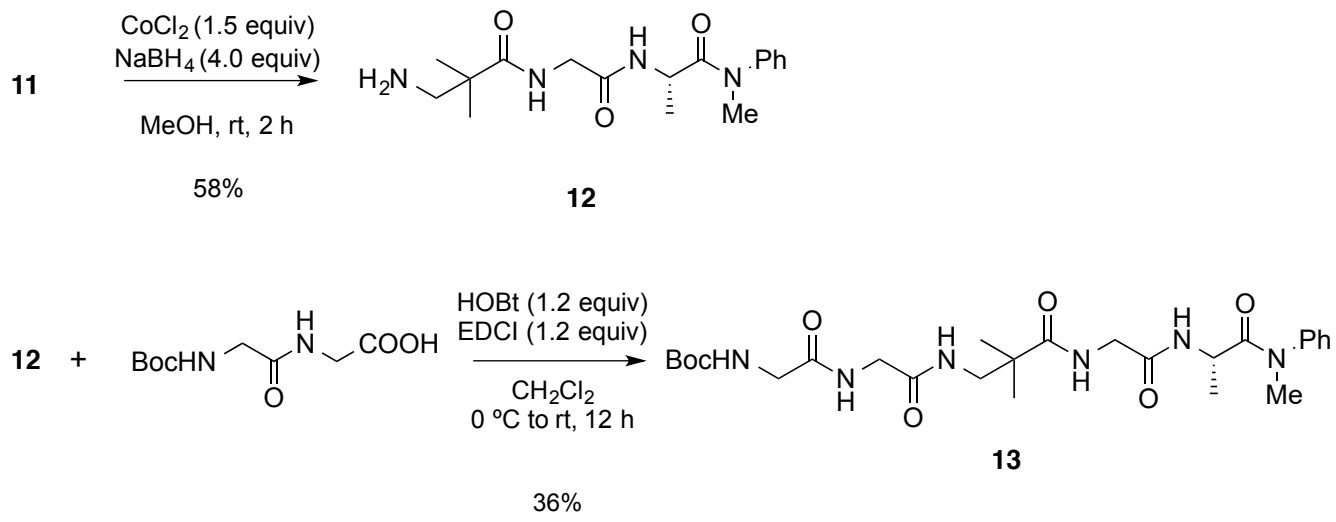

Synthesis of 13: To a solution of $11(0.330 \mathrm{~g}, 1.00 \mathrm{mmol})$ in dry $\mathrm{MeOH}(5.0 \mathrm{~mL})$ was added $\mathrm{CoCl}_{2}$ $(0.195 \mathrm{~g}, 1.50 \mathrm{mmol})$ at $0^{\circ} \mathrm{C} . \mathrm{NaBH}_{4}(0.150 \mathrm{~g}, 4.00 \mathrm{mmol})$ was then added portionwise. The resulting mixture was stirred at $0{ }^{\circ} \mathrm{C}$ for $30 \mathrm{~min}$ and stirred at $25{ }^{\circ} \mathrm{C}$ for $2 \mathrm{~h}$. sat. aq. $\mathrm{NH}_{4} \mathrm{Cl}$ (ca. 10 $\mathrm{mL})$ was added, then basified with aq. $\mathrm{NaOH}(1.0 \mathrm{M}, 30 \mathrm{~mL})$ and extracted with ethyl acetate $(3 \mathrm{x}$ $30 \mathrm{~mL}$ ). The combined organic extracts were washed with brine, dried over anhydrous $\mathrm{MgSO}_{4}$, filtered, and concentrated in vacuo to give $12(0.194 \mathrm{~g}, 58 \%)$ as a colorless solid. 12 was used in next step without further purification.

To a mixture of $12(0.194 \mathrm{~g}, 0.580 \mathrm{mmol}), N$-Boc-glycylglycine $(0.135 \mathrm{~g}, 0.580 \mathrm{mmol})$, and diisopropylethylamine $(0.150 \mathrm{~g}, \quad 1.16 \mathrm{mmol})$ in dry $\mathrm{CH}_{2} \mathrm{Cl}_{2} \quad(5 \mathrm{~mL})$ was added 1-(3-dimethylaminopropyl)-3-ethylcarbodiimide hydrochloride (EDCI, $0.134 \mathrm{~g}, 0.702 \mathrm{mmol}$ ) and 1-hydroxybenzotriazole (HOBt, $0.0945 \mathrm{~g}, 0.700 \mathrm{mmol}$ ) in portions at $0{ }^{\circ} \mathrm{C}$. The reaction mixture was stirred at $0{ }^{\circ} \mathrm{C}$ for $2 \mathrm{~h}$ and then stirred at $25^{\circ} \mathrm{C}$ for $12 \mathrm{~h}$. The mixture was washed with sat. aq. $\mathrm{NaHCO}_{3}(1 \times 5 \mathrm{~mL})$, citric acid $(1 \times 5 \mathrm{~mL})$, and $\mathrm{H}_{2} \mathrm{O}(1 \times 5 \mathrm{~mL})$, then dried over anhydrous $\mathrm{MgSO}_{4}$, filtered, and concentrated. The resulting crude material was purified by column chromatography on 
silica gel $\left(\mathrm{CHCl}_{3} / \mathrm{MeOH}=10 / 1\right)$ to give $13(0.114 \mathrm{~g}, 36 \%)$ as a colorless oil. ${ }^{1} \mathrm{H}$ NMR $(400 \mathrm{MHz}$, $\left.\mathrm{CDCl}_{3}\right) \delta 7.67(\mathrm{~s}, 1 \mathrm{H}), 7.52(\mathrm{~s}, 1 \mathrm{H}), 7.41-7.48(\mathrm{~m}, 2 \mathrm{H}), 7.34-7.40(\mathrm{~m}, 1 \mathrm{H}), 7.31(\mathrm{~d}, J=7.6 \mathrm{~Hz}, 2 \mathrm{H})$, $7.17(\mathrm{~s}, 1 \mathrm{H}), 5.57(\mathrm{~s}, 1 \mathrm{H}), 4.48(\mathrm{qd}, J=6.8 \mathrm{~Hz}, 1 \mathrm{H}), 3.70-4.06(\mathrm{~m}, 6 \mathrm{H}), 3.26-3.48(\mathrm{~m}, 2 \mathrm{H}), 3.26(\mathrm{~s}$, $3 \mathrm{H}), 2.27$ (s, 1H), $1.42(\mathrm{~s}, 9 \mathrm{H}), 1.19(\mathrm{~s}, 6 \mathrm{H}), 1.15$ (d, $J=6.8 \mathrm{~Hz}, 3 \mathrm{H}) ;{ }^{13} \mathrm{C} \mathrm{NMR}\left(100 \mathrm{MHz}, \mathrm{CDCl}_{3}\right) \delta$ $177.4,173.1,170.3,169.5,169.4,156.2,142.4,130.0,128.4,127.3,79.9,48.0,46.2,43.9,43.4$, 43.2, 38.0, 28.3, 23.1, 22.6, 18.0; FT-IR (neat, $\mathrm{cm}^{-1}$ ) 3293, 2976, 2933, 2246, 1643, 1595, 1526, $1496,1393,1367,1248,1166,1035,908,863,752,729$; HRMS $\left(\mathrm{FAB}^{+}\right)$calcd. for $\mathrm{C}_{26} \mathrm{H}_{41} \mathrm{~N}_{6} \mathrm{O}_{7}$ $[\mathrm{M}+\mathrm{H}]^{+}$549.3031, found 549.3038. 


\section{Optimization tables for cyanations}

Table S1 Cyanation of a-bromocarboxamide 4a (monopeptide)
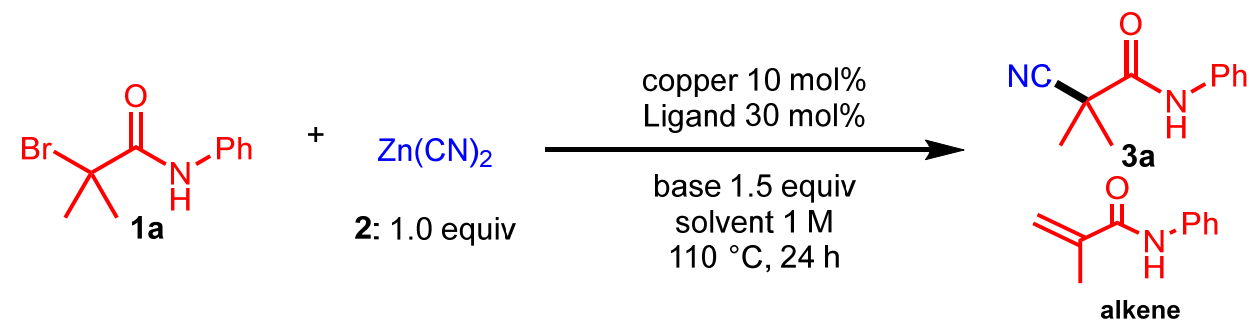

\begin{tabular}{|c|c|c|c|c|c|}
\hline Entry & copper & Ligand & base & solvent & 3a yield $(\%)$ \\
\hline 1 & $\mathrm{CuBr} \cdot \mathrm{SMe}_{2}$ & TMEDA & $\mathrm{K}_{3} \mathrm{PO}_{4}$ & 1,4-dioxane & 81(Alkene 17\%) \\
\hline 2 & Cul & TMEDA & $\mathrm{K}_{3} \mathrm{PO}_{4}$ & 1,4-dioxane & 65(Alkene 12\%) \\
\hline 3 & CuCN & TMEDA & $\mathrm{K}_{3} \mathrm{PO}_{4}$ & 1,4-dioxane & 80 (Alkene $9 \%$ ) \\
\hline 4 & $\mathrm{CuBr}_{2}$ & TMEDA & $\mathrm{K}_{3} \mathrm{PO}_{4}$ & 1,4-dioxane & 74(Alkene 8\%) \\
\hline 5 & $\mathrm{CuBr} \cdot \mathrm{SMe}_{2}$ & none & $\mathrm{K}_{3} \mathrm{PO}_{4}$ & 1,4-dioxane & 11(Alkene 14\%) \\
\hline 6 & $\mathrm{CuBr} \cdot \mathrm{SMe}_{2}$ & $\mathrm{PPh}_{3}$ & $\mathrm{~K}_{3} \mathrm{PO}_{4}$ & 1,4-dioxane & 33(Alkene 17\%) \\
\hline 7 & $\mathrm{CuBr} \cdot \mathrm{SMe}_{2}$ & TPMA & $\mathrm{K}_{3} \mathrm{PO}_{4}$ & 1,4-dioxane & 9(Alkene trace) \\
\hline 8 & $\mathrm{CuBr} \cdot \mathrm{SMe}_{2}$ & 2,2'-bpy & $\mathrm{K}_{3} \mathrm{PO}_{4}$ & 1,4-dioxane & 23(Alkene 12\%) \\
\hline 9 & $\mathrm{CuBr} \cdot \mathrm{SMe}_{2}$ & PMDETA & $\mathrm{K}_{3} \mathrm{PO}_{4}$ & 1,4-dioxane & 44(Alkene 6\%) \\
\hline 10 & $\mathrm{CuBr} \cdot \mathrm{SMe}_{2}$ & TMEDA & none & 1,4-dioxane & trace(Alkene $22 \%$, SM $70 \%$ \\
\hline 11 & $\mathrm{CuBr} \cdot \mathrm{SMe}_{2}$ & TMEDA & $\mathrm{Cs}_{2} \mathrm{CO}_{3}$ & 1,4-dioxane & 21(Alkene 20\%) \\
\hline 12 & $\mathrm{CuBr} \cdot \mathrm{SMe}_{2}$ & TMEDA & tBuOK & 1,4-dioxane & complex(Alkene 12\%) \\
\hline 13 & $\mathrm{CuBr} \cdot \mathrm{SMe}_{2}$ & TMEDA & $\mathrm{Pr}_{2} \mathrm{NEt}$ & 1,4-dioxane & trace(Alkene 89\%) \\
\hline 14 & $\mathrm{CuBr} \cdot \mathrm{SMe}_{2}$ & TMEDA & $\mathrm{K}_{3} \mathrm{PO}_{4}$ & toluene & 70(Alkene 6\%) \\
\hline 15 & $\mathrm{CuBr} \cdot \mathrm{SMe}_{2}$ & TMEDA & $\mathrm{K}_{3} \mathrm{PO}_{4}$ & xylene & 29(Alkene 35\%) \\
\hline 16 & $\mathrm{CuBr} \cdot \mathrm{SMe}_{2}$ & TMEDA & $\mathrm{K}_{3} \mathrm{PO}_{4}$ & $\mathrm{MeCN}$ & 78(Alkene 13\%, ) \\
\hline 17 & $\mathrm{CuBr} \cdot \mathrm{SMe}_{2}$ & TMEDA & $\mathrm{K}_{3} \mathrm{PO}_{4}$ & THF & 93(Alkene 6\%) \\
\hline $18^{a}$ & $\mathrm{CuBr} \cdot \mathrm{SMe}_{2}$ & TMEDA & $\mathrm{K}_{3} \mathrm{PO}_{4}$ & THF & 67(Alkene 18\%) \\
\hline $19^{b}$ & $\mathrm{CuBr} \cdot \mathrm{SMe}_{2}$ & TMEDA & $\mathrm{K}_{3} \mathrm{PO}_{4}$ & THF & 61(Alkene 7\%) \\
\hline $20^{c}$ & $\mathrm{CuBr} \cdot \mathrm{SMe}_{2}$ & TMEDA & $\mathrm{K}_{3} \mathrm{PO}_{4}$ & THF & 86(Alkene 8\%) \\
\hline $21^{d}$ & $\mathrm{CuBr} \cdot \mathrm{SMe}_{2}$ & TMEDA & $\mathrm{K}_{3} \mathrm{PO}_{4}$ & THF & 85(Alkene 13\%) \\
\hline $22^{e}$ & $\mathrm{CuBr} \cdot \mathrm{SMe}_{2}$ & TMEDA & $\mathrm{K}_{3} \mathrm{PO}_{4}$ & THF & 88 (Alkene $11 \%$ ) \\
\hline
\end{tabular}

All yields were determined by ${ }^{1} \mathrm{H}-\mathrm{NMR}$ with $\mathrm{C}_{2} \mathrm{H}_{2} \mathrm{Cl}_{4}$ as internal standard.

a: at $80^{\circ} \mathrm{C}$.

$b$ : at $130^{\circ} \mathrm{C}$.

$c$ : stirred for $6 \mathrm{~h}$.

$d$ : stirred for $12 \mathrm{~h}$.

$e: \mathrm{Zn}(\mathrm{CN})_{2} 1.5$ equiv was used. 
Table S2 Cyanation of a-bromocarboxamide 4a (monopeptide)

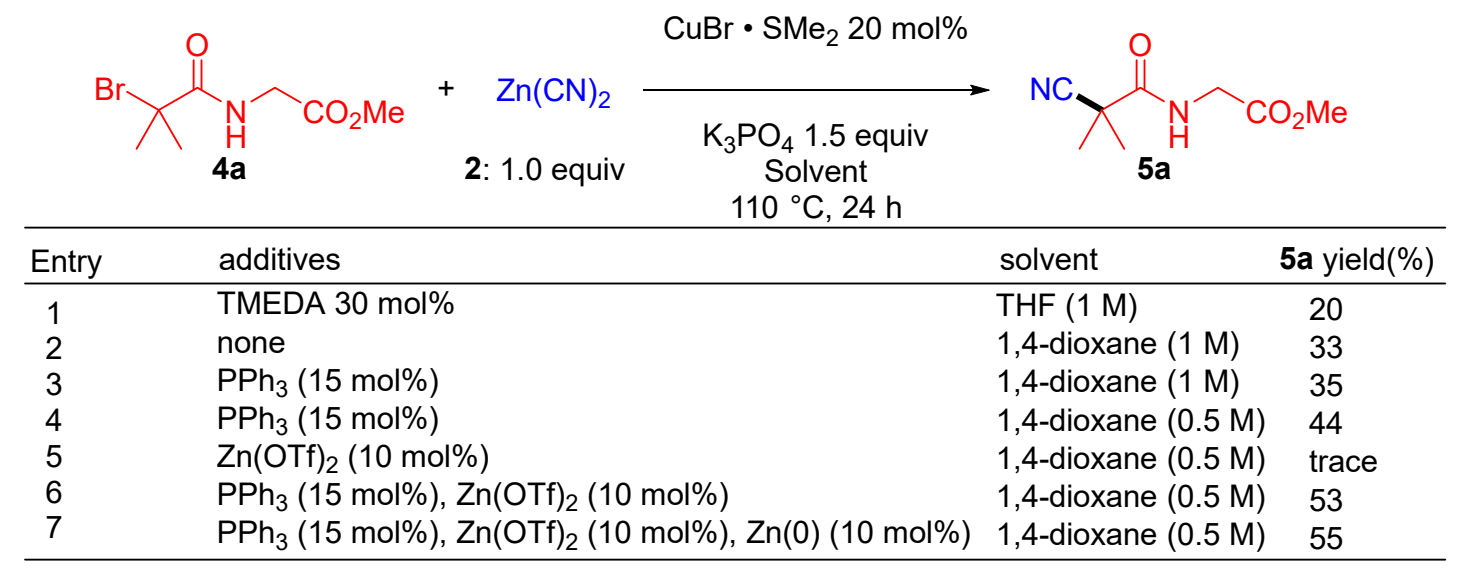




\section{Spectral charts for products}

${ }^{1} \mathrm{H}$ NMR $\left(500 \mathrm{MHz}, \mathrm{CDCl}_{3}\right.$ )

(1)
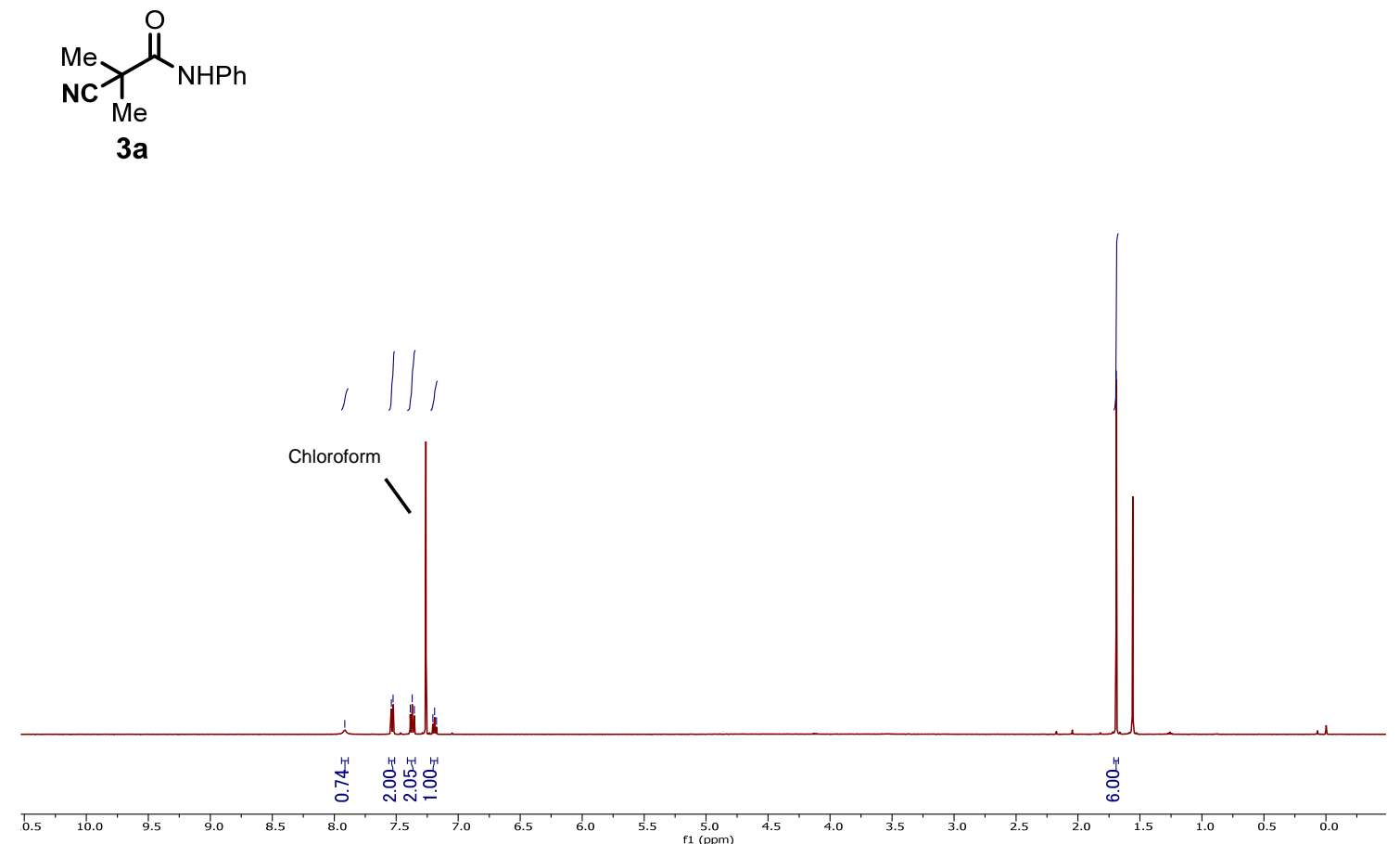

${ }^{13} \mathrm{C}$ NMR $\left(125 \mathrm{MHz}, \mathrm{CDCl}_{3}\right)$

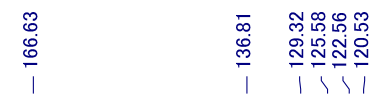

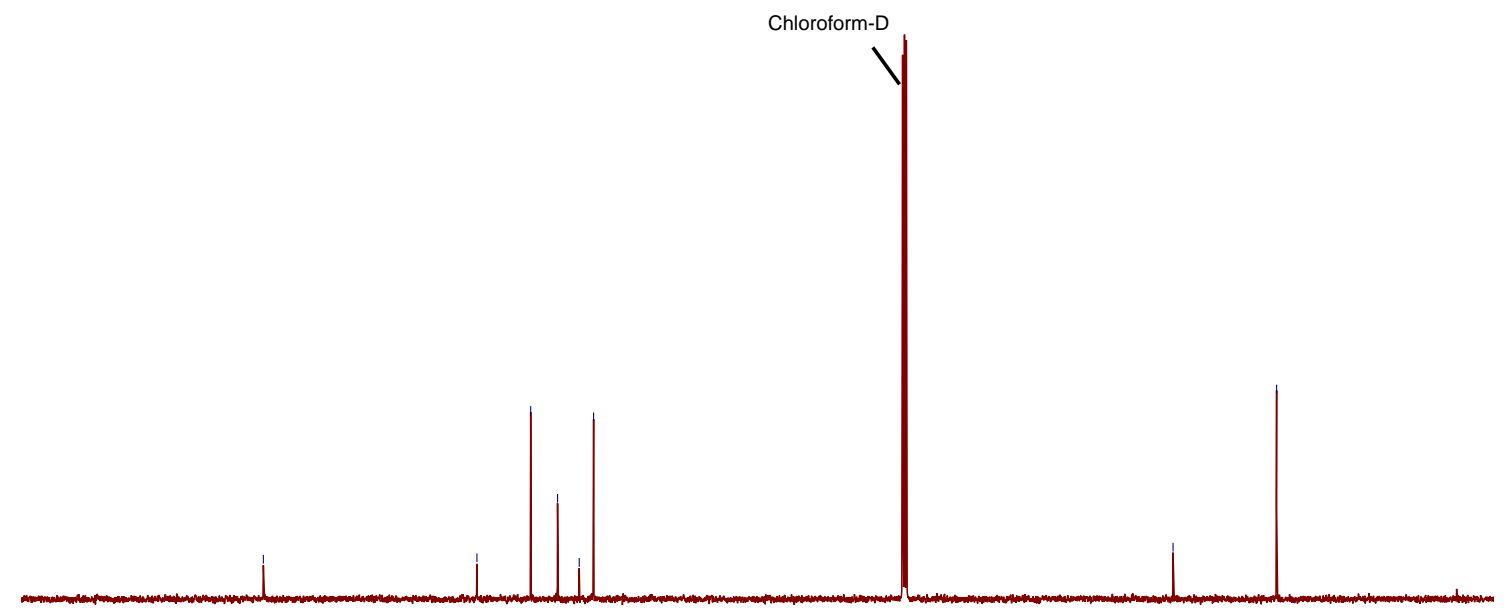

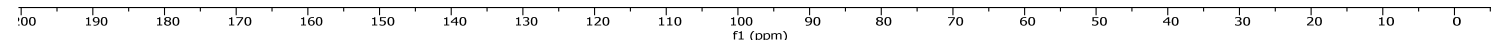


${ }^{1} \mathrm{H}$ NMR (500 MHz, $\mathrm{CDCl}_{3}$ )

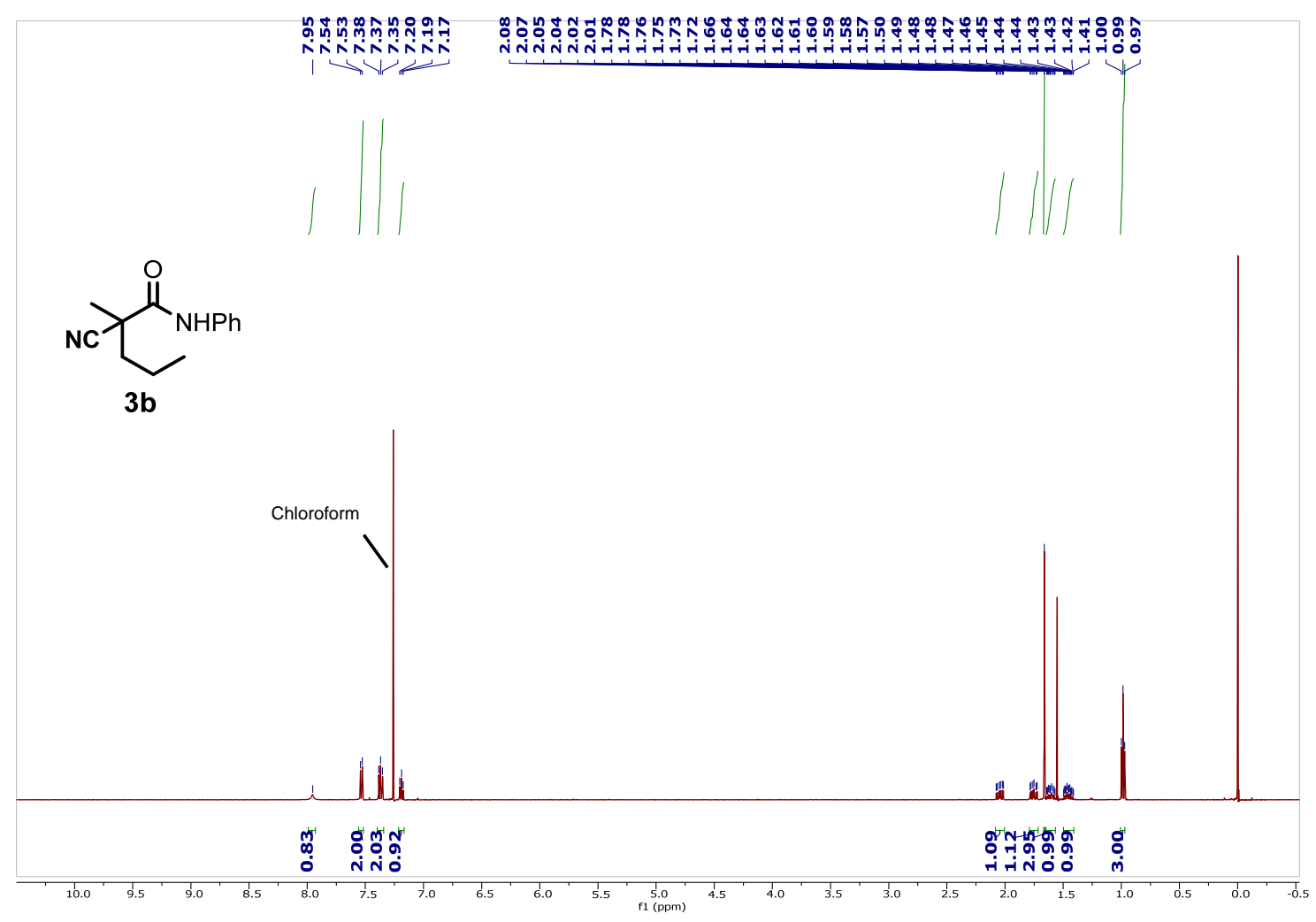

${ }^{13} \mathrm{C}$ NMR $\left(125 \mathrm{MHz}, \mathrm{CDCl}_{3}\right)$

$19021813213 \mathrm{C}$

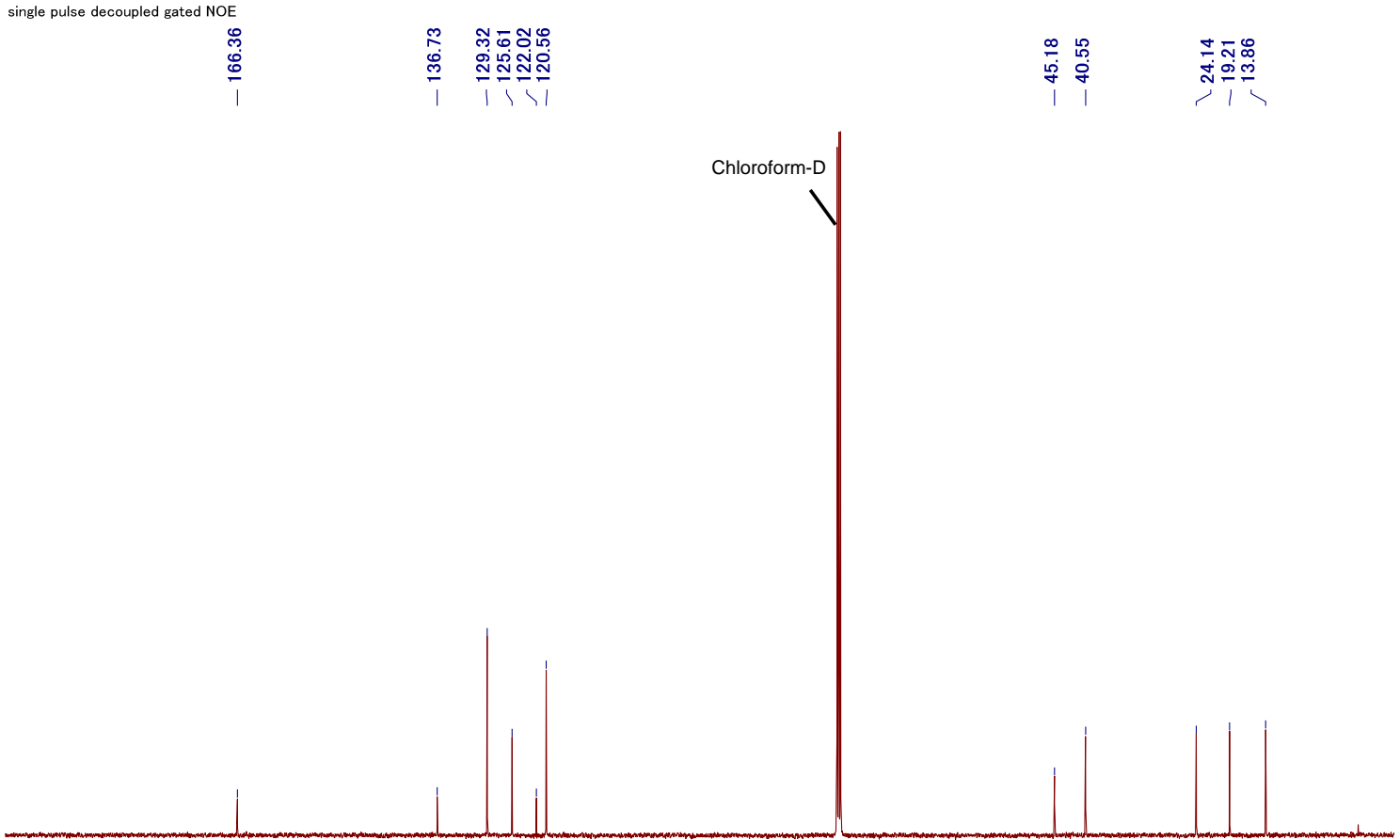

$? 00$

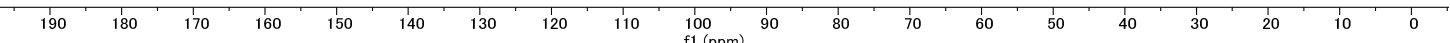


${ }^{1} \mathrm{H}$ NMR $\left(500 \mathrm{MHz}, \mathrm{CDCl}_{3}\right)$

190211147 iso

年

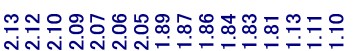

ivivivitin

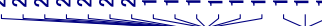

$\underbrace{\mathrm{Oll}_{\mathrm{NHPh}}}_{3 \mathrm{C}}$
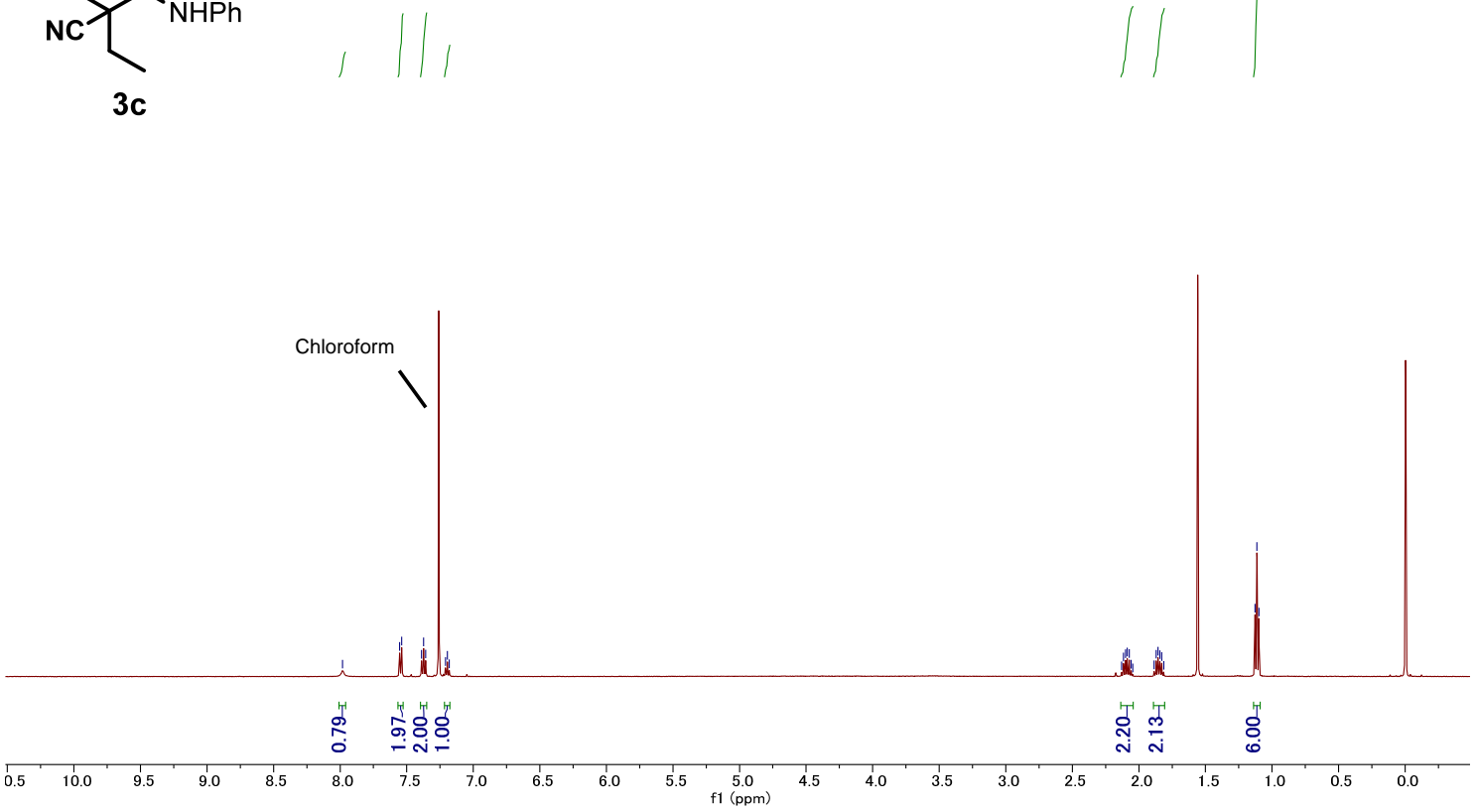

${ }^{13} \mathrm{C}$ NMR $\left(125 \mathrm{MHz}, \mathrm{CDCl}_{3}\right)$

$19021814713 \mathrm{C}$

NOE

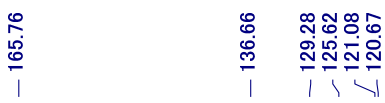

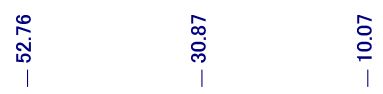

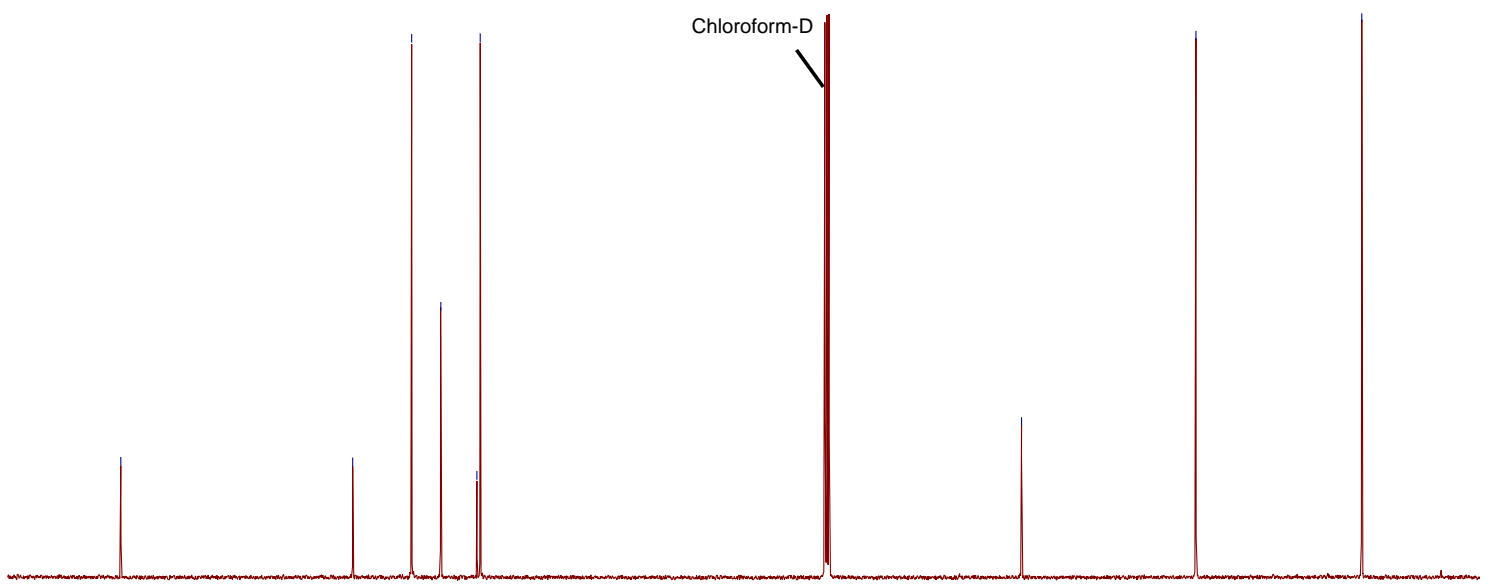

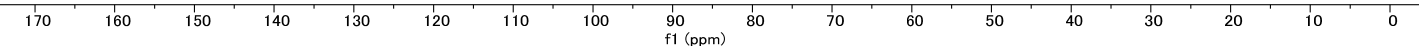


${ }^{1} \mathrm{H}$ NMR $\left(500 \mathrm{MHz}, \mathrm{CDCl}_{3}\right)$

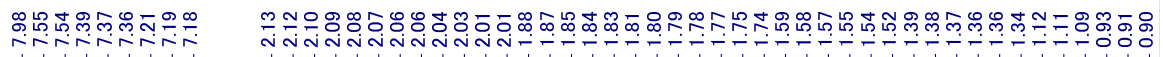<smiles>CCCCC(C)(CC)C(=O)Nc1ccccc1</smiles>
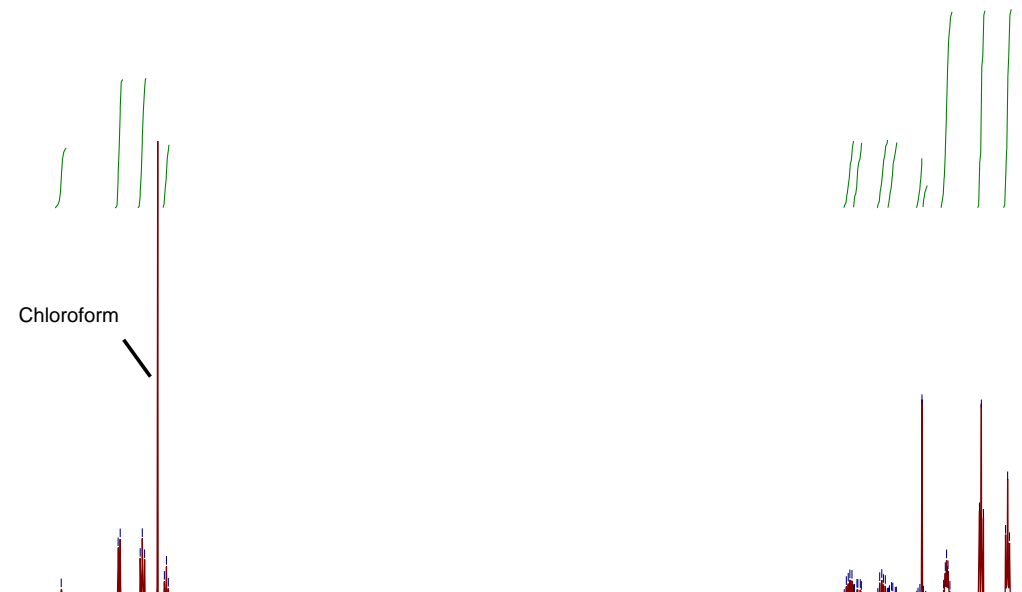

年

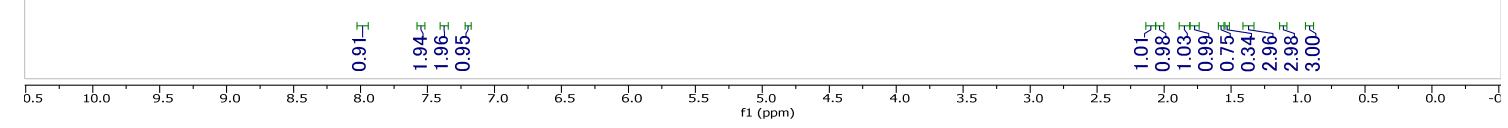

${ }^{13} \mathrm{C}$ NMR $\left(125 \mathrm{MHz}, \mathrm{CDCl}_{3}\right)$

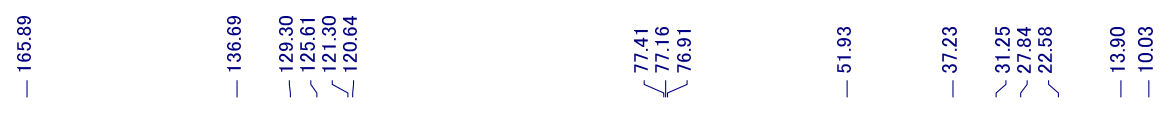
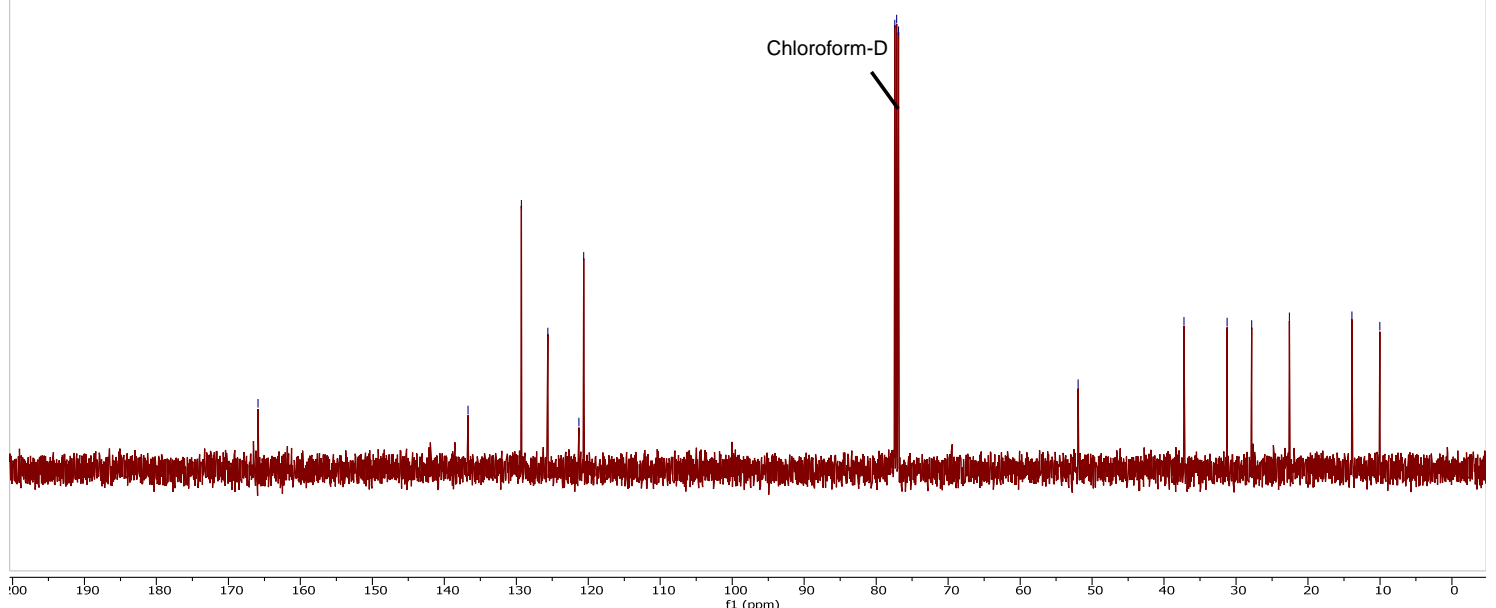
${ }^{1} \mathrm{H}$ NMR $\left(500 \mathrm{MHz}, \mathrm{CDCl}_{3}\right)$

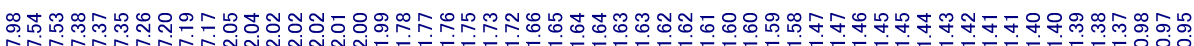<smiles>CCCC(C)(CCC)C(=O)Nc1ccccc1</smiles>

3e
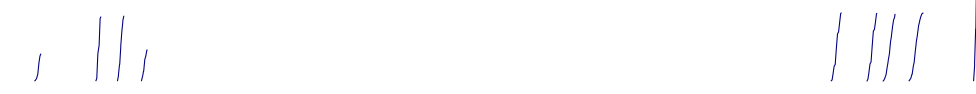

$\backslash$

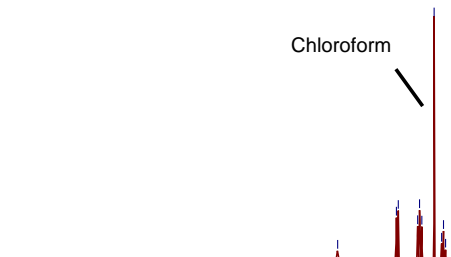

14

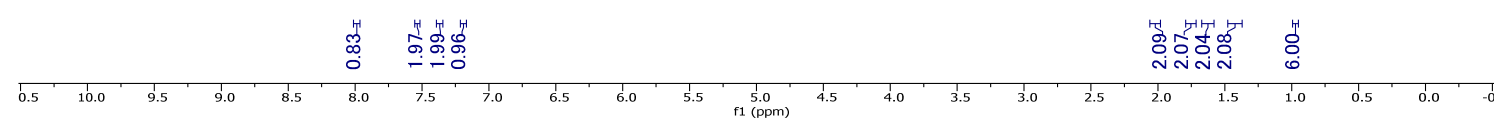

${ }^{13} \mathrm{C}$ NMR $\left(125 \mathrm{MHz}, \mathrm{CDCl}_{3}\right)$

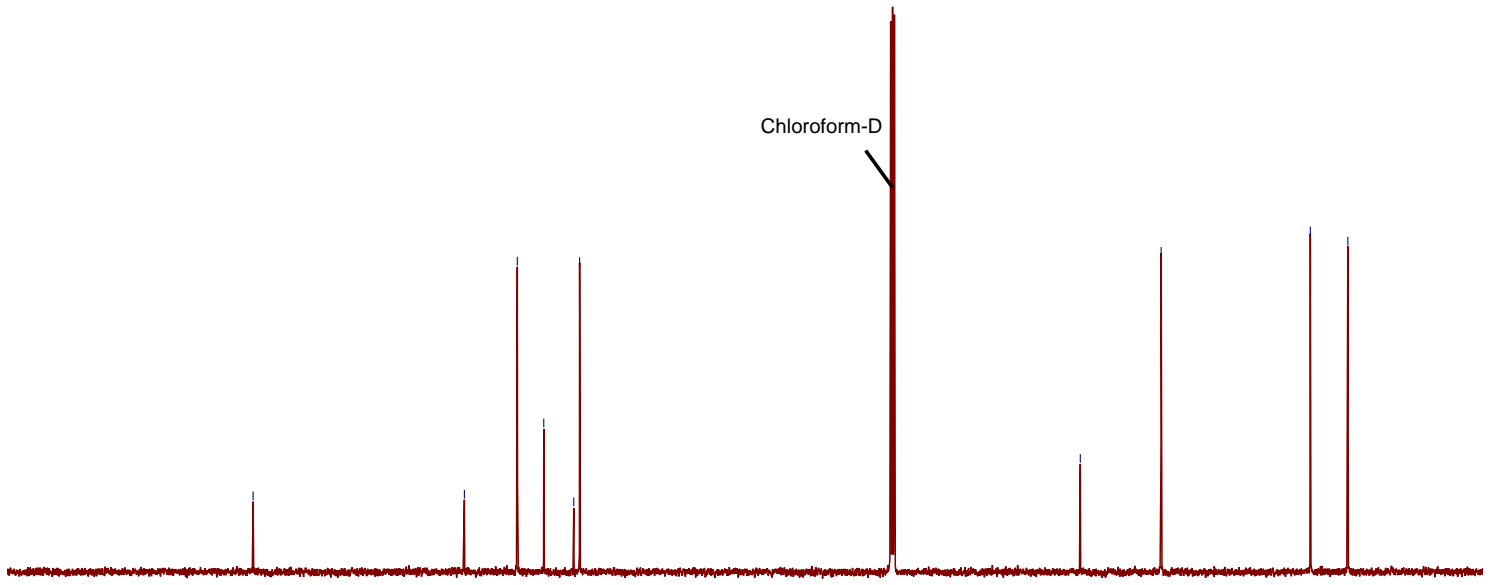

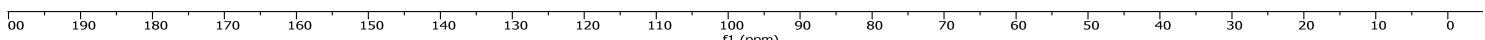


${ }^{1} \mathrm{H}$ NMR $\left(500 \mathrm{MHz}, \mathrm{CDCl}_{3}\right)$

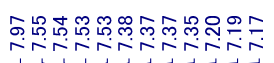

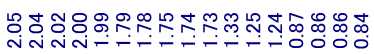

$\overbrace{\text { NC }}^{\mathrm{N}_{\mathrm{NHPh}}}$
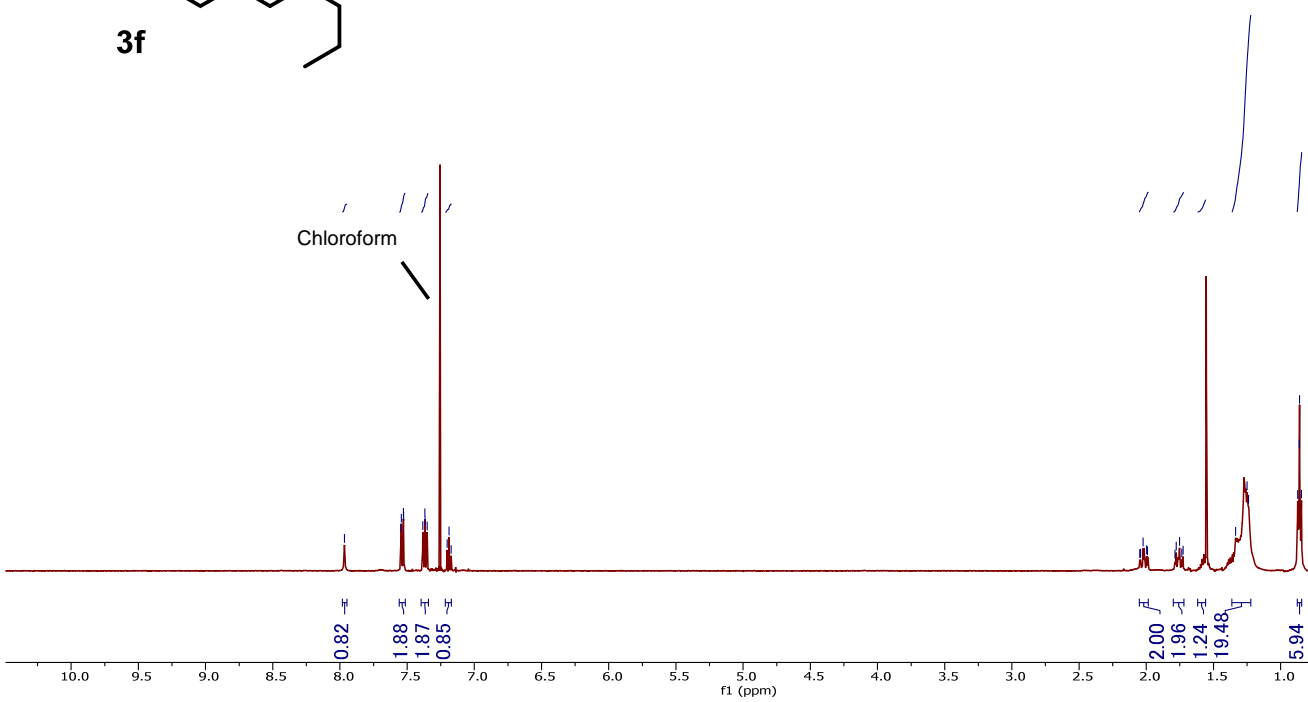

${ }^{13} \mathrm{C}$ NMR $\left(125 \mathrm{MHz}, \mathrm{CDCl}_{3}\right)$

\begin{tabular}{l}
1 \\
0 \\
0 \\
0 \\
\hline
\end{tabular}

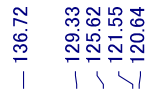

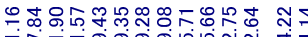

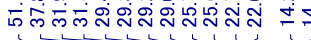

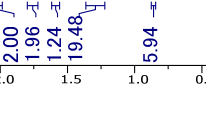

Chloroform-D

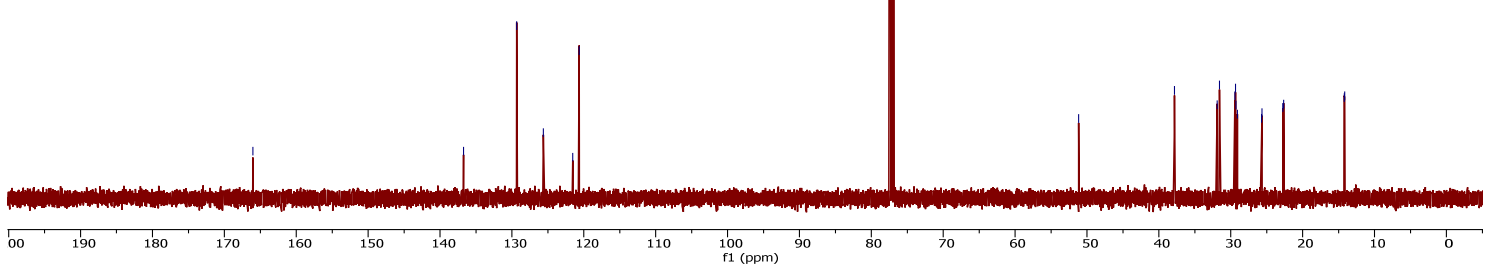


${ }^{1} \mathrm{H}$ NMR $\left(500 \mathrm{MHz}, \mathrm{CDCl}_{3}\right)$

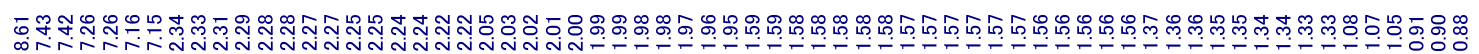

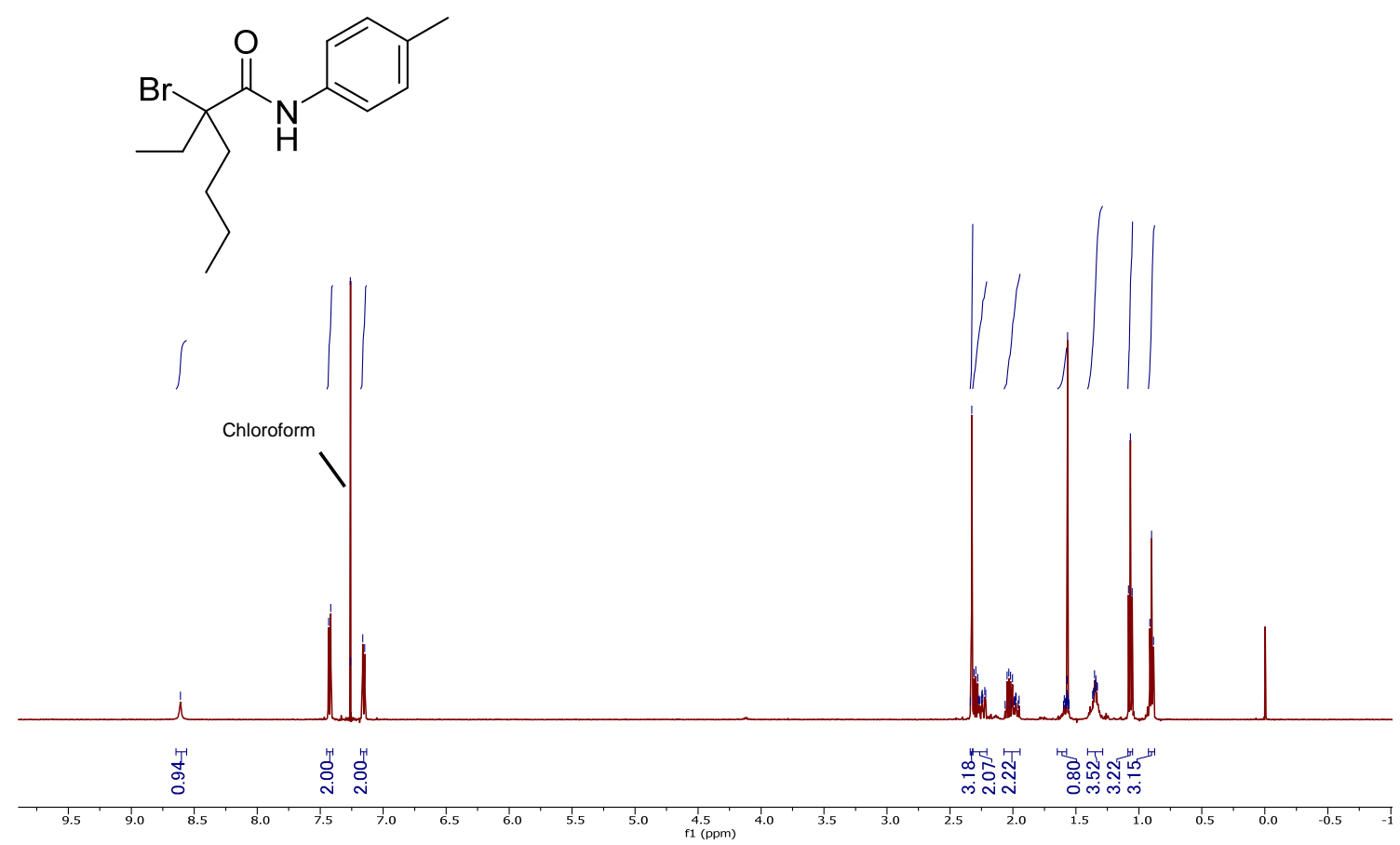

${ }^{13} \mathrm{C}$ NMR $\left(125 \mathrm{MHz}, \mathrm{CDCl}_{3}\right)$

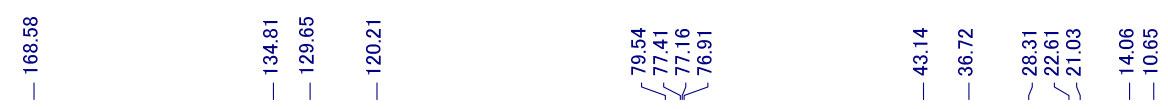

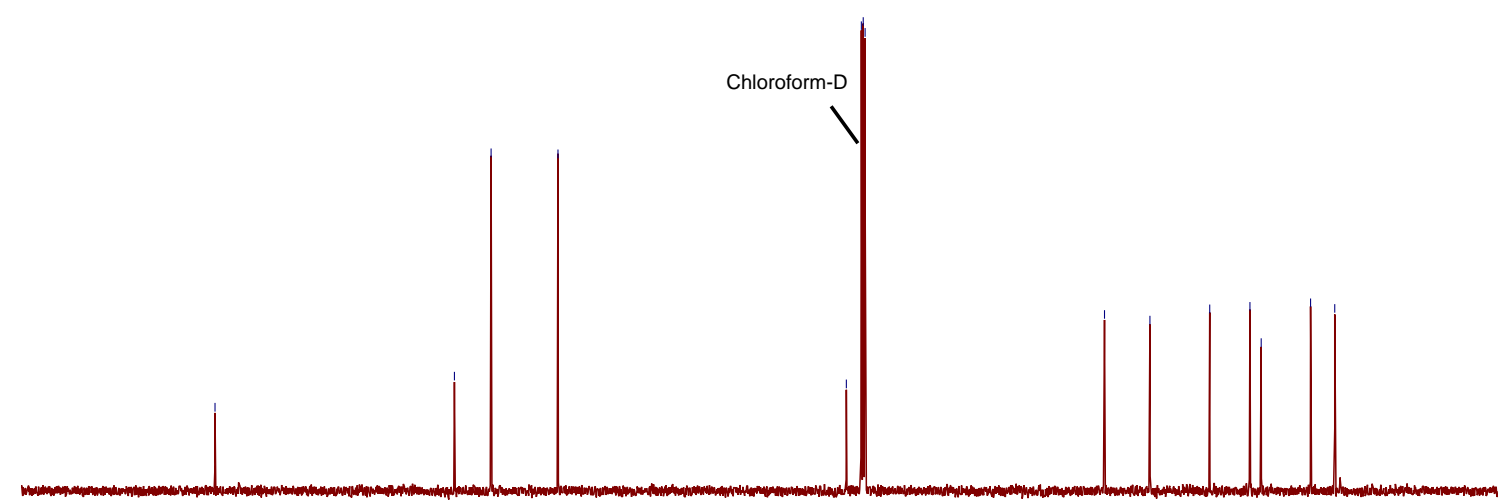

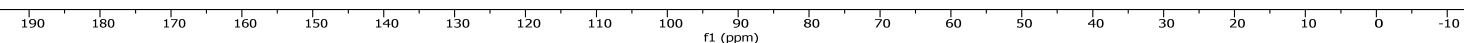


${ }^{1} \mathrm{H}$ NMR $\left(500 \mathrm{MHz}, \mathrm{CDCl}_{3}\right)$

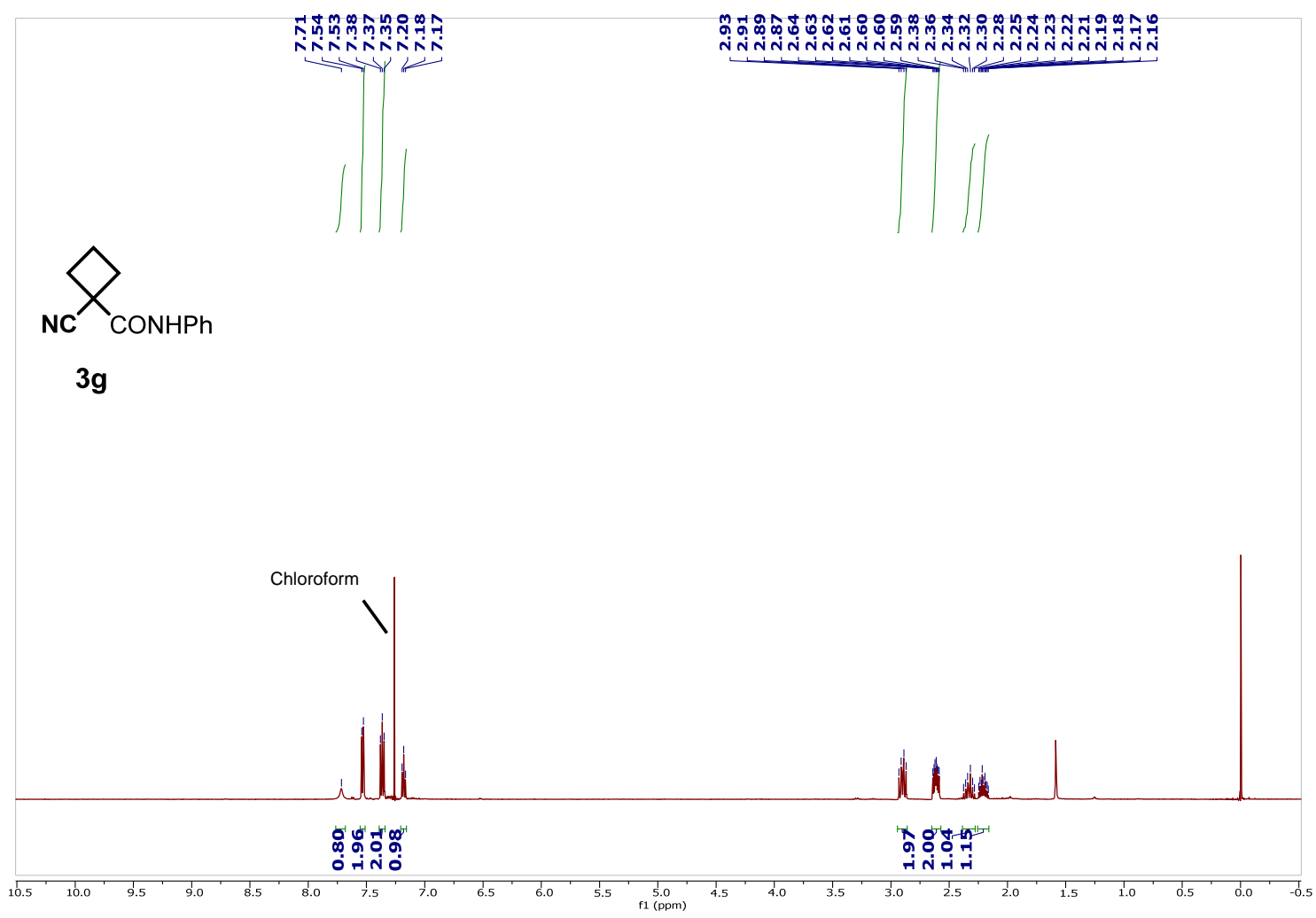

${ }^{13} \mathrm{C}$ NMR $\left(125 \mathrm{MHz}, \mathrm{CDCl}_{3}\right)$

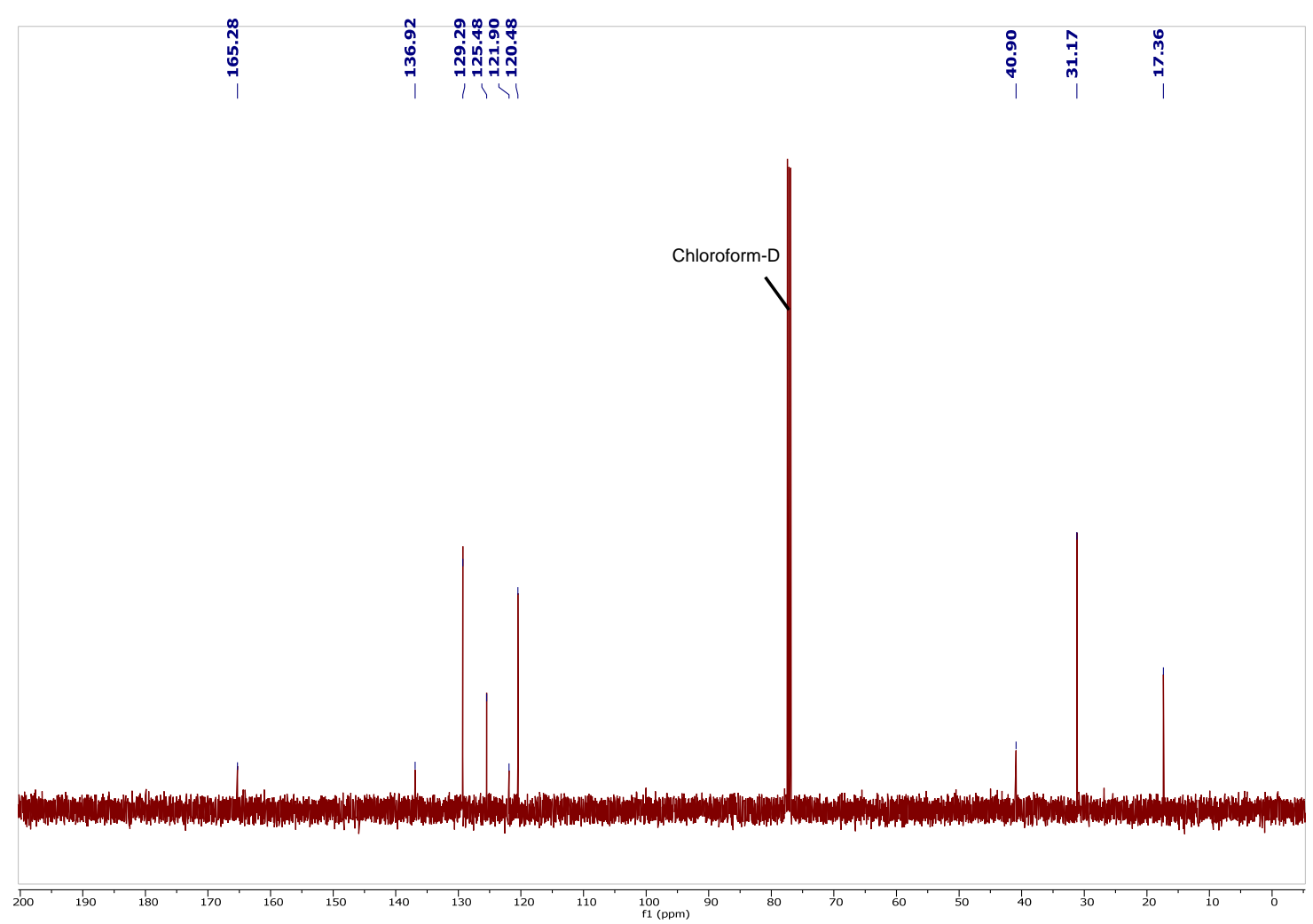


${ }^{1} \mathrm{H}$ NMR $\left(500 \mathrm{MHz}, \mathrm{CDCl}_{3}\right)$

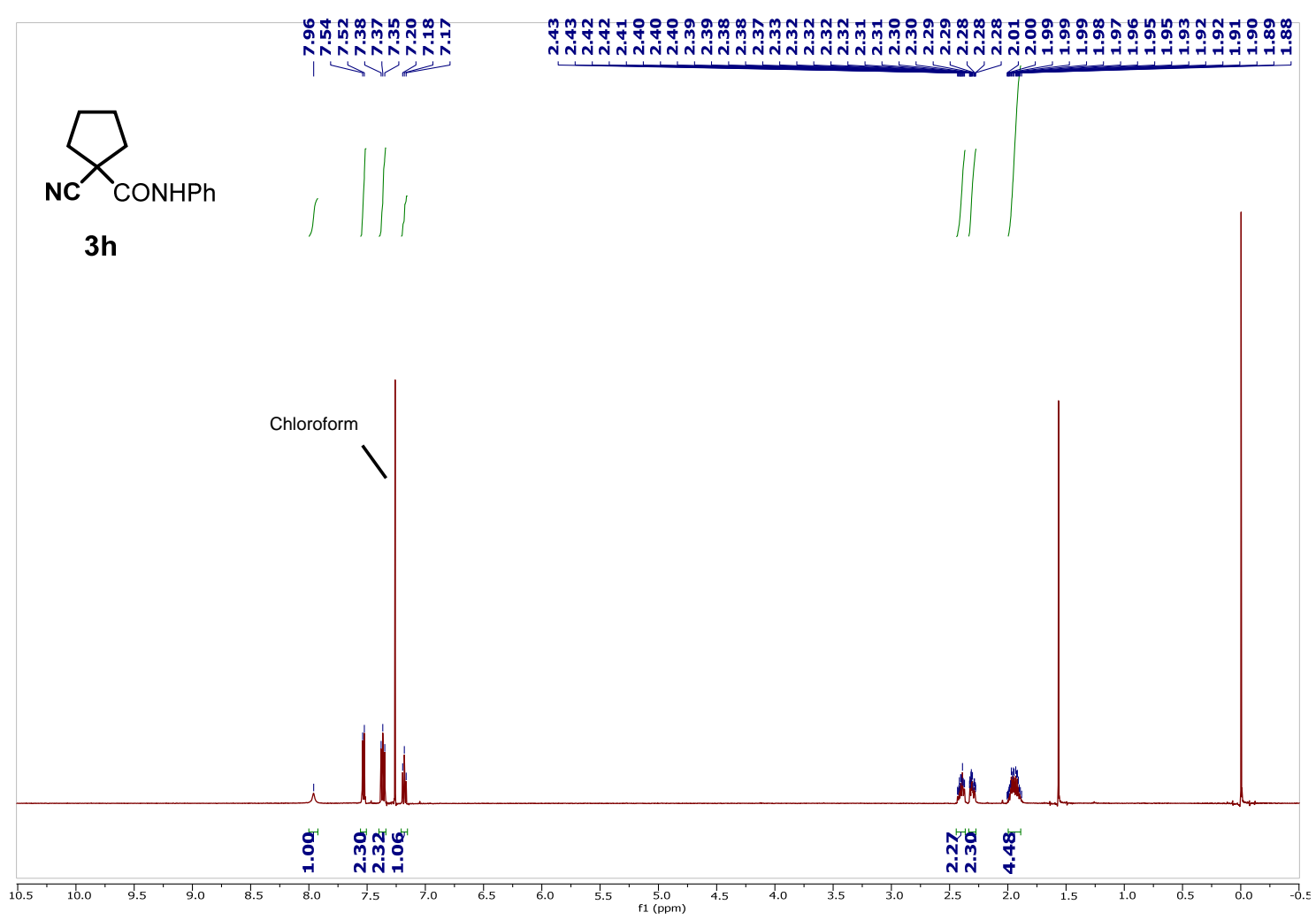

${ }^{13} \mathrm{C}$ NMR $\left(125 \mathrm{MHz}, \mathrm{CDCl}_{3}\right)$

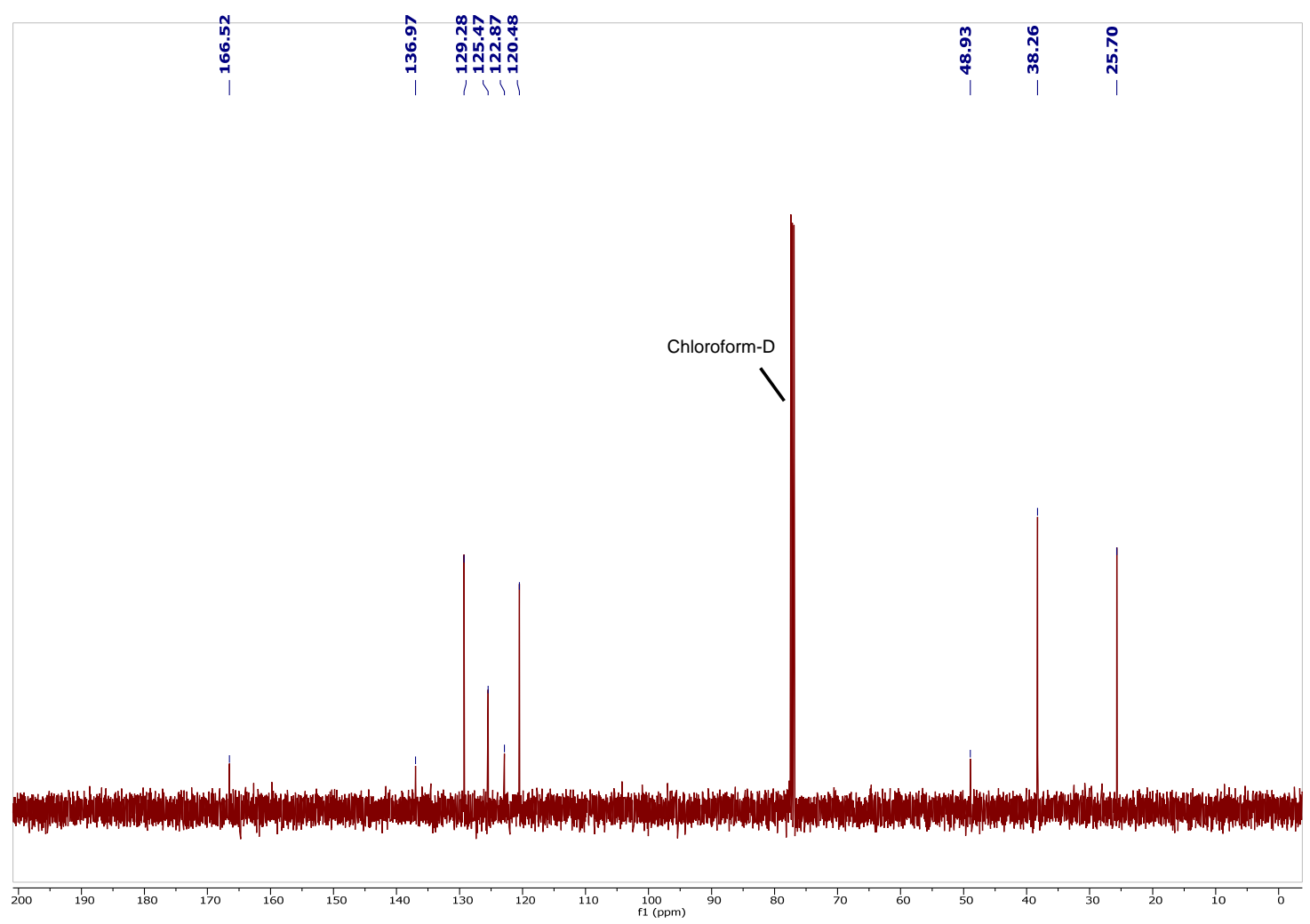


${ }^{1} \mathrm{H}$ NMR (500 MHz, $\mathrm{CDCl}_{3}$ )

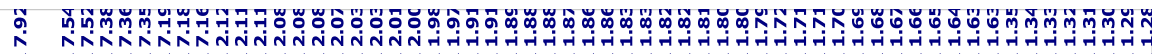

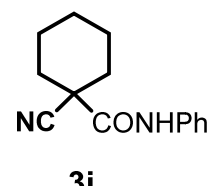

3i

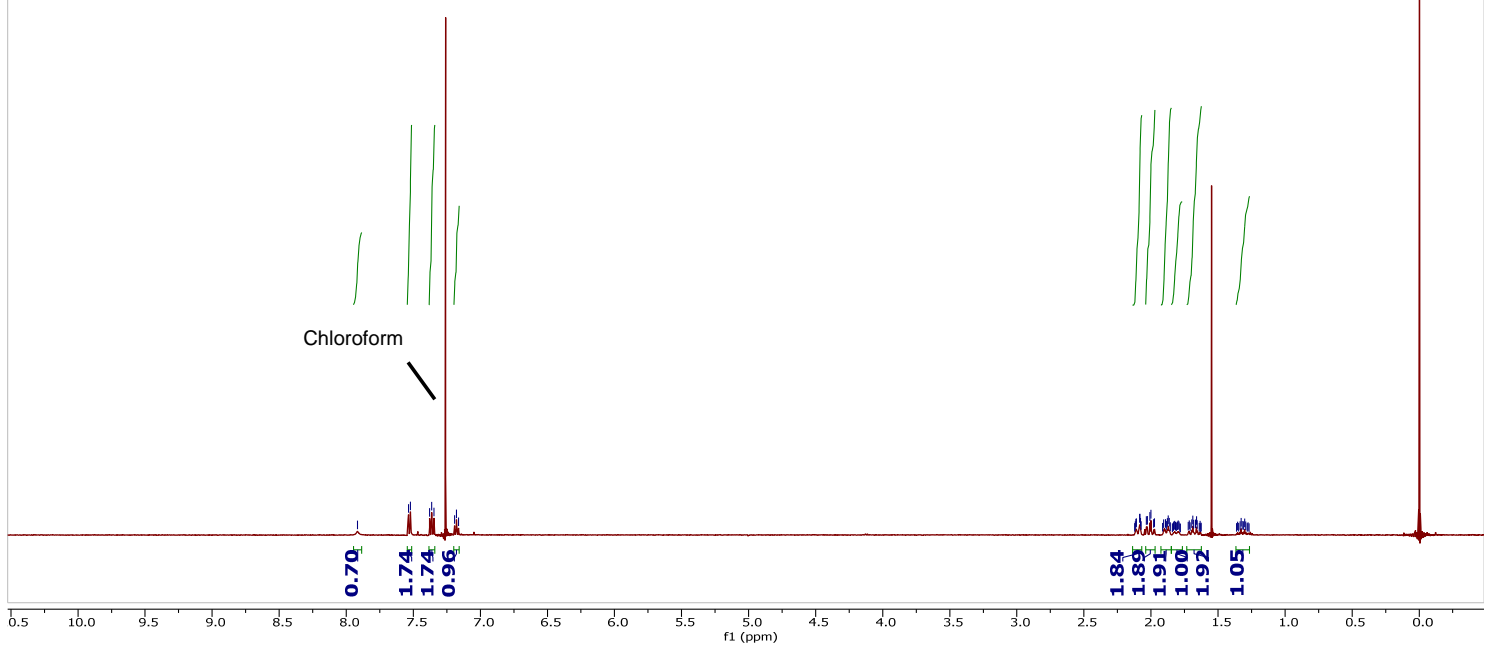

${ }^{13} \mathrm{C}$ NMR $\left(125 \mathrm{MHz}, \mathrm{CDCl}_{3}\right)$

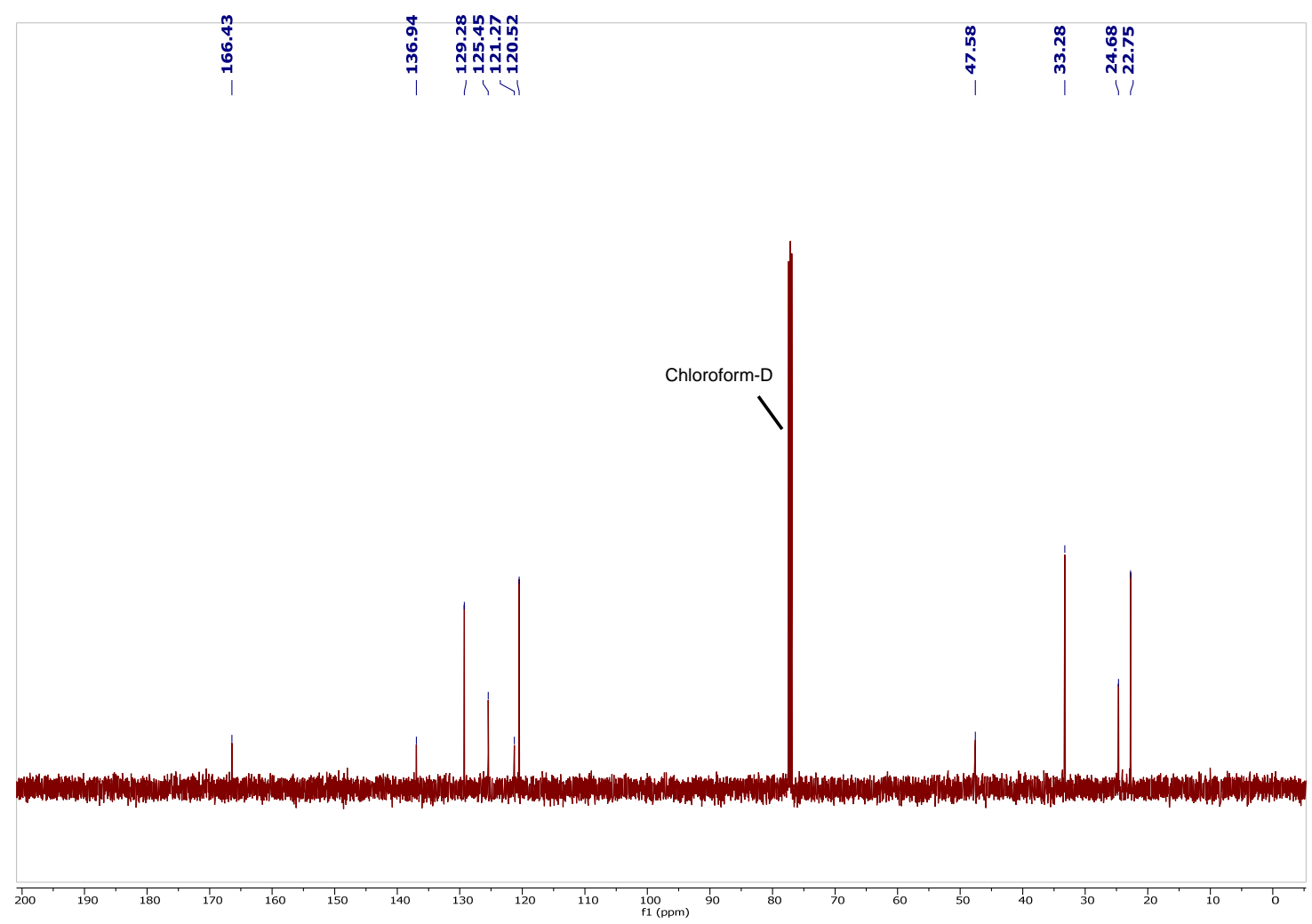


${ }^{1} \mathrm{H}$ NMR (500 MHz, $\mathrm{CDCl}_{3}$ )

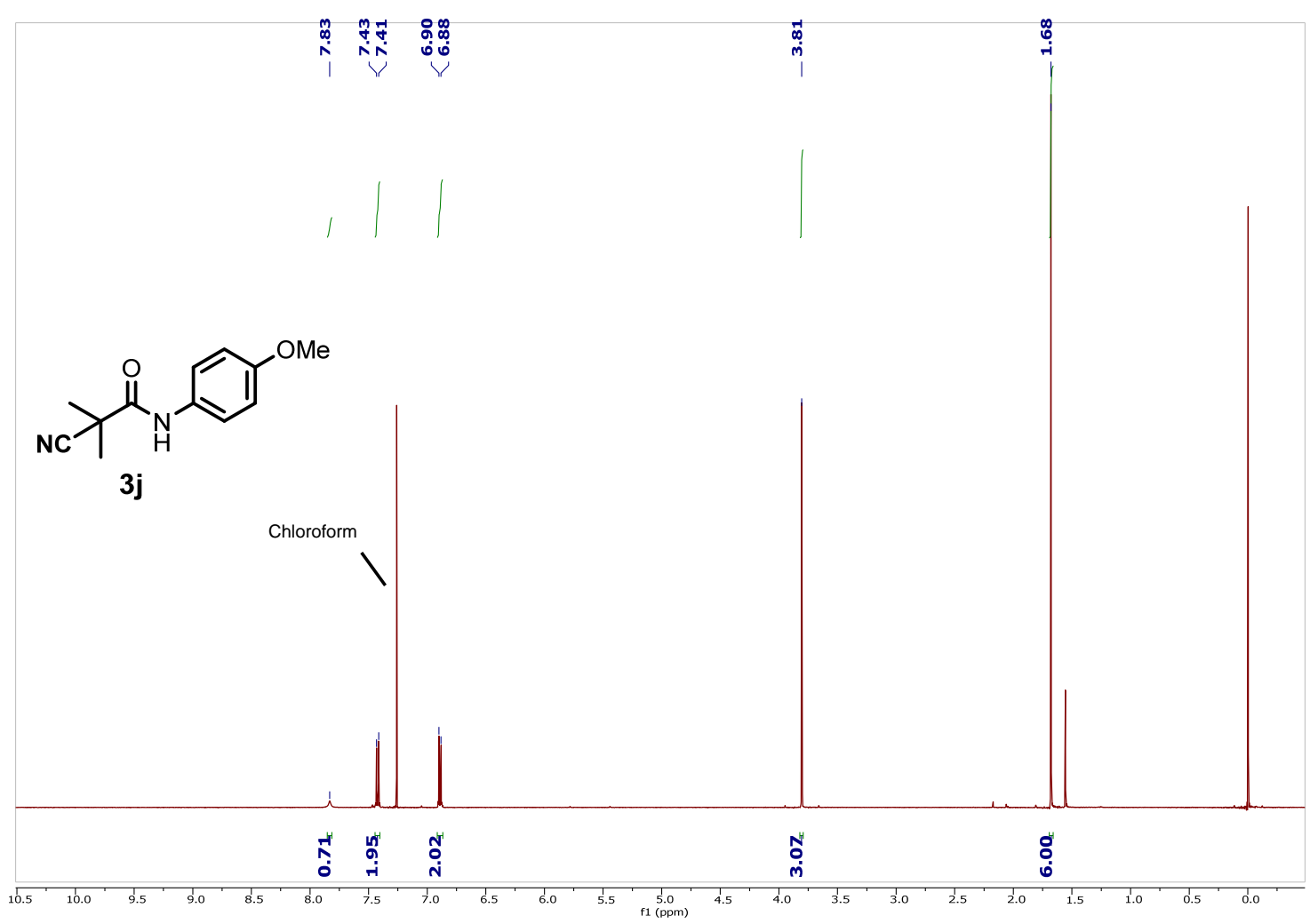

${ }^{13} \mathrm{C}$ NMR $\left(125 \mathrm{MHz}, \mathrm{CDCl}_{3}\right)$

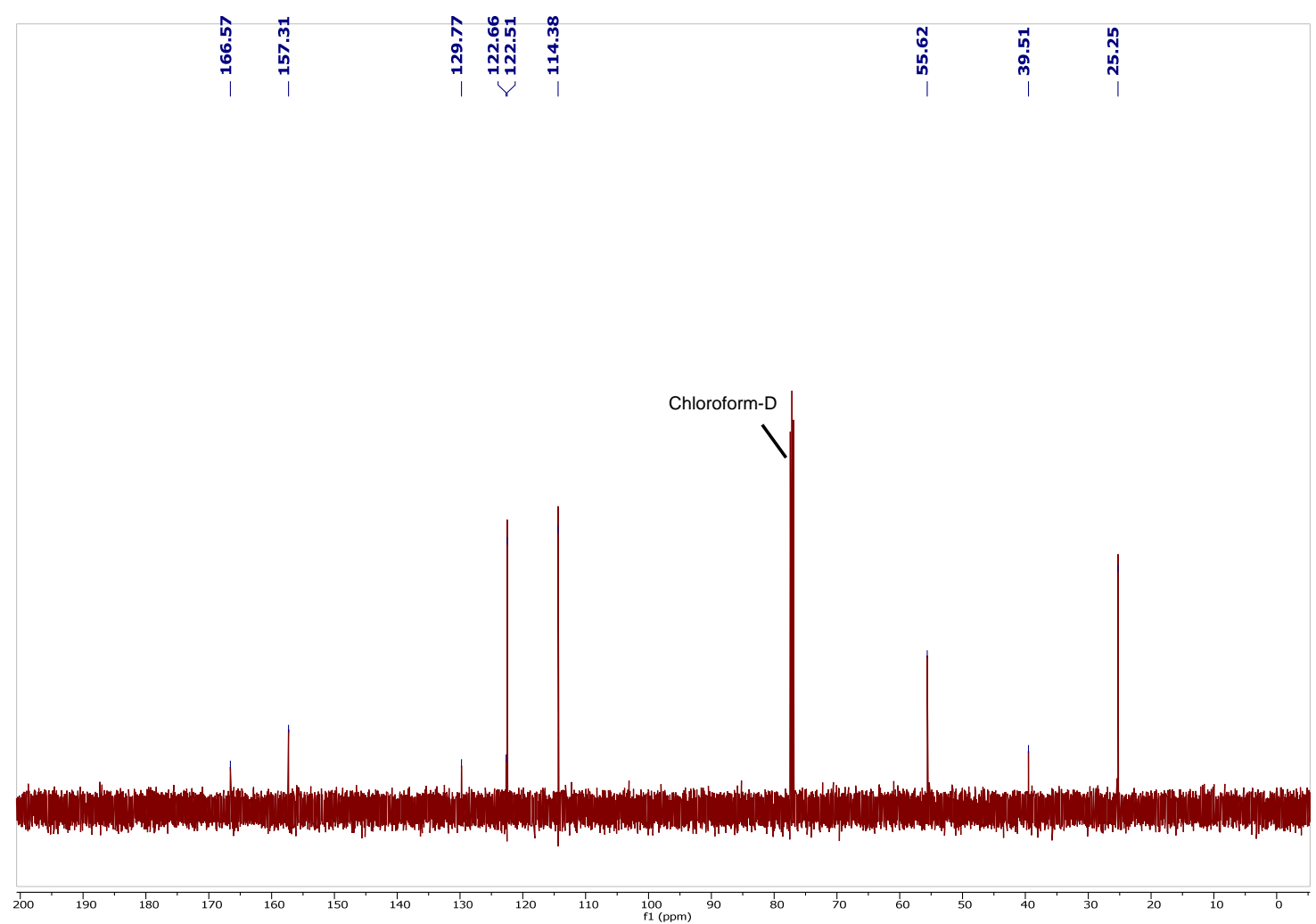


${ }^{1} \mathrm{H}$ NMR (500 MHz, $\mathrm{CDCl}_{3}$ )

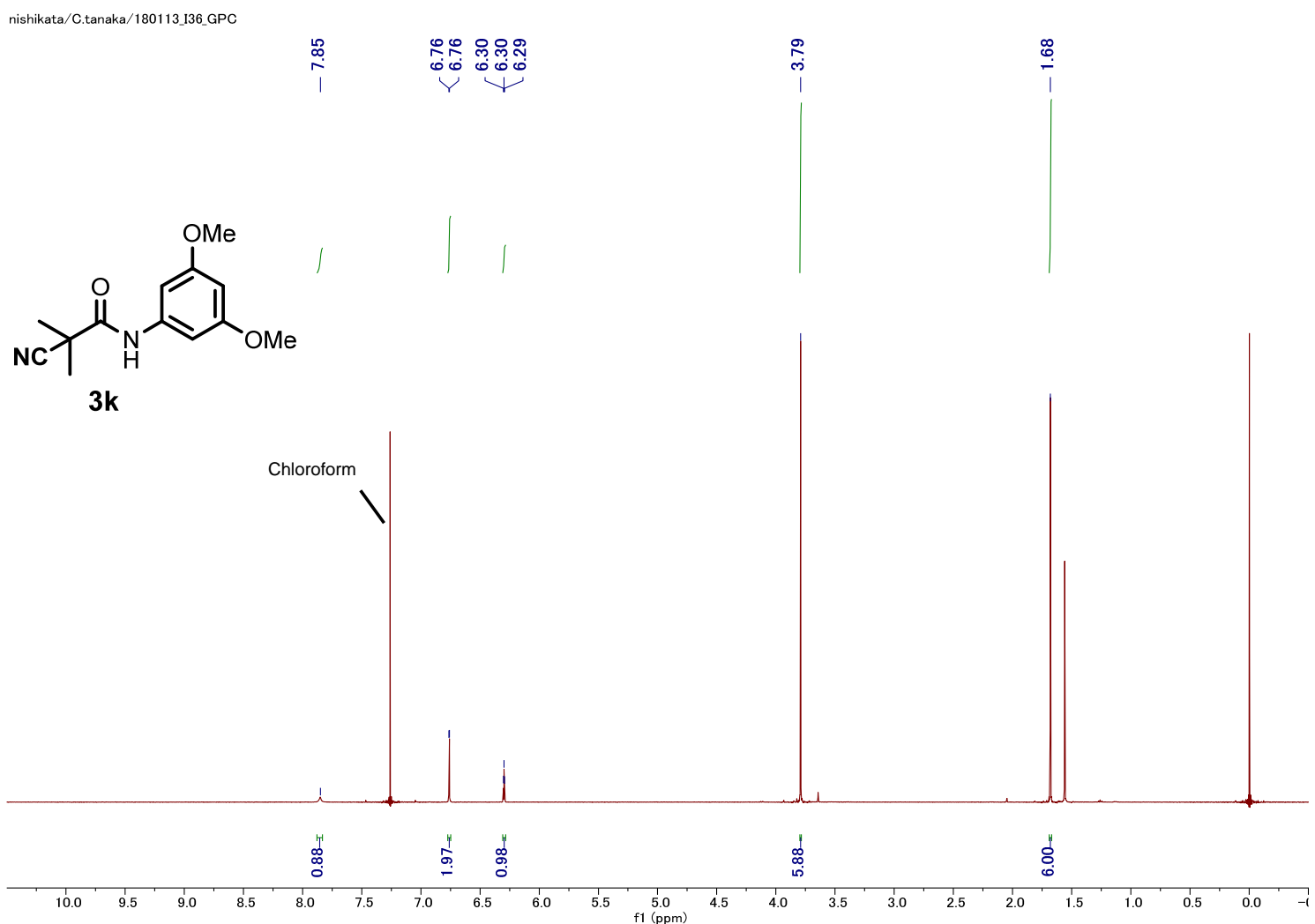

${ }^{13} \mathrm{C}$ NMR (125 MHz, $\mathrm{CDCl}_{3}$ )

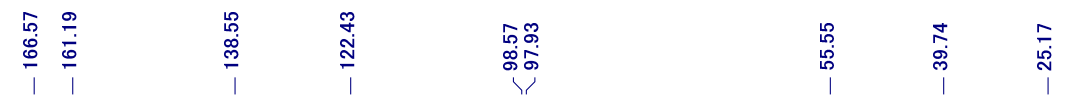

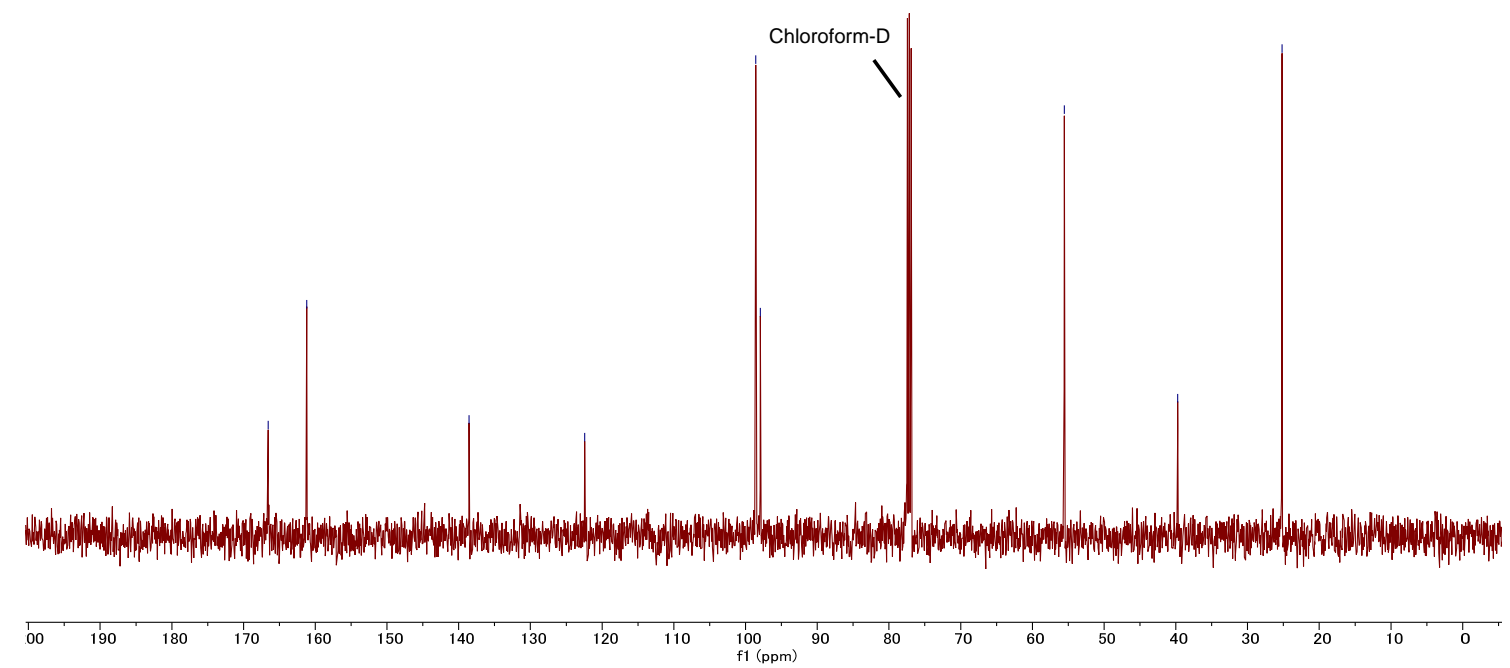


${ }^{1} \mathrm{H}$ NMR $\left(500 \mathrm{MHz}, \mathrm{CDCl}_{3}\right)$

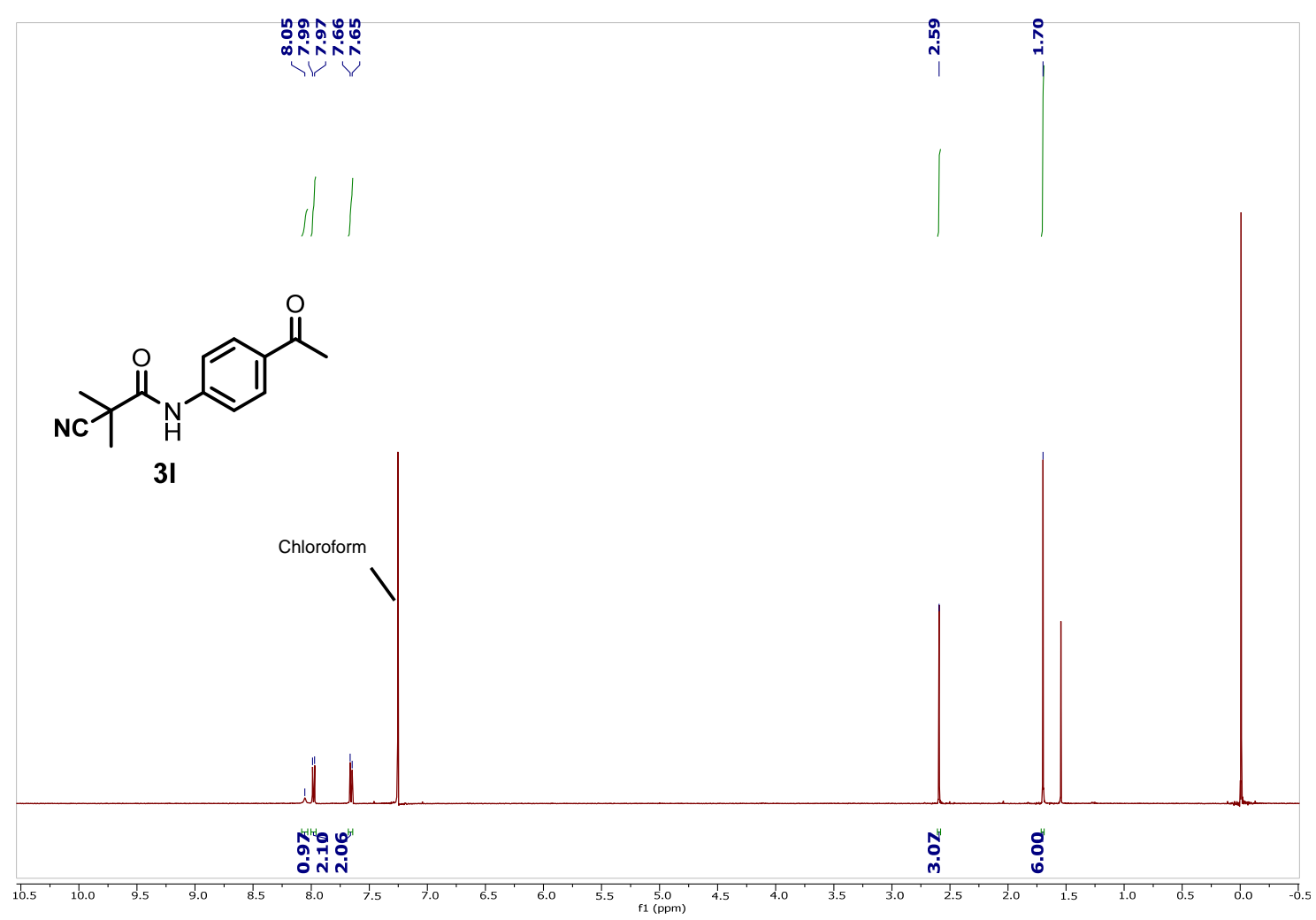

${ }^{13} \mathrm{C}$ NMR $\left(125 \mathrm{MHz}, \mathrm{CDCl}_{3}\right)$

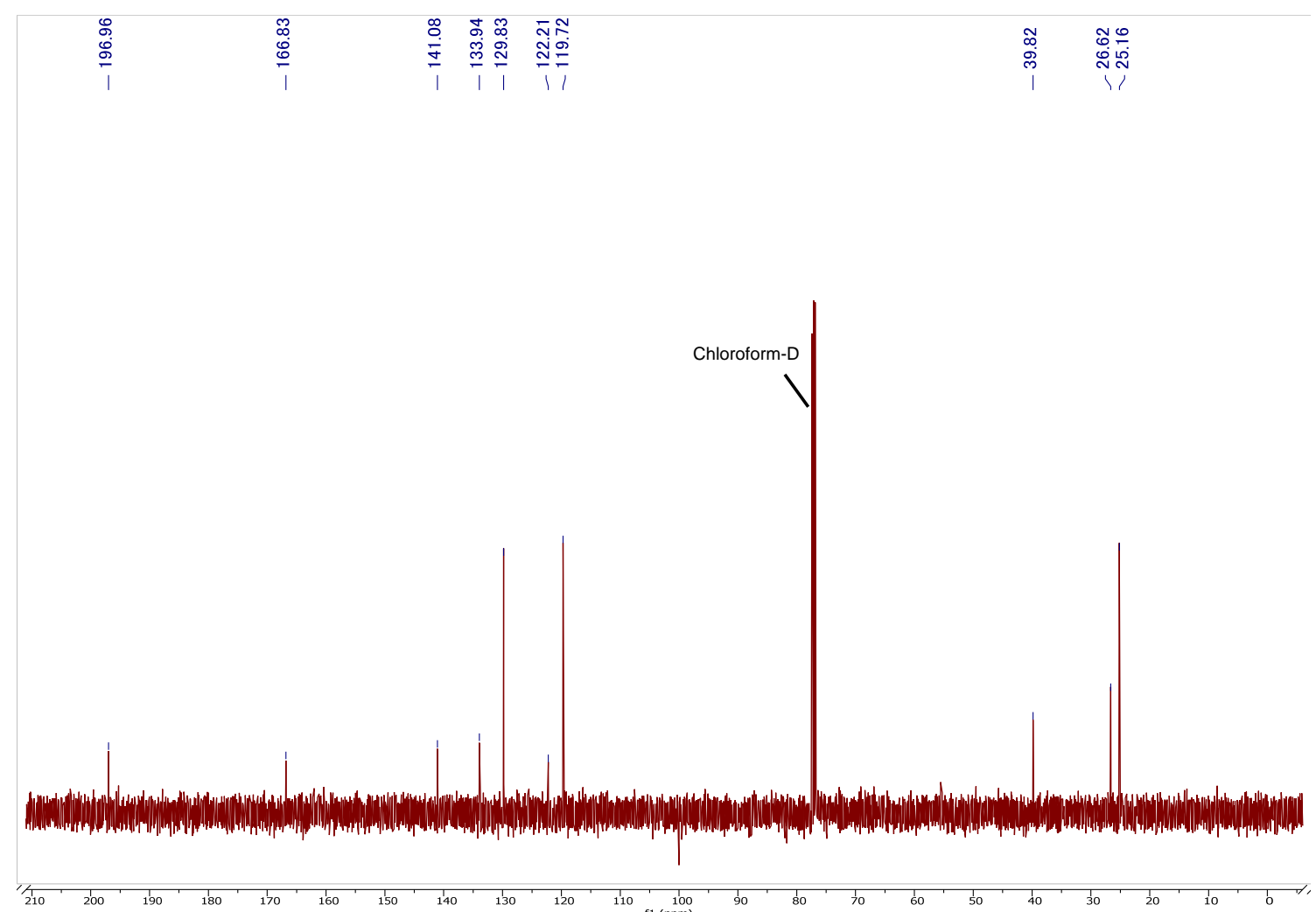


${ }^{1} \mathrm{H}$ NMR (500 MHz, $\left.\mathrm{CDCl}_{3}\right)$

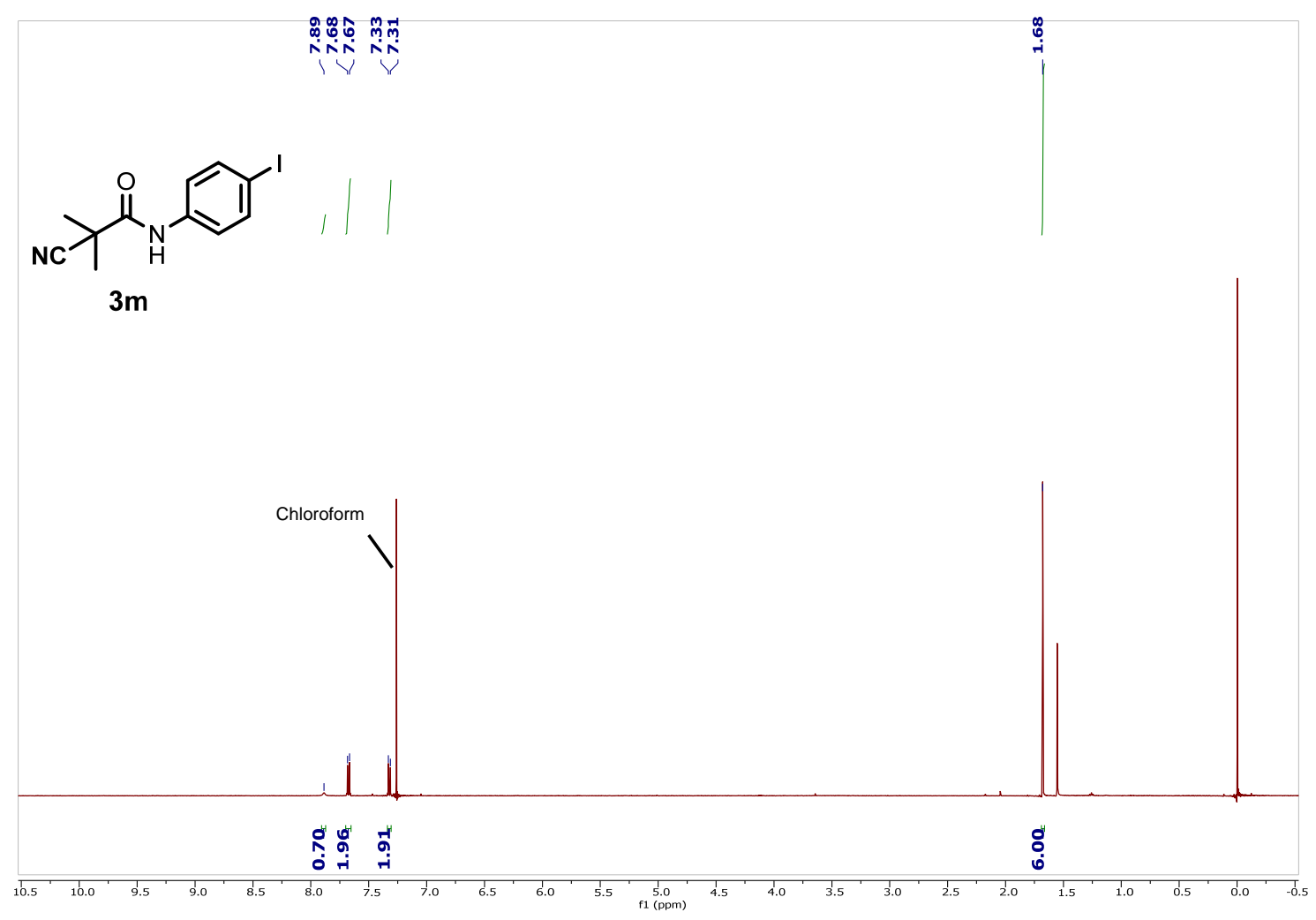

${ }^{13} \mathrm{C} \mathrm{NMR}\left(125 \mathrm{MHz}, \mathrm{CDCl}_{3}\right)$

nishikata/C.tanaka/181122_I11_13C

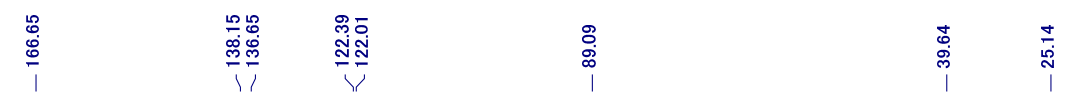

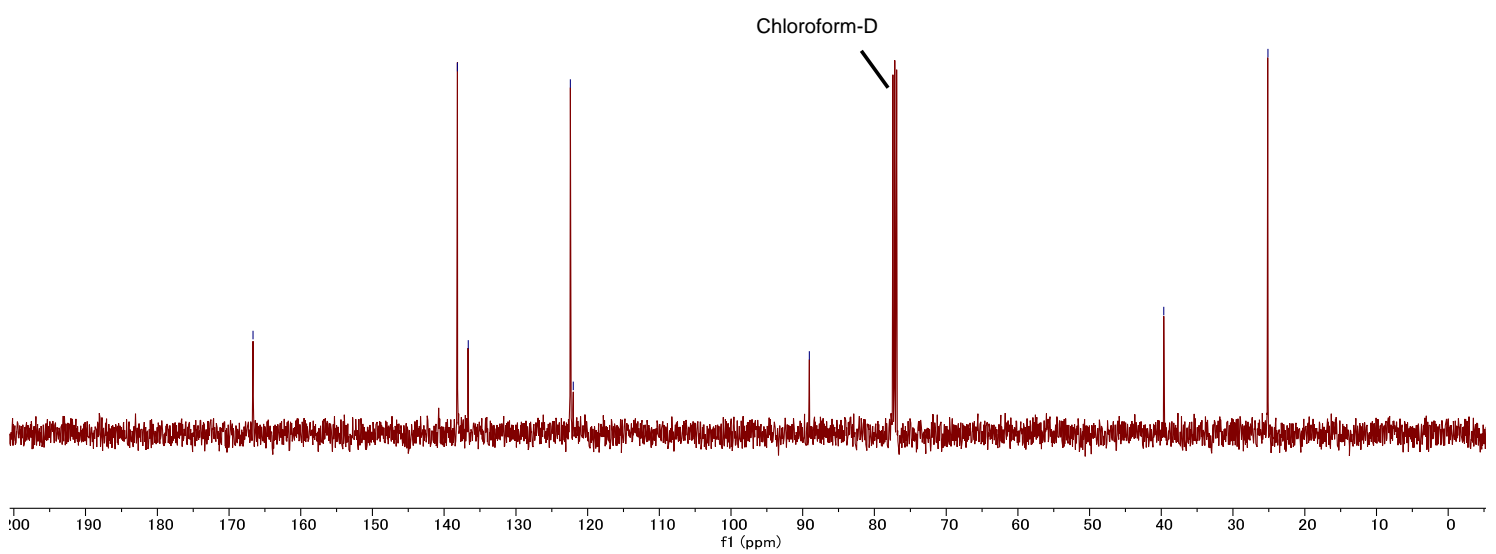


${ }^{1} \mathrm{H}$ NMR $\left(500 \mathrm{MHz}, \mathrm{CDCl}_{3}\right)$

nishikata/C.tanaka/180113_130_GPC

ำ

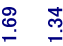

vivin

广<smiles>CC(C)(C)C(=O)Nc1ccc(Br)cc1</smiles>

$3 n$

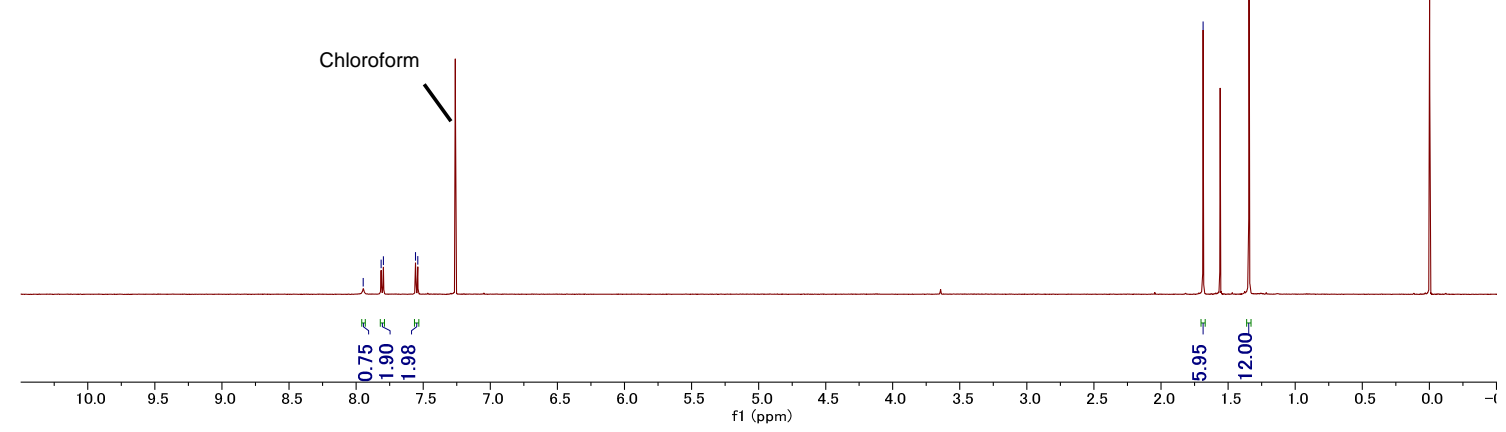

${ }^{13} \mathrm{C}$ NMR $\left(125 \mathrm{MHz}, \mathrm{CDCl}_{3}\right)$

190204130130

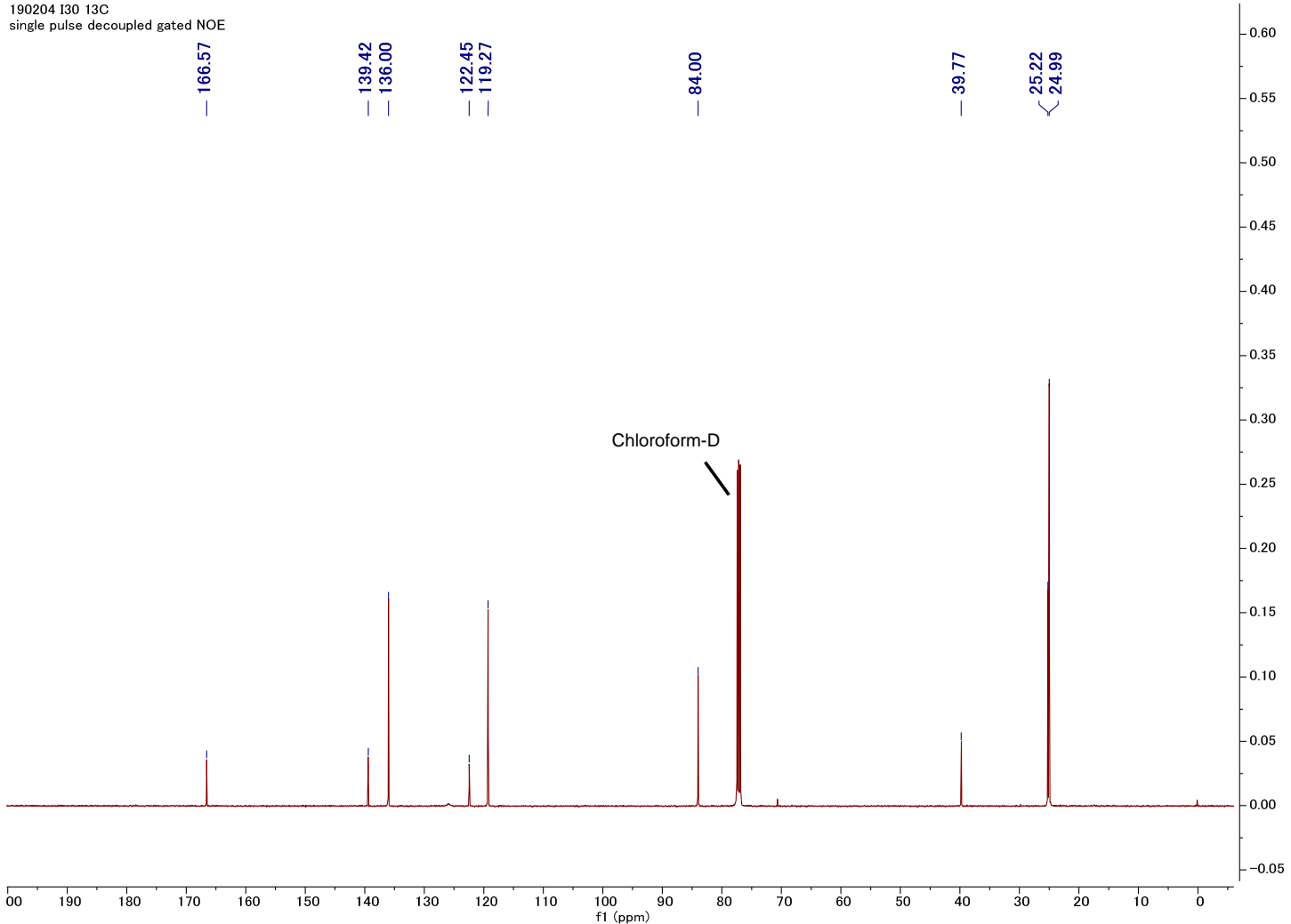


${ }^{1} \mathrm{H}$ NMR $\left(500 \mathrm{MHz}, \mathrm{CDCl}_{3}\right)$

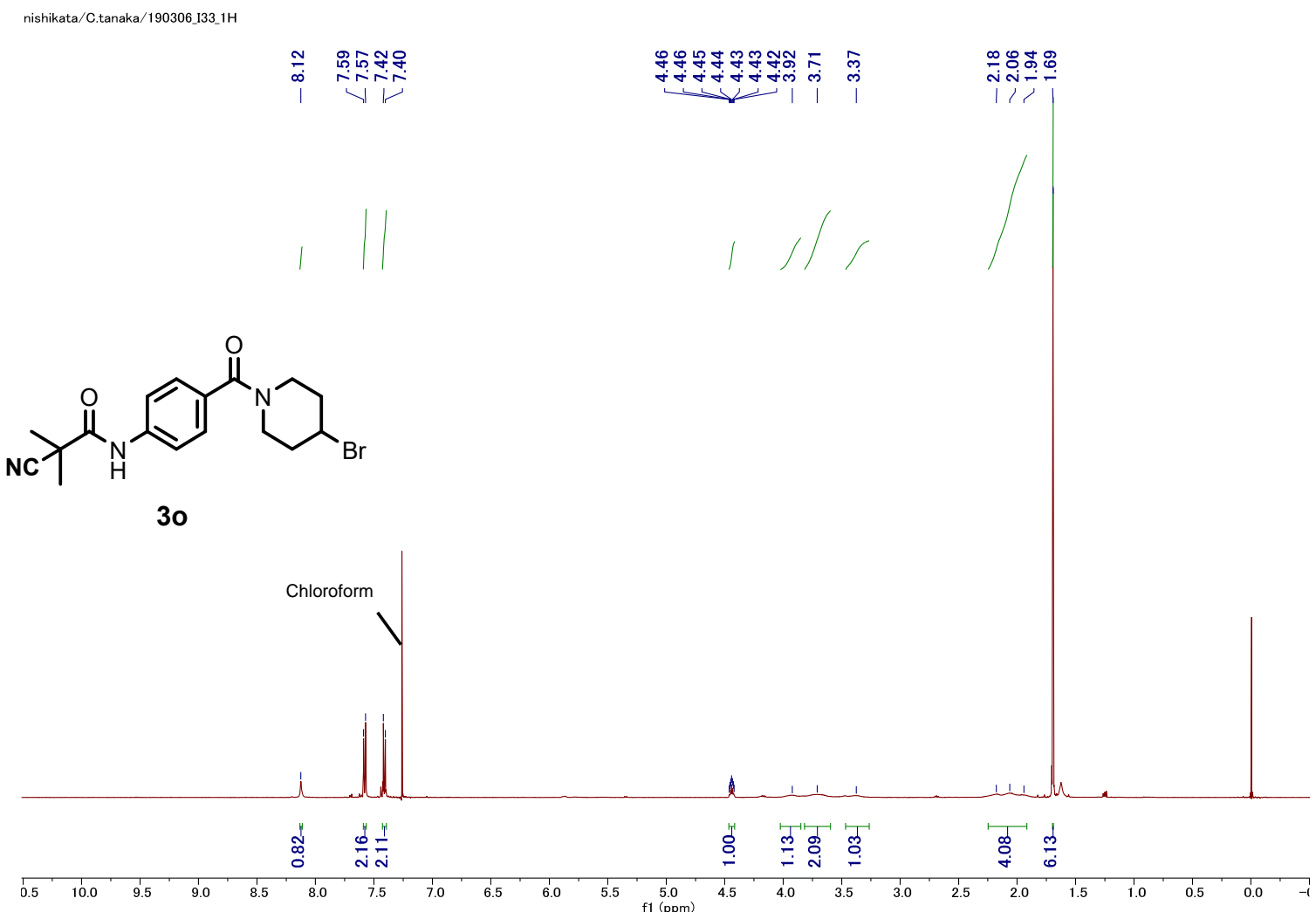

${ }^{13} \mathrm{C} \mathrm{NMR}\left(125 \mathrm{MHz}, \mathrm{CDCl}_{3}\right)$

$19030513313 \mathrm{C}$

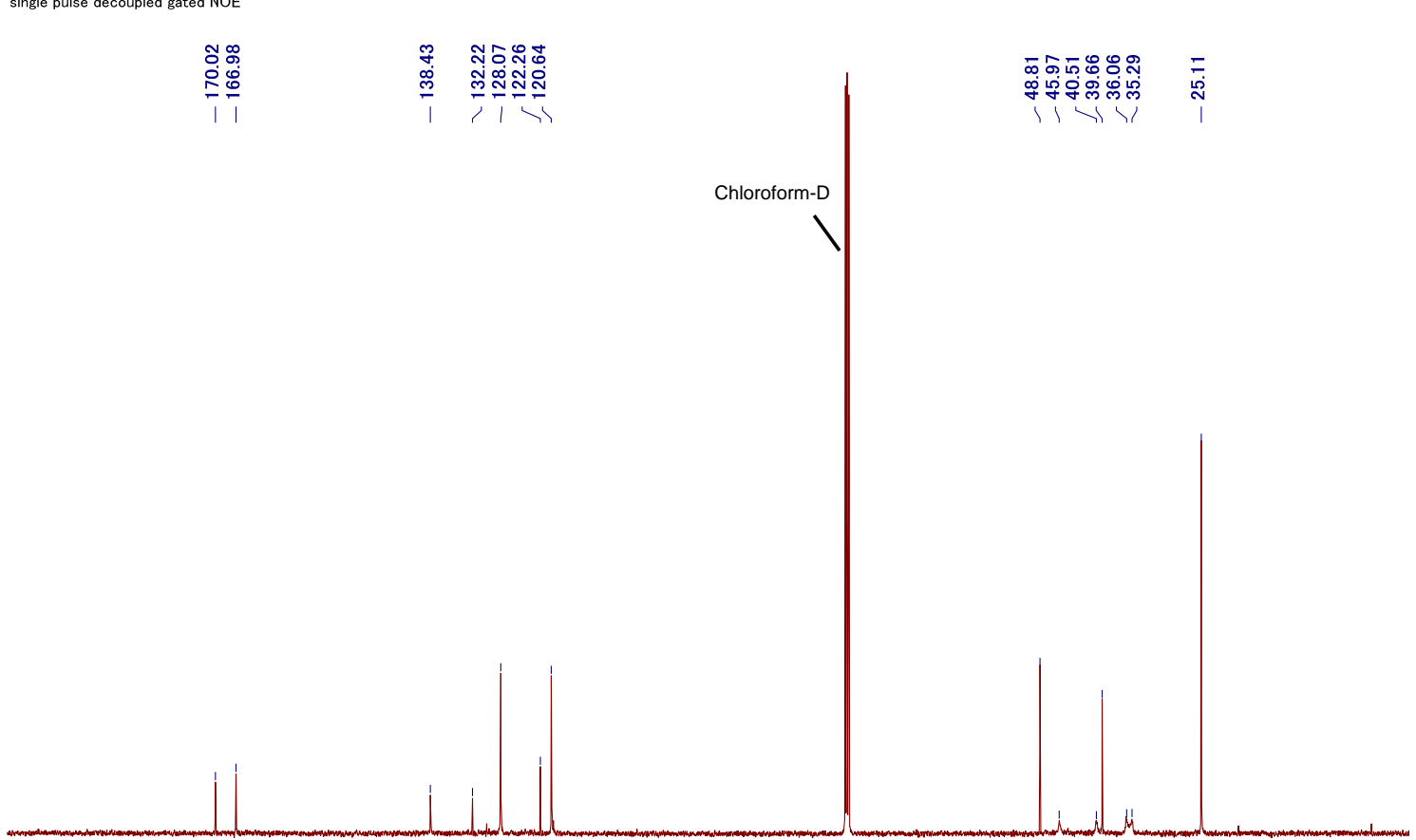

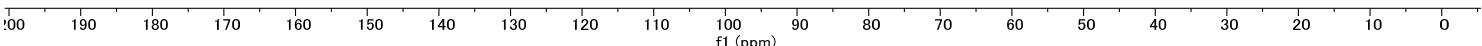


${ }^{1} \mathrm{H}$ NMR $\left(500 \mathrm{MHz}, \mathrm{CDCl}_{3}\right)$

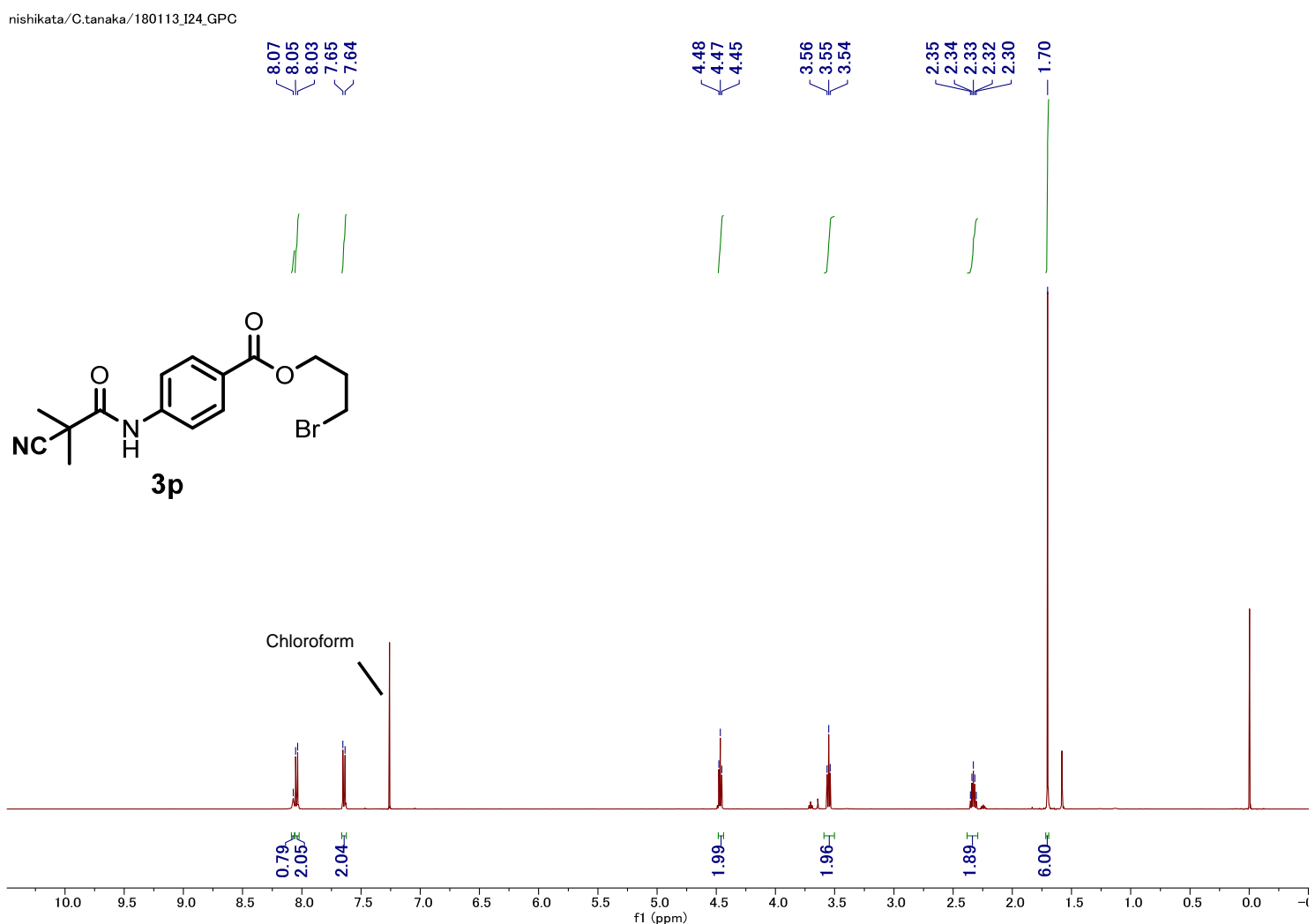

${ }^{13} \mathrm{C}$ NMR $\left(125 \mathrm{MHz}, \mathrm{CDCl}_{3}\right)$

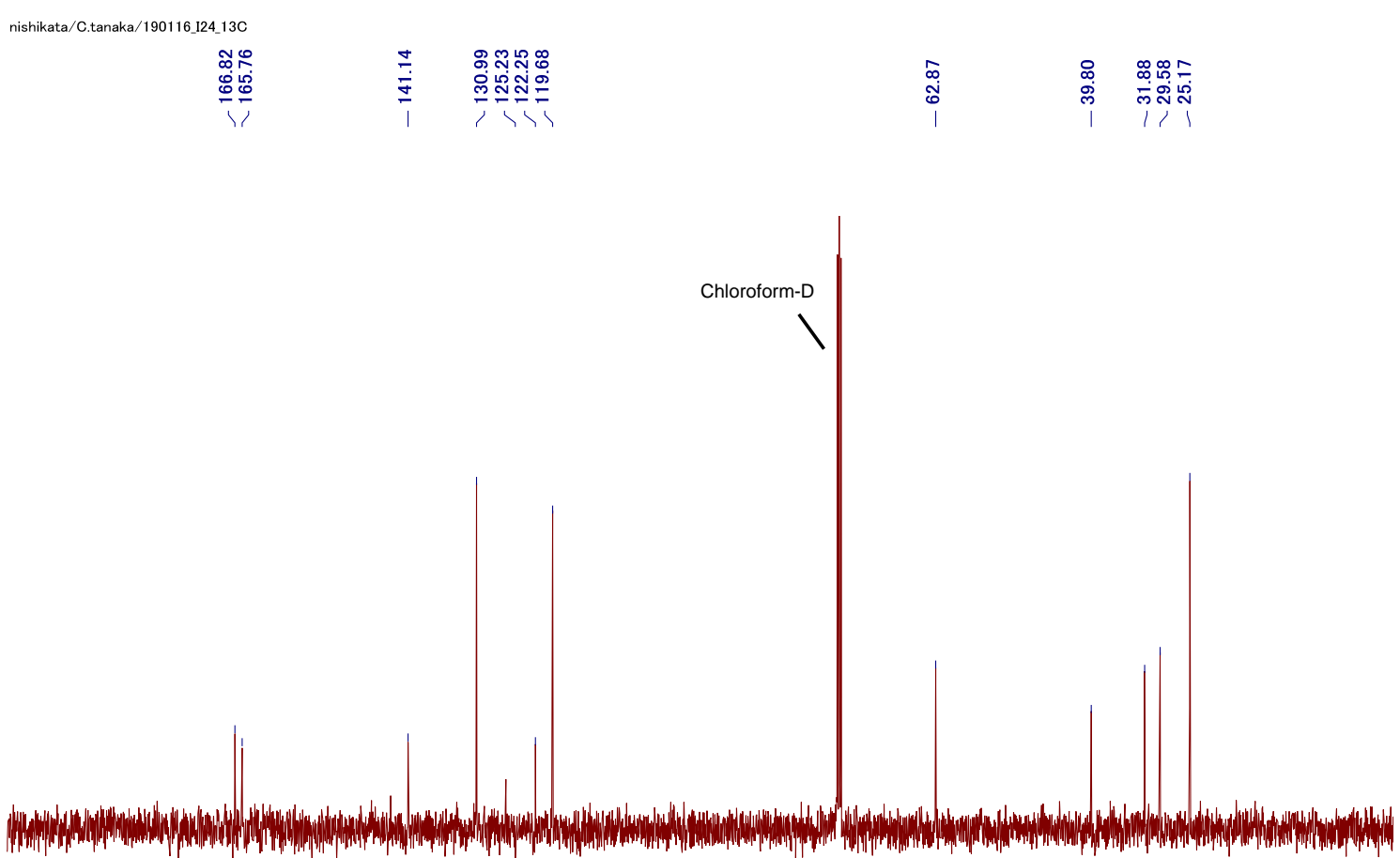

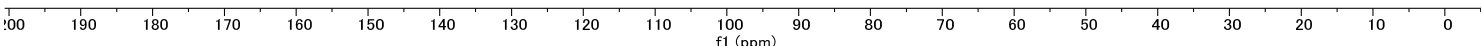


${ }^{1} \mathrm{H}$ NMR $\left(500 \mathrm{MHz}, \mathrm{CDCl}_{3}\right)$

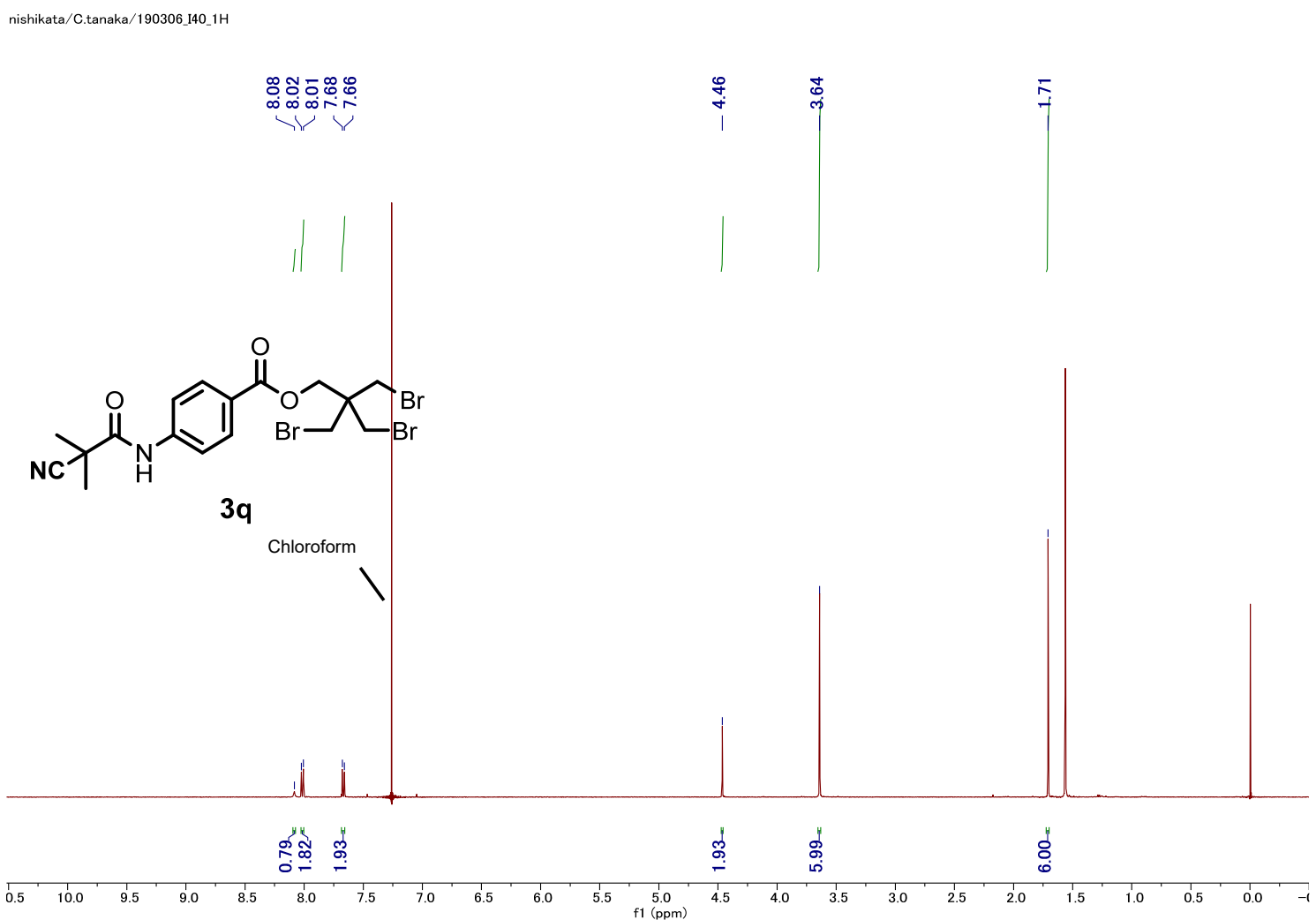

${ }^{13} \mathrm{C} \mathrm{NMR}\left(125 \mathrm{MHz}, \mathrm{CDCl}_{3}\right)$

$19022714013 \mathrm{C}$

The227 40 soc

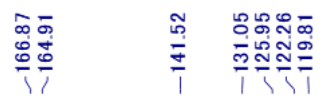

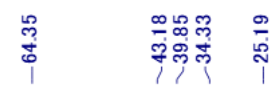

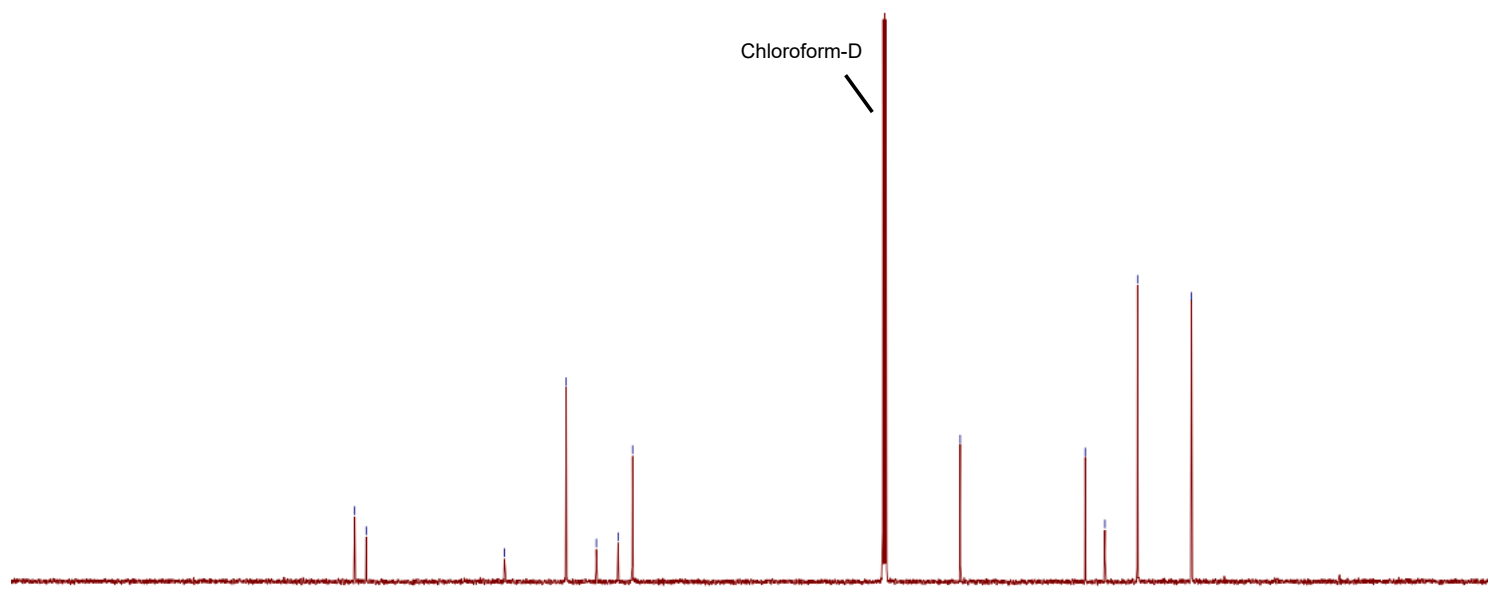

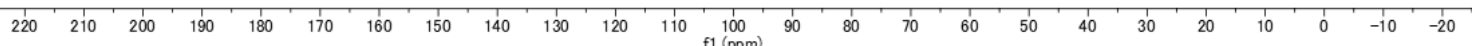


${ }^{1} \mathrm{H}$ NMR $\left(500 \mathrm{MHz}, \mathrm{CDCl}_{3}\right)$

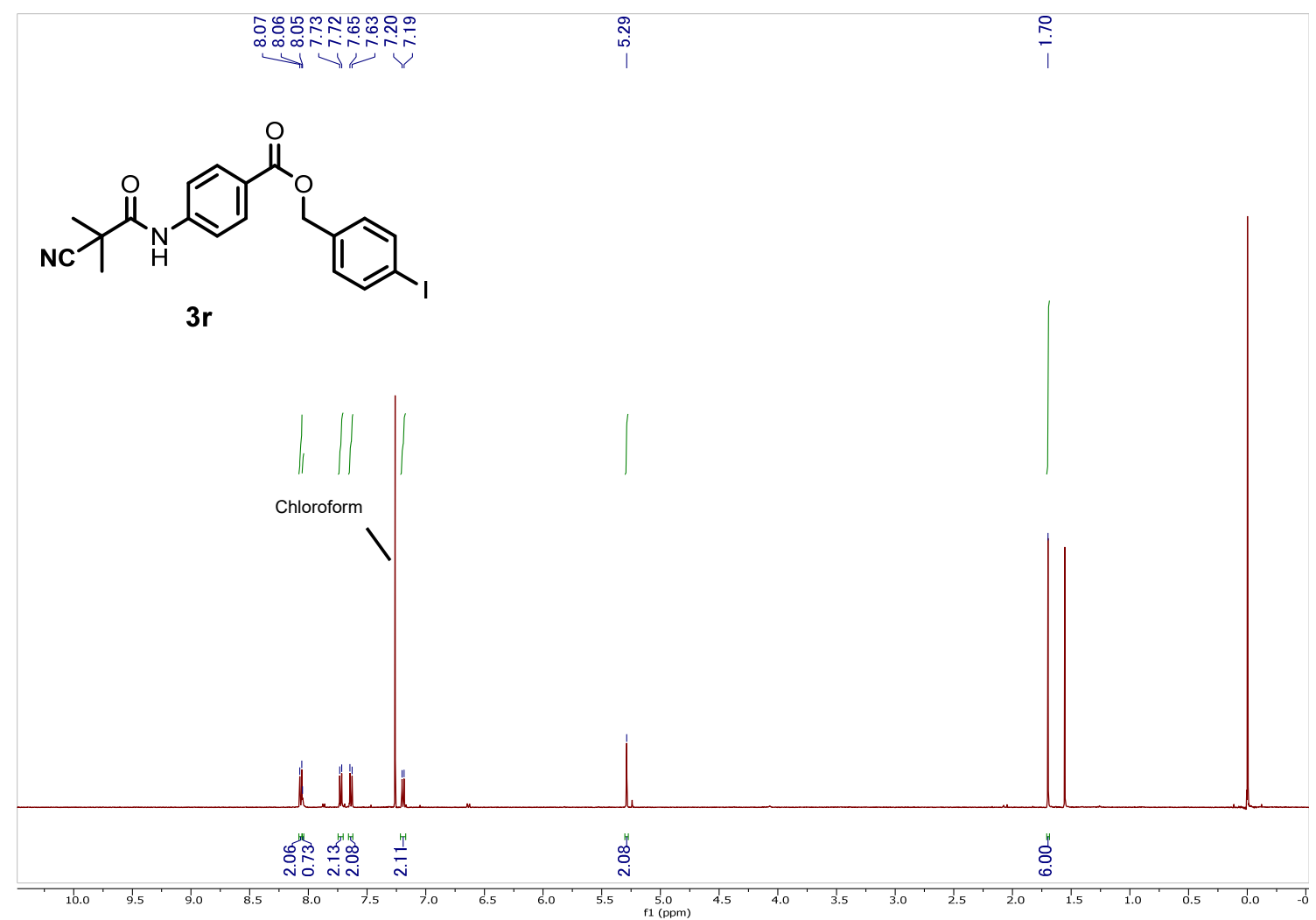

${ }^{13} \mathrm{C} \mathrm{NMR}\left(125 \mathrm{MHz}, \mathrm{CDCl}_{3}\right)$

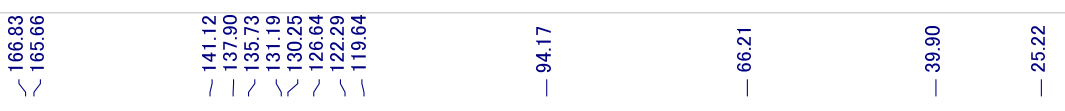

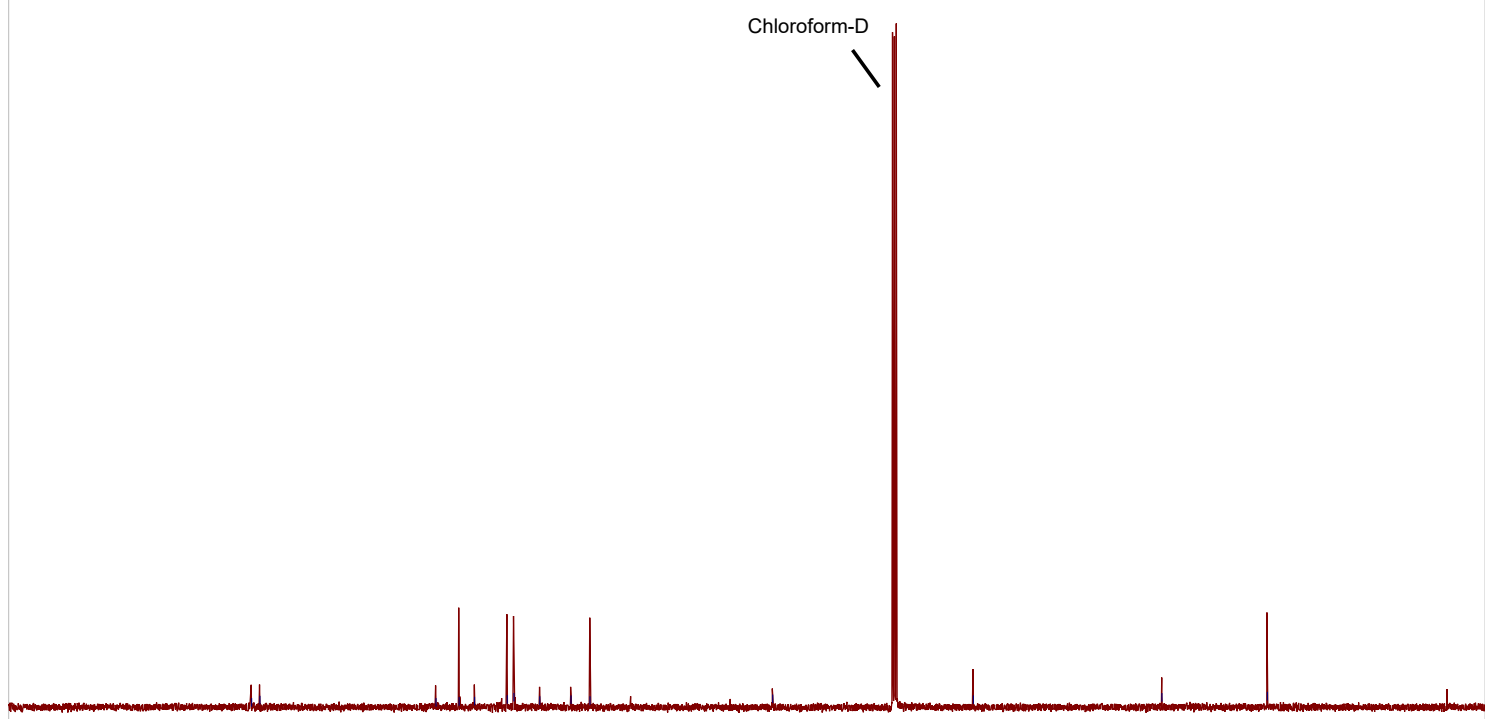

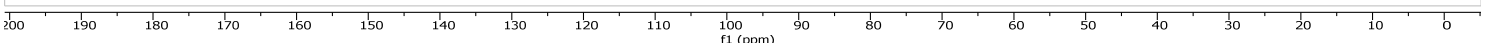


${ }^{1} \mathrm{H}$ NMR $\left(500 \mathrm{MHz}, \mathrm{CDCl}_{3}\right.$ )

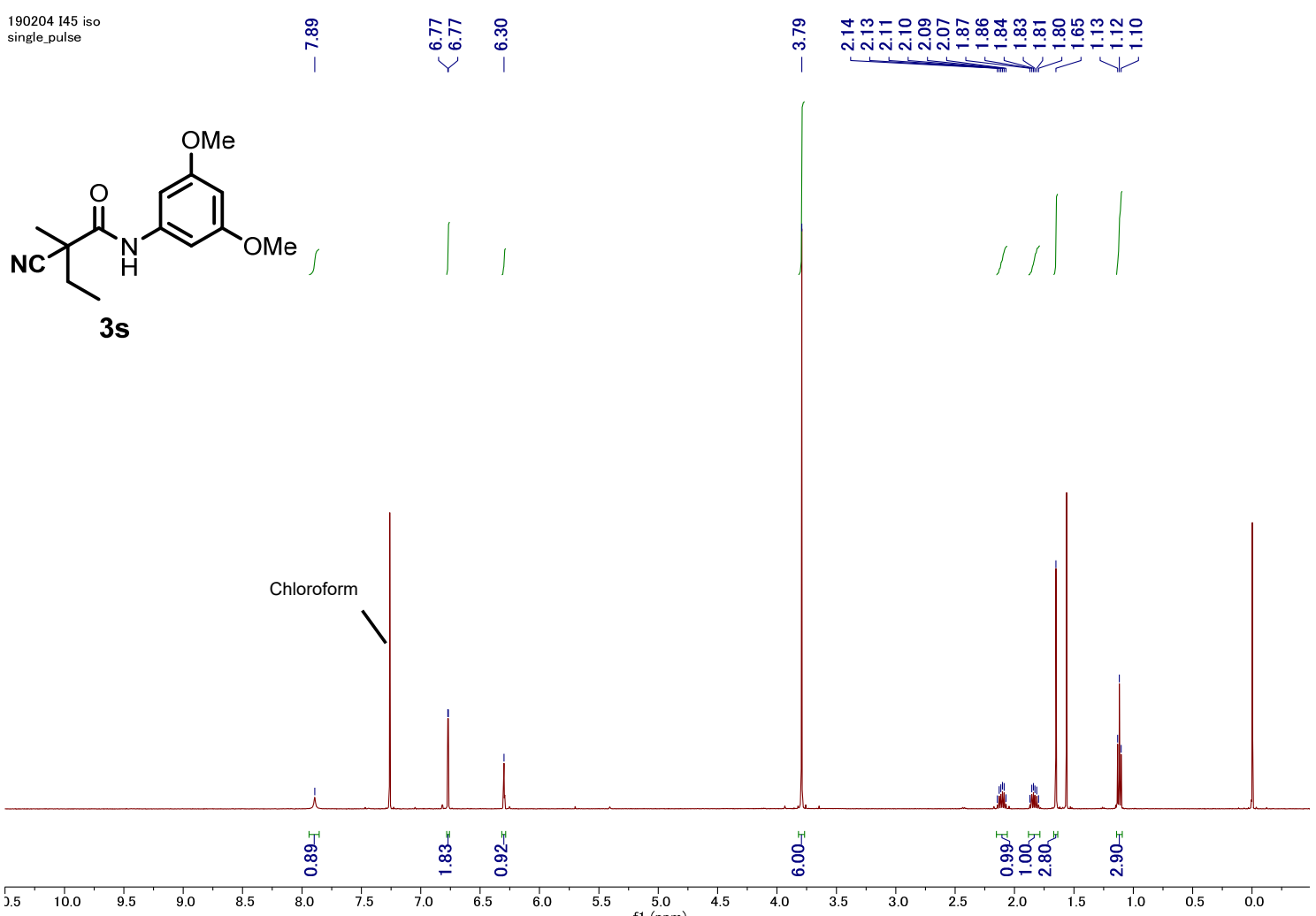

${ }^{13} \mathrm{C}$ NMR $\left(125 \mathrm{MHz}, \mathrm{CDCl}_{3}\right)$

190205146130

single pulse decoupled gated NOE

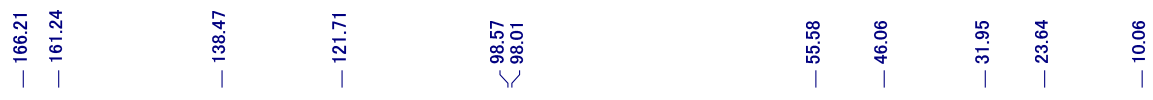

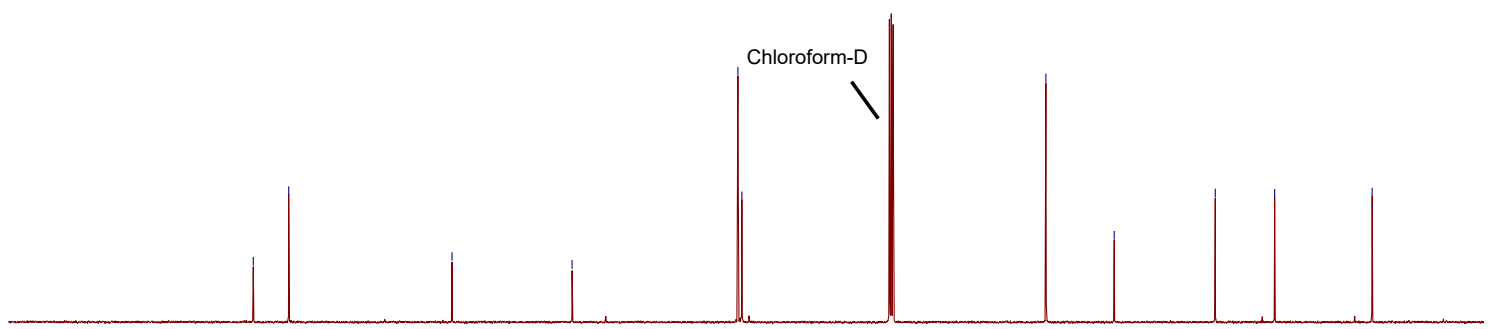

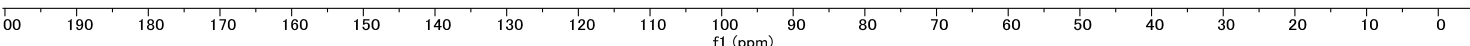


${ }^{1} \mathrm{H}$ NMR $\left(500 \mathrm{MHz}, \mathrm{CDCl}_{3}\right)$

兽

事

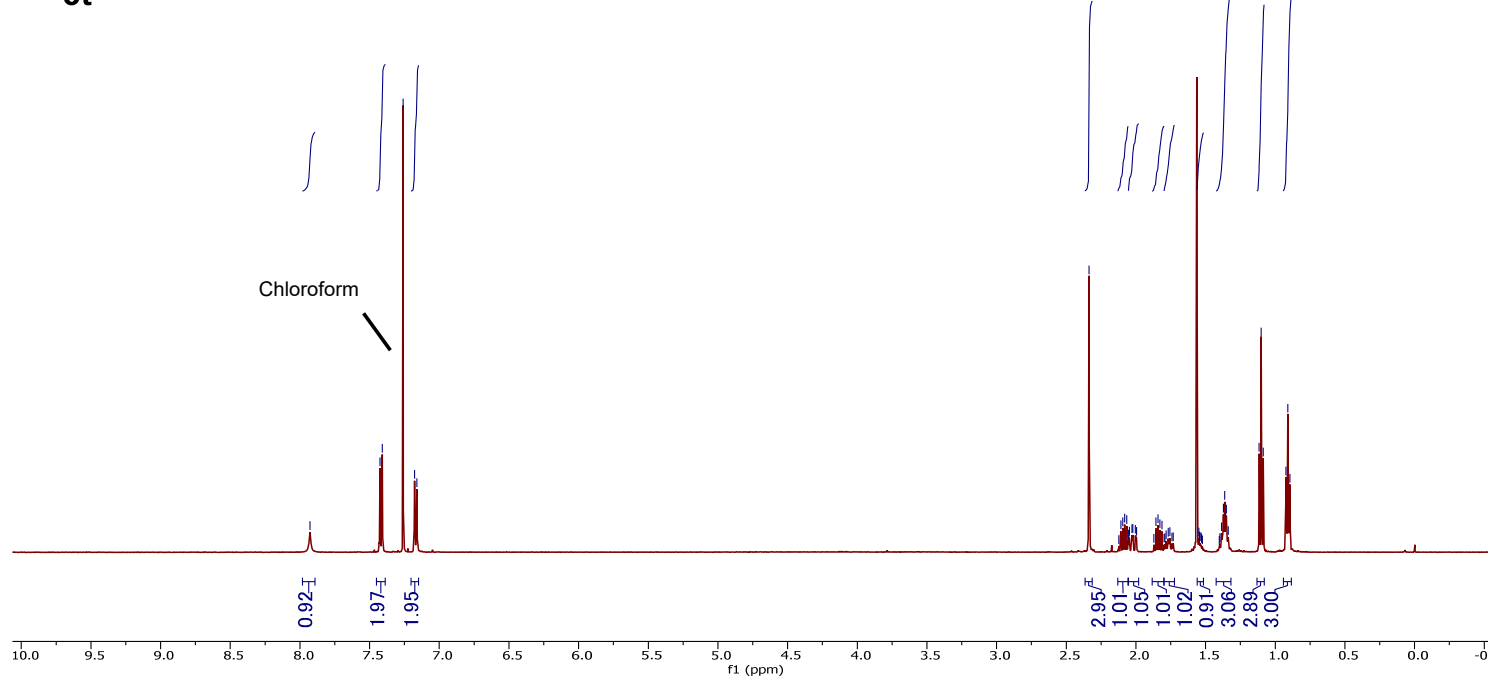

${ }^{13} \mathrm{C}$ NMR $\left(125 \mathrm{MHz}, \mathrm{CDCl}_{3}\right)$

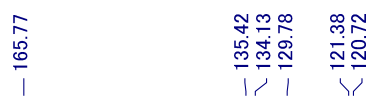

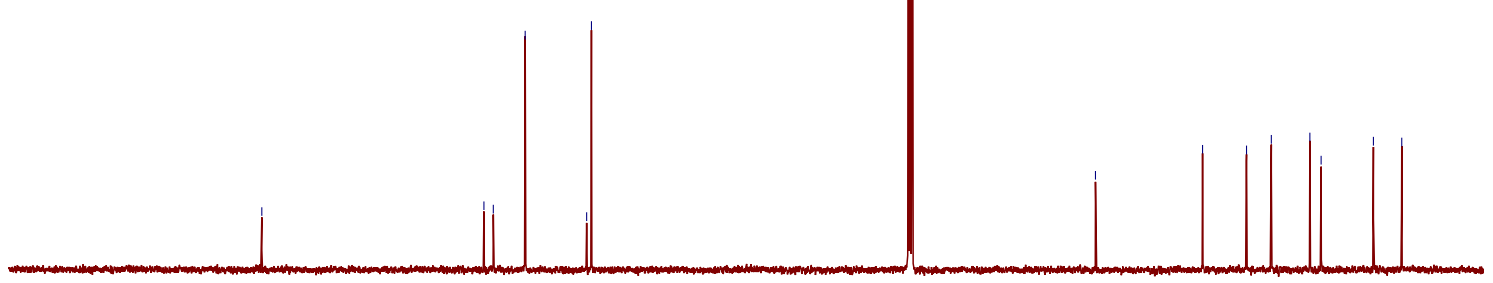

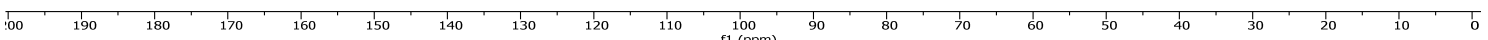


${ }^{1} \mathrm{H}$ NMR $\left(500 \mathrm{MHz}, \mathrm{CDCl}_{3}\right)$

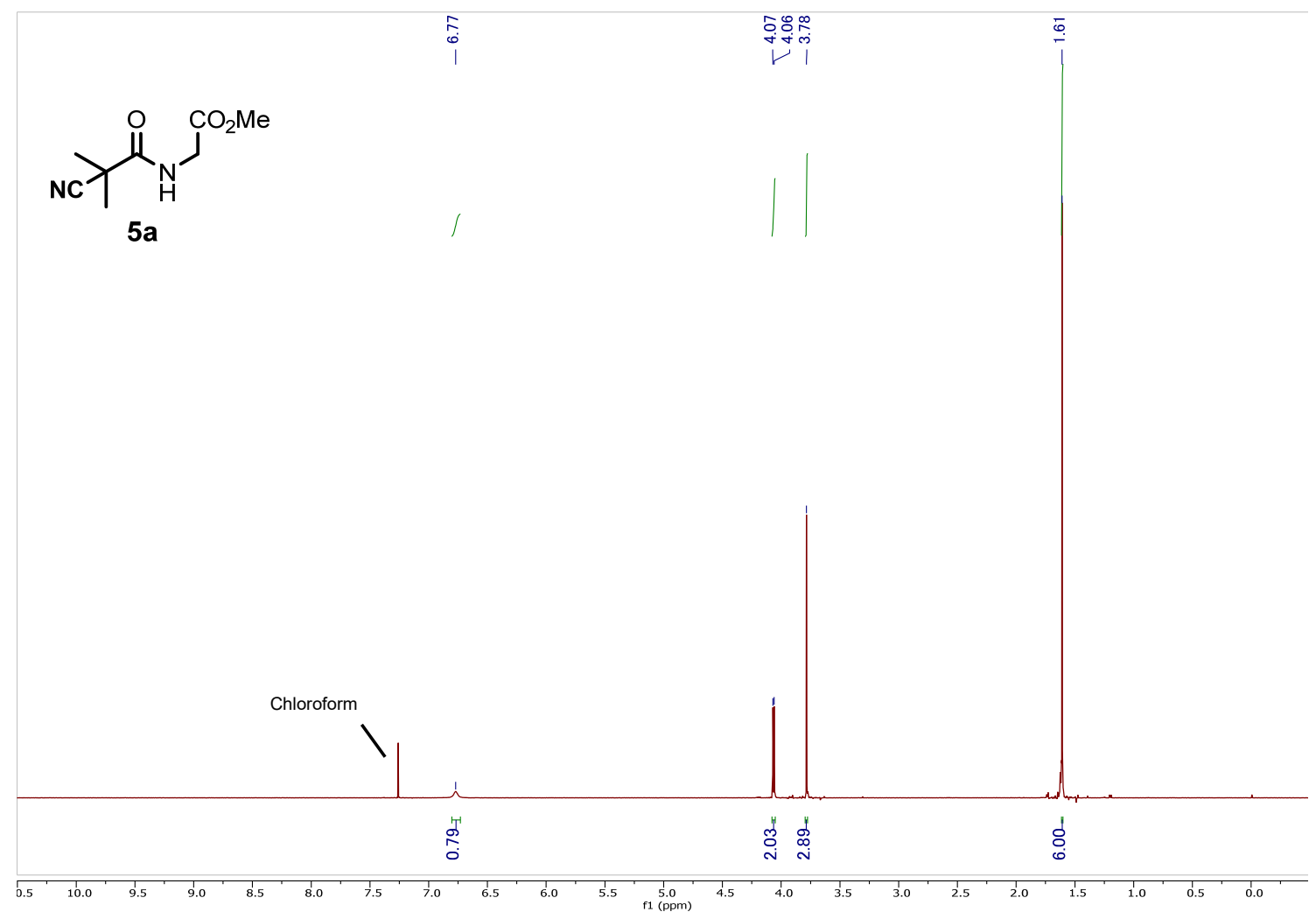

${ }^{13} \mathrm{C}$ NMR (125 MHz, $\mathrm{CDCl}_{3}$ )

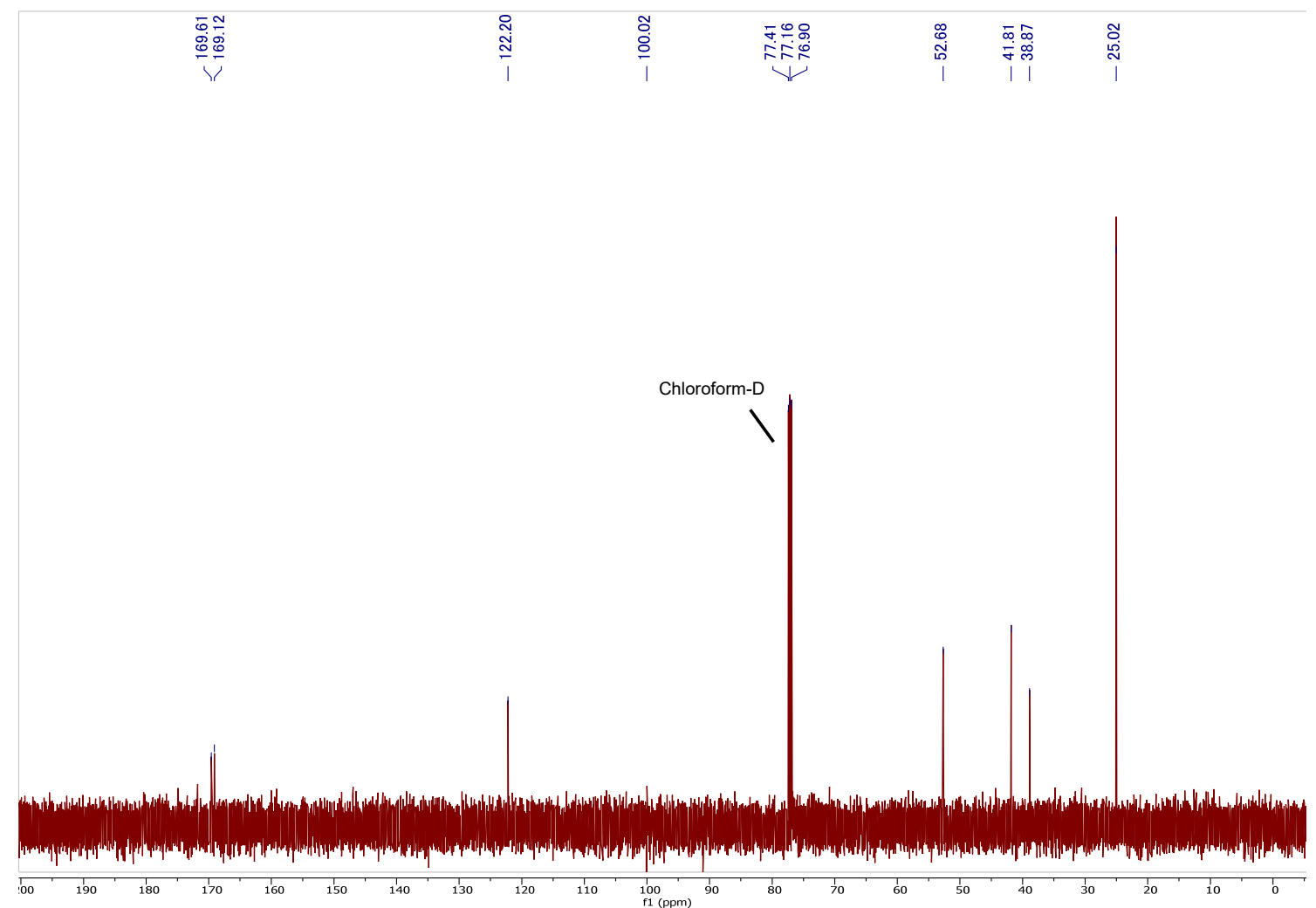


${ }^{1} \mathrm{H}$ NMR (500 MHz, $\mathrm{CDCl}_{3}$ )<smiles>CCC(C)(C)C(=O)NCC(C)=O</smiles>

5b

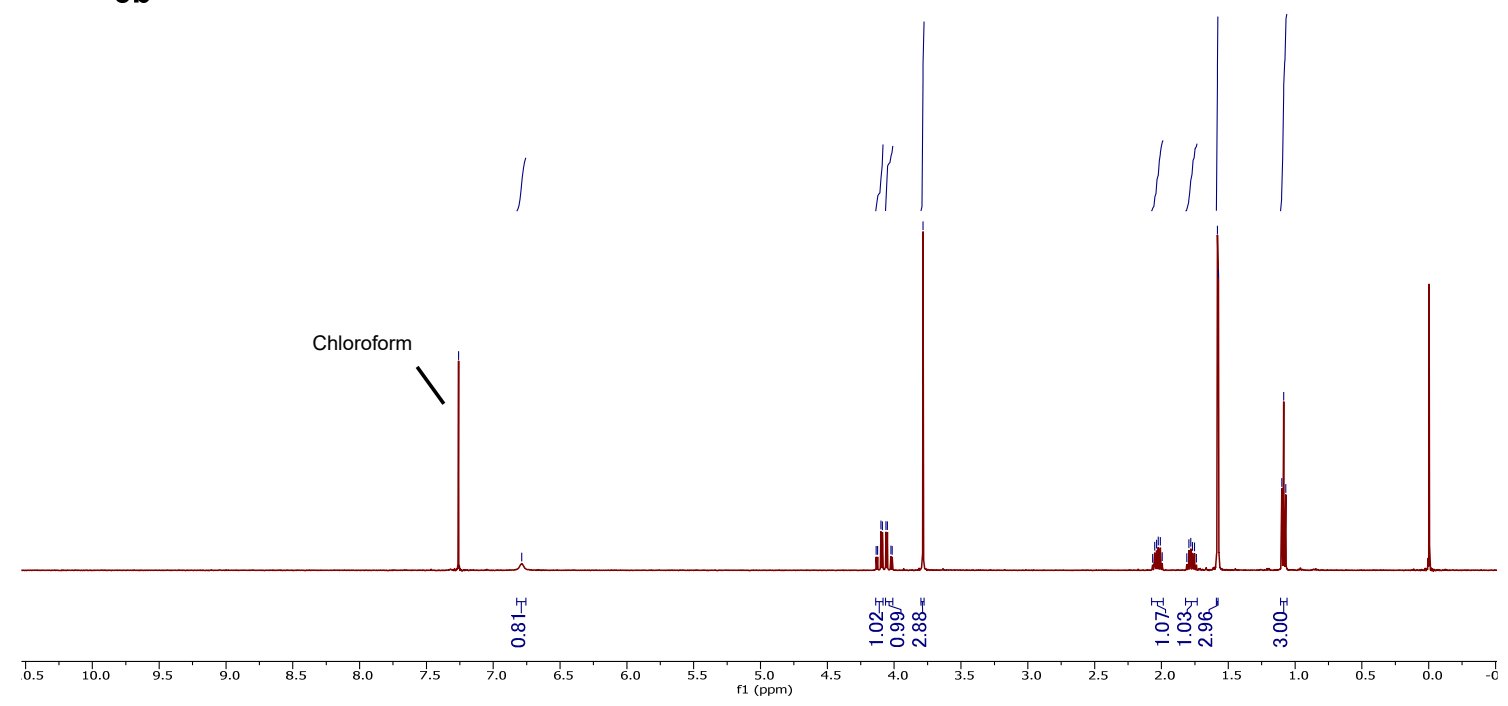

${ }^{13} \mathrm{C}$ NMR $\left(125 \mathrm{MHz}, \mathrm{CDCl}_{3}\right)$

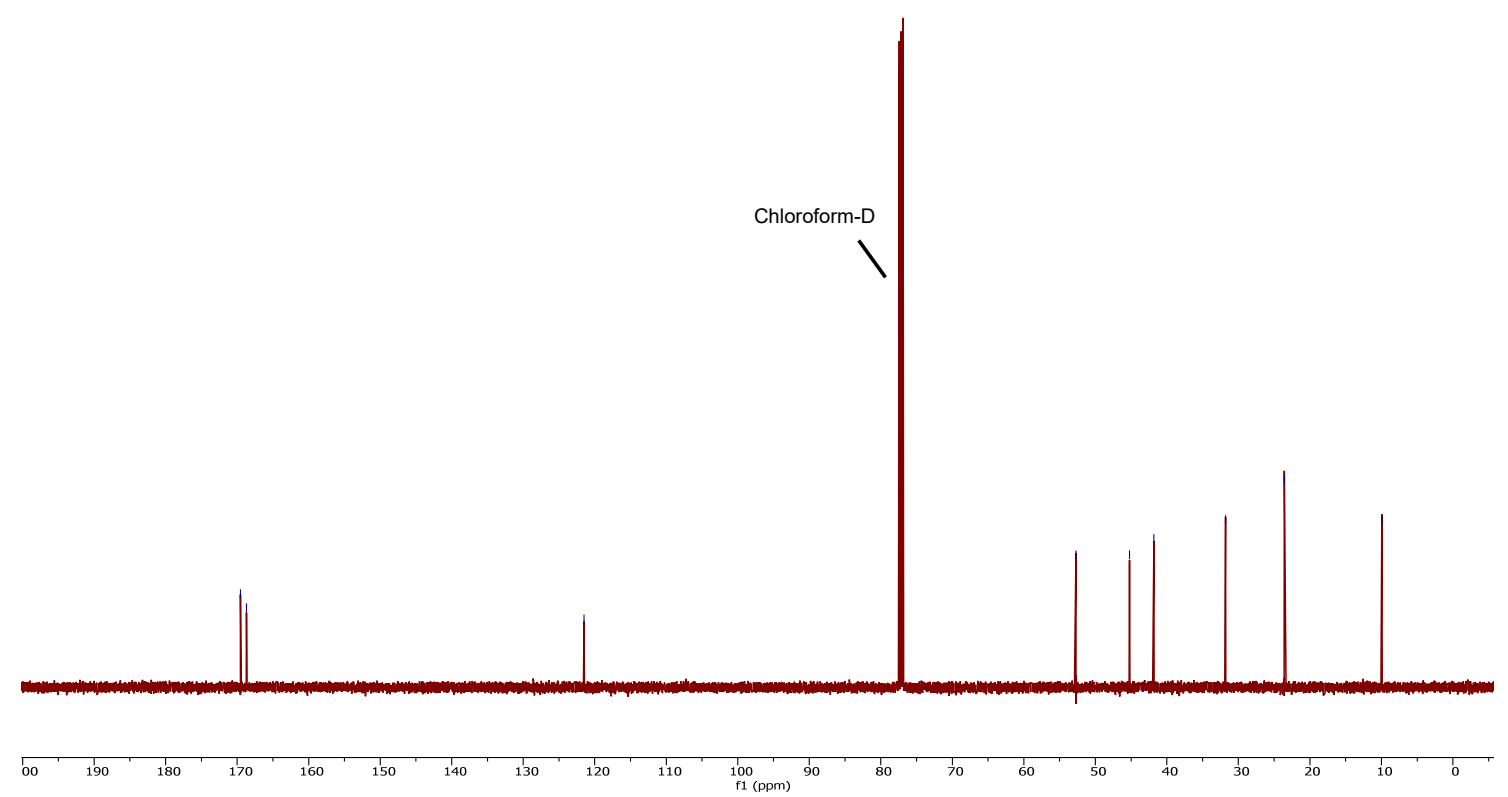


${ }^{1} \mathrm{H}$ NMR (500 MHz, $\left.\mathrm{CDCl}_{3}\right)$

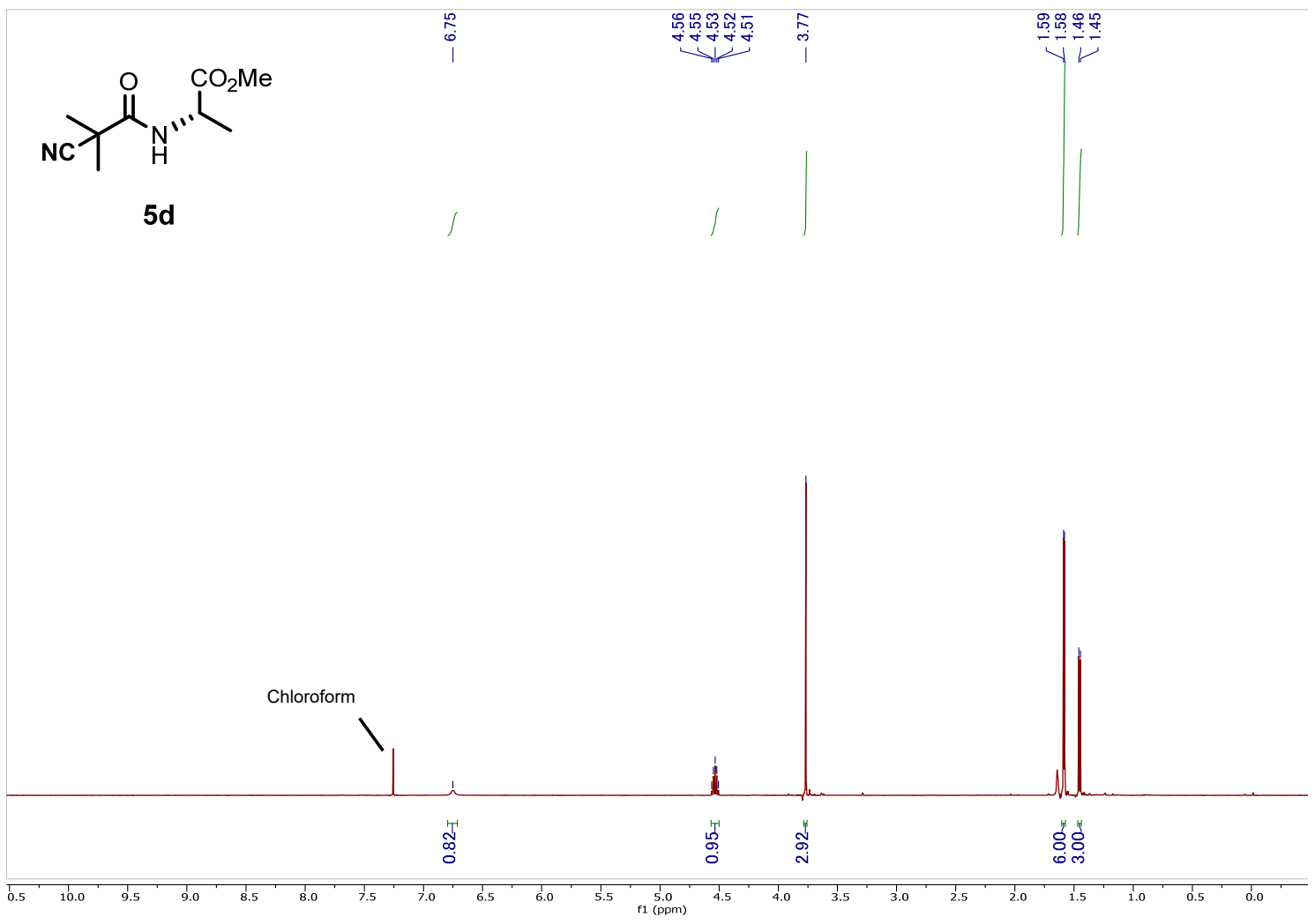

${ }^{13} \mathrm{C}$ NMR (125 MHz, $\left.\mathrm{CDCl}_{3}\right)$
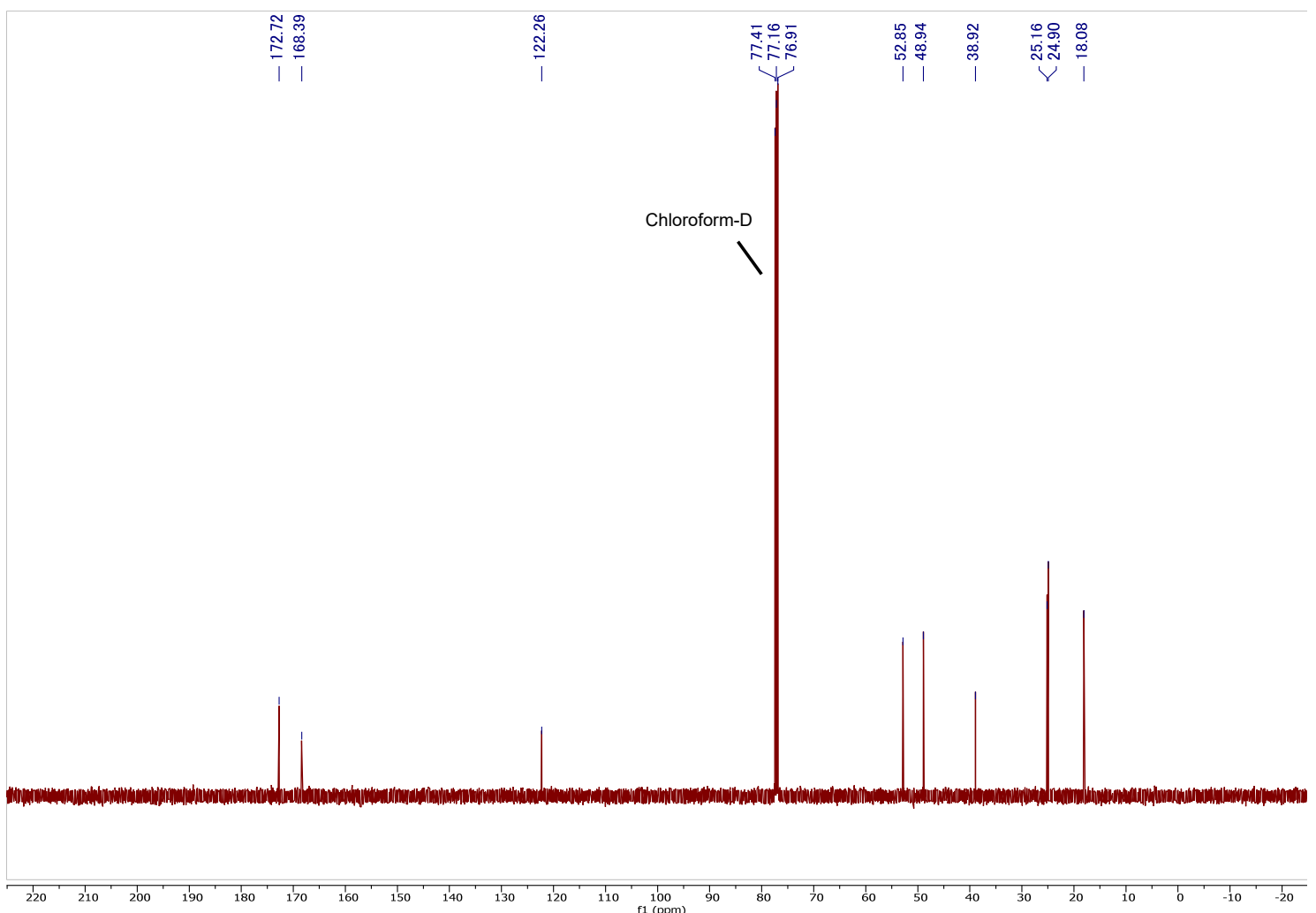
${ }^{1} \mathrm{H}$ NMR $\left(500 \mathrm{MHz}, \mathrm{CDCl}_{3}\right)$

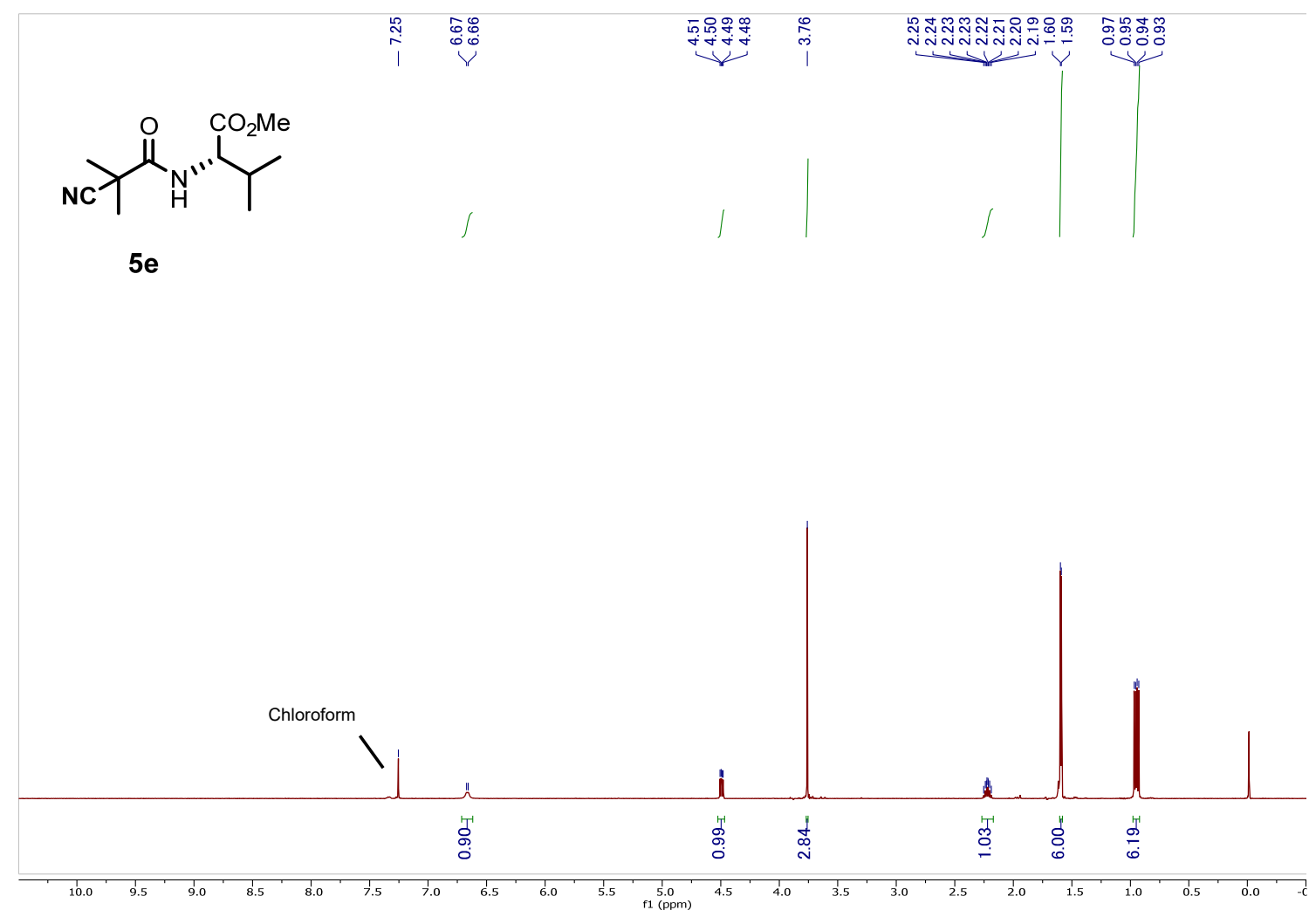

${ }^{13} \mathrm{C}$ NMR (125 MHz, $\mathrm{CDCl}_{3}$ )

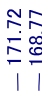

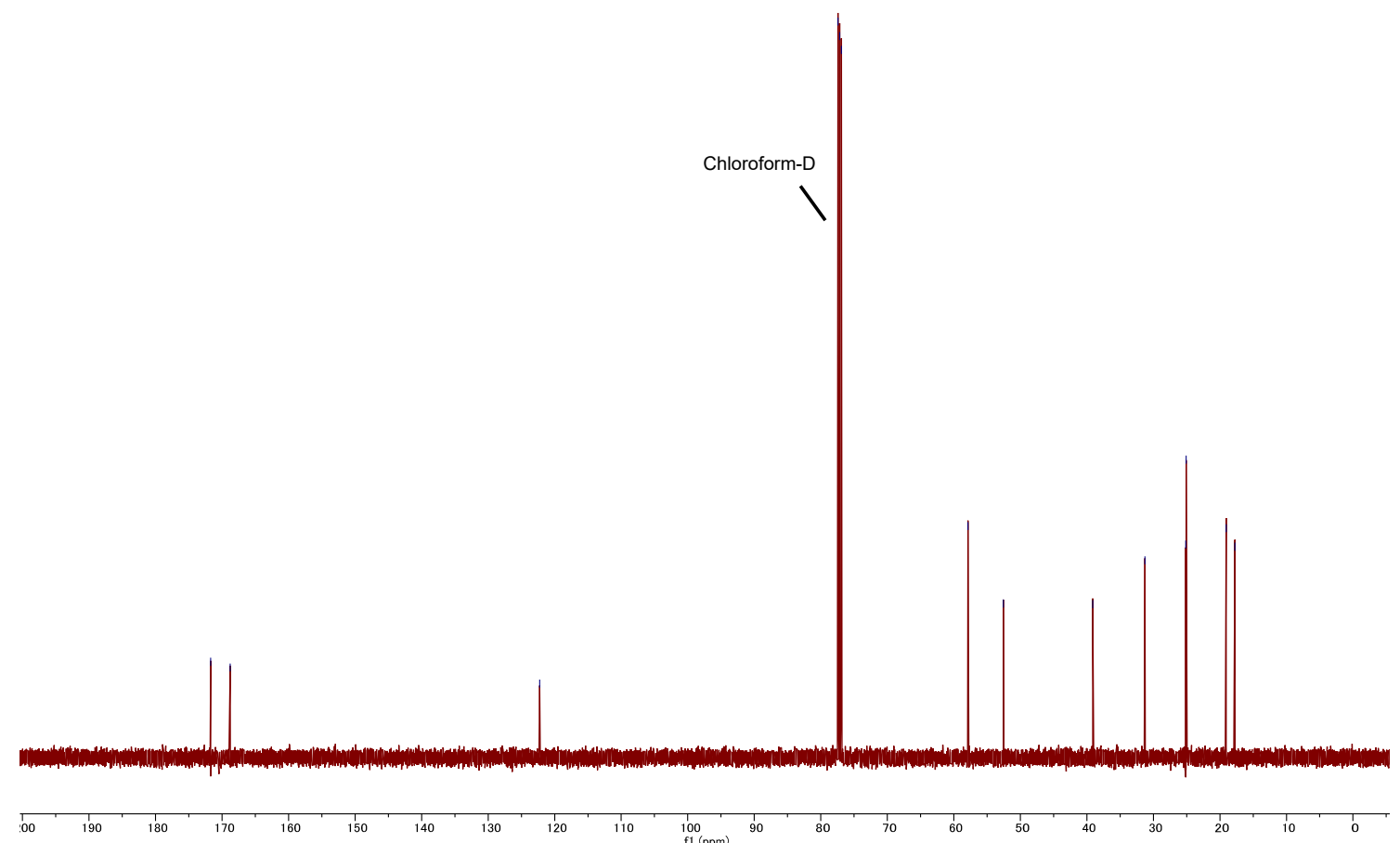


${ }^{1} \mathrm{H}$ NMR (500 MHz, $\mathrm{CDCl}_{3}$ )

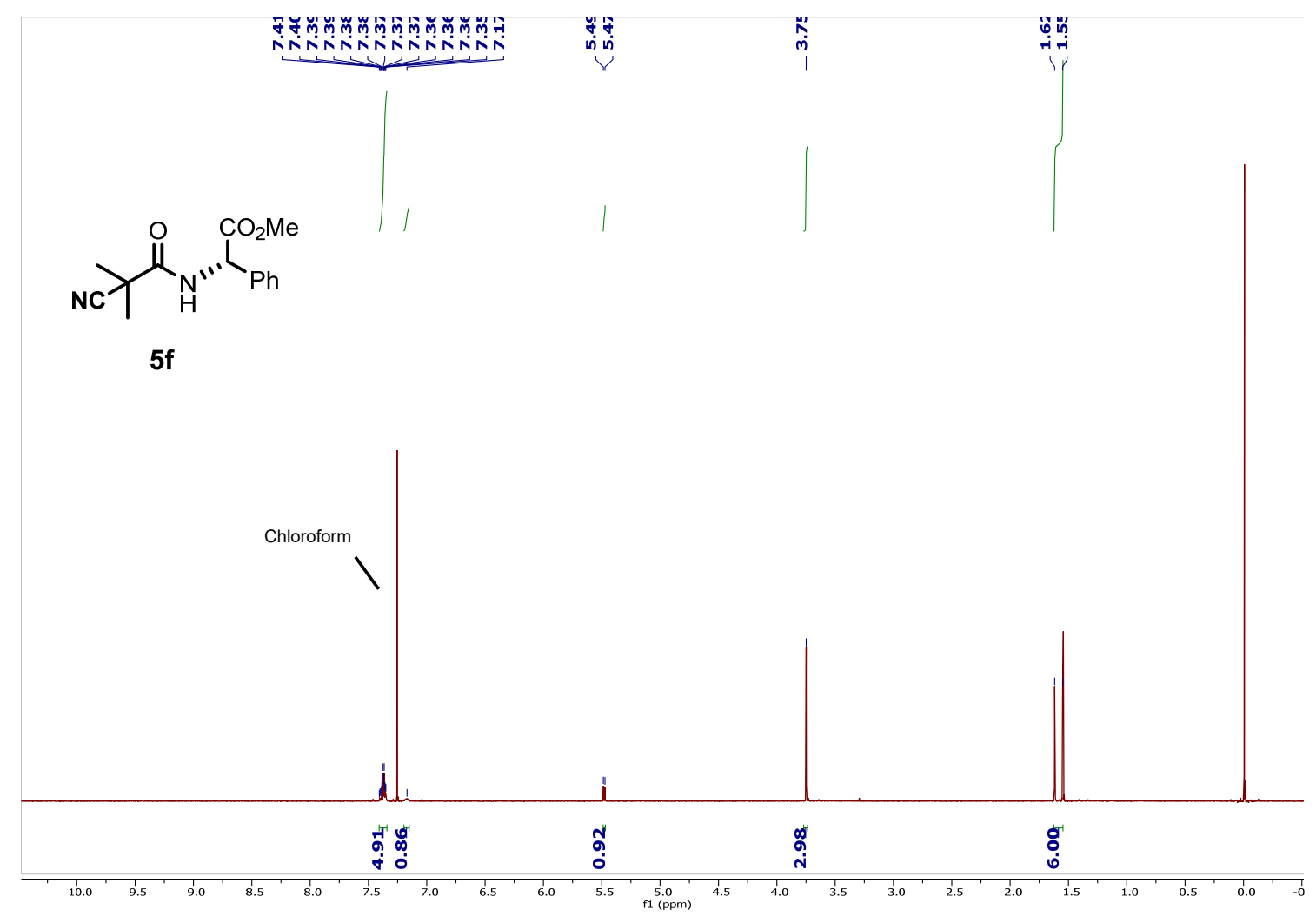

${ }^{13} \mathrm{C}$ NMR (125 MHz, $\mathrm{CDCl}_{3}$ )

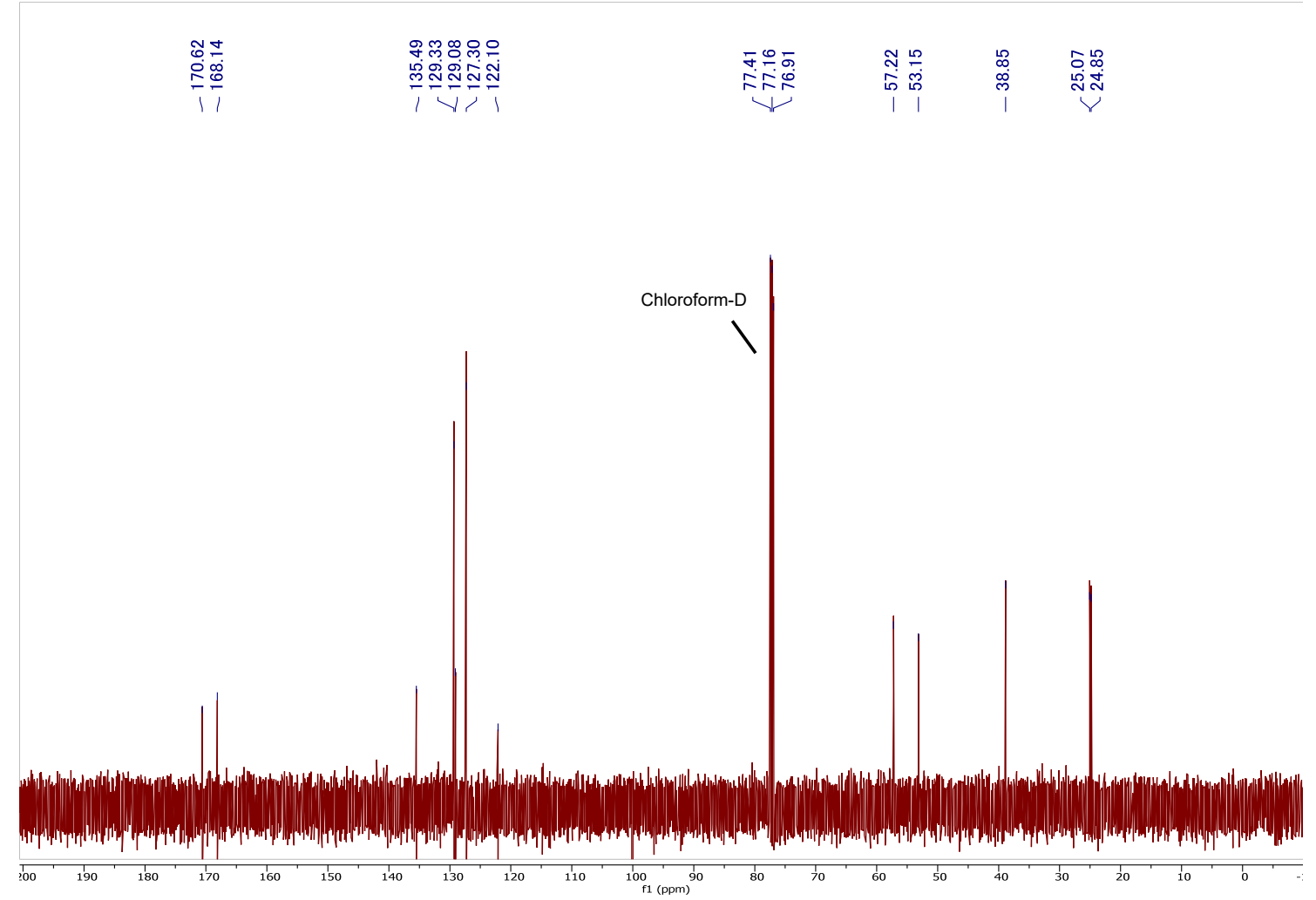


${ }^{1} \mathrm{H}$ NMR (500 MHz, $\mathrm{CDCl}_{3}$ )

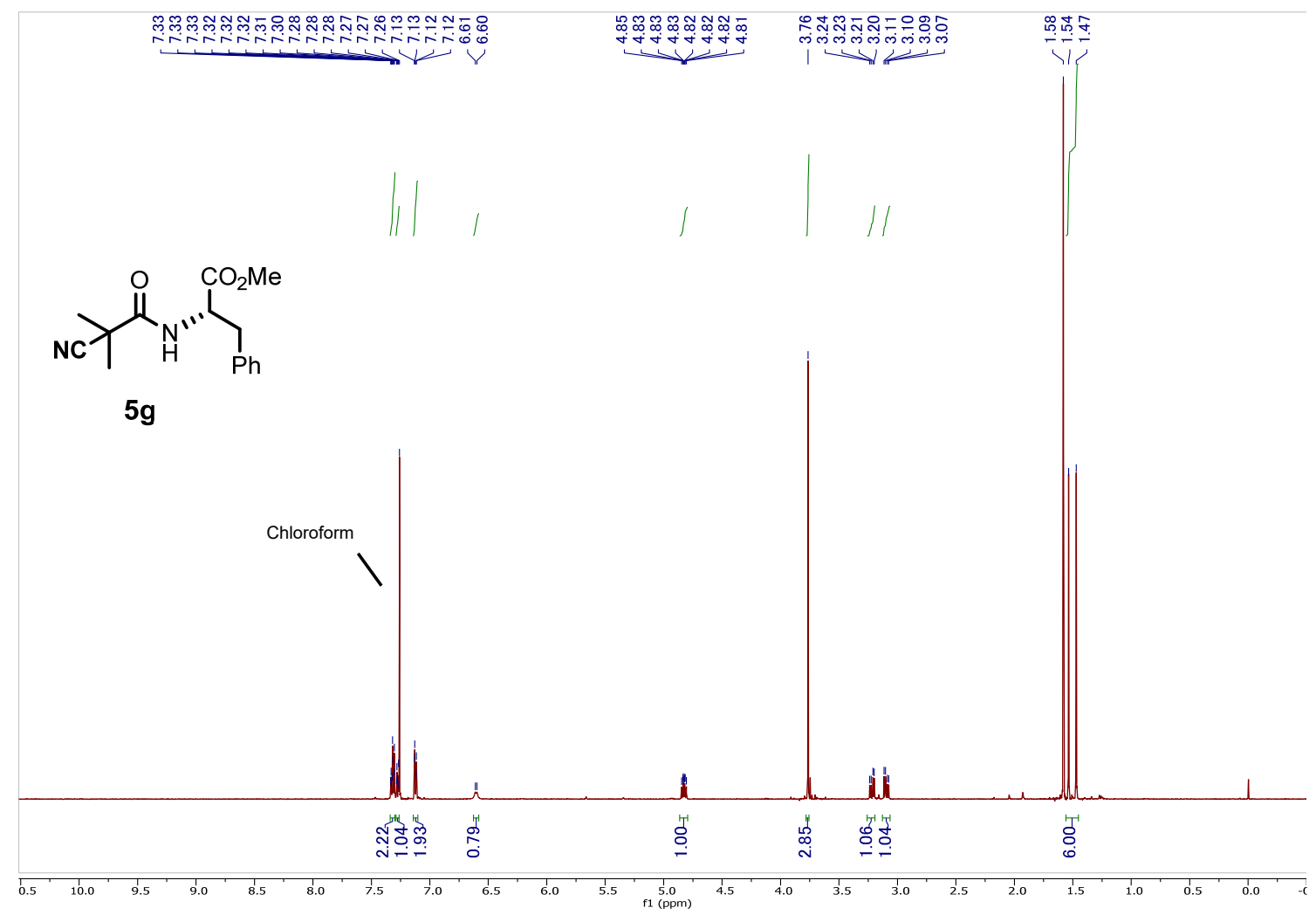

${ }^{13} \mathrm{C}$ NMR $\left(125 \mathrm{MHz}, \mathrm{CDCl}_{3}\right)$

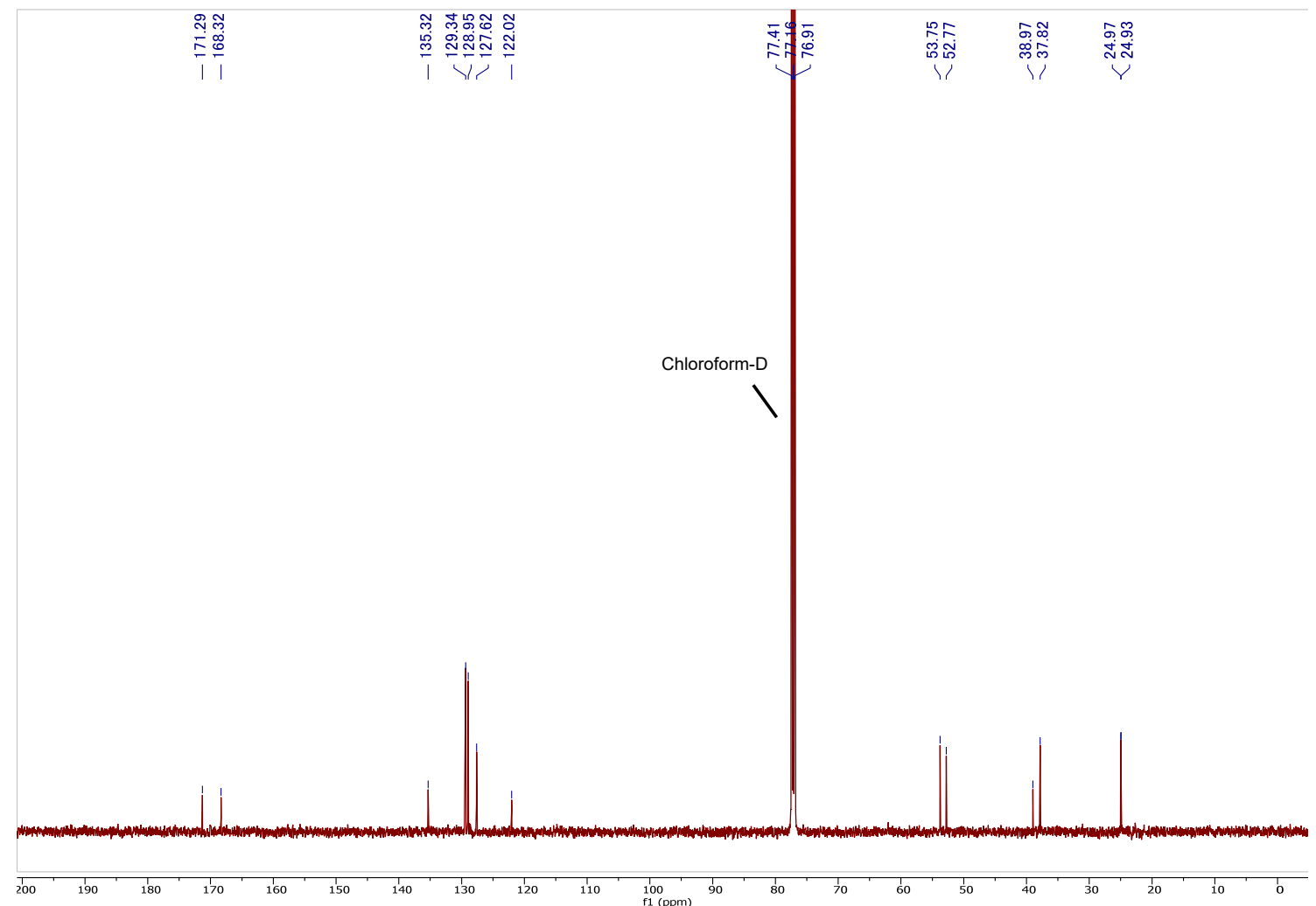


${ }^{1} \mathrm{H}$ NMR $\left(500 \mathrm{MHz}, \mathrm{CDCl}_{3}\right)$

꾺ํㅛ

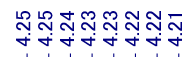

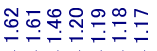

${ }_{\mathrm{NC}}^{\mathrm{O}} \mathrm{C}_{\mathrm{H}}^{\mathrm{OtBu}}$

$5 \mathrm{~h}$

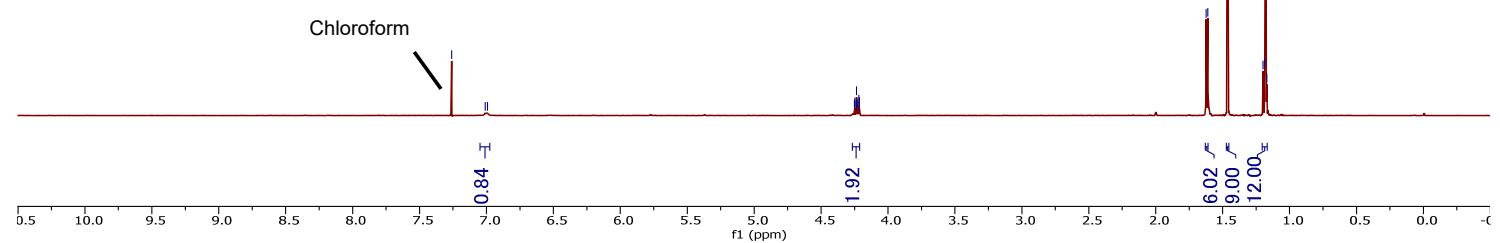

${ }^{13} \mathrm{C}$ NMR $\left(125 \mathrm{MHz}, \mathrm{CDCl}_{3}\right)$

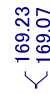

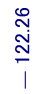

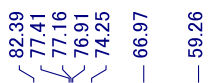

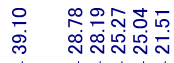

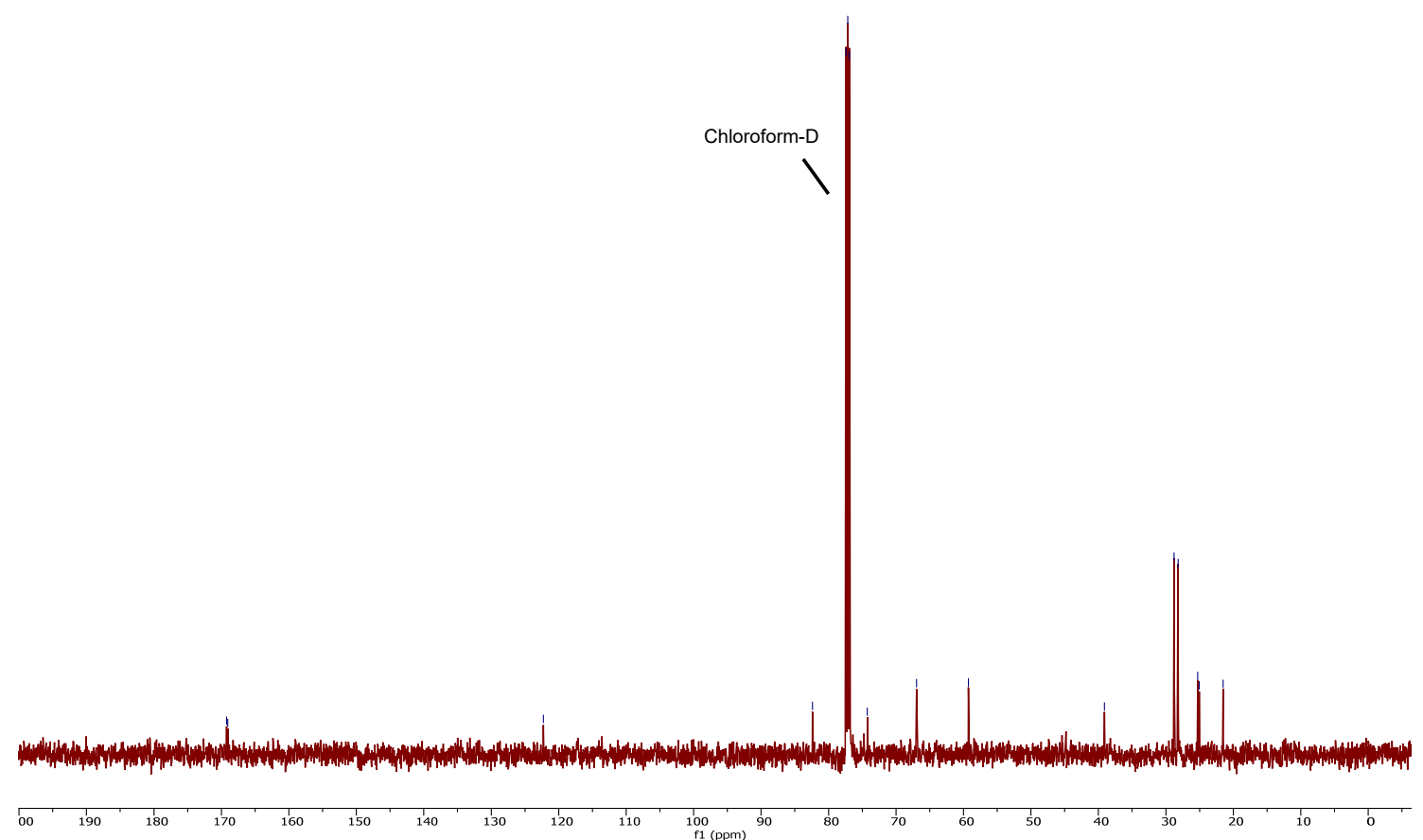


${ }^{1} \mathrm{H}$ NMR (500 MHz, $\mathrm{CDCl}_{3}$ )

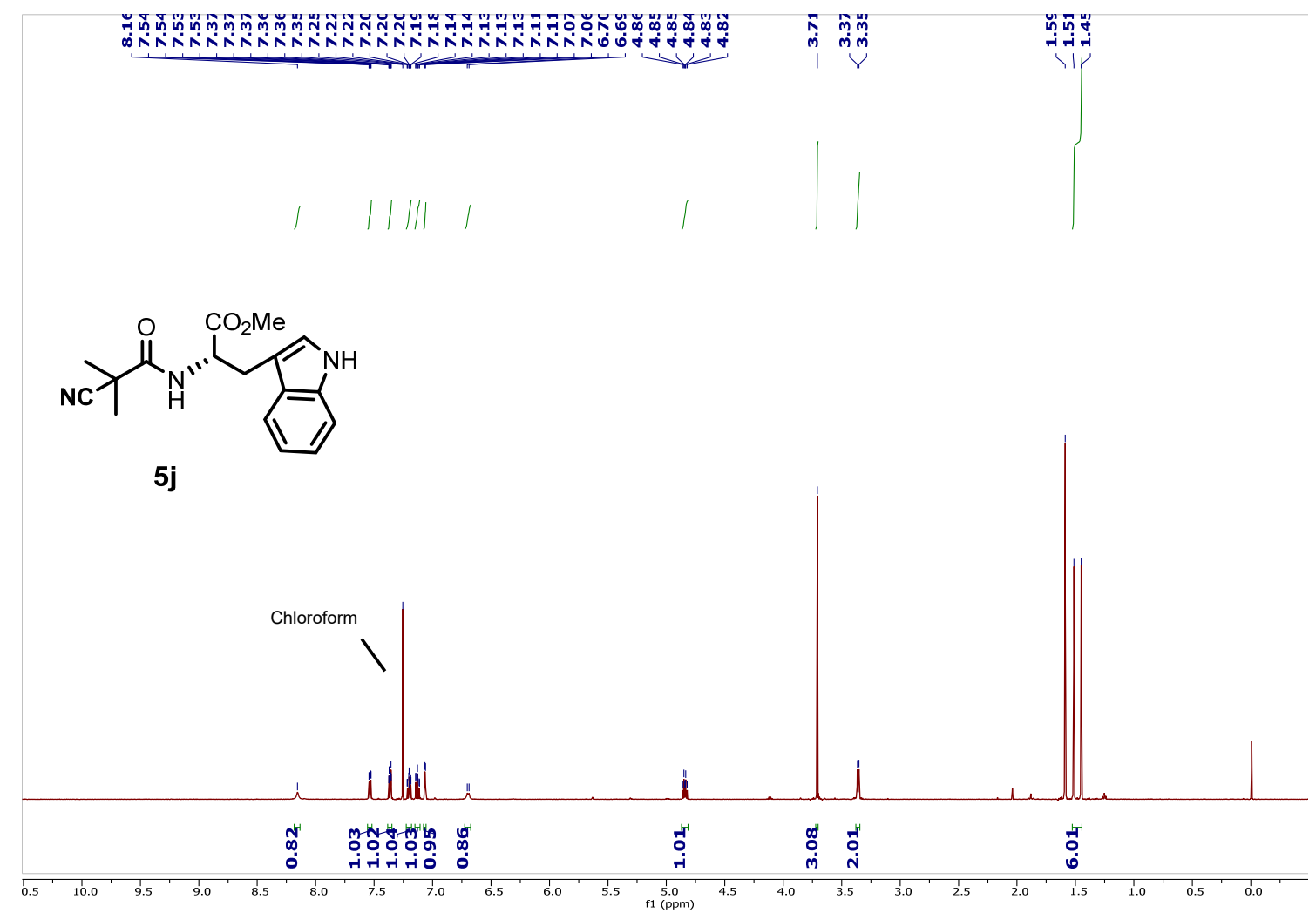

${ }^{13} \mathrm{C}$ NMR $\left(125 \mathrm{MHz}, \mathrm{CDCl}_{3}\right)$

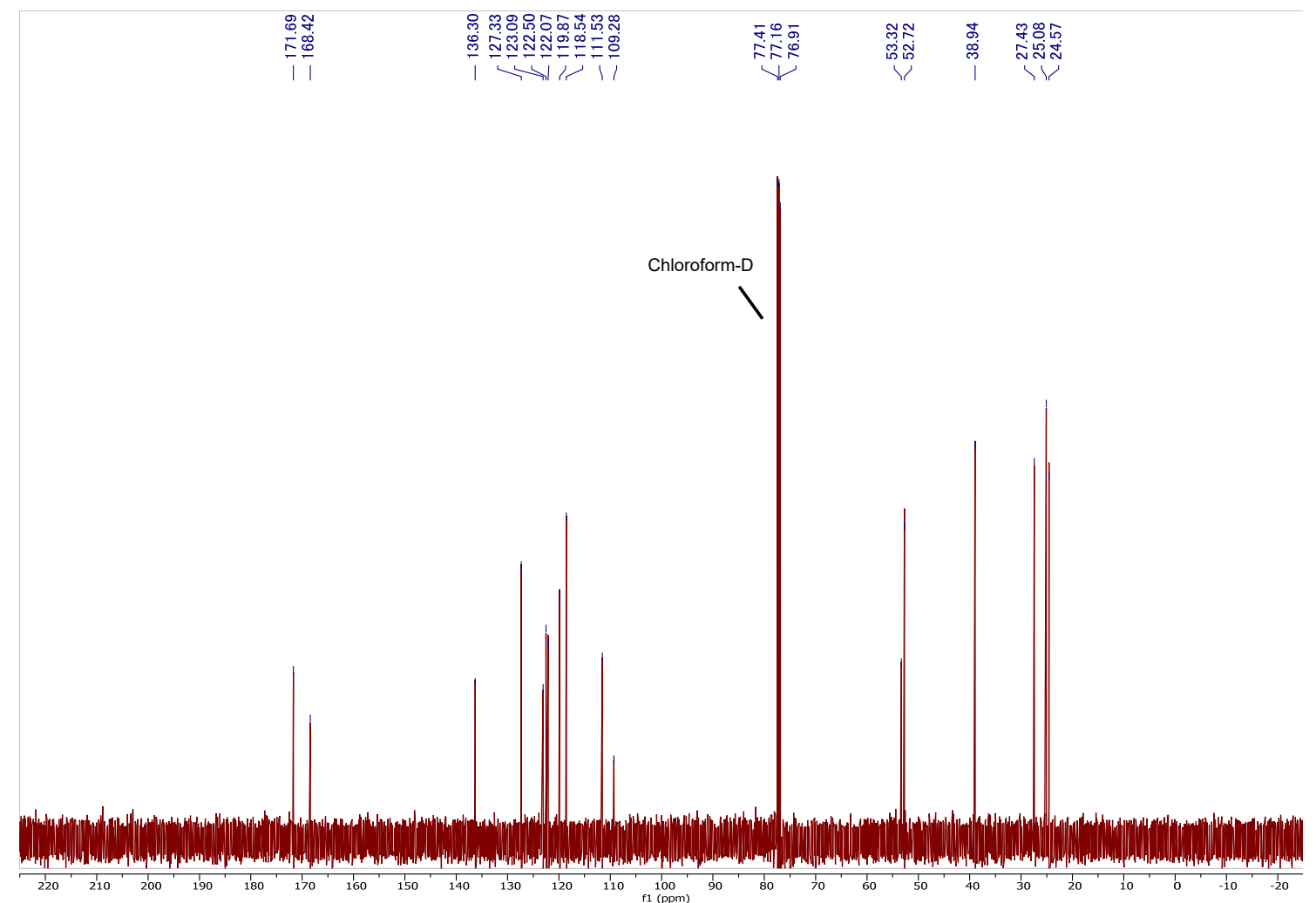


${ }^{1} \mathrm{H}$ NMR $\left(500 \mathrm{MHz}, \mathrm{CDCl}_{3}\right)$

\section{染}<smiles>COC(CC(C)C)NC(=O)CNC(=O)C(C)(C)C</smiles>

$5 \mathbf{k}$

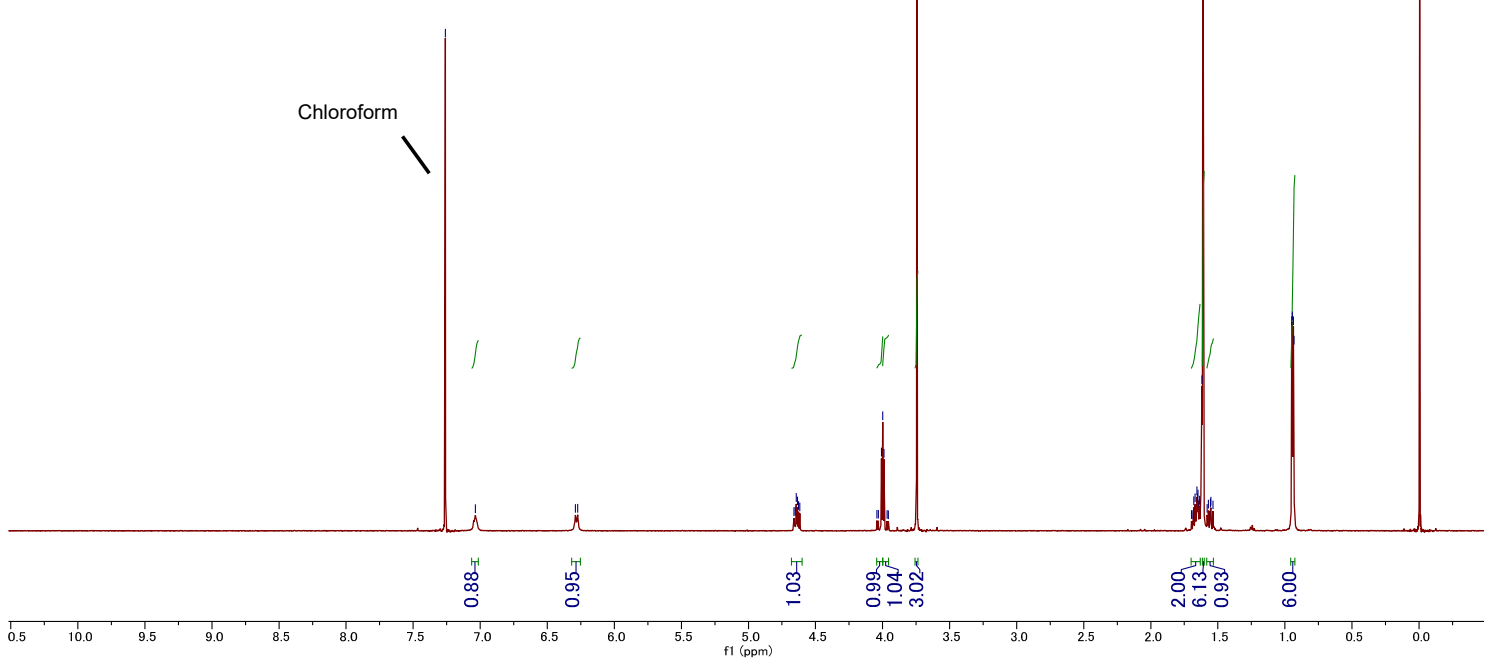

${ }^{13} \mathrm{C}$ NMR (125 MHz, $\left.\mathrm{CDCl}_{3}\right)$

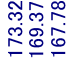

ำ

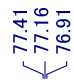

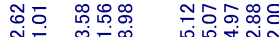

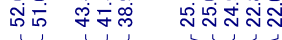

$1>1$

$\gamma \Vdash$

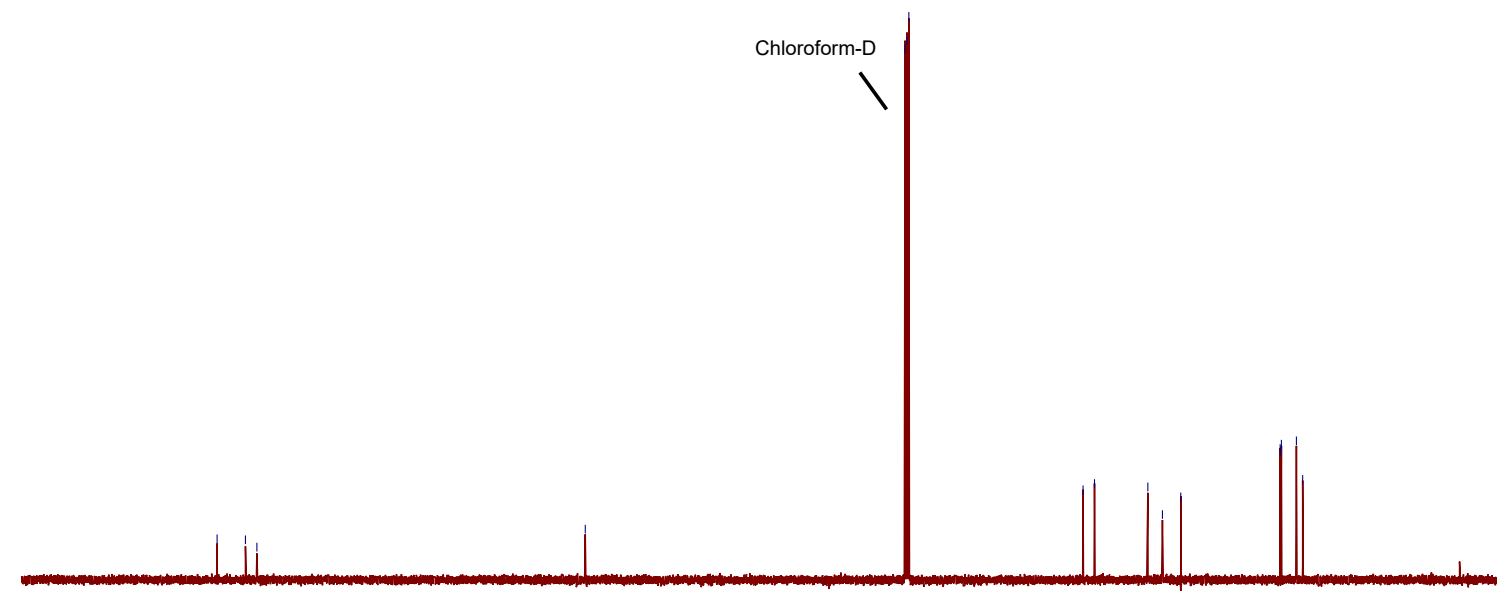

$\begin{array}{lllllllllllllllllllllll}200 & 190 & 180 & 170 & 160 & 150 & 140 & 130 & 120 & 110 & 100 & 10 & 10 & 10 & 10 & 10 & 40 & 10 & 10 & 10 & 0\end{array}$ 
${ }^{1} \mathrm{H}$ NMR $\left(500 \mathrm{MHz}, \mathrm{CDCl}_{3}\right)$

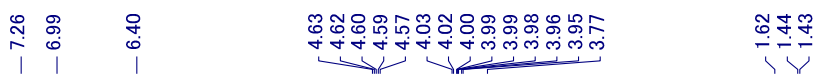<smiles>CC(=O)NC(=O)CNC(=O)C(C)(C)C#N</smiles>

5

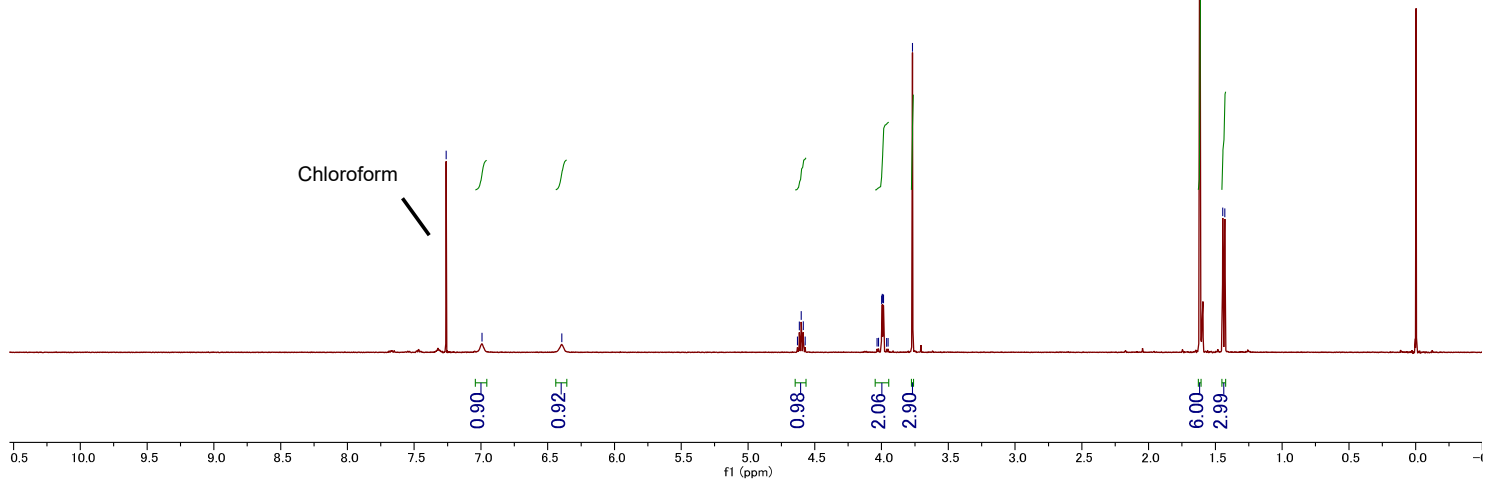

${ }^{13} \mathrm{C}$ NMR (125 MHz, $\left.\mathrm{CDCl}_{3}\right)$

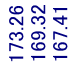

1 11

ํํำ

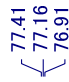

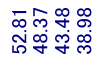

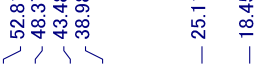

Chloroform-D

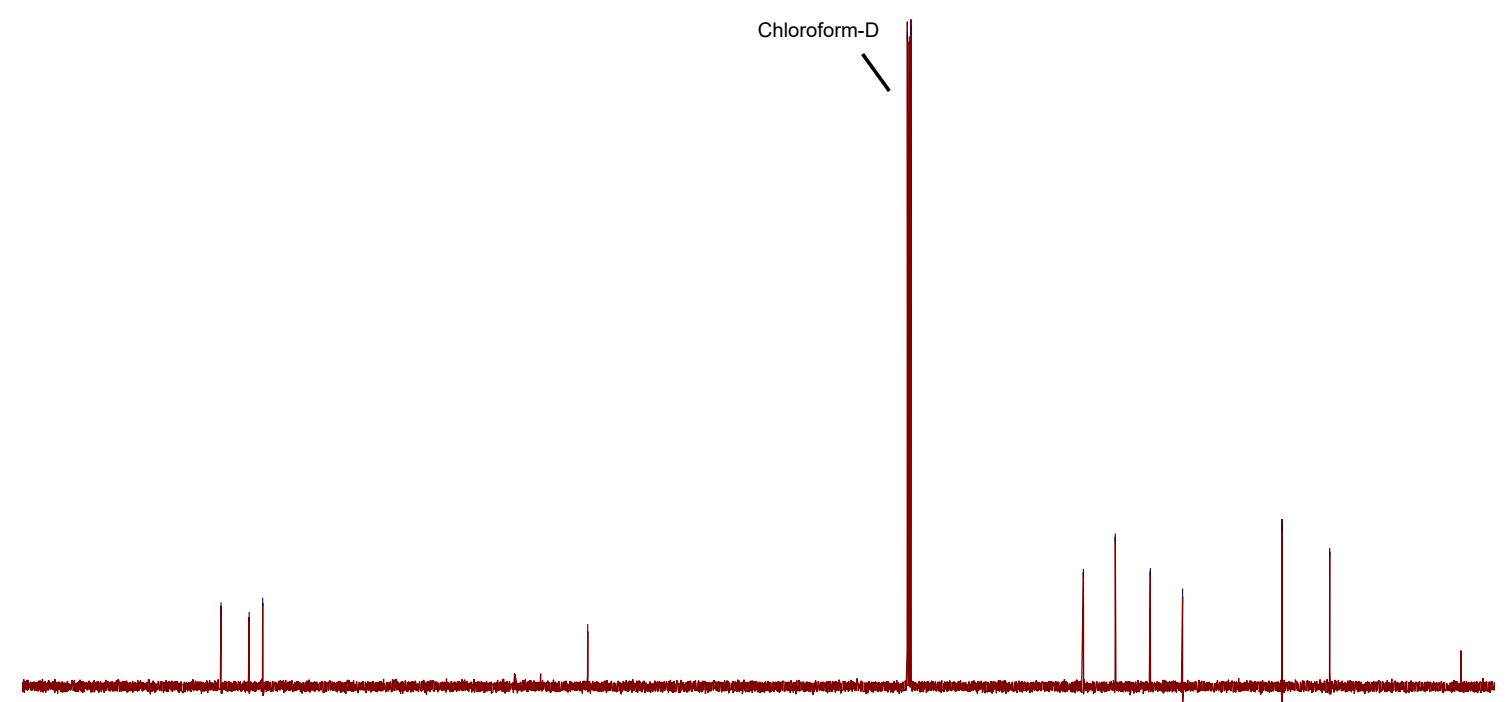

$\stackrel{7}{200}$

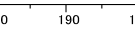

$\frac{1}{170}+100$

$\frac{150}{150} 140$

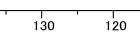

100

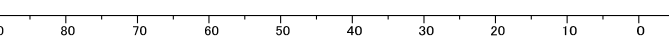


${ }^{1} \mathrm{H}$ NMR $\left(500 \mathrm{MHz}, \mathrm{CDCl}_{3}\right)$

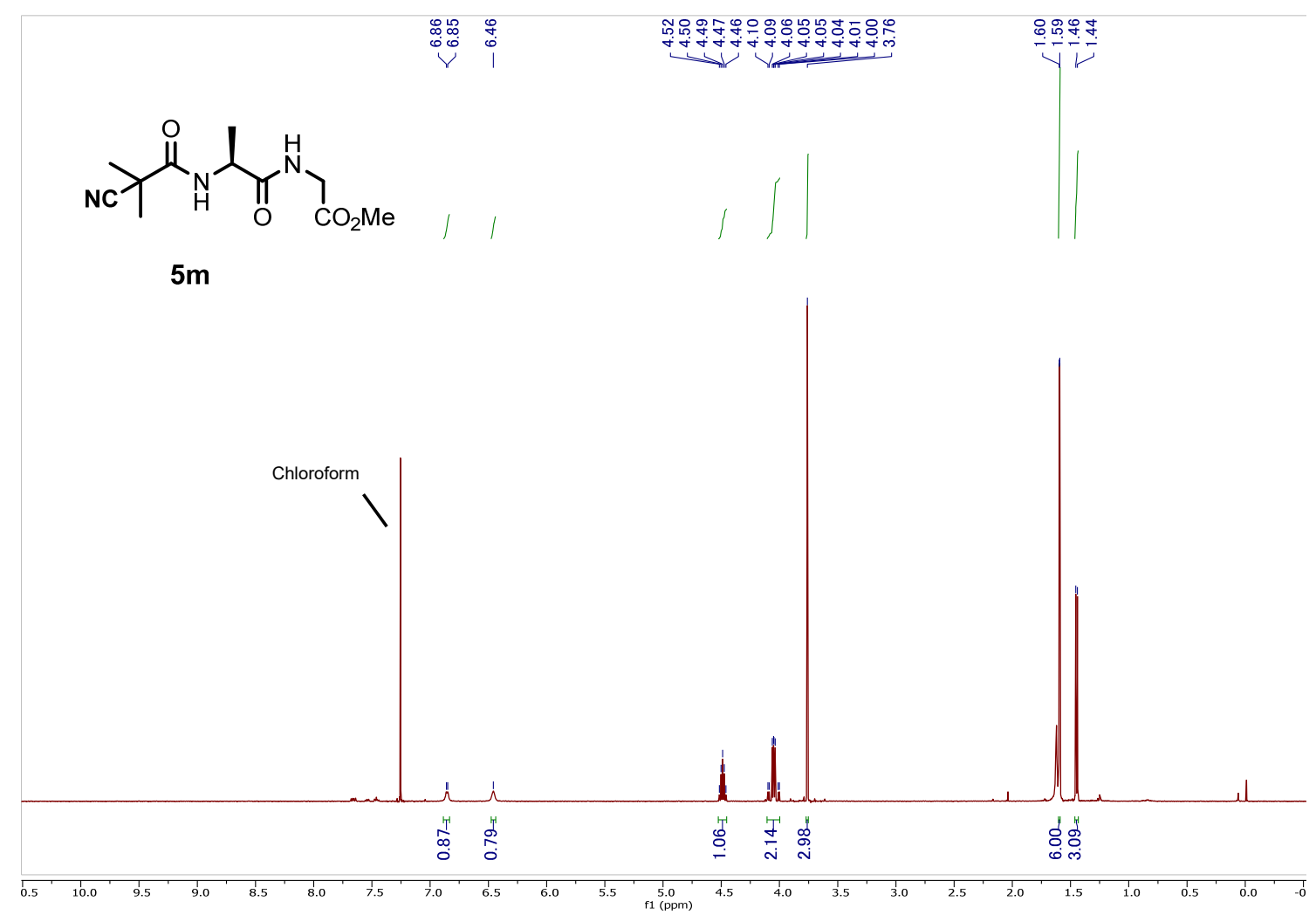

${ }^{13} \mathrm{C}$ NMR $\left(125 \mathrm{MHz}, \mathrm{CDCl}_{3}\right)$

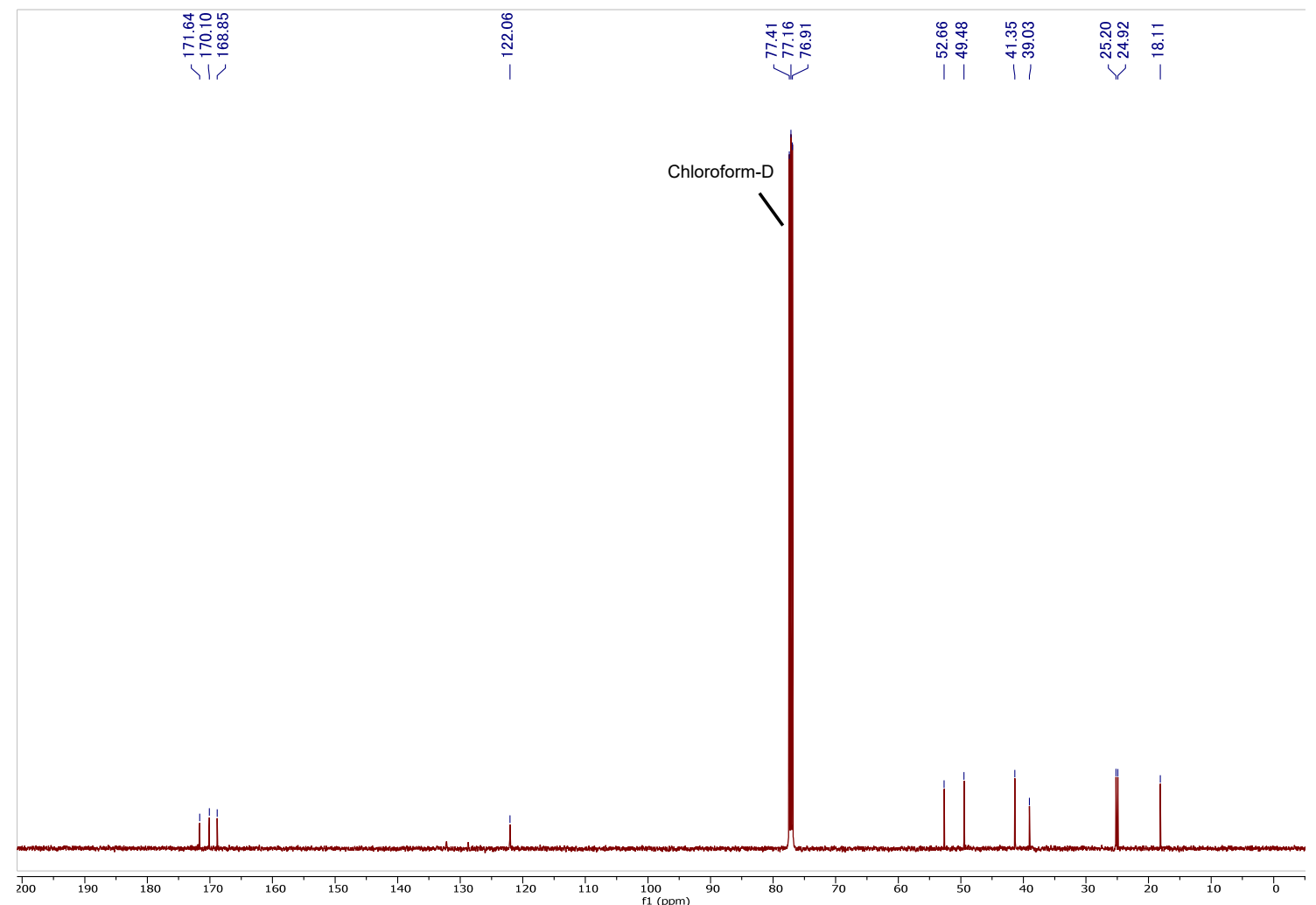


${ }^{1} \mathrm{H}$ NMR $\left(500 \mathrm{MHz}, \mathrm{CDCl}_{3}\right)$

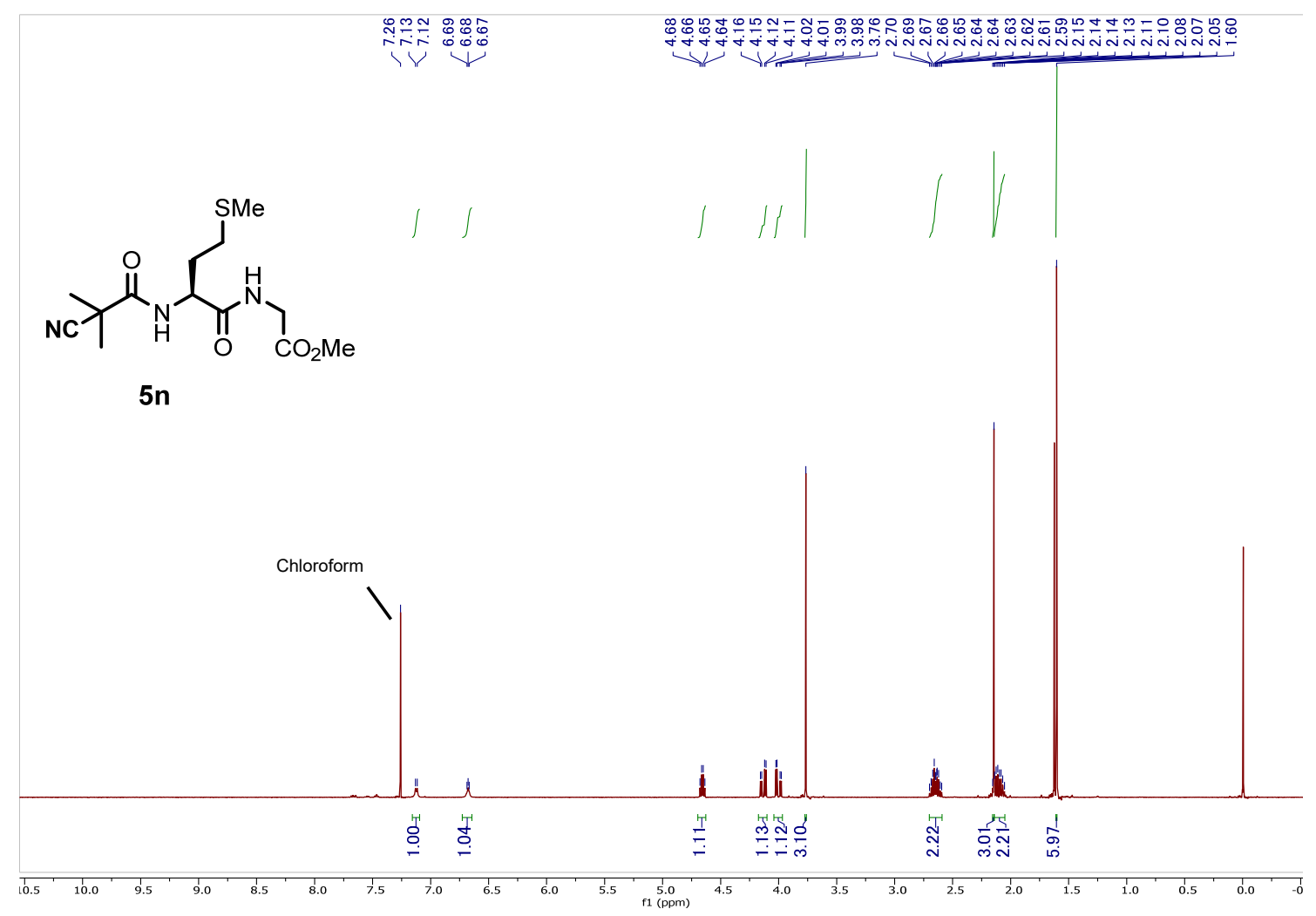

${ }^{13} \mathrm{C}$ NMR (125 MHz, $\mathrm{CDCl}_{3}$ )

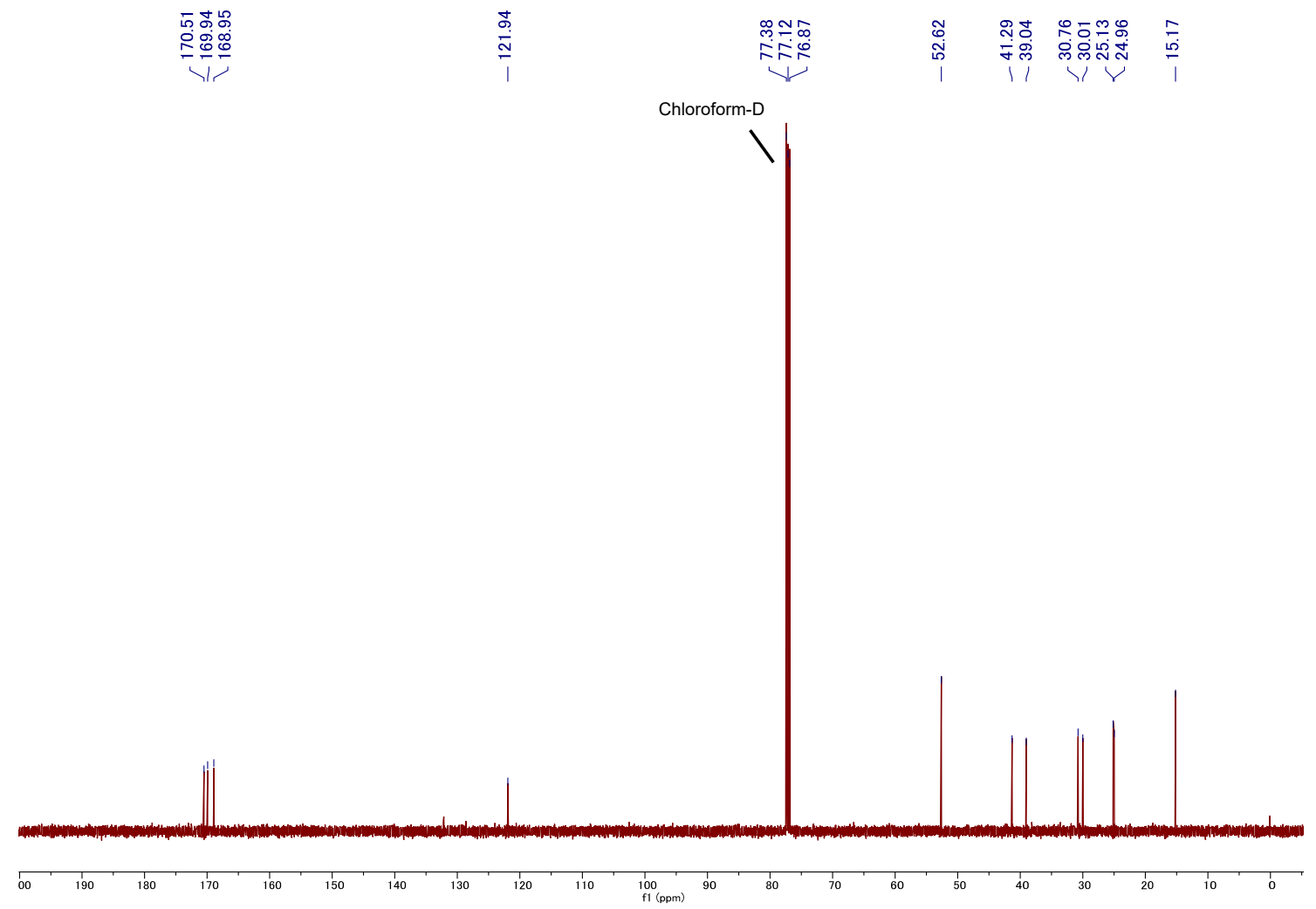


${ }^{1} \mathrm{H}$ NMR $\left(500 \mathrm{MHz}, \mathrm{CDCl}_{3}\right)$

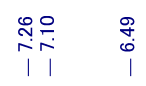

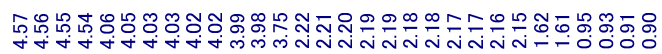

${ }_{\mathrm{NC}}^{\mathrm{O}} \mathrm{H}_{\mathrm{O}}^{\mathrm{N}} \overbrace{\mathrm{CO}_{2} \mathrm{Me}}^{\mathrm{N}}$

50

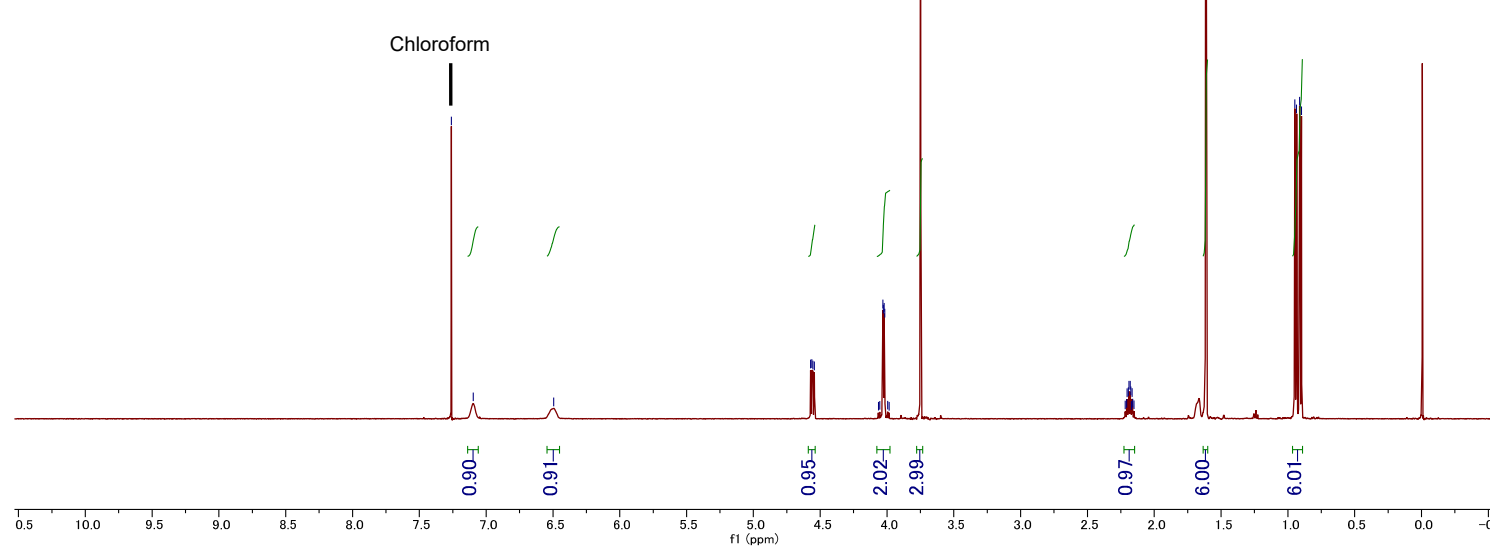

${ }^{13} \mathrm{C}$ NMR $\left(125 \mathrm{MHz}, \mathrm{CDCl}_{3}\right)$

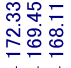

$\underset{\substack{\text { ลิ } \\ \text { । }}}{ }$

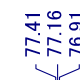

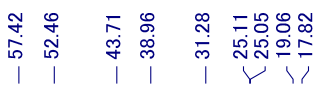

$\mid 11$

Chloroform-D

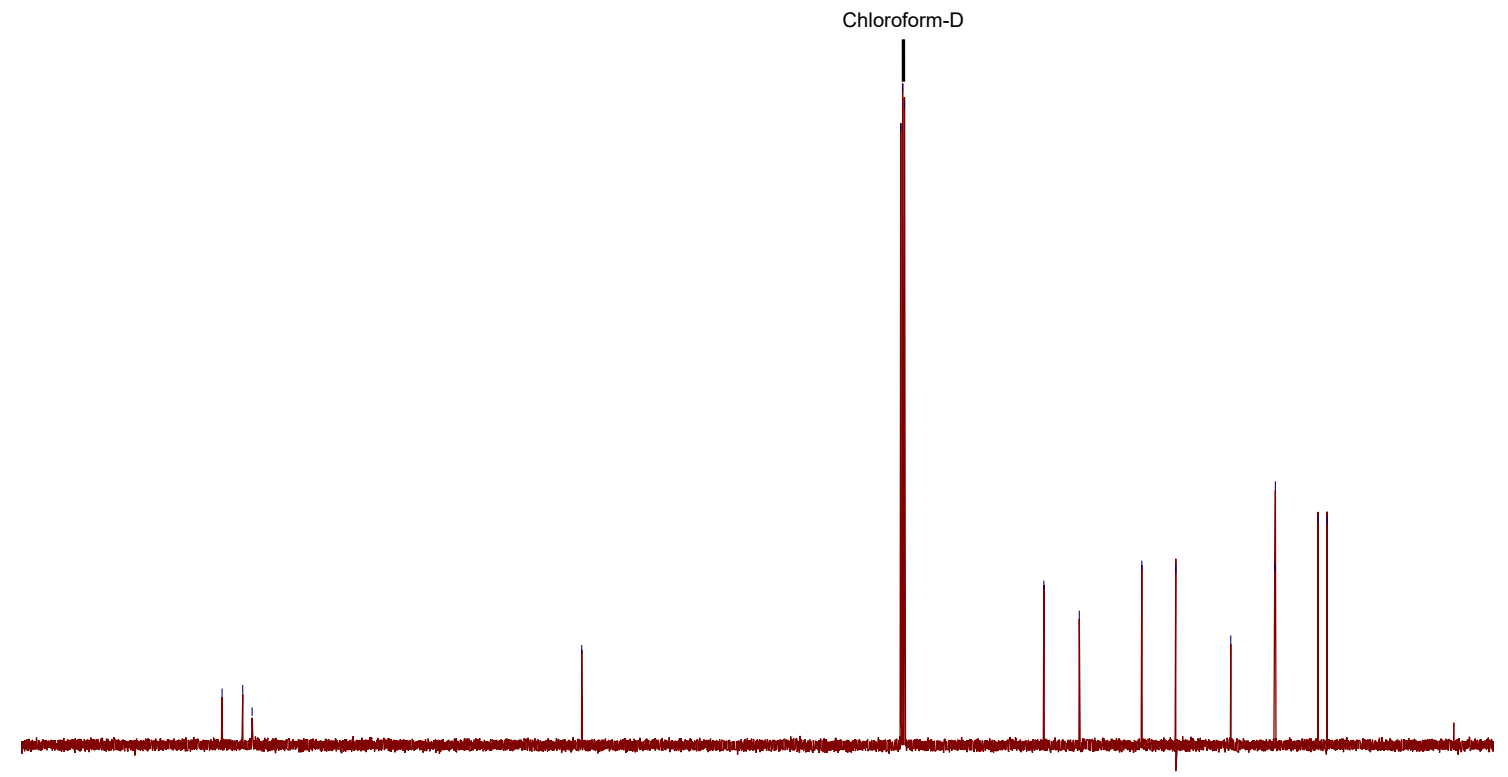

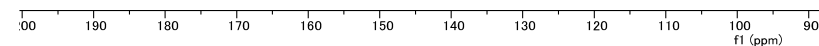

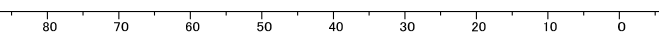


${ }^{1} \mathrm{H} \mathrm{NMR}\left(500 \mathrm{MHz}, \mathrm{CDCl}_{3}\right)$

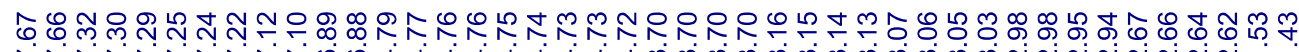

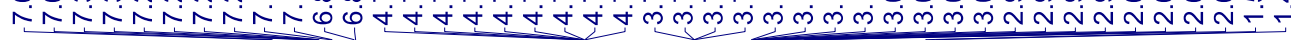
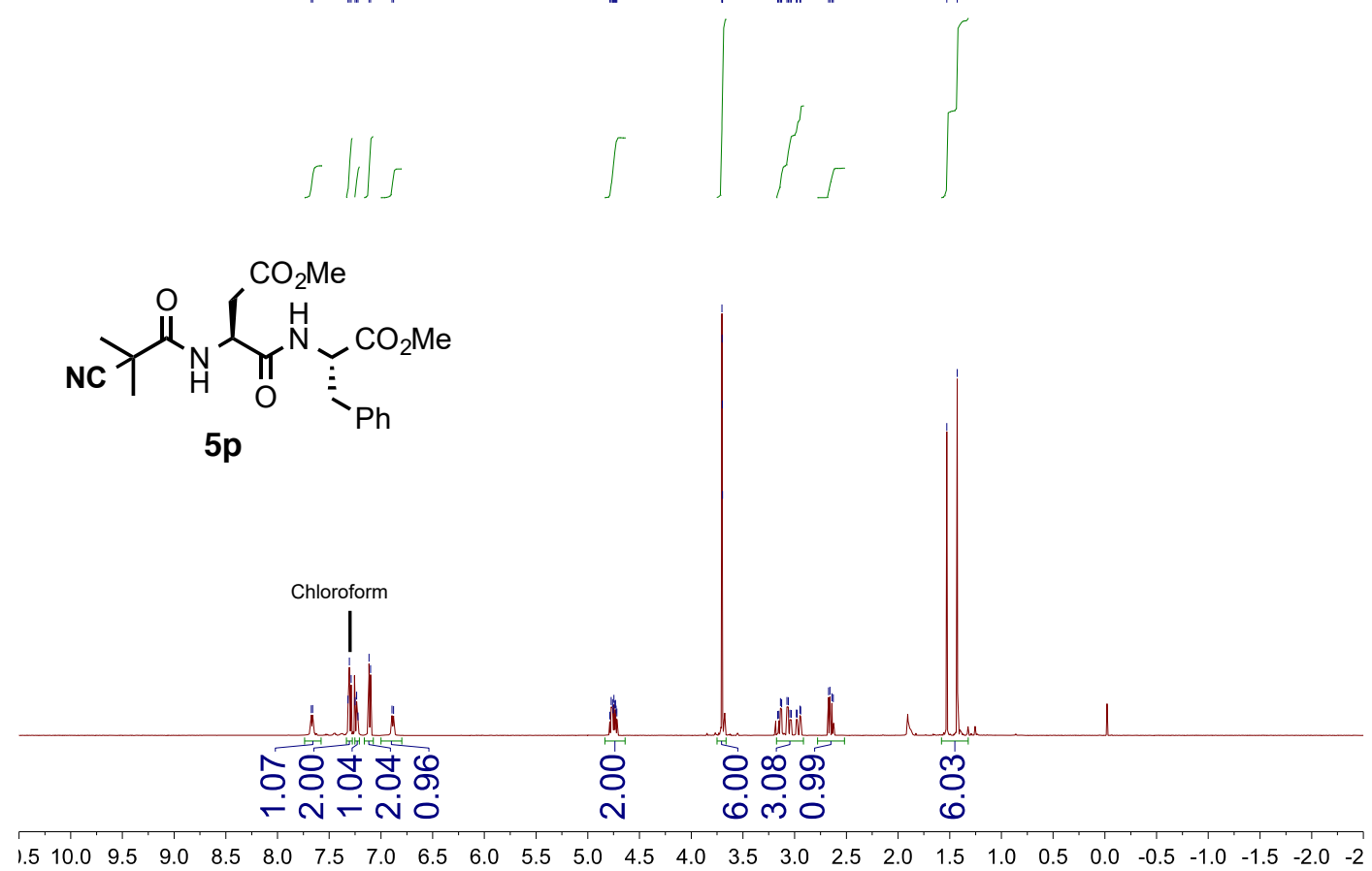

${ }^{13} \mathrm{C}$ NMR (125 MHz, $\left.\mathrm{CDCl}_{3}\right)$

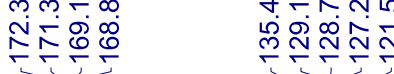

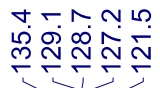
L. t.

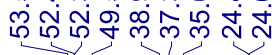<smiles>CC(=O)CC(NC(=O)C(C)(C)C)C(=O)N[C@@H](CC(C)=O)c1ccccc1</smiles>

$5 p$

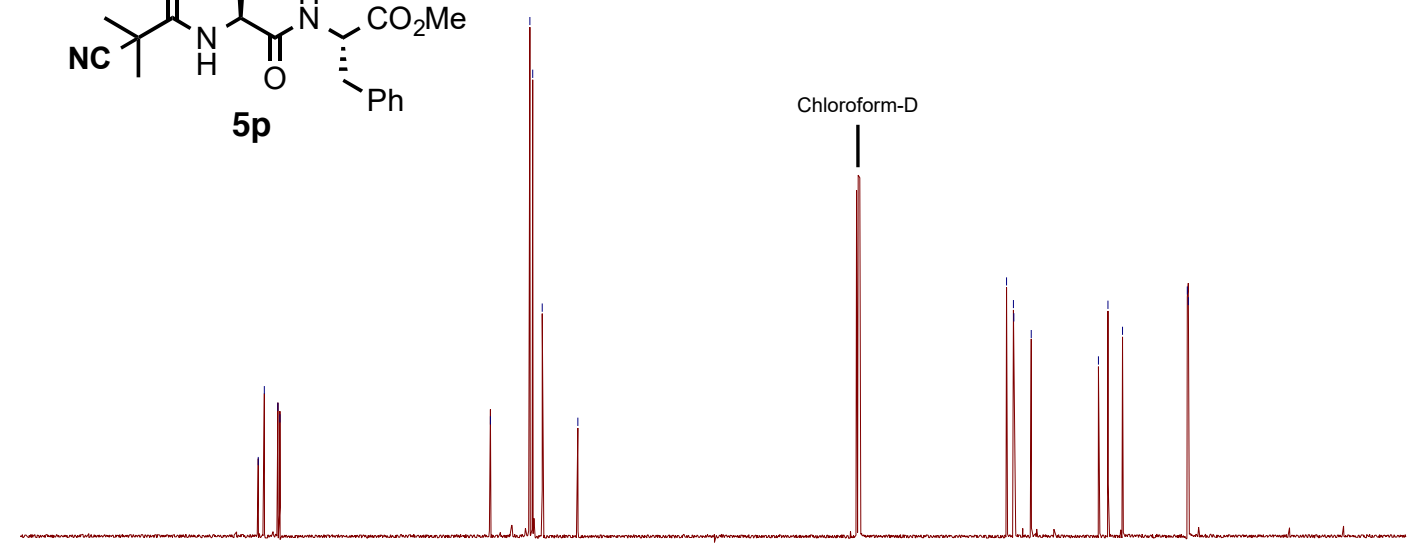

Chloroform-D

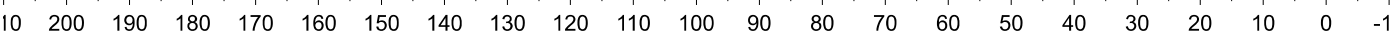


${ }^{1} \mathrm{H}$ NMR (500 MHz, $\left.\mathrm{CDCl}_{3}\right)$

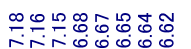

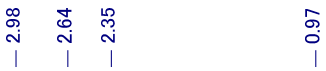
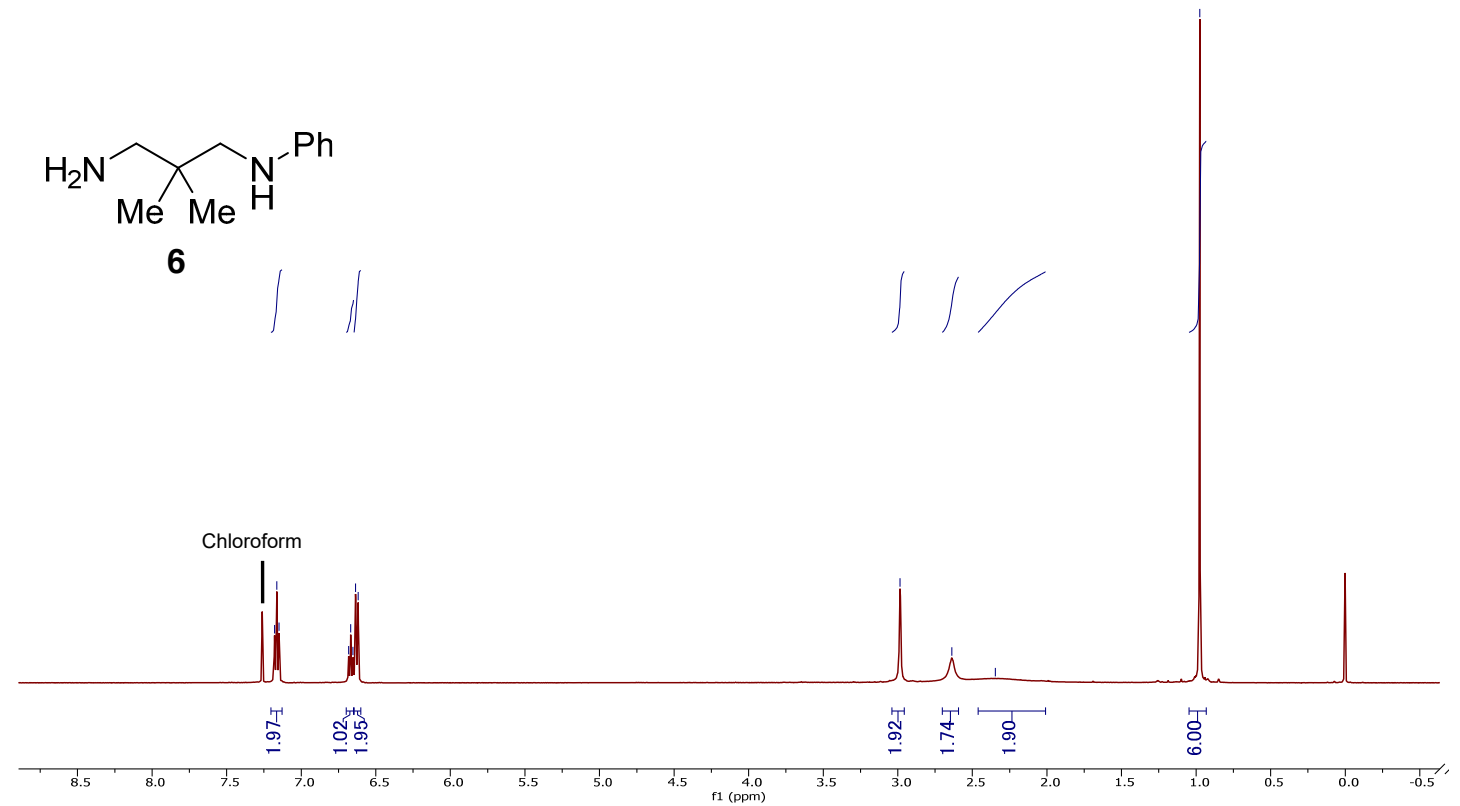

${ }^{13} \mathrm{C}$ NMR (125 MHz, $\left.\mathrm{CDCl}_{3}\right)$

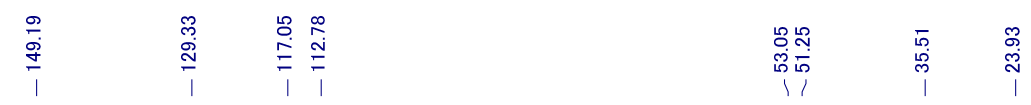

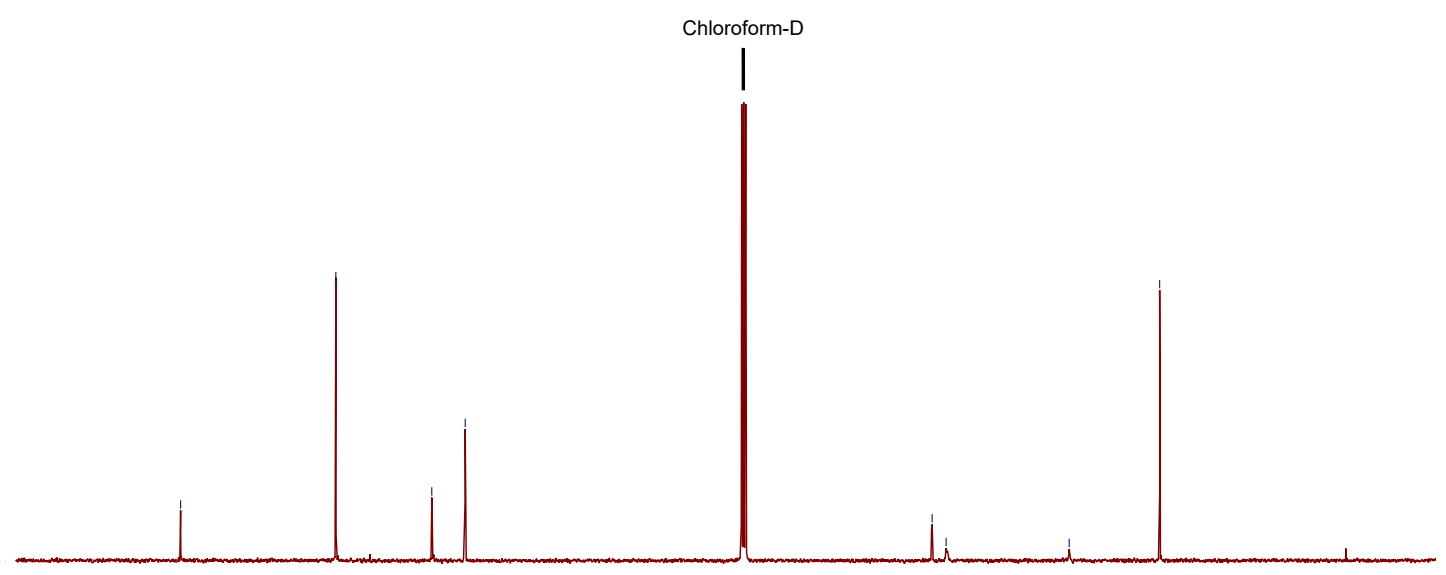

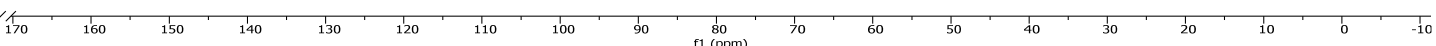


${ }^{1} \mathrm{H}$ NMR (500 MHz, $\left.\mathrm{CDCl}_{3}\right)$

我<smiles>CC(C)(C(N)=O)C(=O)Nc1ccccc1</smiles><smiles>C=CC1C=CC1C</smiles>

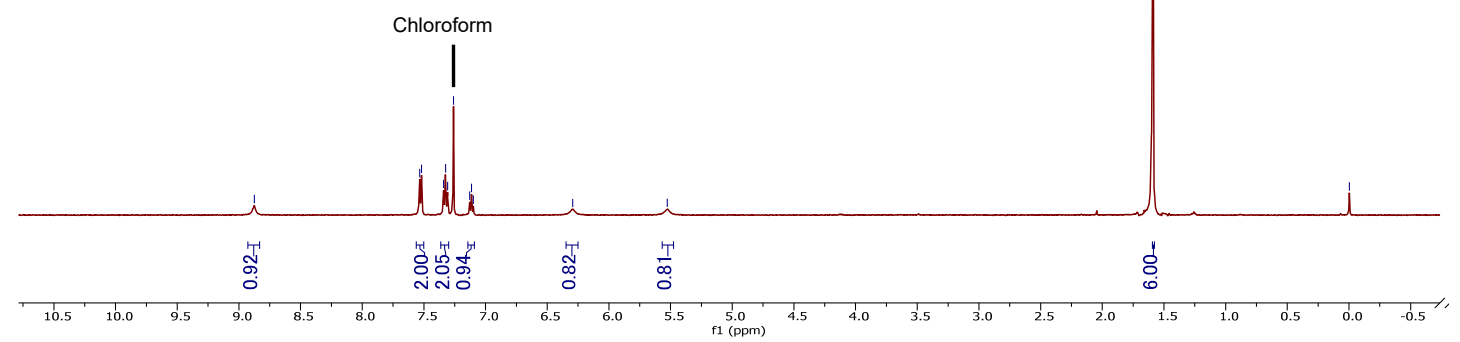

${ }^{13} \mathrm{C}$ NMR (125 MHz, $\left.\mathrm{CDCl}_{3}\right)$

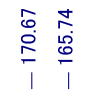

Chloroform-D
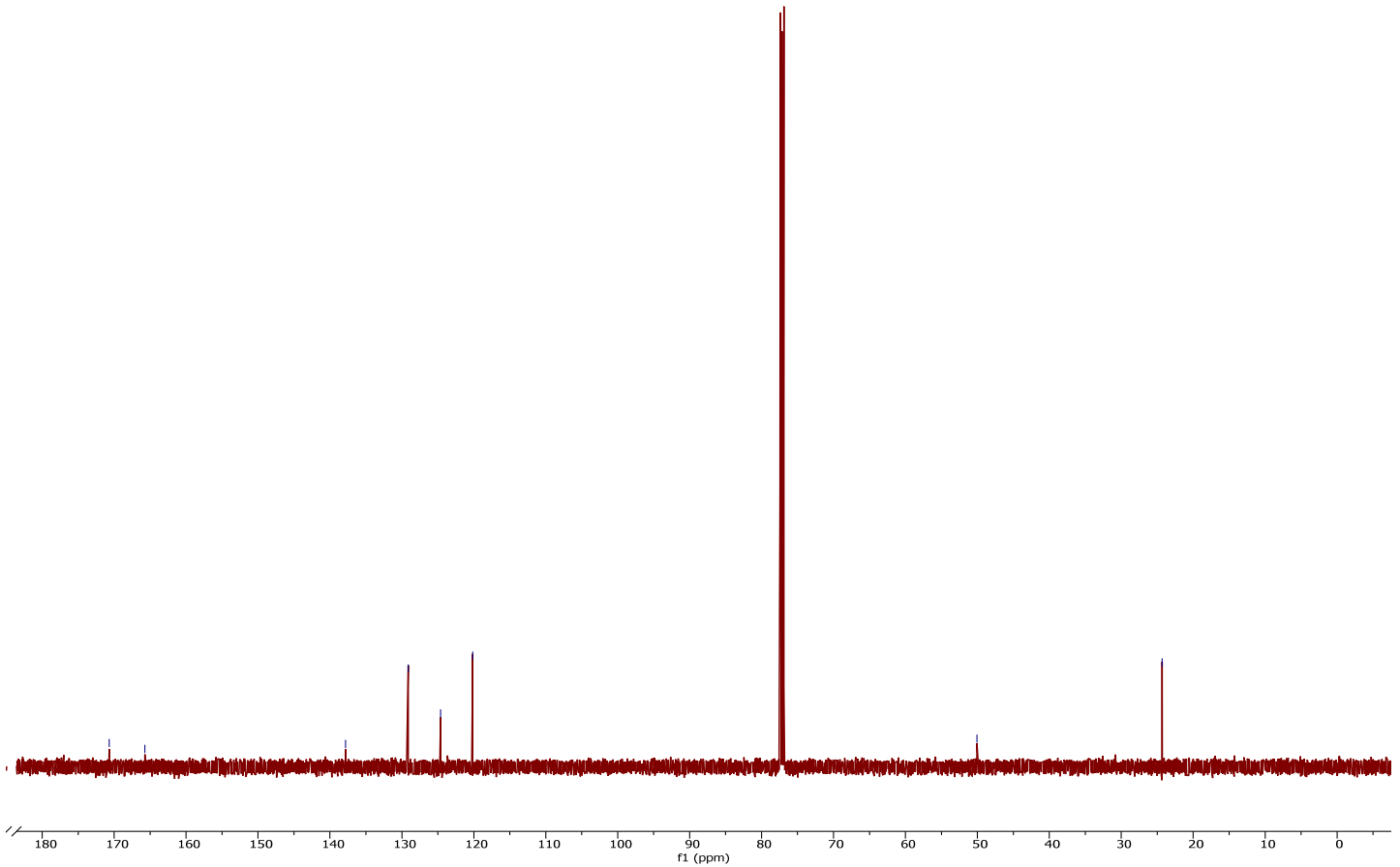
${ }^{1} \mathrm{H}$ NMR $\left(500 \mathrm{MHz}, \mathrm{D}_{3} \mathrm{COD}\right)$

$\underbrace{\frac{0.00}{00}}$

Methanol

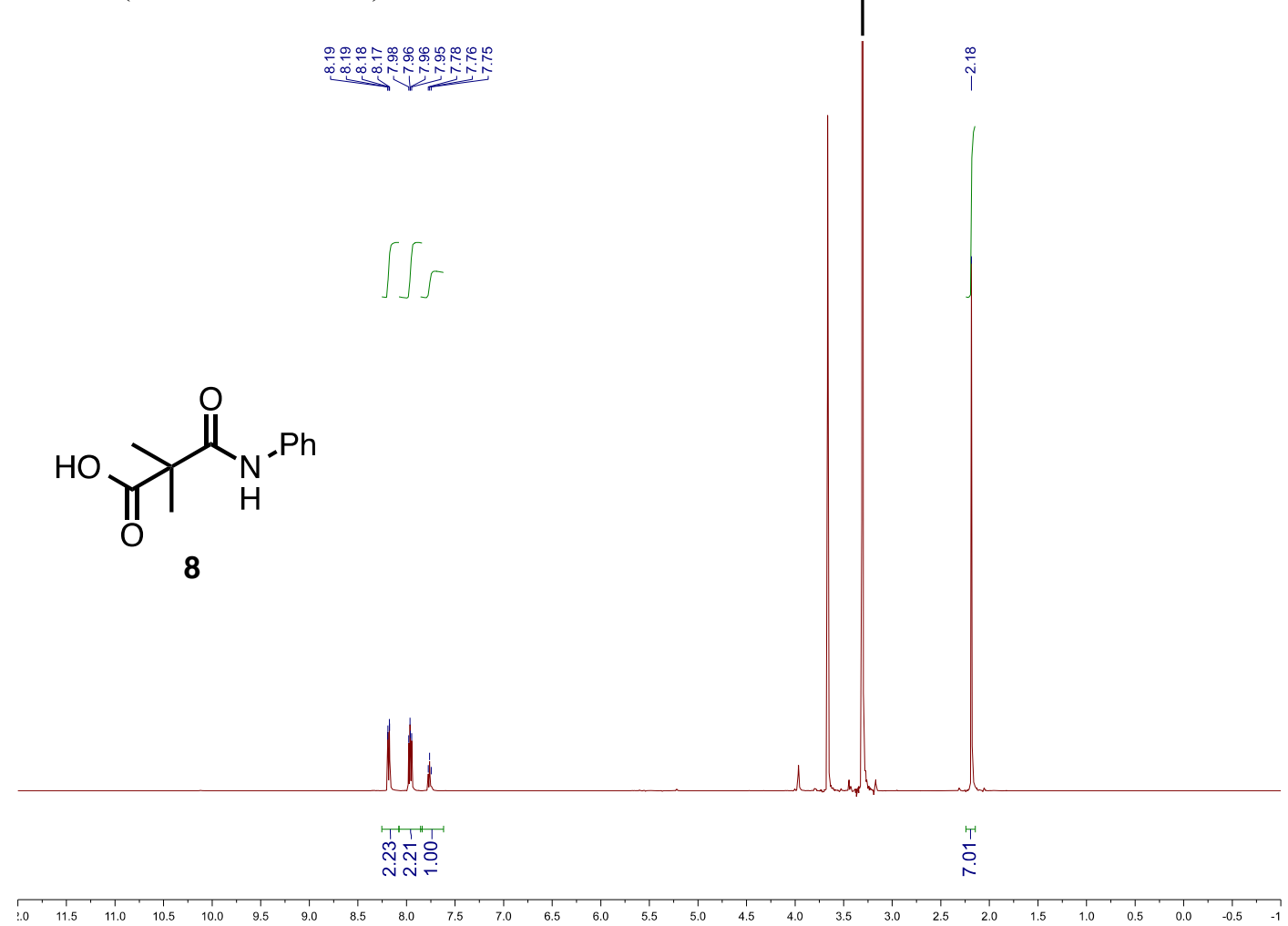

${ }^{13} \mathrm{C}$ NMR (125 MHz, $\left.\mathrm{D}_{3} \mathrm{COD}\right)$

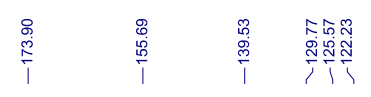<smiles>CC(C)(C(=O)O)C(=O)Nc1ccccc1</smiles>

8

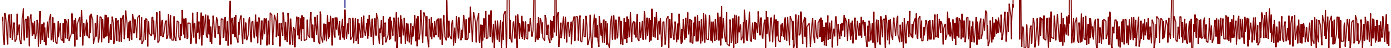

$\begin{array}{lllllllllll}10 & 200 & 190 & 180 & 170 & 160 & 150 & 140 & 130 & 120 & 110\end{array}$ 
${ }^{1} \mathrm{H}$ NMR (500 MHz, $\mathrm{CDCl}_{3}$ )

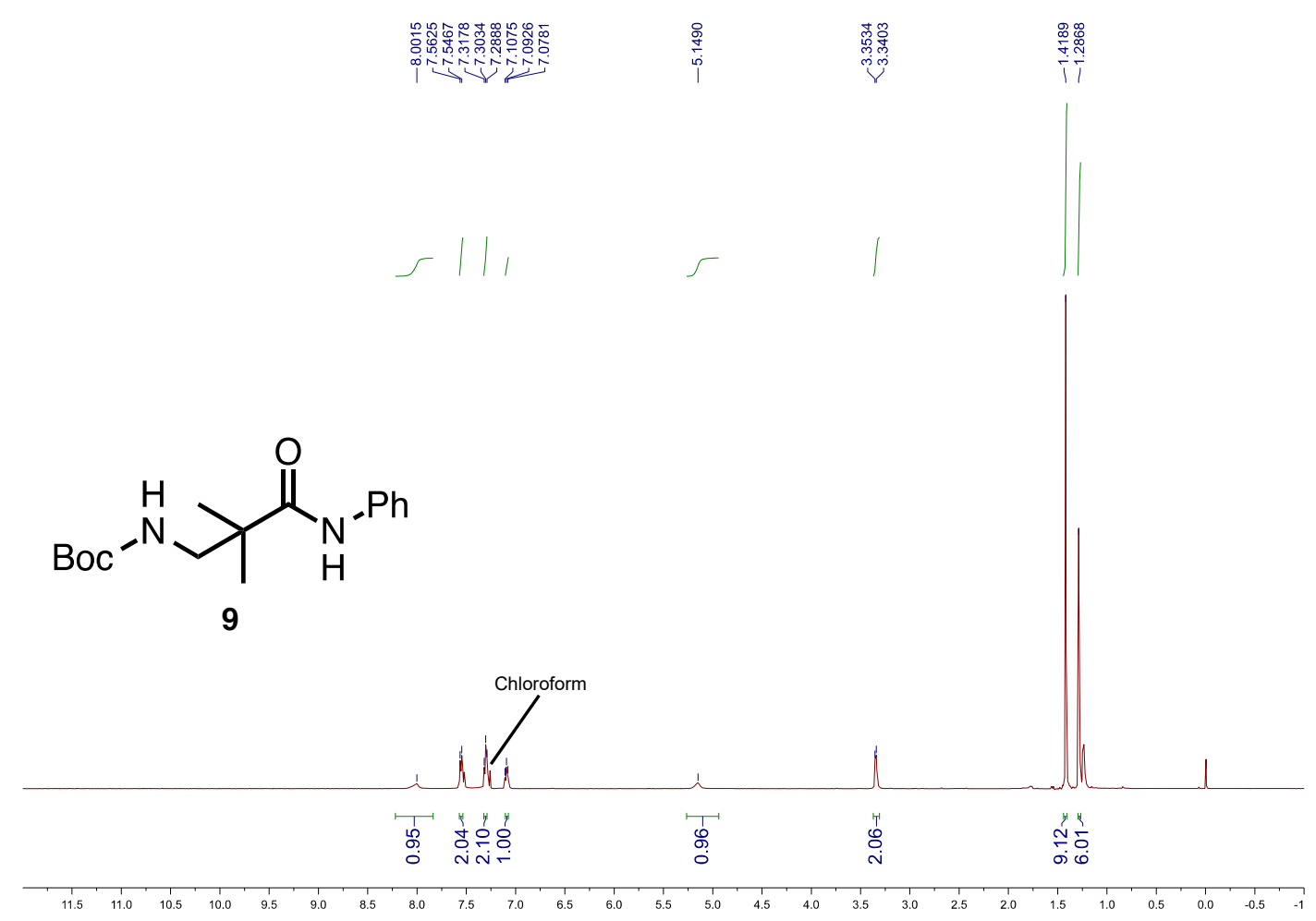

${ }^{13} \mathrm{C}$ NMR (125 MHz, $\left.\mathrm{CDCl}_{3}\right)$

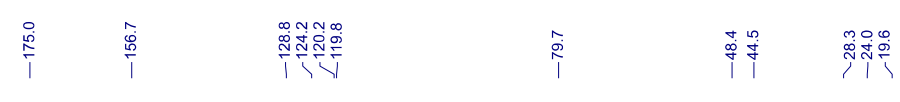<smiles>CC(C)(C)OC(=O)NCC(C)(C)C(=O)Nc1ccccc1</smiles>
Chloroform-D

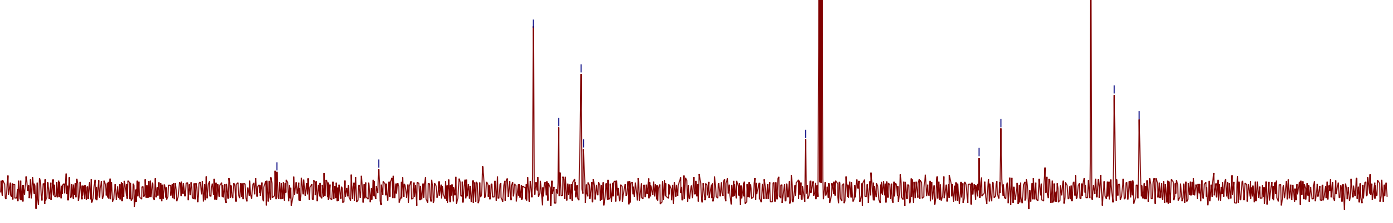

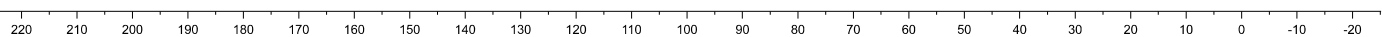


${ }^{1} \mathrm{H}$ NMR $\left(500 \mathrm{MHz}, \mathrm{CDCl}_{3}\right)$

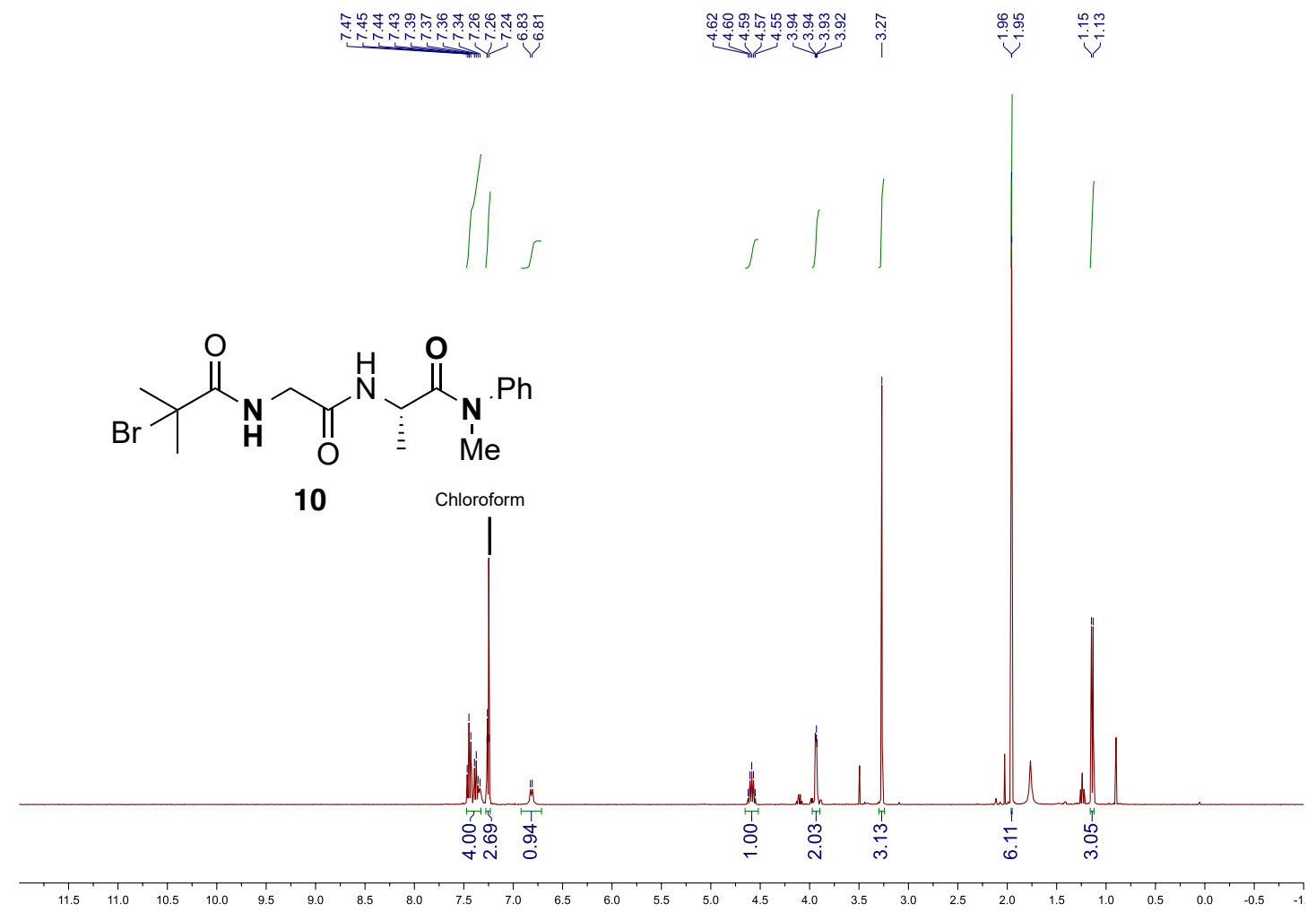

${ }^{13} \mathrm{C}$ NMR (125 MHz, $\left.\mathrm{CDCl}_{3}\right)$

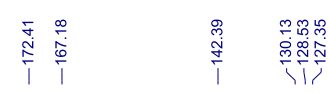

Chloroform-D D 
${ }^{1} \mathrm{H}$ NMR (500 MHz, $\left.\mathrm{CDCl}_{3}\right)$

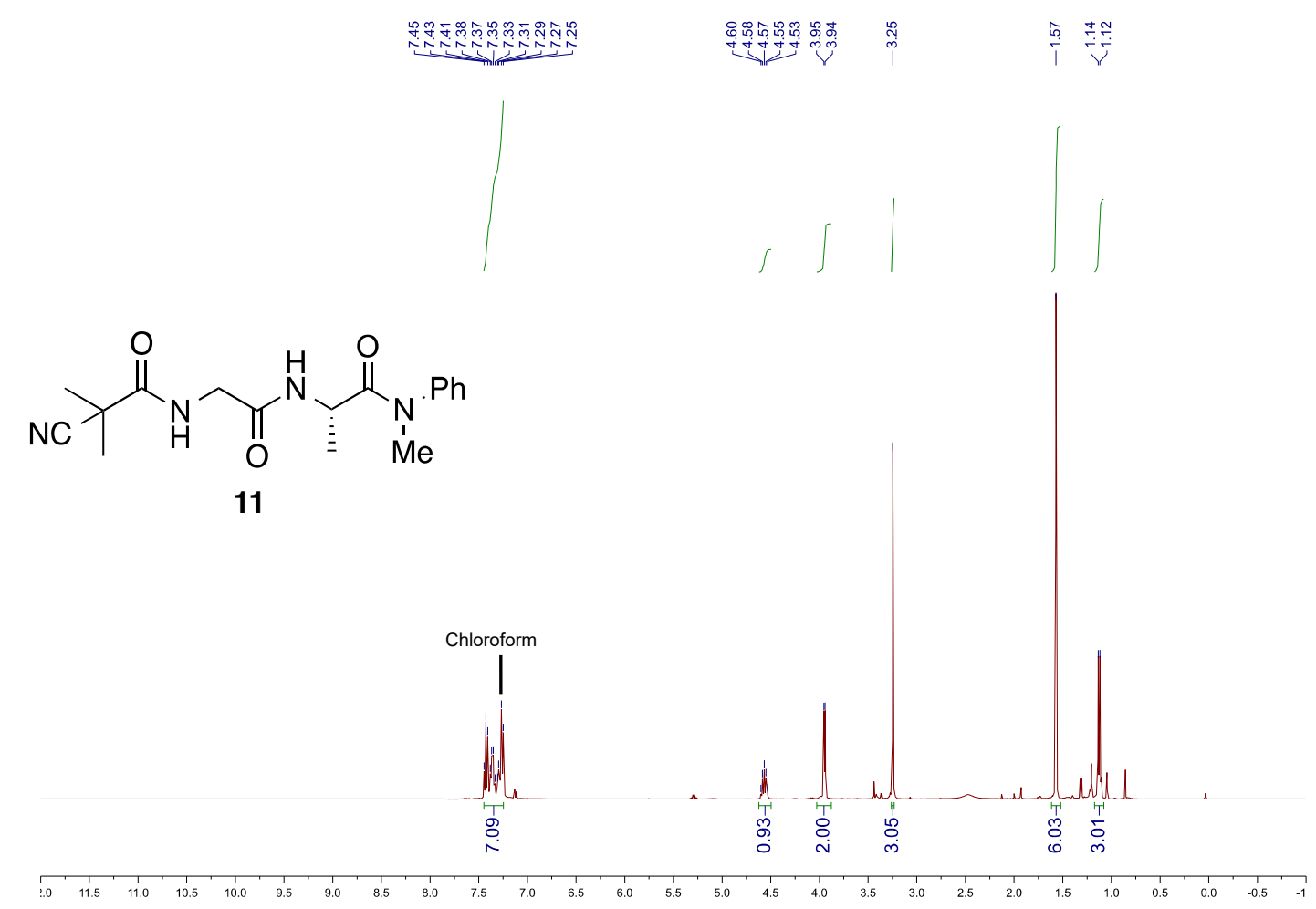

${ }^{13} \mathrm{C}$ NMR (125 MHz, $\mathrm{CDCl}_{3}$ )

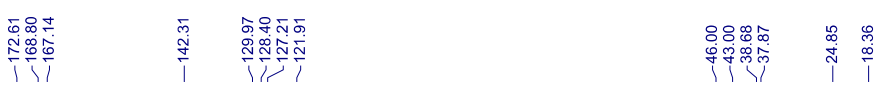

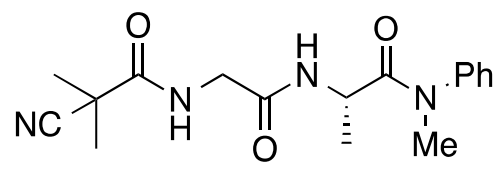

11

Chloroform-D

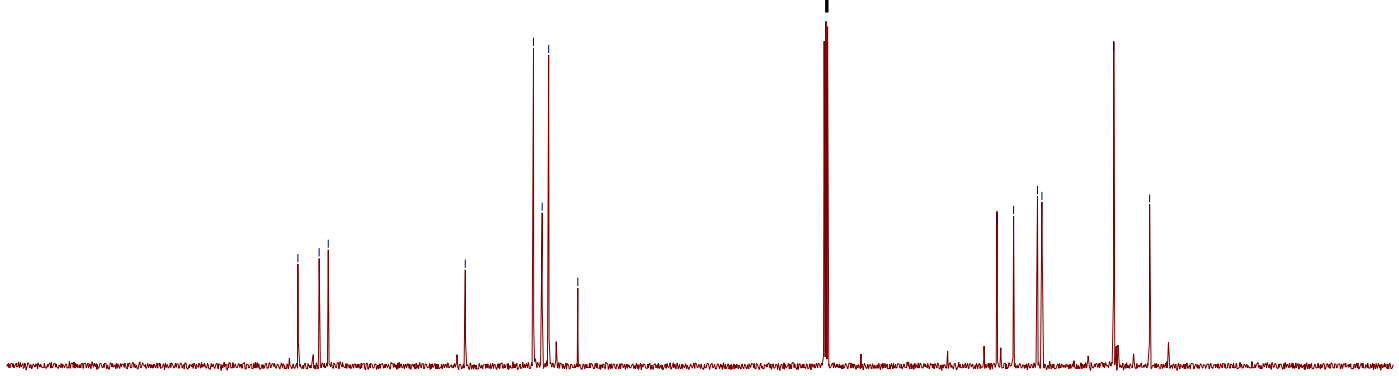


${ }^{1} \mathrm{H}$ NMR (400 MHz, $\left.\mathrm{CDCl}_{3}\right)$

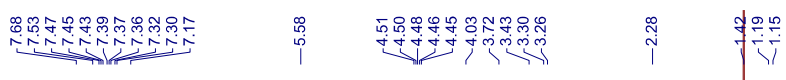<smiles>CC(NC(=O)CNC(=O)C(C)(C)CNC(=O)CNC(=O)CNC(=O)OC(C)(C)C)C(=O)N(C)c1ccccc1</smiles>

13

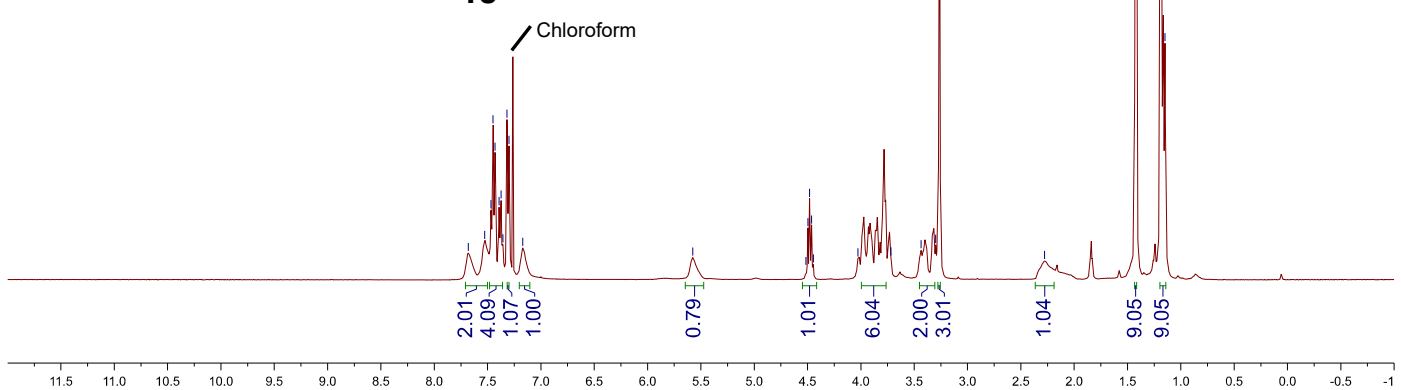

${ }^{13} \mathrm{C}$ NMR (100 MHz, $\left.\mathrm{CDCl}_{3}\right)$

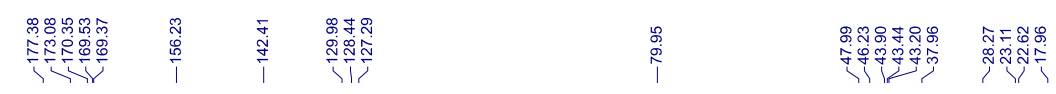

BocHN

13

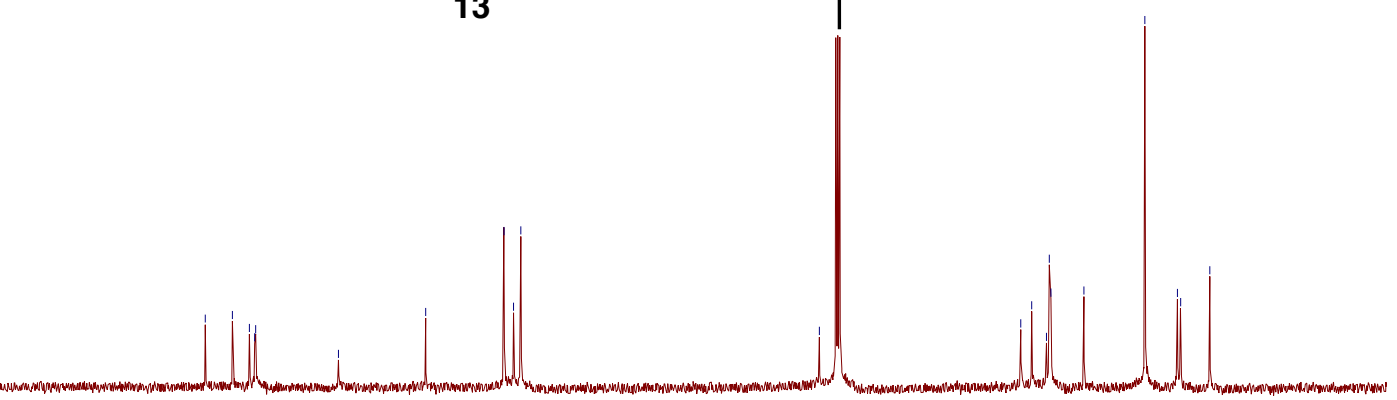

